\title{
Liquefied Natural Gas as a Transportation Fuel for Heavy-Duty Trucks: Volume I
}

State of Utah Office of Energy Services; Jack B. Kelley, Inc.; Bruderly Engineering Associates, Inc.; and Cryenco Sciences, Inc.

Jack B. Kelley Project Coordinator: Steve Bartlett NREL Technical Monitor: Paul Norton

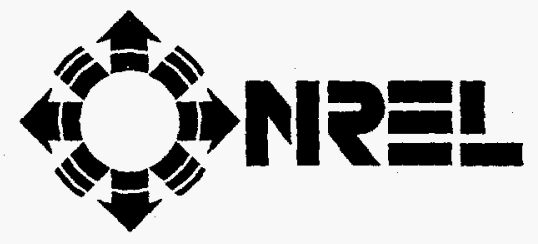

Alternative Fuels Hotline: 1-800-423-1DOE

Alternative Fuels Data Center World Wide Web Site: http://www.afdc.doe.gov

National Renewable Energy Laboratory

1617 Cole Boulevard

Golden, Colorado 80401-3393

A national laboratory of the

U.S. Department of Energy

Managed by the Midwest Research Institute

For the U.S. Department of Energy

Under Contract No. DE-AC36-83CH10093

Prepared under Subcontract Number ACl-6-15700-01

December 1997

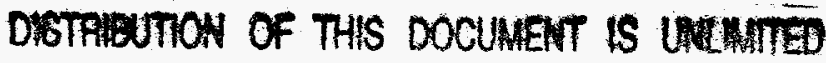




\section{Table of Contents}

Tables vi

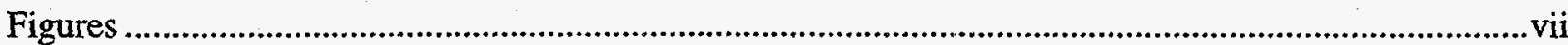

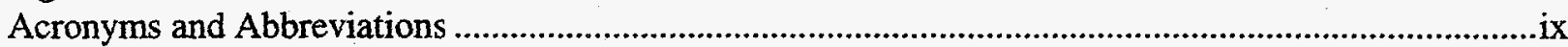

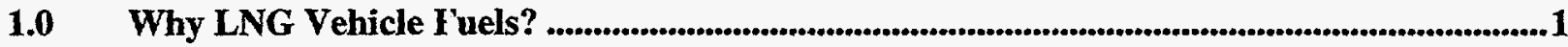

1.1. What Is LNG?

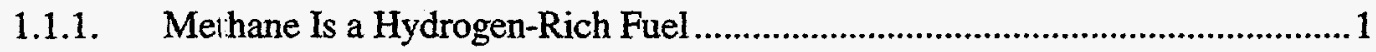

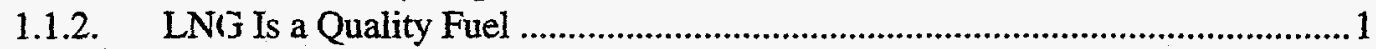

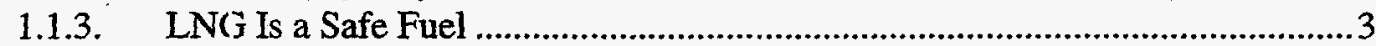

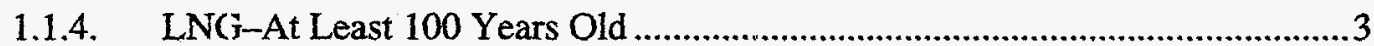

1.1.5. Compressed Natural Gas or Liquefied Natural Gas? ......................................3

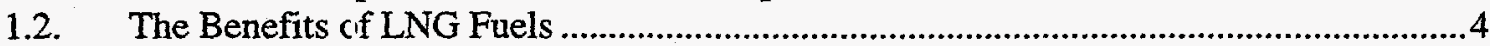

1.2.1. The Business Benefits of LNG Fuels: LNG Fuels Make Sense (Cents) .........4

1.2.2. Envi:onmental Benefits to Your Business from Using LNG Fuels....................6

1.2.3. The Safety Benefits to Your Business from Using LNG Fuels .........................8

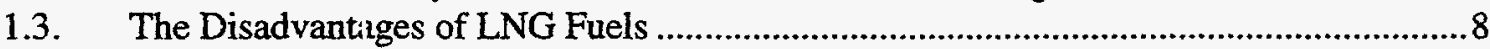

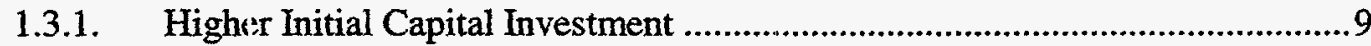

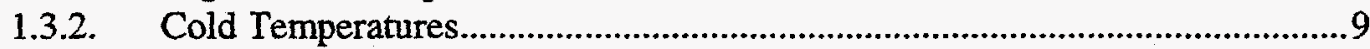

1.3.3. Infrastructure Is Limited-LNG for Vehicles Involves a New Industry .............9

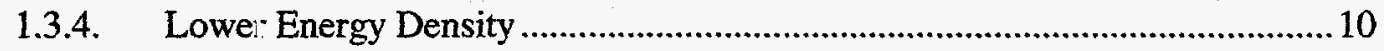

1.4. LNG Helps Sol re Many Regional and National Public Policy Issues ...........................10

1.4.1. Oil Imports, Energy and Economic Security, and Trade Deficits ..................11

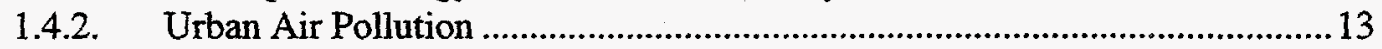

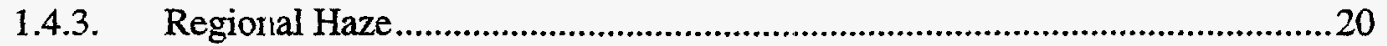

1.4.4. The Role of Medium- and Heavy-Duty Trucks in Urban Air Pollution.........20

1.4.5. Population Growth and Energy Use ........................................................22

1.4.6. Global Climate Change-Report of the Intergovernmental Panel on Climate

Change (IPCC) .................................................................................22

1.5. Laws, Regulations, and Programs that Affect Fleet Conversion to LNG ......................23

1.5.1. Can Government Create Win/Win Opportunities?.........................................23

1.5.2. Relevant Federal Legislation, Regulations, and Treaties .............................24

1.5.3. The Role of the Federal Government ........................................................31

1.5.4. The Role of State, Regional, and Local Government State Energy Offices... 32

1.5.5. Mobil Emission Reduction Credit (MERC) Trading ....................................32

1.5.6. Clean Cities-A Government/Industry Partnership ....................................33

1.5.7. Interstat: Clean Transportation Corridors ...................................................34

1.5.8. Global Climate Change Action Plan ...............................................................37

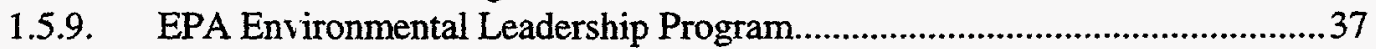

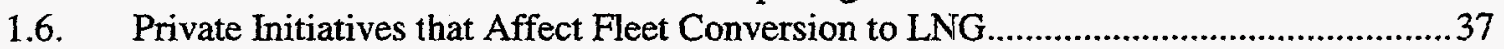

1.6.1. ISO 140C0 Environment Management Standards...........................................37

1.6.2. Sample Is:O 14000 Environmental Management System...............................39

1.6.3. Sustainable Development-A Market Driver for LNG Fuels ........................40

1.6.4. Coalition for Responsible Economies (CERES) .......................................42

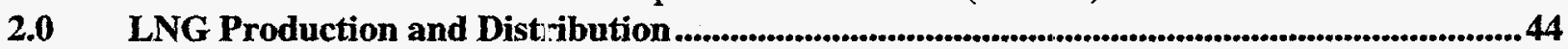

2.1. Potential Supply frcm Existing Infrastructure..........................................................44

2.2. Peak-Shaving and Satellite Storage Facilities ..................................................47

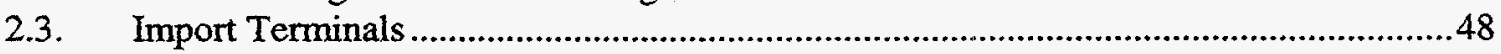

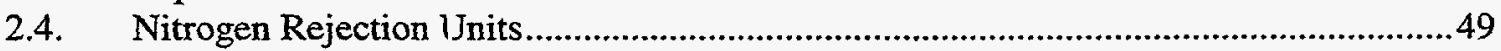

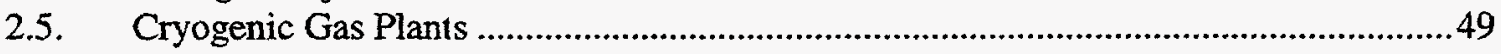




\section{DISCLAIMER}

This report was prepared as an account of work sponsored by an agency of the linited States Government. Neither the United States Government nor any agency thereof, nor any of their employees, make any warranty, express or implied, or assumes any legal liabiitty or responsibility for the accuracy, completeness, or usefulness of any information, apparatus, product, or process disclosed, or represents that its use would not infringe privately owned rights. Reference herein to any specitic commercial product, process, or service by trade name, trademark, manufacturer, or otherwise does not necessarily constitute or imply its endorsement, recommendation, or favoring by the United States Government or any agency thereof. The views and opinions of authors expressed herein do not necessar. ily state or reflect those of the United States Government or any agency thereof. 


\section{DISCLAMMER}

Portions of this docament may be illegibie in electronic image produets. Images are produced from the best available origionl document 


\section{Table of Contents (Continued)}

2.6. Synthesis and Olefin Petrochemical Plants ..................................................................50

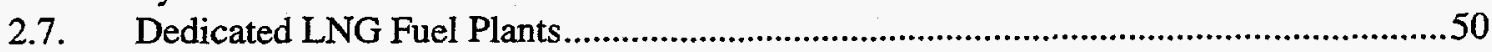

2.7.1. Topock, AZ-Needle Mountain ...................................................................51

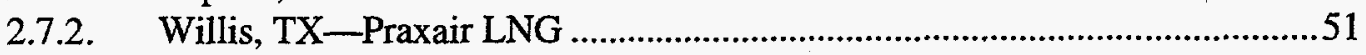

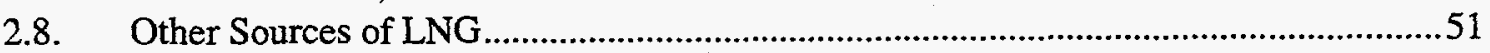

2.9. Small LNG Liquefiers-Emerging Opportunities ….................................................52

2.9.1. Stirling Cycle Liquefiers..........................................................................53

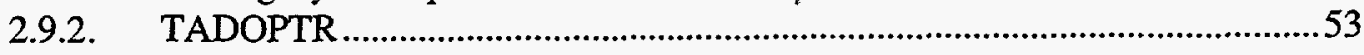

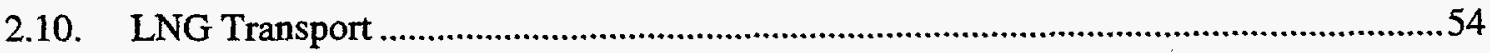

2.10.1. U.S. Department of Transportation Code ......................................................54

2.10.2. Highway Transport Trailers.........................................................................5

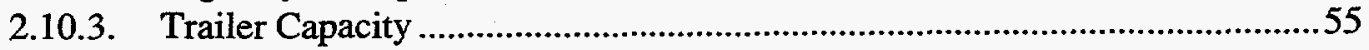

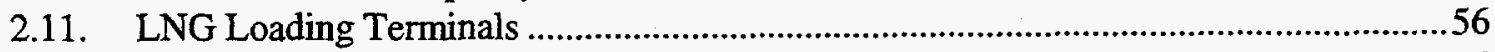

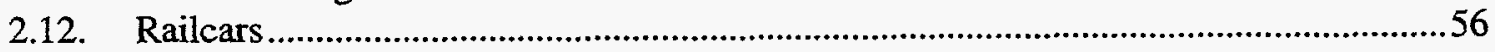

2.13. Other Transportation Opportunities .........................................................................56

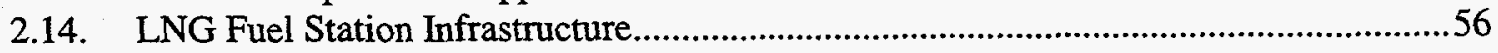

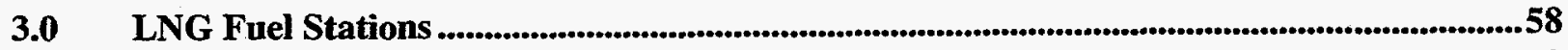

3.1. The Unique Characteristics of LNG .........................................................................58

3.1.1. Pressure and Temperature Are Important .....................................................59

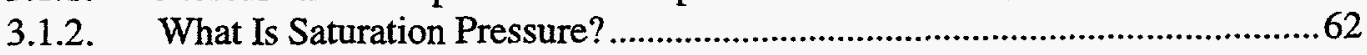

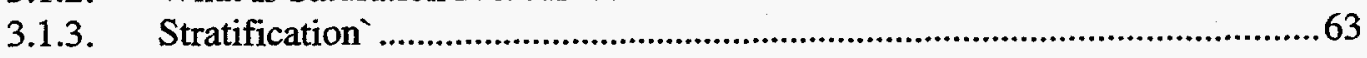

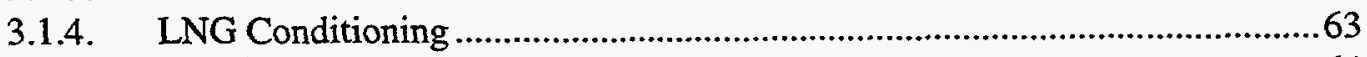

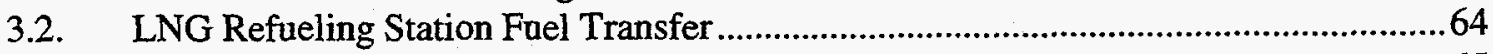

3.2.1. External Pump........................................................................................65

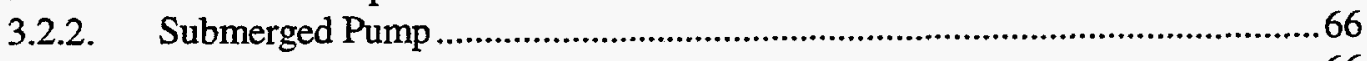

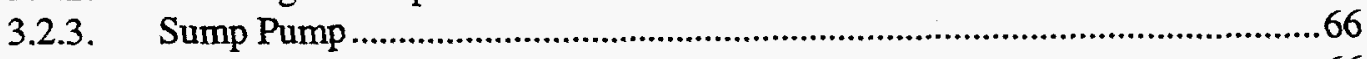

3.2.4. Pressure Transfer ..................................................................................66

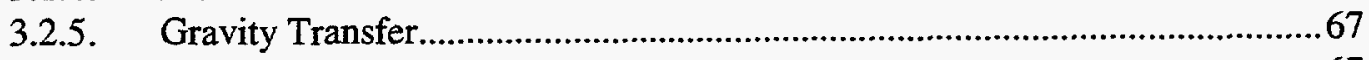

3.3. Vapor Recovery and Handling Systems ....................................................................67

3.3.1. Flare System for Recovered Vapor.............................................................68

3.3.2. Vapor Recovery to Pipeline ...........................................................................69

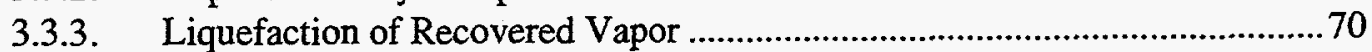

3.3.4. Pressurized Vapor Recovery......................................................................... 71

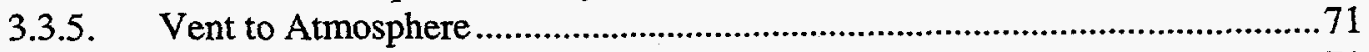

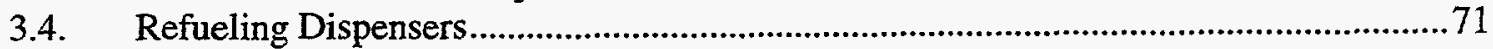

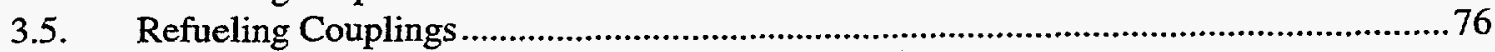

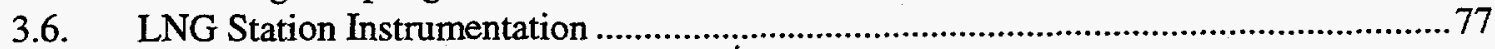

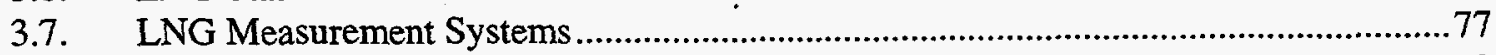

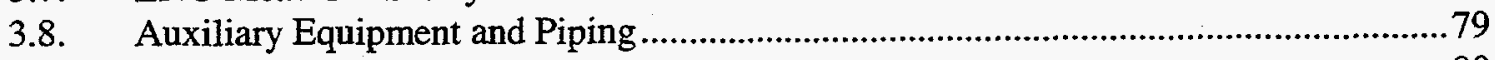

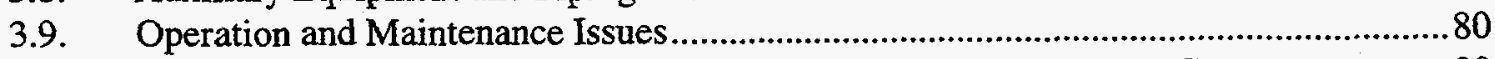

3.9.1. Design Decisions Determine Operation and Maintenance Costs ....................80

3.9.2. Parts and Service Are Important .................................................................. 81

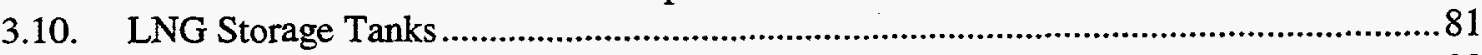

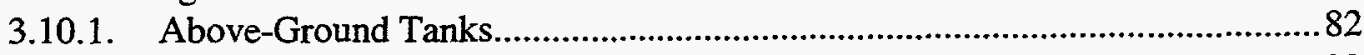

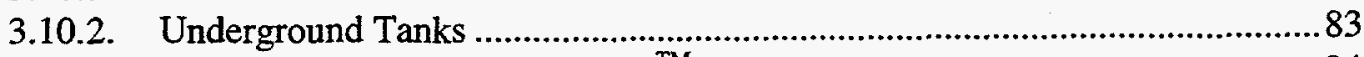

3.11. LNG Intermodal Container Tanks (TVAC ${ }^{\mathrm{TM}}$ ) ......................................................8

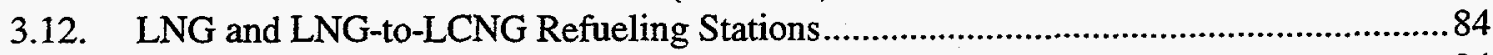

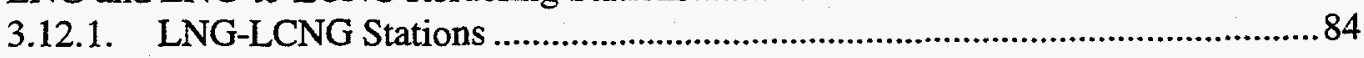




\section{Table of Contents (Continued)}

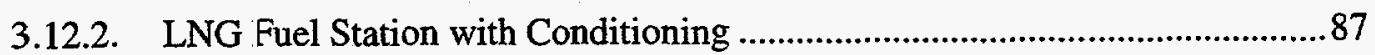

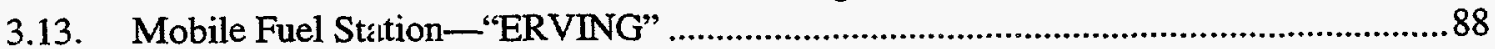

3.14. LNG Station Siting and Code Compliance ................................................................ 89

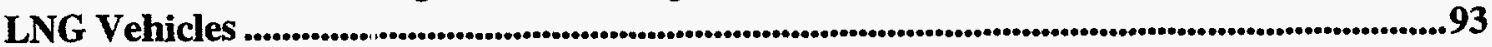

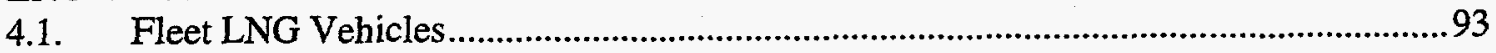

4.1.1. Transit Buses, Shuttles, Motor Coaches, and School Buses ..........................93

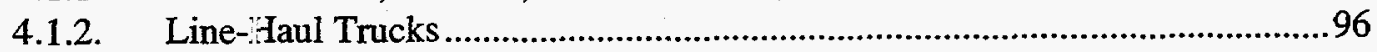

4.1.3. Heavy- and Medium-Duty P\&D Trucks ......................................................97

4.1.4. Light-Duty P\&D Trucks and Vans ...........................................................98

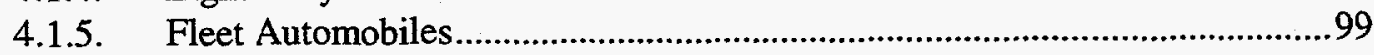

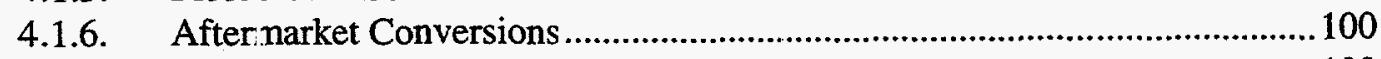

4.2. Off-Highway Vehicles and Equipment ................................................................... 100

4.2.1. Mining, Construction, and Landfill Equipment Applications ......................100

4.2.2. Industrial, Agricultural, and Specialty Vehicle Applications ........................ 101

4.2.3. Railroad Locomotives................................................................................. 103

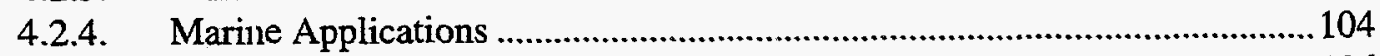

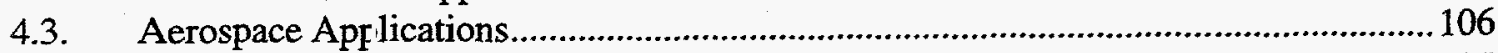

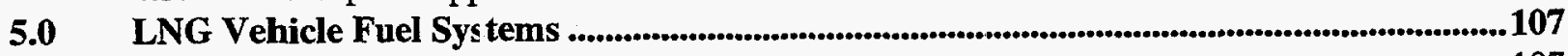

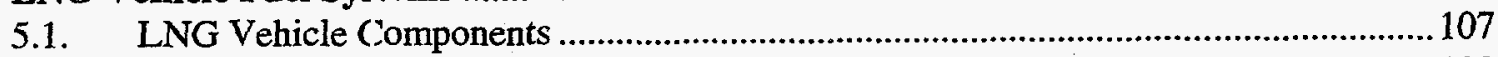

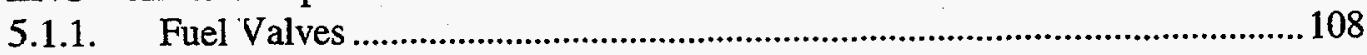

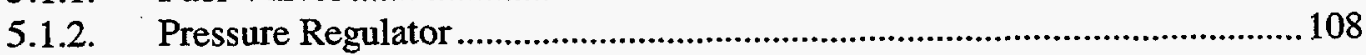

5.1.3. Heat Exchanger ("Vaporizer") ................................................................ 108

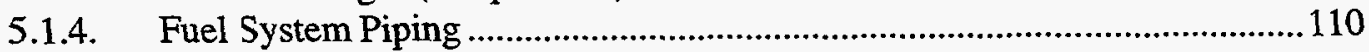

5.1.5. Liquid-Vapor Pressure Control System..................................................110

5.1.6. Fuel Transfer to the Engine ....................................................................110

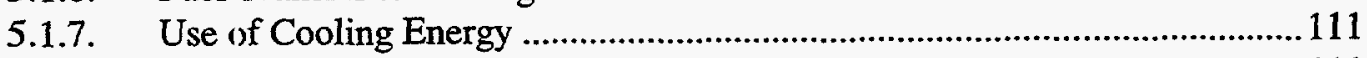

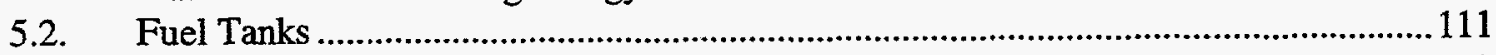

5.2.1. Hold Time, Relief Valves, and Vents .......................................................113

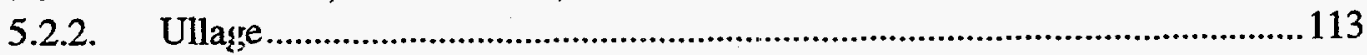

5.2.3. Tank Level Measurement ...................................................................... 114

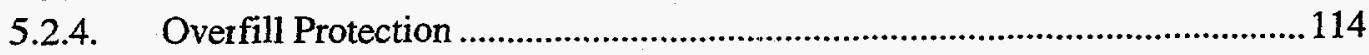

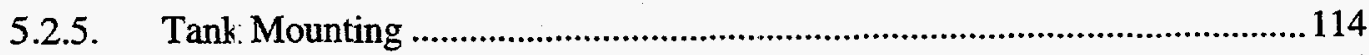

5.2.6. Research and Development Needs ............................................................114

6.0 Natural Gas Engines and Power Systems ......................................................................116

6.1. Natural Gas Is Not a New Engine Fuel ..................................................................116

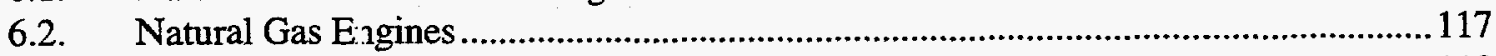

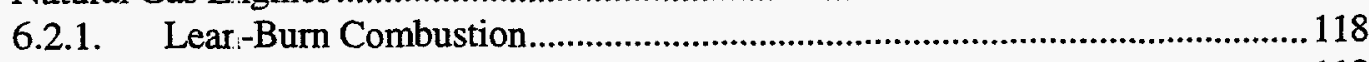

6.2.2. Dua-Fuel "Pilot Ignition" Diesel Combustion...............................................118

6.2.3. Stoiv'hometric, Spark-Ignition Diesel Combustion ....................................... 119

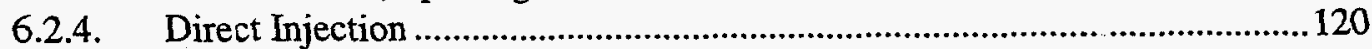

6.2.5. Conversion of Gasoline Engines to Natural Gas ..........................................120

6.2.6. Other Issues Associated with Heavy-Duty Natural Gas Engines .................. 120

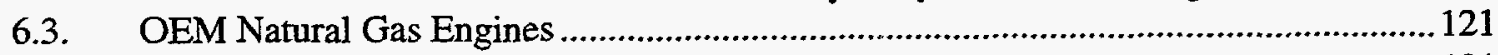

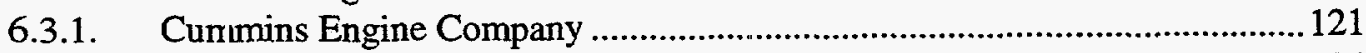

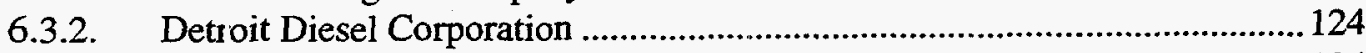

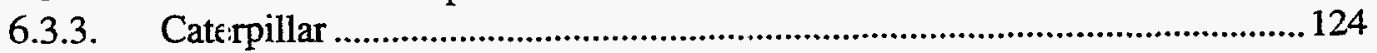

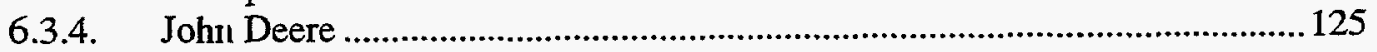

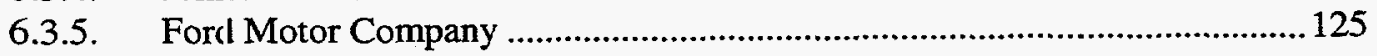




\section{Table of Contents (Concluded)}

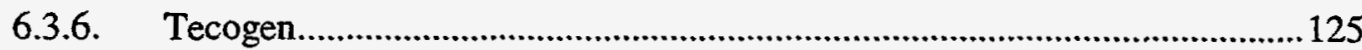

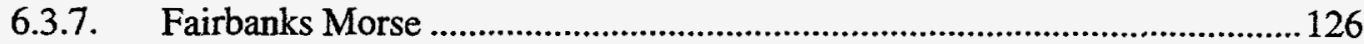

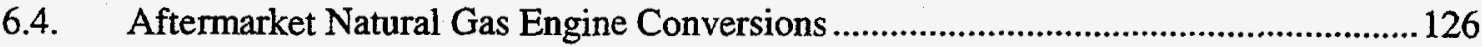

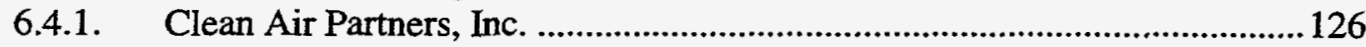

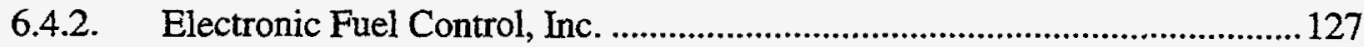

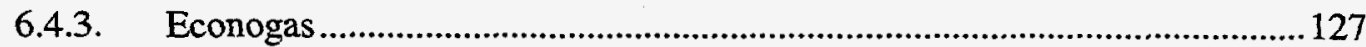

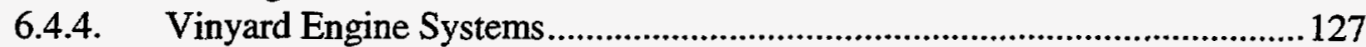

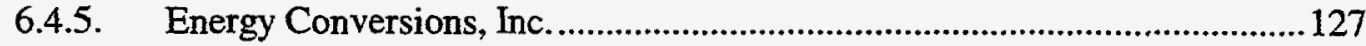

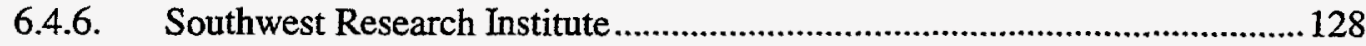

6.4.7. DAI Controls/Synchro-Start Products, Inc.................................................129

6.4.8. Beacon Power Systems, Inc.................................................................129

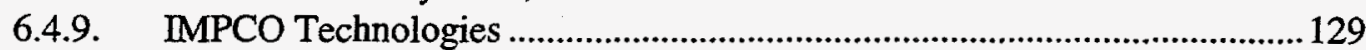

7.0 LNG/LCNG Project Case Studies.......................................................................................130

7.1. Los Angeles International Airport-Los Angeles, CA ............................................130

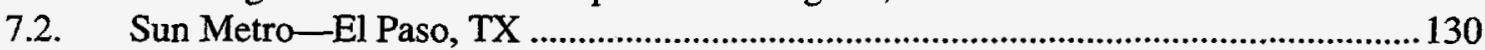

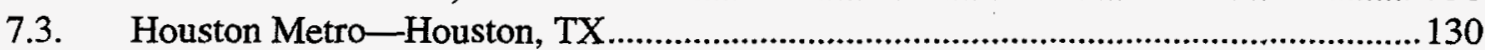

7.4. Jack B. Kelley, Inc.-San Manuel, AZ …......................................................... 130

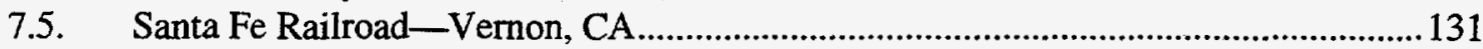

7.6. Gary Public Transportation Corporation-Gary, IN.................................................131

8.0 Commercial Status of LNG Fuels: Barriers and Opportunities............................................132

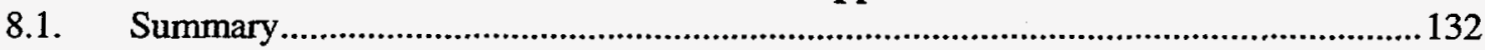

8.2. Engine and Vehicle Technology Issue and Commercialization Status ........................132

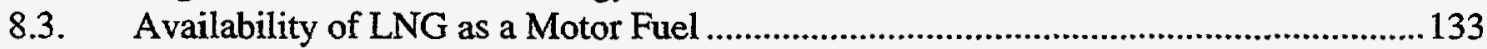

8.4. Key Stakeholders in Commercializing LNG as a Motor Fuel ...................................133

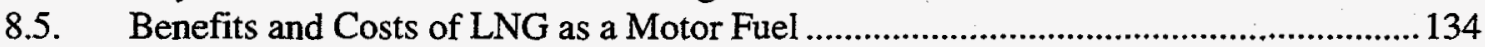

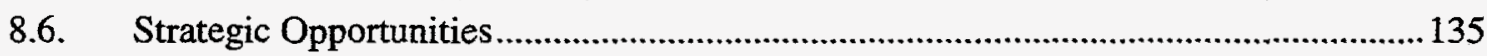

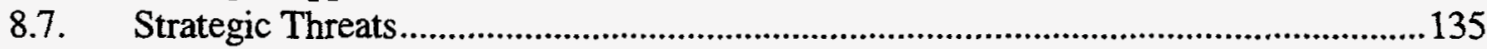

8.8. Suggested Key Elements of a Commercialization Strategy for LNG ........................135 


\section{Tables}

Table 1-1. Composition of LNG

Table 1-2. Schedule for Mandzted Purchases of New Alternative Fuel Vehicles

Table 1-3. On-Road Heavy-Duty Engine Emission Standards 26

Table 1-4. Transit Bus Emissicn Standards 26

Table 1-5. Off-Road Heavy-Duty Engine Emissions Standards 28

Table 1-6. Existing and Proposed NAAQS for Ozone and Particulate Matter 29

Table 1-7. Potential MERCs from Conversion to LNG 33

Table 2-1. Types of LNG Liquefaction or Storage Plants 45

Table 2-2. Domestic Facilities Capable of Supplying LNG 46

Table 2-3. LNG Transport Capacities 54

Table 2-4. U.S. LNG Transport Trailers and Railcars 55

Table 5-1. Effect of Saturation Pressure on LNG Physical Properties 107

Table 6-1. Summary of Current LNG Locomotive Engine Development Projects 128 


\section{Figures}

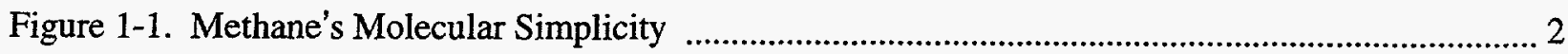

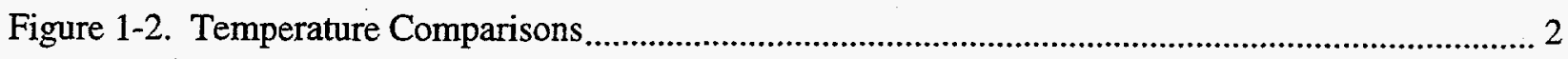

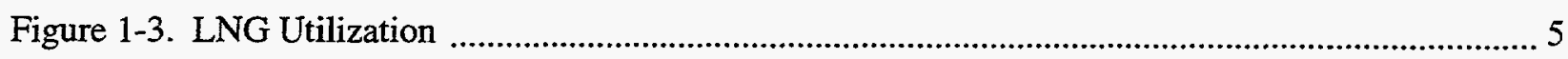

Figure 1-4. In-Use Emissions Benefits of Natural Gas ..................................................................... 7

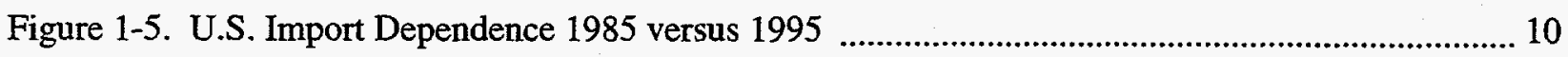

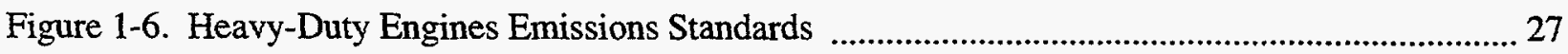

Figure 1-7. The Southwest ICTC Corridors ................................................................................... 36

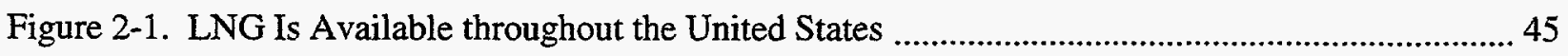

Figure 2-2. Planned Jack B. Kelley Network of LNG Fuel Stations ................................................... 57

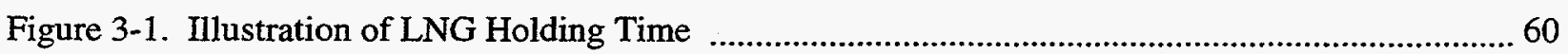

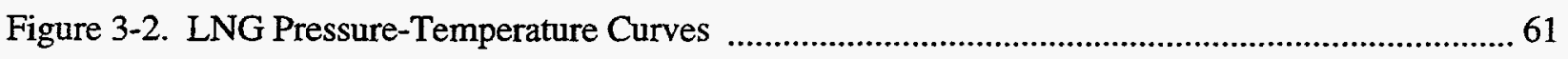

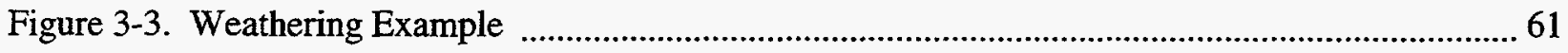

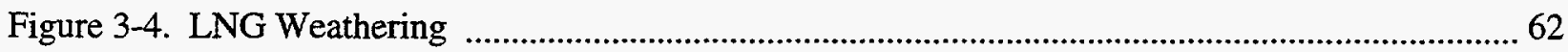

Figure 3-5. Five Fuel Transfer Techniques Used at LNG Fuel Stations ........................................... 65

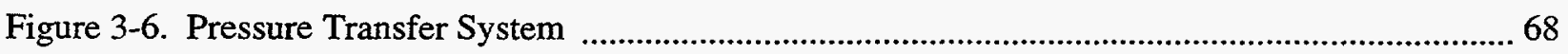

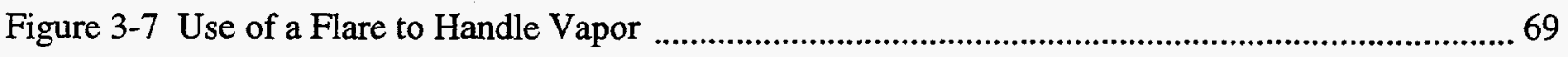

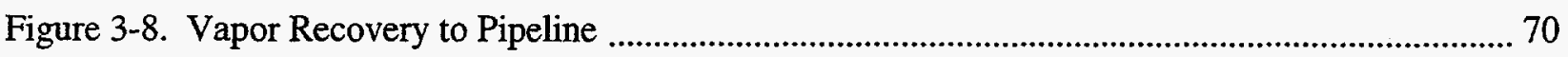

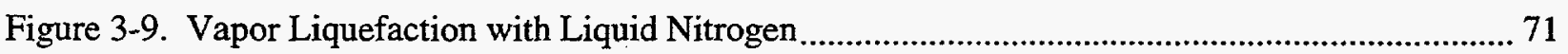

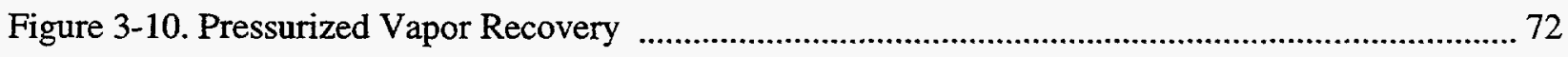

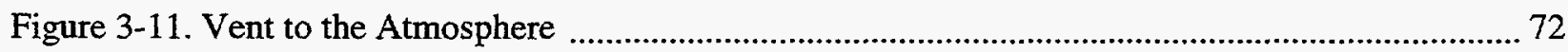

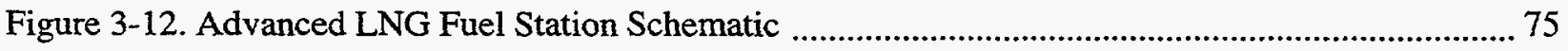

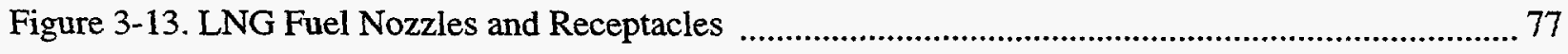

Figure 3-14. Usage of Various Insulation Methods to Reduce Heat Leaks ........................................... 79 
Figures (Concluded)

Figure 3-15. Total Station Storage Capacity 82

Figure 3-16. Typical LNG-to-I.CNG Fuel Station Modules 86

Figure 3-17. Typical LNG Fuel Station Modules 87

Figure 3-18. Mobile Fuel Stations-the Jack B. Kelley ERVING 89

Figure 4-1. Categories of Fleet Vehicles 94

Figure 5-1. LNG Fuel System 'Components 109

Figure 5-2. LNG Vehicle Fuel Tank Design Elements 113

Figure 5-3. 30-Gallon LNG Tank for Medium-Duty Vehicle Applications 115

Figure 5-4. 160-Gallon LNG 'Tank with Submerged Pump for Transit Bus Applications 115

Figure 6-1. Heavy-Duty Natusal Gas OEM Engines 122

Figure 6-2. Cummins Natural Gas Engines 123

Figure 6-3. Typical Emissions from a Natural Gas Engine 123 


\section{Acronyms and Abbreviations}

\begin{tabular}{|c|c|}
\hline $\mathrm{AFV}$ & alternative fuel vehicle \\
\hline AIWW & Atlantic Intercoastal Waterway \\
\hline ANSI & American National Standards Institute \\
\hline $\mathrm{AP}$ & Air Products \& Chemicals \\
\hline ASME & American Society of Mechanical Engineers \\
\hline bhp & brake-horsepower \\
\hline Btu & British thermal unit \\
\hline CAAA & Clean Air Act Amendments of 1990 \\
\hline CAP & Clean Air Partners, Inc. \\
\hline CARB & California Air Resources Board \\
\hline CERCLA & Comprehensive Environmental Response, Compensation, and Liabiity Act \\
\hline CERES & Coalition for Responsible Economics \\
\hline $\mathrm{CFV}$ & clean fuel vehicle \\
\hline $\mathrm{CH}_{4}$ & methane \\
\hline $\mathrm{CNG}$ & compressed natural gas \\
\hline $\mathrm{CO}$ & carbon monoxide \\
\hline $\mathrm{CO}_{2}$ & carbon dioxide \\
\hline DDC & Detroit Diesel Corporation \\
\hline DEGADIS & dense gas dispersion \\
\hline DOD & U.S. Department of Defense \\
\hline DOE & U.S. Department of Energy \\
\hline DOT & U.S. Department of Transportation \\
\hline $\mathrm{ECI}$ & Energy Convrsions, Inc. \\
\hline $\mathrm{ECU}$ & electronic control unit \\
\hline EFC & Electronic Fuel Control, Inc. \\
\hline EIA & Energy Information Administration \\
\hline ELP & Environmental Leadership Program \\
\hline
\end{tabular}




$\begin{array}{ll}\text { EMD } & \text { Electromotive Division (General Motors) } \\ \text { EMS } & \text { environmenta management system } \\ \text { EPA } & \text { U.S. Environrnental Protection Agency } \\ \text { EPAct } & \text { Energy Policy Act of } 1992 \\ \text { ERVING } & \text { Equipment Refueling Vehicle Natural Gas } \\ \text { FET } & \text { Federal Excis Tax } \\ \text { GIWW } & \text { Gulf Coast In ercoastal Waterway } \\ \text { gpd } & \text { gallons per day } \\ \text { GPTC } & \text { Gary Public T'ransportation Corporation } \\ \text { GRI } & \text { Gas Research Institute } \\ \text { GSA } & \text { General Services Administration } \\ \text { ICTC } & \text { Interstate Clein Transportation Corridor } \\ \text { INEL } & \text { Idaho Nationil Engineering Laboratory } \\ \text { IPCC } & \text { Intergovernmental Panel on Climate Change } \\ \text { ISO } & \text { International Standards Organization } \\ \text { ISTEA } & \text { Intermodal Sirface Transportation Efficiency Act of 1992 } \\ \text { JBK } & \text { Jack B. Kelley, Inc. } \\ \text { LANL } & \text { Los Alamos INational Laboratory } \\ \text { LCNG } & \text { liquefied compressed natural gas } \\ \text { LDV } & \text { Light-duty vehicle } \\ \text { LEV } & \text { Low-emission vehicle } \\ \text { LIN } & \text { Liquid nitrogen } \\ \text { MBOD } & \text { million barrels of oil per day } \\ \text { MERC } & \text { Mobile Emission Reduction Credit } \\ \text { Multilayer insulation } \\ \text { Milimeters Fer square feet per day }\end{array}$


NAFTA North American Free Trade Association

NFPA National Fire Protection Association

NGV Natural gas vehicle

NIST National Institute of Standards and Testing

NMHC Nonmethane hydrocarbon

NMRH Nonmethane reactive hydrocarbon

$\mathrm{NO}_{\mathrm{x}} \quad$ Oxides of nitrogen

$\mathrm{NO}_{2} \quad$ Nitrogen dioxide

NPSH Net positive suction head

NRU Nitrogen rejection unit

OEM Original equipment manufacturer

O\&M Operations and maintenance

OPEC Organization of Petroleum Exporting Countries

P\&D Pickup and delivery

P-T Pressure-temperature

PAN Peroxy carboxylic nitric anhydrides

PM Particulate matter

PNA Polynuclear aromatic compound

Ppm Parts per million

Psia Per square inch absolute

Psig Per square inch gauge

RCRA Resource Conservation and Recovery Act

RFG Reformulated gasoline

RVP Reid vapor pressure

$\mathrm{SO}_{2} \quad$ Sulfur dioxide

SOP Statement of Principles

TADOPTR thermo-acoustic driven orifice pulse tube refrigeration

TAG Technology Advisory Group 
TCM

THC

TQM

TSP

ULEV

USPS

VOC

WHO

traffic control measure

total hydrocarbon

total quality management

total suspended particulate

ultra-low emission vehicle

U.S. Postal Strvice

volatile organic compound

World Health Organization 


\subsection{Why LNG Vehicle Fuels?}

This three-volume manual is designed to be used with a 2- to 3-day liquefied natural gas (LNG) training course. The material will help executives, planners, and engineers responsible for operations, fleet management, transportation, and /or environmental policy learn how to plan and implement a phased conversion of heavy-duty engines to LNG. Transportation and off-road agricultural, mining, construction, and industrial applications are discussed. The planning and engineering material in the manual is organized into three volumes.

Volume I provides a brief introduction to the physics and chemistry of LNG; an overview of several ongoing LNG projects; the economics of converting fleets to LNG; a summary of federal government programs, mandated and voluntary, that encourage conversion to LNG; a summary of LNG fuel station technology; a description of the LNG production and distribution infrastructure; and a description of available LNG medium- and heavy-duty vehicles, fuel systems, and engines.

Volume II presents a detailed discussion of the safety issues, codes, and regulations that have guided the development of modern LNG technology and have established a framework that will facilitate growth of the emerging LNG vehicle industry.

Volume III provides basic technical and safety information needed to train drivers, equipment operators, and fuel station operators in the use and maintenance of LNG vehicles and fuel stations.

\subsection{What is LNG ?}

Natural gas is a fossil fuel composed primarily of methane $\left(\mathrm{CH}_{4}\right)$; other hydrocarbons such as ethane, propane, and butane; and trace amounts of other gases, such as nitrogen, oxygen, hydrogen sulfide, and carbon dioxide $\left(\mathrm{CO}_{2}\right)$ (see Figure 1-1 and Table 1-1).

\subsubsection{Methane Is a Hydrogen-Rich Fuel}

Similar in appearance to water, $\mathrm{CH}_{4}$ is a colorless, odorless, tasteless, flammable gas. The first member of the paraffin (aliphatic or saturated) series of hydrocarbons, it is the major constituent of natural gas. Methane is soluble in alcohol or ether, and slightly soluble in water. Natural gas and $\mathrm{CH}_{4}$ are shipped as a nonliquefied compressed gas in cylinders at pressures of as much as 6000 psig at $70^{\circ} \mathrm{F}(41,368 \mathrm{kPa}$ at $\left.21.1^{\circ} \mathrm{C}\right)$.

\subsubsection{LNG Is a Quality Fuel}

LNG is manufactured in facilities that remove nearly all of the nonhydrocarbon contaminants and impurities normally found in natural gas. Before liquefying natural gas, substances that would freeze during the liquefaction process, such as water, $\mathrm{CO}_{2}$, sulfur, and some of the heavier hydrocarbons (see Figure 1-2 and Table 1-1), are removed. Pure liquefied $\mathrm{CH}_{4}$ boils at $-258.68^{\circ} \mathrm{F}\left(-161.7^{\circ} \mathrm{C}\right)$. The raw gas is cooled to $-260^{\circ} \mathrm{F}\left(-162^{\circ} \mathrm{C}\right)$ at atmospheric pressure so that the $\mathrm{CH}_{4}$ and heavier hydrocarbons in the gas condense to LNG (Figure 1-2). LNG typically contains 92 percent to 97 percent $\mathrm{CH}_{4}$. Some manufacturers of LNG go a step further by removing almost all nonmethane constituents, making LNG that is 99 percent plus pure $\mathrm{CH}_{4}$. Liquefied methane (LNG) is shipped in bulk quantities as a cryogenic liquid on trailers, railcars, barges, and tankers. 
Figure 1-1. Methane's Molecular Figure 1-2. Temperature Simplicity

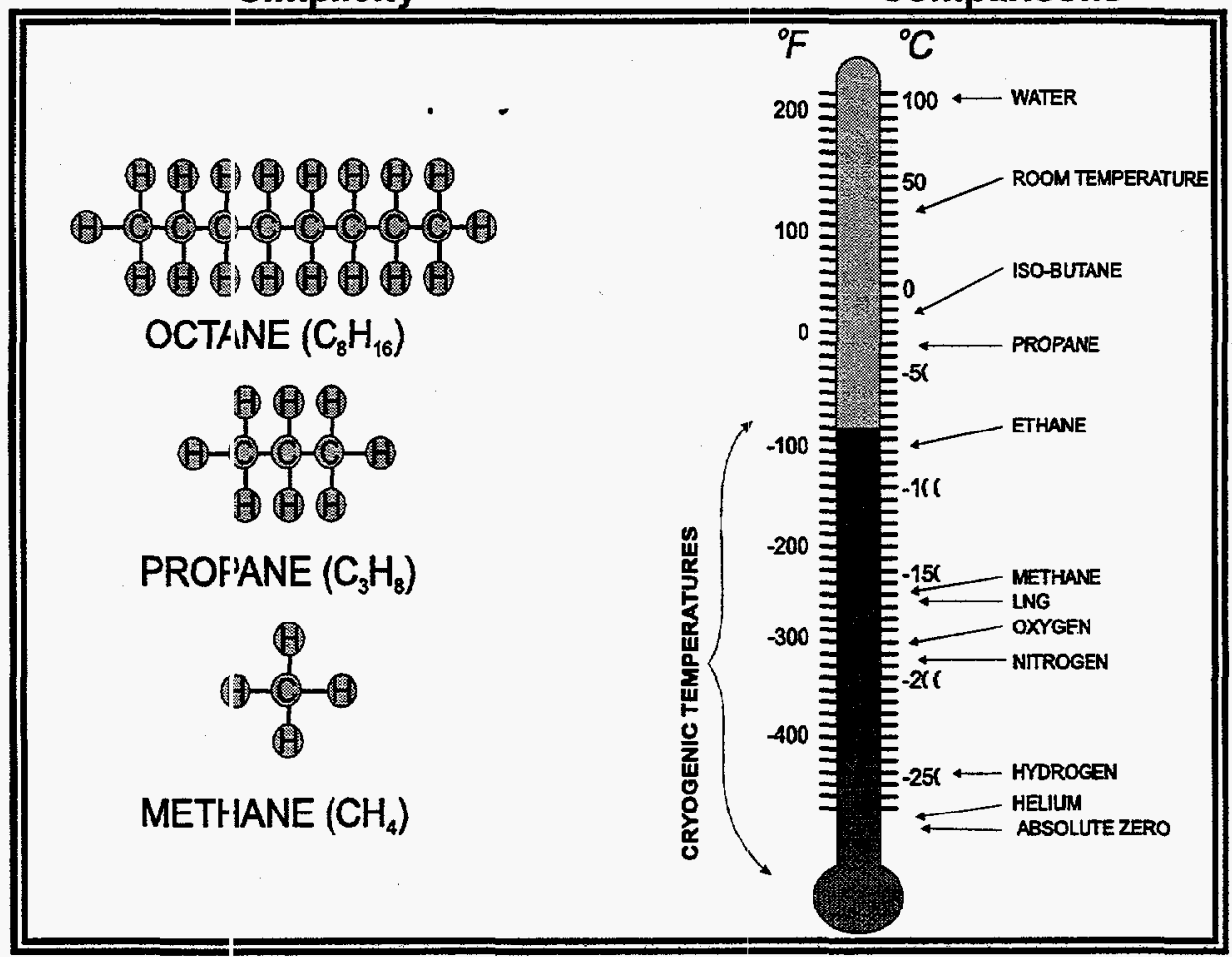

Table 1-1. Composition of LNG

\begin{tabular}{|l|c|c|c|}
\hline \multicolumn{1}{|c|}{ Component } & $\begin{array}{c}\text { Pipeline Inlet } \\
\text { Gas }\end{array}$ & $\begin{array}{c}\text { Typical Peak- } \\
\text { Shaving LNG }\end{array}$ & $\begin{array}{c}\text { Typical Higher } \\
\text { Purity LNG }\end{array}$ \\
\hline Methane & $81.3-97.5 \%$ & $95.3 \%$ & $97.5-99.5 \%$ \\
\hline Ethane & $2.0-7.0 \%$ & $4.1 \%$ & $<1 \%$ \\
\hline Propane & $0.27-3.00 \%$ & $0.43 \%$ & $<0.1 \%$ \\
\hline Iso-butane & $0.03-0.32 \%$ & $0.04 \%$ & - \\
\hline N-butane & $0.01-0.25 \%$ & $0.04 \%$ & - \\
\hline N-pentane & $0.01-0.90 \%$ & $0.01 \%$ & - \\
\hline Hexane & $0.02-0.17 \%$ & $0.05 \%$ & - \\
\hline Water & $3.5-201 \mathrm{bs} / \mathrm{MMcf}$ & - & - \\
\hline Nitrogen & $0.26-10.0 \%$ & $0.02 \%$ & $<2.5 \%$ \\
\hline Oxygen & $0-10 \mathrm{ppm}$ & - & - \\
\hline Carbon Dioxide & $0.47-1.50 \%$ & - & - \\
\hline Sulfur & $0-1.2 \# \mathrm{MMcf}$ & - & - \\
\hline
\end{tabular}

Because LNG exists at cryogeric temperatures, odorants can only be added after vaporization. Natural gas is combustible only in concentrations of 5 percent to 15 percent in air. LNG exists at a very low temperature $\left(-260^{\circ} \mathrm{F},-162^{\circ} \mathrm{C}\right)$ a: atmospheric pressure. However, compared to other cryogenic liquids, LNG is fairly warm. Liquid nitrogen, oxygen, carbon monoxide (CO), hydrogen, and helium are all considerably colder (see Figure: 1-2). LNG weighs about $3.5 \mathrm{lb} /$ gallon-approximately half the density of water. 


\subsubsection{LNG Is a Safe Fuel}

At ambient temperature and pressure, LNG will absorb heat and vaporize into a gas. It expands to occupy about 618 times its liquid volume. LNG will not ignite or burn in the liquid state; it must be in the vapor or gaseous state before it can be ignited. In an unconfined environment, neither LNG nor its vapor can explode.

When LNG is released or spilled, it evaporates and forms a visible plume of cold vapor in the immediate area. The visible limits of the cloud approximately define the lower flammability of the gas mixture. The vapor is initially heavier than air but quickly warms to become lighter than air. Methane is buoyant in ambient air when warmed to a temperature of $-160^{\circ} \mathrm{F}\left(-106^{\circ} \mathrm{C}\right)$. Under most atmospheric conditions, the buoyant gas will rapidly dissipate into the atmosphere.

\subsubsection{LNG-At Least 100 Years Old}

LNG has been used commercially for more than 100 years. In 1845, Michael Faraday was the first person to liquefy natural gas. In 1895 , Dr. Karl Von Linde developed a commercial cryogenic air separation process. Godfrey Cabot began transporting natural gas by barge in 1914 . The use of cryogenic liquid expanded during World War II. In 1942, the first large natural gas liquefaction plant was built in Cleveland, Ohio. Peak-shaving plants, which became popular during the energy crises of the 1960 s and 1970s, have provided pipeline companies and utilities with backup reserves of gas during periods of high demand. Large LNG liquefaction plants, terminals, and ocean-going ship construction also expanded during this period.

In 1992, Houston Metro started using LNG to run dual-fueled pilot ignition buses ( 80 percent natural gas usage and 20 percent diesel). From 1992 to the present, the technology for trucks, buses, and refueling stations has improved steadily and dramatically.

The production and transportation of LNG by commercial vehicles on public roads is an established and well-regulated industry. The industry has had an excellent safety record for the past 30 years.

\subsubsection{Compressed Natural Gas or Liquefied Natural Gas?}

Compressed natural gas (CNG) is an excellent vehicle fuel. It offers many benefits for light-duty vehicles, especially nonrevenue vehicles that have the space and weight available to store adequate fuel in high-pressure cylinders. LNG has several advantages for heavier duty vehicles that require onboard storage of larger quantities of fuel than is possible with CNG.

- First, vehicles can be designed to carry substantially more fuel as LNG than CNG in the same size and weight container. This increases vehicle range considerably and is especially important to fleets that have limited weight or space for cargo-where every pound or cubic foot of fuel storage displaces revenue-generating cargo.

- Second, LNG's composition of $\mathrm{CH}_{4}$ and other naturally occurring gases can be standardized within relatively narrow limits. Substances that degrade engine performance, like water, compressor oil, and $\mathrm{CO}_{2}$, are not found in LNG. Pure LNG (more than 99 percent plus $\mathrm{CH}_{4}$ ) can be purchased for slightly higher cost than standard LNG ( 85 to 97 percent $\mathrm{CH}_{4}$ ). Under certain operating conditions, some engines may perform better on high-purity or consistent-quality fuel. 
- Third, LNG is a liquid. It can be pumped, pressurized, and transferred more efficiently than a gas. Vehicles can be fueled as quickly with LNG as with conventional fuels.

- Fourth, because LNG can be transported hundreds of miles via truck or train and thousands of miles via ship or barge, multiple fuel suppliers will compete for fuel supply contracts.

Competition among LNG suppliers will help ensure that natural gas vehicle (NGV) fleets receive competitive and efficient market prices.

- Fifth, an LNG station can be converted to dispense CNG for little additional capital expense. This means that one LNG station can fuel some vehicles directly with LNG while others are fueled with CNG.

- Last, the LNG distribution system is dependable. Metropolitan transit fleets have documented that LNG fueling faciliiies can continue to operate in the event of a major catastrophe, like a hurricane or earthquaks. Most stations are designed to store a week's supply or more of LNG on site. A simple backup generator can provide required power in the event of a general power outage. LNG can also se obtained from multiple backup sources should the primary source become unavailable.

\subsection{The Benefits of LNG Fuels}

LNG is a superior fuel for internal combustion engines. It is abundant, clean burning, safe to handle, and inexpensive. LNG is produced at hundreds of facilities throughout the United States and in oil-producing regions. Although LNG can be imported, most LNG used for vehicle operations is produced from the extensive reserves of North American natural gas. The LNG vehicle fueling and supply infrastructure uses proven technology that ha: been developed by a mature and competitive cryogenics industry. LNG fuel stations, which are as relatively simple to operate and maintain as traditional diesel stations (Figure 1-3), are now available. With adequate investment in the LNG distribution and refueling infrastructure, LNG could be made available in the quantities needed to support a competitive market for LNG fleets operating in nearly all regions of the United States. The business, environmental, public health, and national security benefits of widespread conversion of heavy-duty engines and vehicles to LNG fuels would be immediate: and significant.

\subsubsection{The Business Beriefits of LNG Fuels: LNG Makes Sense (Cents)}

Public fleet managers, off-road equipment operators, and facility managers with applications that are exempt from the federal highway fuel excise tax can save on fuel costs by voluntary conversion to LNG fuels. In addition, replacement of diesel and gasoline fuels with LNG will provide employee health and environmental protection benefits that go far beyond regulatory requirements mandated by federal, state, and local laws and ordinances and enforced by governmental agencies. As an added bonus, conversion to LNG fuels will protect existing jobs in the fuel distribution industry and create additional jobs. Conversion to LNG fuels will also promote national security by reducing dependence on imported oil and relieving supply constrictions that could cause severe energy price increases. Direct cost savings can be realized in the following areas.

Lower Fuel Costs. In current niche markets, LNG is less expensive than gasoline and diesel fuel. Recent bids for LNG have beaten diesel by significant margins when compared on an equal British thermal unit (Btu) basis. For example, ALT-USA sells LNG from an Ontario, California, station for $\$ 0.685$ per LNG gallon (including taxes). This price is equivalent to $\$ 1.10$ per diesel equivalent gallon. 
Figure 1-3. LNG Utilization

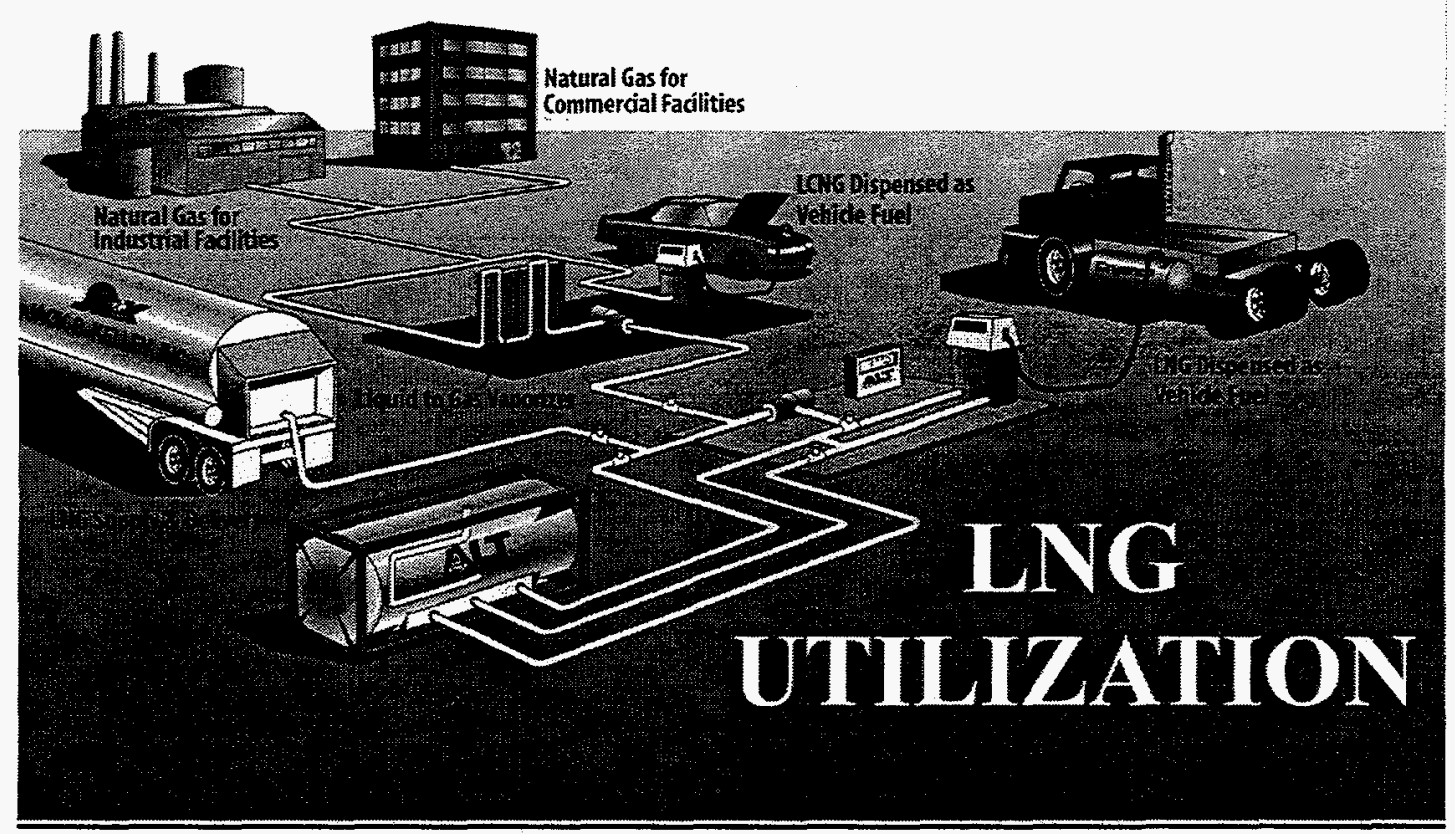

Fully taxed diesel prices in Southern California now average $\$ 1.50$ per gallon. Thus, fleet perators can lower fuel cost by operating their trucks on LNG rather than diesel fuel. The amount of savings will be affected by local fuel prices and the efficiency of the natural gas engine used.

Nationally, the average cost of diesel fuel (including all taxes) for an LNG fleet run by Jack B. Kelley, Inc. (JBK), fleet has been as follows for the past 3 years:

\section{$1994 \$ 1.119$ \\ $1995 \$ 1.113$ \\ $1996 \$ 1.201$}

For the past 30 years, natural gas has sold for 20 percent to 60 percent less per unit of energy than crude oil. Historically, LNG prices have closely tracked natural gas prices. The cost of LNG will depend on a number of regional factors, so it is difficult to make general statements about the cost and availability of LNG in any given location. However, in urban regions where LNG is available and environmental restrictions require clean fuels, LNG will be competitive with diesel fuel.

The Federal Excise Tax (FET) is lower for LNG than for diesel. Diesel is taxed at $\$ 0.244$ per gallon. The Taxpayer Relief Act of 1997 set the FET for LNG at $\$ 0.119$ per gallon. Because it takes approximately 1.7 gallons of LNG to provide the same energy as a gallon of diesel, the FET tax on LNG is about $\$ 0.202$ per diesel equivalent gallon-a saving of $\$ 0.042$ per diesel equivalent gallon.

Lower Environmental Compliance Costs. LNG can reduce, and eventually eliminate, the compliance costs associated with operating on-site fuel stations. The U.S. Environmental Protection Agency (EPA), as well as state and local environmental agencies, are currently exploring voluntary programs, such as Project XL, Pollution Prevention, and Climate Wise, as alternatives to traditional command-and-control 
regulation and enforcement programs. Conversion to LNG fuels offers the transportation industry the opportunity to make real envircnmental improvements and reduce overall costs.

Eliminate Environmental Liatility and Insurance Costs. Conversion to LNG can reduce and eventually eliminate the enviroumental risk and liability that accompany releases of diesel and gasoline fuels, which contain toxic chemicals that can contaminate surface water, groundwater, and soil. Compliance and remediation costs to clean up a single accidental release of only a few hundred gallons of diesel fuel can easily exceed $\$ 100,000$. Cleaning up larger releases can cost millions. Premiums for special environmental impairment liability insurance for petroleum storage tanks and on-the-road incidents are a significant operating expense that can be eliminated by conversion to LNG.

In addition to direct fuel cost and overhead cost savings, LNG offers the following indirect benefits.

\section{Indirect Cost Savings from the Use of LNG Fuels}

Longer Engine Life. LNG is a. clean fuel. Depending on the engine and exhaust system, natural gas has been reported to provide reductions of more than 90 percent in $\mathrm{CO}$, more than 80 percent in reactive hydrocarbons, more than 90 percent in particulate matter (PM), and more than 70 percent in oxides of nitrogen $\left(\mathrm{NO}_{\mathrm{x}}\right)$. These cleaner-burning attributes may lead to lower maintenance costs and longer engine life because less carbon builds up in the engine.

Stable Fuel Prices. Natural gas reserves are abundant; in fact, natural gas is believed to be the most abundant fossil fuel on Earth. Iixtensive gas reserves are located throughout the United States, Canada, Mexico, and in many other non-OPEC (Organization of Petroleum Exporting Countries) nations. In the United States, many oil and ga:s fields contain larger reserves of natural gas than oil. Consequently, the supply and price of natural gas is less dependent on the political stability of local governments or geographic regions.

Tax Incentives. Federal, state, and local tax incentives are available for conversion to LNG. For details, visit the Alternative Fuels Datc. Center on the World Wide Web at http://www.afdc.doe.gov.

Emission Credits. The EPA has proposed a national framework for emission credit trading. Although several states are developing p.ograms, California is the first state to actually implement an emission credit trading program for mobile sources. Sales of emission credits for $\mathrm{NO}_{\mathrm{x}}$ and fine particulate $\left(\mathrm{PM}_{10}\right.$ and $\mathrm{PM}_{2.5}$ ) could be significant revenue sources for fleets that voluntarily convert heavy-duty trucks to LNG.

\subsubsection{Environmental Benefits to Your Business from Using LNG Fuels}

In addition to direct and indirezt cost savings, conversion to LNG offers many intangible benefits stemming from its cleaner and safer working environment.

Much Lower Emissions-With their ultra-low pollution emissions, natural gas engines satisfy public health concerns. They emit significantly less $\mathrm{CO}, \mathrm{CO}_{2}$, reactive hydrocarbons, $\mathrm{NO}_{\mathrm{x}}$, and fine particulates than diesel engines (see Figure 1-4). When LNG is used in optimized lean-burn engines, $N_{x}$ plus nonmethane hydrocarbon (NM.HC) and particulate emissions can be reduced by more than 70 percent compared to 1998 technology diesel engines. 
Figure 1-4. In-Use Emissions Benefits of Natural Gas

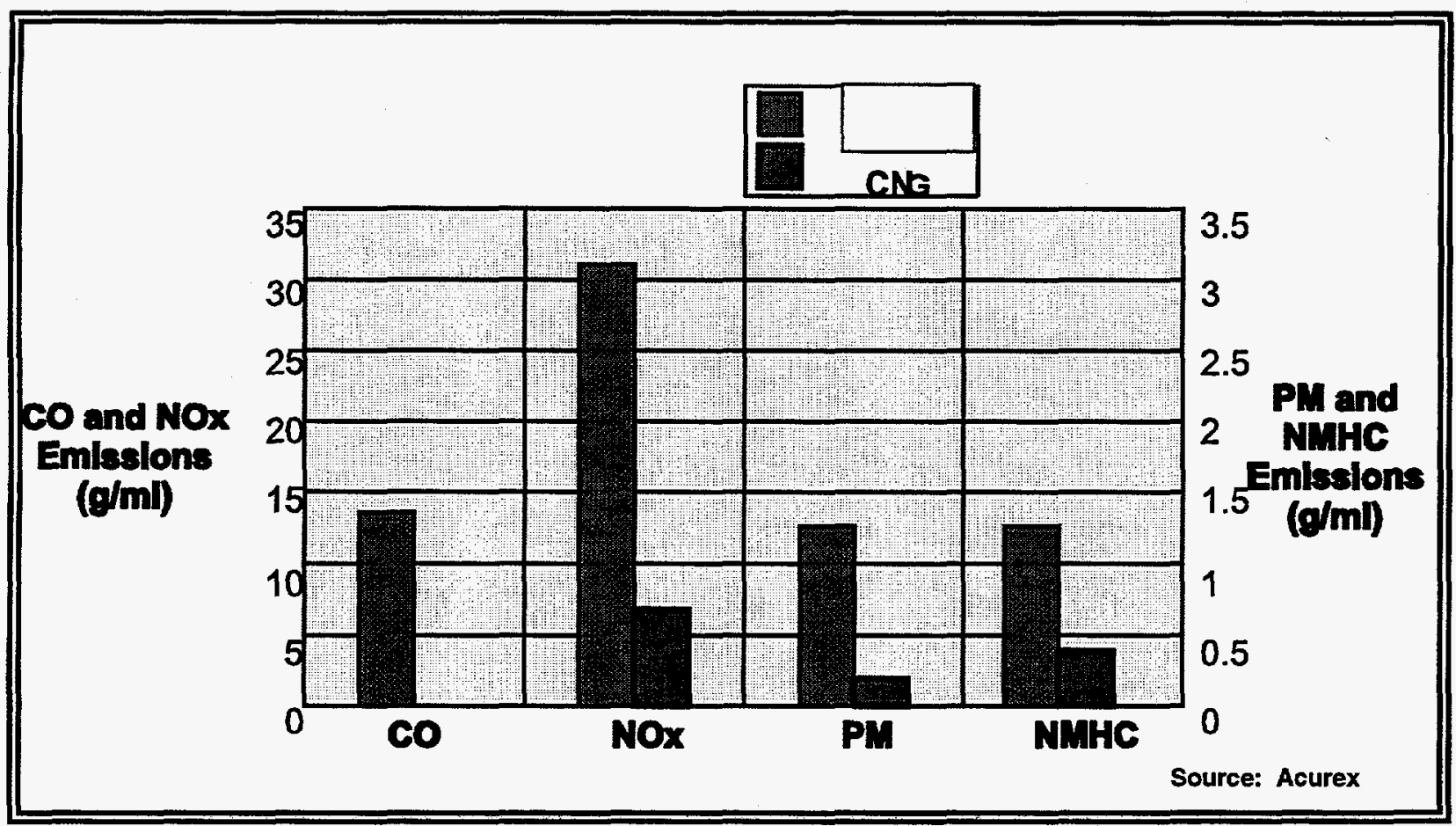

Employee Health-LNG is neither toxic nor carcinogenic. People who work with LNG fuels and engines will not be exposed to chemicals normally found in diesel and gasoline fuels and by-products of combustion. These chemicals, including benzene, ethylbenzene, polynuclear aromatic hydrocarbons, toluene, and xylene, are known to cause a broad range of health problems, including birth defects, cancer, heart disease, and respiratory disease.

Third-Party Liability - LNG is not a threat to soil, surface water, or groundwater. A spill or leak of LNG causes no lasting or residual contamination. Conversion to LNG effectively eliminates the longterm environmental liability associated with spills caused by traffic accidents, underground storage tank leakage, and routine fuel transfer spills.

Positive Relationships with Environmental Regulators-Emissions of all regulated and nonregulated pollutants are much lower when LNG is used in place of diesel. Soon-to-be regulated pollutants, such as fine particulates and polyaromatic hydrocarbons, are virtually eliminated when heavy-duty engines operate on LNG.

Exemption from Traffic Control Measures (TCMs)-Emissions of all regulated pollutants $\left(\mathrm{CO}, \mathrm{NO}_{\mathrm{x}}\right.$, reactive hydrocarbons, and large particulates) can also be reduced 50 percent to 90 percent as compared to diesel fuel. Methane is a nonreactive hydrocarbon, meaning that it does not contribute to the formation of smog (ground-level ozone). Mandatory TCMs are often lifted from clean vehicles.

Public Image- The general public associates smoke from trucks and the odor of diesel fuel with air pollution. The image of black smoke belching from the exhaust of a heavy truck laboring up a hill or 
shifting gears through an intersection is quite common. Clean, odor- and smoke-free trucks will be very visible and, with appropriate publicity, can be used to generate a positive image with customers and the public.

\subsubsection{The Safety Benefits to Your Business from Using LNG Fuels}

LNG must be handled with the same caution given all flammable fuels. Low temperatures, pressurized storage tanks (commonly 50 to 150 pounds per square inch gauge [psig]), and lack of odor require the operator to learn new procedures. When properly handled, LNG is an extremely safe fuel:

- First, LNG has a higher minimum flammability limit than most other fuels. Concentrations less than 5.3 percent will not burn, according to the U.S. Bureau of Mines. For comparison, the Bureau lists the lower 1ammability limit of gasoline at 1.4 percent and diesel at 0.6 percent.

- Second, LNG has a high ignition temperature. Temperatures exceeding $1000^{\circ} \mathrm{F}\left(538^{\circ} \mathrm{C}\right)$ are required to ignite $\mathrm{CH}_{4}$, compared to $428^{\circ} \mathrm{F}\left(220^{\circ} \mathrm{C}\right)$ for gasoline and $485^{\circ} \mathrm{F}\left(252^{\circ} \mathrm{C}\right)$ for diesel.

- Third, LNG spills disferse very quickly. The vapor becomes lighter than air when it has warmed to roughly $-160^{\circ} \mathrm{F}\left(71^{\circ} \mathrm{C}\right)$, and the gas will begin to disperse into the atmosphere. Consequently, the dangrer of fire is over within minutes after a small spill.

- Fourth, because LNG is a very cold liquid, leaks and spills are highly visible. As LNG vaporizes, the cold gas freezes water vapor in the surrounding air, causing a white vapor cloud. The flammable perimeter of the air-gas mixture generally coincides with the visible boundaries of this cloud. Emergerıcy response crews and bystanders can easily see and thus avoid the visible cloud.

- Fifth, $\mathbf{C H}_{4}$ is nontoxic. It is a simple asphyxiate. Exposures to concentrations of up to 9 percent $\mathrm{CH}_{4}$ have been reported without ill effects. Inhalation of higher concentrations will eventually cause a feeling of presisure on the forehead and eyes, but the sensation is temporary and has no lasting effects. Symptioms end when fresh air is provided. Extended exposure to high concentrations of $\mathrm{CH}_{4}$ can cause unconsciousness and/or asphyxiation.

- Sixth, momentary cortact with LNG is harmless to exposed skin; however, extended contact can cause severe freezi: burns and destruction of tissue. Methane does not contain any toxic compounds that are absorbed through the skin.

- Last, LNG has been handled safely for decades in very large quantities for power generation and natural gas pipeline distribution, beating the safety records of most other fossil fuels. Millions of truckloads of LNG have been hauled over U.S. highways without any significant incidents. Other cryogenic liquids, such as liquid oxygen $\left(-297^{\circ} \mathrm{F},-182^{\circ} \mathrm{C}\right)$ and liquid nitrogen (LIN) $\left(-320^{\circ} \mathrm{F},-195^{\circ} \mathrm{C}\right)$, have been safely adapted for thousands of common daily uses in hospitals, clinics, universities, and manufacturing facilities.

\subsection{The Disadvantages of LNG Fuels}

Several disadvantages associated with conversion to LNG stem from the higher capital costs and technology risk associated witl a new or emerging technology. These disadvantages are most pronounced when viewed from a short-term perspective. 


\subsubsection{Higher Initial Capital Investment}

Cryogenic storage and transportation systems are more expensive than mild steel diesel tanks and pipe. Special cryogenic-tolerant materials, such as stainless steel, must be used rather than less expensive mild steel. However, the cryogenic equipment is corrosion resistant and has a longer service life.

LNG must be stored in highly efficient, insulated tanks. Because every piece of equipment must be designed to keep heat absorption rates as low as possible, highly insulated containers, pipe, and other equipment must be used. All equipment and piping used to handle LNG must be carefully designed and fabricated. During the past 40 years, however, the industrial gas and aerospace industries have developed specialized equipment for storing and transferring "cryogenic" liquids, because of the significant weight and space benefits of transporting liquid gases rather than compressed gases.

Natural gas engines are nearly identical to their diesel counterparts. The newer natural gas engines, however, will be priced at a premium compared to diesel engines until production volumes increase and manufacturers can spread out their investments in design and tooling.

Federal and state tax incentives are available to reduce the net cost of an LNG infrastructure.

\subsubsection{Cold Temperatures}

LNG is cold $\left(-260^{\circ} \mathrm{F},-162^{\circ} \mathrm{C}\right)$. Temperatures below $-240^{\circ} \mathrm{F}\left(-151^{\circ} \mathrm{C}\right)$ are referred to as "cryogenic." Many common gases are stored as liquids at these temperatures (see Figure 1-1). Oxygen used in hospitals is commonly stored at about $-297^{\circ} \mathrm{F}\left(-182^{\circ} \mathrm{C}\right)$, nitrogen used in preparing frozen foods is stored at about $-320^{\circ} \mathrm{F}\left(-195^{\circ} \mathrm{C}\right)$, and liquid helium is stored at about $-452^{\circ} \mathrm{F}\left(-268^{\circ} \mathrm{C}\right)$. In storage, the cryogenic liquid warms slowly, gradually increasing in pressure as the liquid absorbs heat from its surroundings.

Most people have never handled cryogenic liquids. Even though liquid oxygen, $\mathrm{LIN}$, argon, $\mathrm{CO}_{2}$ have many everyday uses, people working with cryogenic liquids must become comfortable with the specialized handling procedures they require.

\subsubsection{Infrastructure Is Limited LNG for Vehicles Involves a New Industry}

Compared to the petroleum industry, there are relatively fewer suppliers for the equipment and services needed to implement an LNG vehicle project. Initially, lack of competition may result in higher prices, slow or unresponsive service, possible price gouging for parts, and longer delivery times than normally expected.

Some of the cryogenic equipment developed for military or aerospace applications is highly specialized. Consequently, some tanks, pipe, and pumps may not have been designed to handle all the conditions found in general commercial service. Equipment failures may occur more frequently than desired until manufacturers learn how to fabricate equipment that will perform in commercial service as well as military Oapplications.

Engine manufacturers are still developing natural gas versions of their diesel engines. Minor problems with natural gas engines may occur more frequently than desired until design and manufacturing glitches are solved. 


\subsubsection{Lower Energy Density}

A gallon of LNG contains about 60 percent of the energy contained in a gallon of petroleum diesel fuel. This lower energy density can be offset by properly sizing the LNG tanks on the trucks.

\subsection{LNG Helps Solve Many Regional and National Public Policy Issues}

The American transportation in dustry is nearly 100 percent dependent on petroleum-derived fuelsgasoline and diesel fuel. This $\epsilon$ xtreme dependence on petroleum-based energy for a strategically critical industry has created a number of public policy issues that can only be addressed comprehensively by national governments. Political instability of many oil-producing nations, projection of military power to protect the sea lanes for free passage of oil tankers, the high cost of maintaining and deploying military power, increased levels of atmospheric $\mathrm{CO}_{2}$ resulting from the combustion of fossil fuels, trade deficits caused by oil imports, and restrictions on free trade, are policy issues that can only be solved by the collaborative efforts of national governments (see Figure 1-5).

The Western nations have strugrgled for decades to accommodate population and economic growth while attempting to maintain the region's unique environment and protect its natural resources. Historically, the Western world has faced these issues alone, often competing to attract investments, jobs, and tourists.

Figure 1.5. U.S. Import Dependence 1985 versus 1995

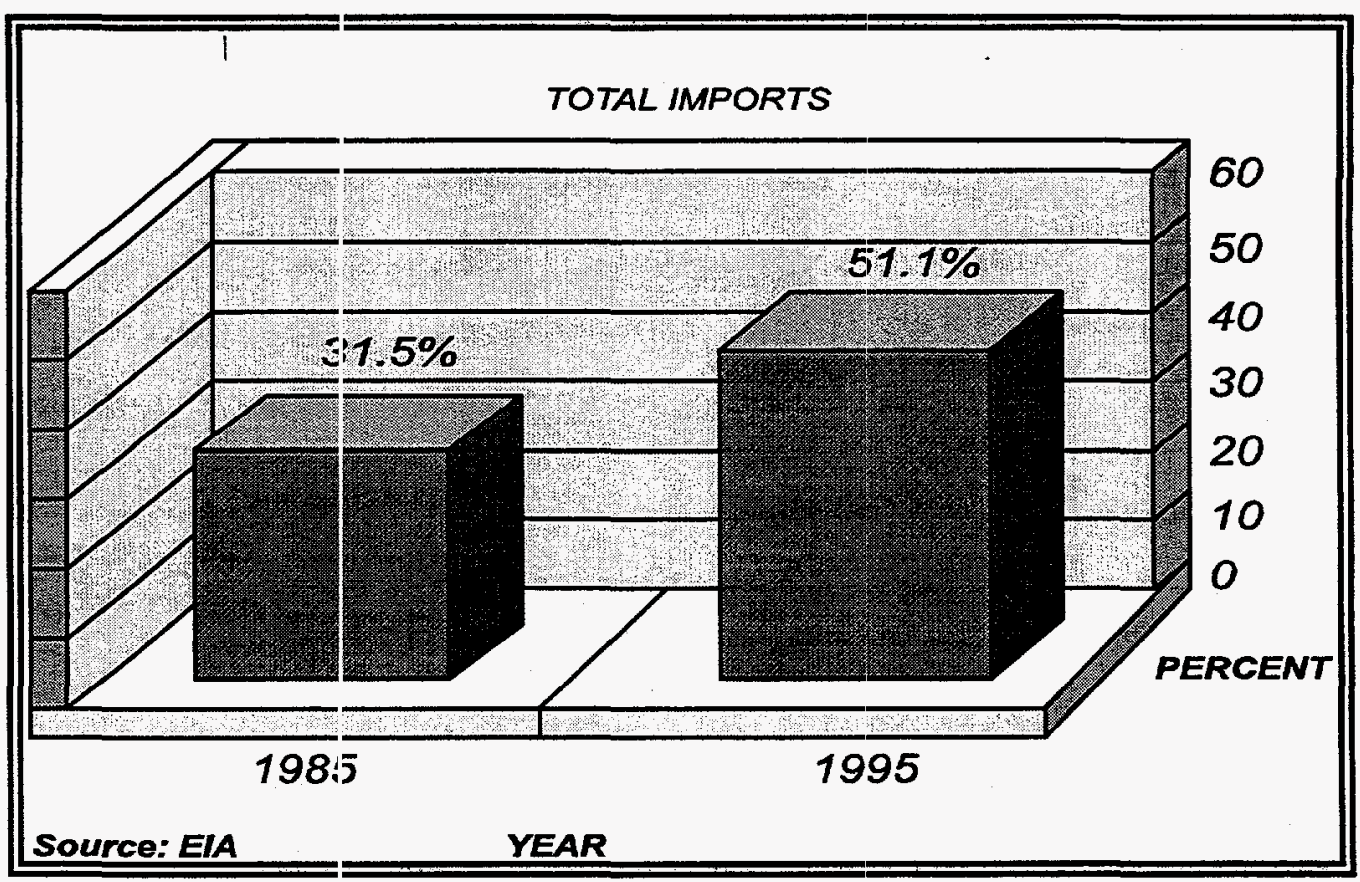


Increasingly in recent years, however, these nations have come to realize that the ecology and the economy of the region are interconnected. To prosper in a healthy, clean environment, the people of the Western world will need to work together.

LNG can play a critical role in protecting public health and the environment and in promoting economic development. Fleet conversion to LNG will reduce environmental compliance costs and long-term liability exposure. Corporate pollution prevention and environmental management programs, such as International Standards Organization (ISO) 14000 , can be used to quantify and demonstrate how conversion from diesel and gasoline fuels to LNG can result in significant reductions in air pollution, oil spills from tankers and barges, leaks from aboveground and underground tanks, and releases of toxic chemicals into the water and air.

These programs can be very cost effective when implemented at the local level. Diversifying energy supplies for critical transportation operations, reducing costs of environmental compliance, reducing operating costs, and enhancing profitability for shareholders are economic benefits that individual companies and local government can capture by converting to LNG fuels.

\subsubsection{Oil Imports, Energy and Economic Security, and Trade Deficits}

In 1995, the United States economy consumed an average of 17.7 million barrels of oil per day (MBOD). Of this amount, less than 7 MBOD were produced domestically. More than 10 MBOD were imported from Mexico, Venezuela, Nigeria, and many other countries, including the major oil-producing nations in the Middle East (EIA, 1996). Ten years ago, imports were only about 31 percent of total use; imports in 1995 were more than 50 percent (Figure 1-5). The trend is for American petroleum imports to increase significantly as domestic production continues to decline.

Unfortunately, global oil consumption is also projected to increase significantly as the rapidly growing economies of Southeast Asia and China dramatically increase consumption of energy, led by aggressive investments in the automobile and truck industries. Global petroleum production may not increase sufficiently to satisfy this projected demand. Although it is impossible to predict when or how much prices will increase, it should be noted that oil prices in December 1996 were about 20 percent higher than those in December 1995, and 50 percent higher than those recorded during the post-Gulf War lows. These recent price jumps appear to result from long-term increases in demand and smaller increases in worldwide production.

Energy Security - The American transportation industry is nearly totally dependent on petroleumderived fuels—gasoline and diesel fuel-to power heavy-duty engines. Cost-effective and reliable transportation services are vital to corporate profitability and the overall health and stability of our national economy. Unfortunately, our exclusive dependence on one fuel source makes our manufacturing economy very vulnerable to rapid increases in oil costs or disruptions in supply.

Arab Oil Embargo of 1973. Prior to 1973, the United States controlled the world oil market. In 1973, however, U.S. oil production peaked and several Arab nations, angered at U.S. support of Israel in the 1973 Arab-Israeli War, instituted an oil embargo against the United States and Holland. The 6-month embargo created short-term shortages and price increases. When the embargo was lifted, world oil prices tripled from the 1973 average to about $\$ 12$ per barrel and OPEC took firm control of the world oil market.

Despite production buildups from the North Sea and Alaska and domestic price and allocation controls, the Arab OPEC share of the U.S. crude oil imports increased from 26 percent in 1973 to 47 percent in 
1977. The large jump in energy prices was a major cause of the economic recession that occurred in 1974 and 1975.

Iranian Revolution of 1978-1:279. The Iranian Revolution, which began in late 1978, and the Iran-Iraq War, which began in 1980, resulted in a drop of $3.9 \mathrm{MBOD}$. The world price of crude oil jumped from about $\$ 14$ per barrel in 1979 to more than $\$ 35$ per barrel in 1981 . Prices then stabilized at about $\$ 28$ per barrel in 1983. In response to ligher prices, fuel-switching and conservation reduced U.S. oil demand from 18.8 MBOD in 1978 to $15.2 \mathrm{MBOD}$ in 1983. World demand also dropped about 5 percent to 60 MBOD. The Petroleum Price and Allocation Decontrol Act of 1981 removed price and allocation controls on the oil industry. Domestic production, mostly in Alaska, increased; a number of small, inefficient refineries closed; and domestic refinery utilization rates increased significantly.

Crude Oil Price Collapse of 1986. Late in 1985, Saudi Arabia abandoned its efforts to defend the official OPEC oil price. A glu: of oil resulted and world prices fell sharply in early 1986 from about $\$ 24$ per barrel to less than $\$ 10$ per barrel. Domestic oil production dropped, consumption increased, and imports from OPEC nations in:reased from 3.2 MBOD in 1985 to 6.1 MBOD in 1992. Most of this increase was met by OPEC, whose share in U.S. crude imports rose from 41 percent in 1985 to 60 percent in 1990.

Persian Gulf War of 1990-19:91. Iraq's invasion of Kuwait on August 2, 1990, caused crude oil and product prices to rise suddenly and sharply for the third time in 17 years. Between late July and September 1990, the world prize of crude oil climbed from about $\$ 16$ per barrel to about $\$ 36$ per barrel as 4.3 MBOD from Iraq and Kuwait was removed from world markets. When the United Nations approved the use of force in Oztober, the price of oil stabilized and then fell. Concurrently, the United States, Japan, and European netions sold about 2 MBOD from government-held stocks and Saudi Arabia and Iran increased production. The United States also increased export of motor gasoline to Europe and Canada to compensate for disruptions caused by the war. The success of the Allied air strike on January 16, 1991, caused a record 1-day drop in oil prices.

The decisive Allied military victory allayed fears of a cutoff in Middle East crude oil production and worldwide oil prices dropped. Unfortunately, the United States has had to maintain more than 35,000 troops, a massive show of air plower, and an attack carrier group in the region to enforce the terms of the Iraqi surrender. Two additional attack carrier groups are within 7 days sailing time of the region. Although these units serve other functions, their primary mission is to ensure the stability of the global oil market.

Economic Security - This sitıation has created a number of unresolved public policy issues that are critical to our national economy and quality of life. Unfortunately, oil supply issues can only be addressed comprehensively by national governments. There are many policy issues that can only be solved by the collective and collaborative efforts of national governments.

American military power is used to enforce peace in the Middle East and thus provide the security needed for global oil trade to function. The American taxpayer pays for this international effort from the general revenues at an annual cost conservatively estimated to be between $\$ 15$ billion and $\$ 35$ billion. Some economists estimate the cost to be as much as $\$ 90$ billion per year. This hidden cost represents a subsidy of between $\$ 4$ and $\$ 24$ for each barrel of oil imported into the United States. Spot oil prices near the end of 1996 fluctuated between $\$ 22$ and $\$ 25$ per barrel. If imported oil were taxed to provide the funds required to provide military security-a user fee-domestic oil prices would increase significantly. Unfortunately for the LNG inilustry, Congress is not likely to eliminate this subsidy. 
However, as the debate about national oil supply policies continues, market conditions can change very quickly. Individual businesses and state and local economies are severely depressed when gasoline and diesel prices rise and/or supplies are constricted because of unanticipated severe weather or political incidents in oil-producing nations. Fortunately, individual businesses and state and local governments now have the opportunity to take prudent action to protect their interests from disruptions in global oil markets by converting to other fuels such as LNG.

Diversified fuel supplies will protect businesses from rapid price increases and protect the domestic economy from inflation caused by runaway fuel prices. In addition, investment in LNG will create local jobs and will have a positive effect on local economies. Conversion to domestically produced, clean LNG will have a favorable influence on several national policy issues associated with our dependence on imported oil.

Trade Deficit-Americans spend about $\$ 5$ to $\$ 50$ billion per year for imported oil. This expenditure represents about 10 percent of the trade deficit and is the single largest category of spending for imported goods and services.

\subsubsection{Urban Air Pollution}

Two of the most significant environmental problems in the United States are urban air pollution and diminishing visibility. The primary pollutants-PM, ozone, $\mathrm{CO}$, and hazardous chemical gases - have multiple adverse public health consequences. Hundreds of millions of tons of these and other hazardous air contaminants are produced in American metropolitan centers every year, resulting in serious air pollution. Nearly all major U.S. cities are in nonattainment for one or more of the criteria air pollutants defined by the Clean Air Act. In addition, recent data indicate that national ambient air quality standards (NAAQS) for fine particulates are inadequate to protect public health. More stringent NAAQS standards were proposed by the EPA in December 1996.

Air pollution has had a dramatic impact on public health and the economy. Air pollution costs the economy of Southern California between $\$ 9$ and $\$ 14$ billion annually in lost productivity, increased health care costs, and damaged crops and structures (Hall, 1989). National health costs of air pollution were estimated to be more than $\$ 50$ billion in 1988 . Although dramatic improvements in urban air quality have been made in the past 25 years, epidemiological studies and improved understanding of the causes of disease suggest that continued progress is needed to protect sensitive individuals, including children, young adults, females of child-bearing age, and the elderly.

The smallest airborne particles, which are created by combustion of petroleum-based vehicle fuels, have been shown to increase mortality by as much as 17 percent in the country's most polluted cities (Pope, 1995). PM is responsible for as many as 60,000 deaths a year in the United States, or 3 percent of total mortality (Dockery, 1995). Additionally, diesel exhaust has been associated with as many as 30,000 lung cancer deaths in California alone (Dawson, 1994). Urban air pollution is one of the country's leading public health problems.

Mobile-Source Pollution Is a Major Air Quality Problem-Regional air pollution is a public health issue that is defined by several chemical parameters, including ground-level ozone, reactive hydrocarbons, $\mathrm{NO}_{\mathrm{x}}, \mathrm{CO}$, and, increasingly, fine particulates and toxins. Emissions from internal combustion engines are a major source of these chemicals.

Historically, California has had such severe air quality problems caused by mobile sources that the California Air Resources Board (CARB) and local air quality management districts have had to develop 
and implement state and region: 1 policies that are much more aggressive than national air quality control policies. In fact, the California air quality programs have shaped national and global environmental policies. State and local goverr ments there have created regulations that have forced development of the technological innovations that have made low-emission vehicles (LEVs) commercially feasible.

Atmospheric pollutants are classified according to the origin and form of the chemical contaminant. Primary pollutants are discharged directly from the source into the atmosphere, whereas secondary pollutants are formed from chemical reactions that occur in the atmosphere. Contaminants can be classified as gases, vapors, smoke, fumes, mists, aerosols, and particulates, and may be composed of toxic mixtures of thousands of halogenated organic compounds, elemental carbon, heavy metals, nitrogen compounds, and sulfur compounds.

Any internal combustion engint: that uses gasoline or diesel fuels releases these contaminants, which are by-products of combustion and volatile hydrocarbons that evaporate from the carburetor, engine block, and gas tank. Passenger cars are a major cause of mobile-source contamination simply because there are so many of them. Trucks and off-road vehicles are also major sources because of their high consumption of diesel fuel.

Gasoline- and diesel-powered vehicles release several types of contaminants, including $\mathrm{CO}$, unburned hydrocarbons, $\mathrm{NO}_{\mathrm{x}}$ sulfur dioxide $\left(\mathrm{SO}_{2}\right)$, and particulates. A complex mixture of chemicals, commonly known as photochemical smog and measured as ozone, is formed in the atmosphere as a result of the reaction of volatile hydrocarbons and $\mathrm{NO}_{\mathrm{x}}$ catalyzed by sunlight. Vehicles also emit other toxic air pollutants, including lead, polyıuclear aromatic compounds (PNA), hydrogen cyanide, organic sulfides, ammonia, organic amines, pher ols, and several aldehydes.

The following sections present the major contaminants from mobile sources and their effects on health and the environment.

Carbon Monoxide. CO formed by incomplete combustion of the fuel in the engine is released to the atmosphere through the exhaus: system. CO concentrations are highest when the engine operates "rich"; i.e., at a low air-to-fuel ratio as during engine cold starts. $\mathrm{CO}$ emissions increase considerably when the engine idles for extended periols or is operated with a heavy load at low speeds.

$\mathrm{CO}$ is colorless, odorless, and highly poisonous. It affects the cardiovascular, central nervous, and pulmonary systems. CO aggravates angina, a form of heart disease; chronic lung disease; and anemia. Fetal development may also be adversely affected by exposure to $\mathrm{CO}$.

When $\mathrm{CO}$ is inhaled it combines with hemoglobin to produce carboxyhemoglobin. This chemical reaction reduces the normal capracity of the blood and the respiratory system to take up oxygen, causing stress to the heart and respiratory system. The heart works at a slower pace and the lungs must work harder to provide more oxygen to the blood. The lack of oxygen could cause, in extreme cases, acute intoxication, producing coma and even death resulting from damage to the nervous system.

Long-term exposure to low levils of $\mathrm{CO}$ has harmful chronic effects on the central nervous system, especially if the concentration of carboxyhemoglobin in the blood is greater than 2 percent for a period of 8 or more hours. Researchers affirm that 6 -week exposure to ambient $\mathrm{CO}$ concentrations of about 50 parts per million (ppm) results in blood concentrations of more than of 8 percent carboxyhemoglobin. This level of exposure can cause structural changes in heart and brain functions. Therefore, the EPA has established an 8-hour NAAQS for CO in addition to the 1-hour standard. 
Hydrocarbons. Hydrocarbon emissions encompass a large number of organic compounds-some are harmful, others are benign. Total hydrocarbons (THCs) is the term used to describe the mass concentration of every organic compound in the sample. A THC sample is generally divided into two classes of hydrocarbons, reactive and nonreactive. Nonreactive hydrocarbons, such as $\mathrm{CH}_{4}$, are stable and do not contribute to the formation of photochemical smog. Reactive hydrocarbons, also called nonmethane reactive hydrocarbons (NMRHs) or volatile organic compounds (VOCs), react in the atmosphere to form photochemical smog. Many reactive hydrocarbons commonly released from mobile sources are also toxic or hazardous contaminants, such as benzene, which is classified as a carcinogen.

Hydrocarbons are released both from the exhaust system and from fugitive sources such as evaporation and engine blow-by. In general, tailpipe emissions of hydrocarbons are highest when the air-to-fuel ratio is lowest or "rich." Incomplete combustion causes the formation of many other organic contaminants, including formaldehyde, acetaldehyde, volatile organics, alcohol, acrolein, and PNAs. These compounds are formed in concentrations between 0.5 and 1 percent and are classed as toxics, carcinogens, mutagens, and/or teratogens. Reactive hydrocarbons are harmful because they react with other contaminants, such as $\mathrm{NO}_{\mathbf{x}}$, to form photochemical smog.

Fugitive hydrocarbon emissions are VOCs. Emission rates are a direct function of the volatility of the fuel, as measured by the Reid vapor pressure (RVP). Benzene and 1,3-butadiene are common constituents in fugitive emissions from gasoline-powered vehicles. Mobile-source regulations in the United States have attempted to reduce fugitive emissions through mandates that forced development of gasoline with lower RVPs; lower concentrations of benzene and other aromatics; oxygenates; reformulated gasoline (RFG); and "clean" diesel fuel. The mandates vary with location and time of year.

Oxides of Nitrogen. $\mathrm{NO}_{\mathrm{x}}$ forms a large family of compounds, including nitrous oxide, nitric oxide, and nitrogen dioxide $\left(\mathrm{NO}_{2}\right)$. $\mathrm{NO}_{\mathrm{x}}$ is a by-product of combustion from stationary and mobile sources. These compounds are formed by reactions between oxygen and nitrogen inside the combustion chamber. $\mathrm{NO}_{x}$ is released through the exhaust pipe. The mass of $\mathrm{NO}_{\mathrm{x}}$ formed depends mainly on the air-to-fuel ratio, combustion efficiency, and in-cylinder peak temperature. Conditions favorable to $\mathrm{NO}_{\mathrm{x}}$ formation are generally unfavorable to formation of $\mathrm{CO}$ or hydrocarbons.

$\mathrm{NO}_{\mathrm{x}}$ can have direct and indirect health effects. $\mathrm{NO}_{\mathrm{x}}$ combines with other volatile hydrocarbons in the atmosphere to form photochemical smog. Smog is the result of an extremely complex series of reactions among $\mathrm{NO}_{\mathrm{x}}$ and reactive hydrocarbons catalyzed by solar radiation. The reactions can form several toxic compounds. For example, these reactions produce aldehydes, ketones, free radicals, and a class of compounds known as peroxy carboxylic nitric anhydrides (PANs). These compounds provoke tears and irritation in the nose and throat.

The human sense of smell can perceive $\mathrm{NO}_{\mathrm{x}}$ at concentrations as low as 1 to 3 parts per million (ppm). Exposure produces the same effect as $\mathrm{CO}$-difficulty in breathing. This occurs when $\mathrm{NO}_{\mathrm{x}}$ combines with the hemoglobin to reduce the capacity of blood to carry oxygen. Exposure to 15 to $25 \mathrm{ppm}$ for more than 1 hour produces a slight to intense discomfort in the thorax. Exposure to $50 \mathrm{ppm}$ for 1 minute can cause severe chest pain. Exposures higher than $50 \mathrm{ppm}$ cause acute intoxication. Fatal cases of pulmonary edema and bronchopneumonia have been documented from exposures extending over a period of hours or days.

Sulfur Dioxide. $\mathrm{SO}_{2}$ is produced by diesel engines and stationary sources that burn heavy oil and coal. Relative to stationary sources, mobile sources are small contributors of $\mathrm{SO}_{2}$. However, small quantities of sulfur in diesel fuel contribute to the formation of large quantities of fine particulate in the exhaust. 
When a diesel engine is operating in a "rich" condition, each gram of fuel will emit about $0.8 \mu \mathrm{g}$ of particulate.

The principal impact of $\mathrm{SO}_{2}$ is its transformation into sulfuric acid, the main component of acid rain. Sulfuric acid is a serious envircnmental concern throughout the world. $\mathrm{SO}_{2}$ affects the health of people, terrestrial and aquatic ecosystens, and buildings. Along with causing serious damage to the lungs, it can be very harmful to the eyes, skin, and respiratory system. Most affected people experience respiratory irritation when exposed to $5 \mathrm{ppm}$ of $\mathrm{SO}_{2}$ for only 30 minutes.

Occasionally, severe reactions zause inflammation of the nasal mucous, lesions on the respiratory passages, and physical disintegration of tissues. The hazard to the respiratory system is greatest when metal-bearing fine particulate suspended in the air acts as a catalyst to convert $\mathrm{SO}_{2}$ directly into sulfuric acid.

As with other contaminants, the harmful effects of $\mathrm{SO}_{2}$ are not only a function of the concentration and time of exposure, but also of the geographical and meteorological conditions. In some regions of the world, large releases of $\mathrm{SO}_{2}$ have caused catastrophes. Three examples include Belgium's Mosa Valley, where in 1930, hundreds of pecople developed serious breathing problems and dozens died; the Donora Valley in Pennsylvania, where in 1948, more than 6,000 people became sick and 18 died; and London, where more than 4,000 died in 1952 . The common conditions in all three of these cases were low temperatures, light winds, thernal inversions, and high emissions of $\mathrm{SO}_{2}$ and other contaminants.

These episodes demonstrate the danger to public health caused by thermal inversions that trap $\mathrm{SO}_{2}$ and other contaminants. Severe health effects occur when $\mathrm{SO}_{2}$ concentrations exceed 300 micrograms per cubic meter $\left(\mu \mathrm{g} / \mathrm{m}^{3}\right)(0.11 \mathrm{ppm})$ averaged over 24 hours.

Total Suspended Particulate (TSP) and Fine Particulate (PM $M_{10}$ and PM 2.5$)$. Total suspended particulate is the measurement of the mass of all solid material present in a measured volume of air. It is generally expressed as $\mu \mathrm{g} / \mathrm{m}^{3}$. Fine partizulate is the mass of all solid material below a specified size present in a measured volume of air. For example, $\mathrm{PM}_{10}$ is the mass measurement of material less than 10 microns and $\mathrm{PM}_{2.5}$ is the measure of material less than 2.5 microns, in $\mu \mathrm{g} / \mathrm{m}^{3}$.

TSP is generally composed of coarse material, such as dust and soot, which is highly visible. Fine particulate is often composed of mists and fumes that are more difficult to see and measure. Air quality monitors for TSP and $\mathrm{PM}_{10}$ are located throughout the United States. Although many TSP and $\mathrm{PM}_{10}$ data have been collected, $\mathrm{PM}_{2.5}$ moritoring is not very common and data are sparse. The actual levels of $\mathrm{PM}_{2.5}$ in most urban areas are not known. Research has demonstrated that measured concentrations of TSP or $\mathrm{PM}_{10}$ are not accurate indicators of $\mathrm{PM}_{2.5}$ concentrations.

Fine particulate is formed direstly in combustion processes and in secondary reactions in the atmosphere of emitted gases, such as heav' hydrocarbons (greater than 8 carbon atoms per molecule), $\mathrm{SO}_{2}$, ammonia, and $\mathrm{NO}_{\mathrm{x}}$. A poorly maintained engine produces large quantities of fine particulate. Even wellmaintained gasoline and diesel engines produce by-products of combustion that include significant quantities of fine particulate.

Scientific evidence linking fint: particulate to health effects is persuasive. Although coarse particulate material is generally captured in the nose and mouth, the extremely small $\left(\mathrm{PM}_{2.5}\right)$ material passes through the nasal cavity and penetrates deep into the pulmonary tract where it can cause severe and irreversible health problems. 
Dr. Joel Schwartz of the Harvard School of Public Health believes that the evidence of disease caused by ambient $\mathbf{P M}_{2.5}$ is as strong as the health effects associated with cigarette smoke. With 19 of its 21 members agreeing, the Clean Air Scientific Advisory Committee to the EPA has voted to recommend new standards for $\mathrm{PM}_{2.5}$. Industry groups even agree that regulation of $\mathrm{PM}_{2.5}$ is needed. However, there is extensive disagreement on the standards proposed by the EPA in November 1996.

In a 16-year study of 8,111 residents of six U.S. cities, researchers at the Harvard School of Public Health found that fine particle pollution was strongly associated with excess mortality from lung cancer and heart disease. Even when other lifestyle risks—-such as cigarette smoking-were factored out, the cities studied all had $\mathrm{PM}_{10}$ levels below the federal health standard. Cities included in the research study were Watertown, Massachusetts; Harriman, Tennessee; St. Louis, Missouri; Steubenville, Ohio; Portage Wisconsin; and Topeka, Kansas.

A 1989 study sponsored by the South Coast Air Quality Management District in Southern California estimated that $\mathrm{PM}_{10}$ pollution was responsible for 1,600 premature deaths a year in the South Coast Air Basin. A follow-up study in 1995 of 552,138 people in 151 U.S. cities documented that the mortality risk was 15 to 17 percent higher in the more polluted cities. Most of the cities studied were in compliance with the existing NAAQS for particulate.

Biological mechanisms that link particulate to specific health effects have also been documented recently. Denissenko, et. al. (Science, October 18, 1996) reported a direct etiological link between a defined chemical carcinogen (benzo(a)pyrene) and occurrence of human cancer.

Lead $(\mathrm{Pb})$ and Other Metal Additives. Tetraethyl and tetramethyl lead have been used as a lubricant and anti-knock additive in gasoline for more than 60 years. Prior to 1970 , it was common practice to add 2.5 grams of lead per gallon of gasoline to increase the octane rating in order to prevent detonation and engine knock. Unfortunately, about two-thirds of the lead additive was released into the atmosphere and one-third accumulated in the engine oil. Prior to 1977, almost all lead emissions to the atmosphere came from motor vehicles.

Approximately 30 to 40 percent of the lead inhaled through the lungs is transferred by the blood to various organs of the body. Most lead is absorbed by the bones and remains there for 2,3, or more years. The remainder is absorbed by other organs such as the liver and kidneys. The effects of lead accumulation in the body are severe. They include loss of red blood cells, damage to the kidney and liver, mental retardation-especially in children-and alteration of the female reproductive cycle.

Tolerable levels of lead in the blood range between 15 and 40 micrograms per decaliter of blood ( $\mu \mathrm{g} / \mathrm{dL})$. The World Health Organization (WHO) considers $40 \mu \mathrm{g} / \mathrm{dL}$ to be the maximum permissible limit. Levels between 40 and $60 \mu \mathrm{g} / \mathrm{dL}$ are considered unacceptable and levels higher than $60 \mu \mathrm{g} / \mathrm{dL}$ are dangerous. In Europe and the United States the average concentrations of lead in the blood are now less than $10 \mu \mathrm{g} / \mathrm{dL}$.

Because of these documented health effects and the fact that lead-fouled catalytic converters are needed to clean up hydrocarbon and $\mathrm{NO}_{\mathrm{x}}$ pollution, lead additives to gasoline were banned. Lead has been replaced with other high-octane hydrocarbon fractions, such as aromatics, isoparaffins, olefins, and oxygenates.

Two other additives to gasoline, methylcyclopentadienyl manganese (MMT) and silicon, also cause problems with emission control systems. Some researchers also believe that MMT may cause direct 
health problems. MMT and silicon physically plug the substrate mesh of catalytic converters, foul oxygen and other sensors, and confuse the electronic control systems used on modern engines.

As little as one tank of gasoline containing these additives is capable of destroying the effectiveness of the emission control system. MMT is used in Canada and oil interests are pushing to bring MMT to the United States. The automotive manufacturers are working to prevent the use of MMT in gasoline sold in the United States.

Ozone. Ozone gas performs tvro critical functions in atmospheric chemistry. In the stratospheric height of more than $20 \mathrm{~km}$ above the Earth's surface, ozone performs the important and beneficial function of absorbing more than 90 percent of the ultraviolet energy in solar radiation. This radiation, which damages almost all life forms, is a major cause of skin cancer.

Although stratospheric ozone is beneficial, when ozone is present in the surface layer of the atmosphere (the troposphere), it is a pollutint commonly known as photochemical smog. Tropospheric ozone - smog - is formed by a series of complex photochemical reactions among $\mathrm{NO}_{\mathrm{x}}$ and hydrocarbons, such as olefins, aldehydes, and alcohol. Nitrogen dioxide acts as a catalyst in reactions that form transformation products such as PAN. These products can also have adverse health effects.

Ozone is a powerful irritant to the respiratory passages. It is capable of penetrating deep into the pulmonary system and damaging lung tissues. Ozone irritates the mucous layer that lines the airway of the respiratory system, which san increase risk of infection. Ozone also causes narrowing of the airways and reduced lung function. Syinptoms of these problems include shortness of breath, wheezing, and coughing.

People particularly susceptible to these symptoms are children, individuals engaged in strenuous outdoor activities, and adults with respiratory problems such as asthma, bronchitis, and emphysema. Other chronic health effects include leadaches; eye, nose, and throat irritations; inflammation; deposition of collagen and protein fibernectin; increased susceptibility to respiratory infection; premature aging (stiffening) of lung tissue; and increased mortality.

People exposed to ozone exhitit a broad range of sensitivity responses. In general, sensitivity is determined by health status, aşe, and activity level of the individual. Children and young adults appear to be the most sensitive, as are individuals with lung disease, such as asthma. Smokers tend to be less sensitive to ozone than nonsmokers.

In addition to adverse health effects on humans, elevated levels of ozone have a detrimental effect on forest ecosystems, agricultural crops, and building materials. Ozone also contributes to acidic deposition and reduced visibility. Elevated ambient concentrations of ozone, often acting synergistically with other air pollutants, is believed to $b \in$ : a major factor in the documented decline in forest ecosystems in North America and Europe. Extensive research on coniferous forests in Southern California indicates that ozone can affect various ecosystem functions, such as carbon cycling, movement of water, mineral nutrient flow, and species diversity.

Ozone has reduced U.S. agricultural crop yields, caused foliage damage, reduced growth, lowered crop quality, and increased susceptibility to biotic and abiotic stresses. Nonbiological materials-such as elastomers, textile fibers, paints, and other manmade materials--are damaged by ozone exposure. As an example, consider the damage that occurs to rubber and elastomers used in automobile tires and seals. 
The WHO recommends ambient ozone concentration of no more than 0.05 to $0.10 \mathrm{ppm}$ per 1 -hour exposure to protect public health. The current NAAQS for ozone is $0.12 \mathrm{ppm}$ averaged over 1 hour. The EPA recently proposed a modified NAAQS for ozone of $0.08 \mathrm{ppm}$ averaged over an 8-hour period.

Additional Mobile-Source Pollutants. Air pollution from mobile sources contains a complex mixture of primary pollutants as well as hundreds of transformation products, or secondary pollutants, formed in the atmosphere. A recent study published by the EPA concluded that emissions from motor vehicles account for almost 60 percent of the total cancer incidence from outdoor exposure to air toxics in the United States. The study also stated that products of incomplete combustion were responsible for about 35 percent of the total. Formaldehyde, benzene, and 1,3-butadiene are three of the chemical contaminants found in mobile-source tailpipe emissions known to represent a public health risk.

Determining the public health risks from exposure to complex mixtures of nonregulated toxic pollutants associated with mobile-source emissions is limited by several factors. It is difficult to characterize the spatial and temporal ambient concentrations of these pollutants and their transformation products.

Varying exposure conditions and sensitivity results also hinder the establishment of the exact toxicological potency and potential synergistic effects of these mixtures on human health.

The data are sufficient to conclude, however, that millions of people, including both the healthy and sensitive populations, are at risk to health problems caused by long-term exposure to toxic air pollutants emitted by vehicles. Chronic long-term effects include cancer, emphysema, pulmonary fibrosis, and chronic obstructive lung disease.

Formaldehyde. Formaldehyde is a primary irritant to the mucous membranes of the eyes, nose, and mouth. Human exposure to concentrations of 0.1 to $5 \mathrm{ppm}$ may cause eye irritation, tearing, and general irritation of the upper respiratory passages. Exposure to higher concentrations may produce coughing, tightening of the chest, a sense of pressure in the head, and heart palpitations. Epidemiological evidence indicates that formaldehyde exposure may be related to an increased incidence of cancer in humans. Based on existing data, the EPA has classified formaldehyde as a "probable human carcinogen."

Benzene. Benzene has been classified as a "known human carcinogen" (IARC, 1982). Several epidemiological studies provide sufficient evidence of a causal relationship between benzene exposure and leukemia in humans (Ott et al., 1987; Wong et al., 1983; Rinsky et al., 1981). Hematotoxicity is the most harmful health effect of chronic benzene exposure. Humans exposed to benzene have developed marked hypoplasia of the bone marrow with pancytopenia, a decrease in the various cells of the blood. This bone marrow depression may lead to leukemia. Acute myelogenous leukemia is most frequently related to benzene exposure, but other types of leukemia have been observed.

1,3-Butadiene. Mild neurological effects have been observed in animals following acute and subchronic exposure to 1,3-butadiene. Chronic inhalation bioassay studies have observed testicular and ovarian atrophy; multiple tumor sites; increases in mortality resulting from malignant neoplasm; and statistically significant increases in Leydig, pancreatic exocrine, and mammary gland tumors. Although current epidemiological evidence is inadequate to attribute carcinogenicity in humans to 1,3-butadiene exposure, the EPA has classified 1,3-butadiene as a "probable human carcinogen."

Peroxy Carboxylic Nitric Anhydrides. Compounds referred to as PANs have been shown to be important secondary products of the $\mathrm{NO}_{\mathrm{x}}$-induced atmospheric photo-oxidation of alkanes, alkenes, and aromatic hydrocarbons. Once formed, these PAN compounds tend to be very stable, with lifetimes ranging up to five daylight periods. Biological testing of several PANs has established that many of these compounds are eye irritants, phytotoxicants, and active mutagens. 
Greenhouse Gases-It is now scientifically accepted that the global climate can be affected directly by the buildup of greenhouse gase; in the atmosphere. The contribution to the radiant forcing of the atmosphere made by $\mathrm{CO}_{2}, \mathrm{CH}_{4}, \mathrm{NO}_{x}$, and chlorofluorocarbons (CFCs) has been established with reasonable accuracy. However the relative influence of manmade greenhouse gases and the magnitude of the effect is still subject to ir tense debate.

$\mathrm{CO}$, water vapor, and cloud cover account for about 90 percent of the greenhouse effect; $\mathrm{CH}_{4}, \mathrm{~N}_{2} \mathrm{O}$, and stratospheric ozone make up the remaining 10 percent. Free tropospheric ozone concentrations have been building up in many regions of the Northern Hemisphere as a result of increased concentrations of $\mathrm{CH}_{4}, \mathrm{CO}, \mathrm{NMHC}$, and $\mathrm{NO}_{\mathrm{x}}$. The primary sources of these gases are transport from the lower troposphere and aircraft emissions. It is now recognized that the tropospheric ozone present 8 to 12 kilometers in altitude has a significant influence on the greenhouse effect.

Effects of Urban Air Pollution on Water Quality-Coastal estuaries, such as Tampa Bay and Chesapeake Bay, once supported productive fisheries and wildlife. These valuable estuaries have been severely degraded by years of credging and unchecked pollution. Massive public investments in wastewater and storm water management systems and other restoration activities have partially restored water quality and habitat. Unfortunately, despite this success, other forms of pollution continue to threaten bays, with potential impacts far greater than previously thought. New studies have identified air pollution caused by nitrogen and toxic compounds as a significant and persistent source of bay pollution.

The EPA established the Great Waters Program in 1995 to research atmospheric deposition on national waterways, such as the Great Lakes, Chesapeake Bay, and Tampa Bay. Nitrogen loading studies conducted for the Tampa Bay National Estuary Program estimate that as much as 67 percent of the total nitrogen load delivered to the bay originates from atmospheric deposition. It is estimated that mobile sources contribute 30 to 50 perient of the $\mathrm{NO}_{\mathrm{x}}$ emissions in the watershed. Ongoing research will attempt to develop a more accurate allocation of nitrogen sources.

\subsubsection{Regional Haze}

The Colorado Plateau is home 1:0 some of the nation's most beautiful natural resources and treasured national parks: the Colorado and Green River Valleys; Grand, Zion; and Bryce Canyons; the Painted Desert; Monument Valley; Caritol Reef; the Petrified Forest; and many other wonders of nature. The Plateau is one of the last major relatively unpolluted air sheds in the United States and serves as a clean air reservoir for the rest of the country. This unique asset, however, is threatened by current trends in diminishing regional visibility.

Some of the pollutants that blanket the urban centers of the West blow over the Colorado Plateau and mix with exhaust from vehicles traveling the regions' highways, smoke from trains operating on the region's railroads, and emissions from coal-fired power plants that generate electricity for the West's great cities. The thickening haze from these activities obscures the breathtaking vistas of the Colorado Plateau. Visibility in the West is deteriorating in much the same pattern as that of the Eastern United States, where natural visibility has deteriorated in some places from more than 60 to less than 7 miles.

\subsubsection{The Role of Medium- and Heavy-Duty Trucks in Urban Air Pollution}

In recent years, air quality officials in America have increased their emphasis on mobile sources. Always the source of a significant portion of air pollution, several factors have increased the overall contribution of mobile sources to air quality problems. First, air pollution regulations on stationary sources have been 
very successful, and their proportional and actual contribution to the emission (pollution) inventories have been dropping for two decades. Second, rapid population growth has been accompanied by even greater growth in the number of vehicles on the road and the distances those vehicles travel. Finally, the decline of the country's railroads since the end of the World War II has been accompanied by a rapid increase in the use of heavy-duty diesel trucks to transport the nation's goods.

Transportation is now the primary cause of much of the air quality problem, and diesel-powered vehicles are a major source of transportation emissions. The vehicles that serve as the backbone of our transit, goods movement, long-haul freight, and delivery systems are also some of the dirtiest vehicles on the road.

In Los Angeles, two-thirds of $\mathrm{NO}_{\mathrm{x}}$ comes from the mobile sector, and one-quarter of those emissions are from diesel-powered trucks and buses. In Sacramento, more than half the pollution comes from heavy trucks. Although heavy-duty diesel trucks, urban buses, and medium-duty trucks make up only 6.5 percent of California's vehicle fleet, they contribute about 44 percent of the state's ozone and PMforming $\mathrm{NO}_{\mathrm{x}}$ and more than 80 percent of the on-road fine particulate (Acurex Environmental, CARB). Over the Colorado Plateau, more than one-third of the visibility problem is caused by vehicles operating in the region; another third of the haze is transported into the region from urban areas heavily affected by diesel-powered vehicles.

The railroads also contribute to urban pollution and regional haze, although not nearly as much as onroad diesel trucks. Until recently, emissions from locomotives escaped regulation by air quality agencies. Although the role of railroads in goods movement has decreased over the past 50 years, in the last 15 years improvements in rail efficiency have led to a rebound in the use of trains in commercial freight traffic.

Because the role of railroads in cargo movement is growing, the impact of trains on future emission reduction strategies must be considered. Increasing train efficiency has led to greater integration of trucks and trains into an intermodal transportation system. According to the Association of Railroads, Railroad Facts, 1995 Edition, intermodal traffic increased by 41 percent between 1988 and 1994 .

In recent years, air quality, energy, and transportation policies have begun to address the significant contribution of diesel-powered vehicles to air pollution. Unfortunately, most programs, including those in the Clean Air Act of Amendments of 1990 (CAAA) and the Energy Policy Act of 1992 (EPAct), concentrate on reducing emissions from or encouraging alternative fuels in light-duty vehicles (LDVs). Perhaps this is due to a perception that practical and economic alternatives to diesel in heavy-duty, interstate cargo movement do not exist. Until recently, long-haul trucks have been, to a great extent, ignored by these regulatory programs.

In 1995 and 1996, the diesel engine industry agreed to massive investments in programs to significantly reduce emissions from heavy-duty engines. To achieve emission goals, the programs require the petroleum industry to effectively eliminate sulfur from diesel fuel.

Engine designers must develop combustion and exhaust treatment strategies that increase efficiency and reduce emissions. Engine manufacturers must improve quality to meet much tighter tolerances needed to certify reliable emissions performance for extended warranty periods. Many of these technologies must be developed and proven. The cost of these cleaner diesel engines and clean diesel fuel will be significantly higher than that of equipment and fuels based on existing technology. 


\subsubsection{Population Growth and Energy Use}

The urban air pollution and regional haze problems that the western and southern states face are compounded by trends in popu ation growth and energy use. The region is one of the nation's fastest growing - the populations of Utah, Nevada, Arizona, and California are projected to increase by 40 percent (14.7 million) between 1990 and 2010, and by 62 percent ( 22.7 million) by 2020 (Leary, 1995).

This growth is expected to place significant additional strain on the region's resources, by adding millions of cars and trucks to the road and expanding the demand for electricity. In California alone, nearly 15.3 billion gallons of gissoline and diesel fuel were sold in 1994 for vehicle use. Although this was only a 2.69 percent increase between 1991 and 1994, the data for diesel sales are far more significant.

Although gasoline consumption stayed relatively flat (increasing only 0.77 percent in 3 years), diesel consumption expanded by moris than 17.5 percent in the same period (CDOT, 1994).

These trends have profound implications for the future of energy use in the West, as well as in the rest of the United States. In 1994, the United States began to import more than 50 percent of its oil needs from foreign sources (refer to Figure 1-5). The vast majority of this petroleum is imported to serve the nation's growing appetite for transportation fuel. In the West, the long distances between major centers of commerce, expanding trade with the Pacific Rim, and increased reliance on interstate trucking to move goods back and forth are rapidly increasing the consumption of diesel. Unless steps are taken to address the region's growing demand for petroleum products, the nation's energy security will continue to deteriorate.

With its large reserves of natural gas, the United States has an opportunity to reduce oil imports and strengthen the trade balance. Clonversion to LNG transportation fuels could reduce the U.S. trade deficit by displacing a significant part of the $\$ 45$ billion worth of crude oil imported annually.

\subsubsection{Global Climate Change-Report of the Intergovernmental Panel on Climate Change (IPCC)}

The possibility of large-scale environmental disasters caused by human activities has become a viable topic for scientific investigation. The rapid, and completely unexpected, depletion of stratospheric ozone by manmade CFCs was so compelling that the international community agreed, in the Montreal Accords, to ban the manufacture and use of many valuable chemicals, such as freon and halon.

Global climate change is now the subject of intense scientific review because of a similar, and unexpected, phenomenon. In the past 150 years, atmospheric concentrations of several critical "greenhouse" gases have increised dramatically from their pre-industrial concentrations.

For example, atmospheric $\mathrm{CO}_{2}$ increased from about $280 \mathrm{ppmv}$ to $360 \mathrm{ppmv} ; \mathrm{CH}_{4}$ from about $700 \mathrm{ppmv}$ to $1,720 \mathrm{ppmv}$; and CFC-11 from zero to $268 \mathrm{pptv}$. Tens of thousands of scientists and technicians are collecting vast amounts of data in an attempt to understand the history of the Earth's climate and the relationships, if any, with estiniated and measured concentrations of these gases in the atmosphere.

The IPCC was formed in 1990 to provide an impartial forum for the world's scientists to consider the issue of global climate change and the effect, if any, of increased greenhouse gas concentrations resulting from human activities. A 1996 report issued by the IPCC stated that the consensus of all the scientists participating in the panel (moris than 1,000 distinguished experts from many disciplines) was that human 
activities have had, and will continue to have, a discernible effect on global climate. There was no agreement on the magnitude of this effect or the consequences of any change.

Many U.S. scientists have been major participants in the scientific investigations that developed the evidence supporting this finding. For example, mathematical models predict average global temperature could change between $0.8^{\circ} \mathrm{C}$ and $4.4^{\circ} \mathrm{C}$ and average global sea level could rise between $12 \mathrm{~cm}$ and $94 \mathrm{~cm}$ in the next 100 years if the rates of increase in atmospheric concentrations of all greenhouse gases are not stabilized.

If these predictions prove accurate, the economic and environmental consequences would be devastating to many regions of the world. For example, much of South Florida would no longer be habitable. Shifts in climate could also turn valuable farmland to arid wasteland and destroy the communities and cultures that depend on these resources.

The scientific process is neither simple nor precise, and there is a high degree of uncertainty associated with this issue. Nevertheless, because the consequences could be severe, the United States, Europe, Japan, and many other nations have agreed to meet in Japan in December 1997 to negotiate binding limits on greenhouse-gas emissions. Recognizing the economic opportunities from early adoption of clean fuels and efficient energy technologies, the Clinton Administration has decided to take an active approach on this issue.

Widespread use of LNG in heavy-duty vehicles could reduce greenhouse-gas emissions by as much as 20 percent as compared to diesel fuel. Conversion to LNG is a strategy that could bring significant benefits to the heavy-duty engine and transportation industries.

\subsection{Laws, Regulations, and Programs that Affect Fleet Conversion to LNG}

Historically, the American people have strongly supported government programs designed to create jobs, improve national security, reduce trade deficits, and protect the environment. In response, Congress has passed several laws designed to facilitate conversion to cleaner, domestically produced, nonpetroleum fuels. Today, the challenge for government is to achieve these goals with incentive-based programs rather than continued use of punitive regulations, higher taxes, and mandates.

\subsubsection{Can Government Create Win/Win Opportunities?}

Conversion from gasoline and diesel transportation fuels to natural gas offers a number of tangible and intangible benefits to the fleet manager, the risk manager, executives, and owners. Because of the many problems associated with regulatory mandates and enforcement of environmental quality standards, federal, state, and local agencies charged with protecting the environment are aggressively seeking opportunities to work with industry and small businesses to find and implement voluntary, cost-effective strategies to clean up air emissions, eliminate human exposure to toxic chemicals, improve water quality, and reduce threats to sensitive ecosystems.

Many innovative programs are being tried throughout the nation. For example, the DOE Clean Cities Program is an aggressive "fuel-neutral" effort designed to replace imported petroleum with domestic alternative fuels. In addition, international standards developed by business and codified in the ISO 14000 Environmental Management Standards are creating a global framework that will encourage cleaner and more efficient vehicles and energy systems. 
Taken superficially, all of these programs could seem to be just more bureaucratic paper pushing and red tape. However, on closer exanination - and with a knowledge of the performance capabilities of LNG - the corporate risk manager can identify opportunities for fleet managers to significantly reduce environmental risks and liabililies while saving money on transportation and environmental compliance.

\subsubsection{Relevant Federal Legislation, Regulations, and Treaties}

Two federal laws and many as:;ociated regulations and executive orders contain either mandates or incentives for fleet conversion to cleaner or nonpetroleum alternative fuels in vehicles. In addition, many environmental laws have established regulatory programs and standards targeted at mitigating pollution caused by using all types of fuels. Many of the regulations established under these laws could be satisfied or completely avoidecl by converting fleets to LNG.

Energy Policy Act of 1992-The intent of EPAct is to restructure the energy markets in the United States to reduce dependence on imported oil and to encourage energy efficiency. EPAct specifically targets centrally fueled fleets for conversion to nonpetroleum alternative fuels. EPAct established a national goal of 10 percent penetration of nonpetroleum fuels in the LDV market by 2000 and 30 percent displacement by 2010 . EPAct mandated that certain public and private fleets must purchase targeted percentages of new LDVs powered by alternative fuels (see Table 1-2). Subsequent executive orders have expanded the programs tc allow fleets to purchase medium- or heavy-duty vehicles to satisfy the alternative fuel vehicle (AFV) purchase requirements.

Federal Fleets. Federal fleets must purchase light-duty AFVs in accordance with the mandated schedule. Medium-duty, heavy-duty, off-road, emergency, police, and vehicles normally garaged at home are exempt from the mandates. However, medium- and heavy-duty vehicles may be substituted for LDVs to satisfy the mandate.

\section{Table 1-2. Schedule for Mandated Purchases of New Alternative Fuel Vehicles}

$\begin{array}{cccc}\text { Fuel Providers } & \text { Federal } & \text { State } \\ 1996 & 30 \% & 25 \% & 10 \% \\ 1997 & 50 \% & 33 \% & 15 \% \\ 1998 & 70 \% & 50 \% & 25 \% \\ 1999 & 90 \% & 75 \% & 50 \% \\ 2000 & 90 \% & 75 \% & 75 \% \\ 2001 & 90 \% & 75 \% & 75 \% \\ 2002 & 90 \% & 75 \% & 75 \% \\ 2003 & 90 \% & 75 \% & 75 \% \\ 2004 & 90 \% & 75 \% & 75 \% \\ 2005 & 90 \% & 75 \% & 75 \% \\ 2006 & 90 \% & 75 \% & 75 \%\end{array}$

State Fleets. State fleets must purchase light-duty AFVs in accordance with the mandated schedule. Medium- and heavy-duty vehicles, off-road vehicles, emergency vehicles, police vehicles, and vehicles normally garaged at home are exempt.

Fuel Provider Fleets. Fleets cwned by businesses that are substantially engaged in the fuels business must convert according to the : ichedule. Businesses that derive 2 percent of their revenue from producing, storing, refining, processing, transporting, distributing, importing, or selling at wholesale or 
retail any alternative fuel other than electricity are required to comply. EPAct also requires business fleets of 50 or more vehicles to have at least 20 that are centrally fueled. Medium- and heavy-duty vehicles, off-road vehicles, emergency vehicles, police vehicles, and vehicles normally garaged at home are exempt.

Private Fleets. In December 1996, DOE determined not to mandate fuel light-duty AFV purchases for municipal and private fleets. Medium- and heavy-duty vehicles, off-road vehicles, emergency vehicles, police vehicles, and vehicles normally garaged at home are exempt.

EPAct also provides economic and other incentives for fuel suppliers, original equipment manufacturers, and fleet owners. EPAct PL-102-486, established provisions for federal tax deductions for business or personal clean-fuel vehicles (CFVs). Maximum tax deductions are provided as follows for the incremental costs (including retrofits) and refueling facilities placed in service after June 30, 1993:

- Trucks or vans of 10,001 to 26,000 lb gross vehicle weight: $\$ 5,000$

- Trucks or vans more than $26,000 \mathrm{lb}$ gross vehicle weight: $\$ 50,000$

- Buses that seat 20 or more adults: $\$ 50,000$

- All other vehicles (excluding off-road vehicles): $\$ 2,000$

- AFV refueling facility: $\$ 100,000$

States may also offer tax incentives. Refer to the DOE publication, Guide to Alternative Fuel Vehicle Incentives and Laws for the latest information on state and local agency incentives. This document can be accessed through the Alternative Fuels Data Center on the World Wide Web at http://www.afdc.doe.gov.

Other Relevant Energy Programs-DOE sponsors several programs available to state and local government to promote energy conservation and efficiency. Grants that may be used for AFV projects are available through the State Energy Conservation Programs. Contact your state energy office for information. The Urban Consortium Energy Task Force awards grants on a competitive basis for localgovernment-sponsored AFV projects.

Funds for AFV demonstration projects may also be available from state energy offices from the Petroleum Violation Escrow Account.

Clean Air Act Amendments of 1990-Strict controls to reduce mobile-source air pollution from the use of gasoline and diesel fuels were mandated under the CAAA, including the following. All these programs have required substantial investment by the oil industry.

Oxygenated Fuels Program. Requires use of oxygenate additives, such as methyl tertiary butyl ether or ethyl tertiary butyl ether, to reduce $\mathrm{CO}$ emissions during the winter months in $39 \mathrm{CO}$ nonattainment areas.

Highway Diesel Fuel Program. Requires the sulfur content of diesel fuel be reduced to 0.05 percent by weight, except for exemptions through 1999 for small refineries. High-sulfur oil can still be used in offroad applications and for heating, but must be stored in separate facilities and must be dyed to prevent illegal sale for highway use.

Reformulated Gasoline Program. Requires sale of RFG in nine ozone nonattainment areas. Limits RFG to maximum 1.0 percent benzene and 2.0 weight-percent oxygen, and bans lead and manganese 
additives. Toxic air pollutants and VOC emissions are to be reduced by a minimum of 20 percent by 2000.

Leaded Gasoline Removal. Prihibits sales of leaded motor gasoline after 1995.

Air Pollution Grant Control Program. The Air Pollution Control Grant Program, known as Section 105, assists state and municipal agencies in planning, developing, establishing, improving, and maintaining adequate programs for prevention and control of air pollution or implementation of national ambient air quality standards. States and municipalities may receive up to 60 percent federal funds to implement their plans.

Fleet Conversion Mandates. Title II of the CAAA affects new light- and medium-duty vehicles in fleets and transit buses. Fleets in 22 urban regions are required to begin operating by the end of the decade. Beginning in 1998, 30 percent of new vehicle purchases by many fleets must be CFVs. This increases to 50 percent by 1999,70 percent by 2000 , and 100 percent by 2001 . RFG and clean, diesel-powered vehicles will satisfy this requirtment. LNG-powered vehicles will reduce emissions much more than the minimum requirements.

Emission Standards for On-Rcad Heavy-Duty Engines. The EPA has adopted a plan that will allow emissions from heavy-duty dies:el engines to meet existing standards until the year 2004. The new 2004 standard will be measured as the sum of $\mathrm{NO}_{\mathrm{x}}$ and hydrocarbon emissions. The TSP and CO standards will not change (see Figure 1-6). The standards are presented in Table 1-3.

\section{Table 1-3. CIn-Road Heavy-Duty Engine Emission Standards}

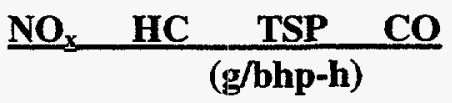

Present Standard

2004 Standard

Current LNG (avg.)

$\begin{array}{rlcc}5.00 & 1.3 & 0.10 & 15.5 \\ * 2.50 & 0.10 & 15.5\end{array}$

2.00 na $\quad 0.03<1.0$

As shown above, LNG-powereil trucks and buses can easily meet the 2004 standard for $\mathrm{NO}_{\mathrm{x}}$ and hydrocarbon with current engire technology. Heavy-duty engines powered by diesel cannot meet the standard. In fact, emissions from current LNG-powered engines are well below the 2004 standard for all regulated pollutants. Perhaps the most compelling difference is the fact that particulate emissions from LNG-powered engines are significantly lower than those from diesel-powered engines. These emission benefits are available today.

Urban Bus Fleets. The law rerognized that urban bus fleets are one of the most visible sources of pollution. The transit bus industry was required to produce buses that meet more stringent emissions limits than other diesel engines. In addition, the EPA is required to test urban bus fleets to determine compliance with 1994 bus engine emission standards.

Takile 1-4. Transit Bus Emission Standards

1994 Bus Standard

\begin{tabular}{|c|c|c|c|}
\hline $\mathbf{N O}_{x}$ & HC & TSP & $\mathrm{CO}$ \\
\hline & \multicolumn{3}{|c|}{$(\mathrm{g} / \mathrm{bhp}-\mathrm{h})$} \\
\hline 5.00 & 1.3 & 0.05 & \\
\hline
\end{tabular}


The EPA may mandate cleaner fuels for those in noncompliance, but clean diesel may meet the standard.

Figure 1-6. Heavy-Duty Engine Emissions Standards

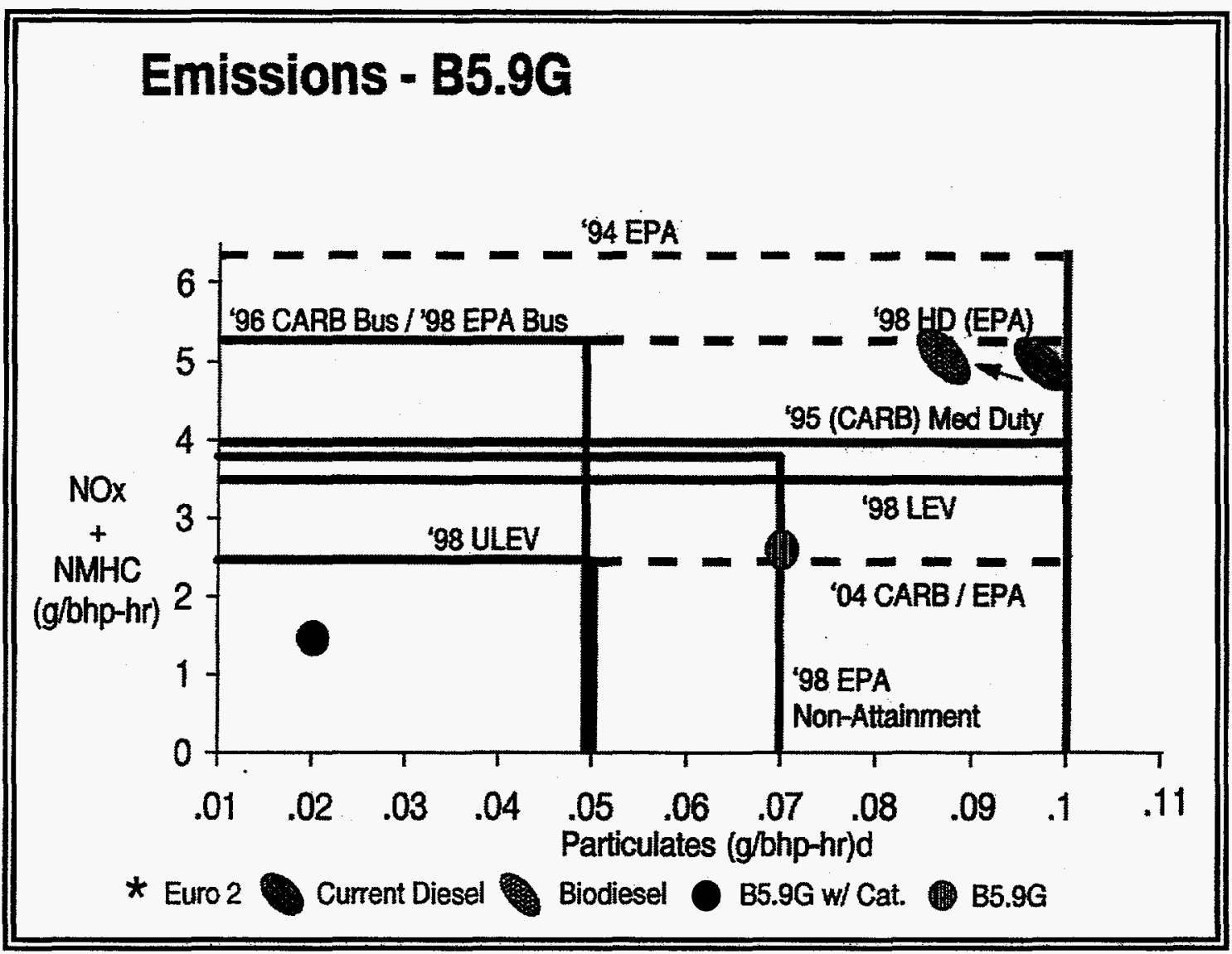

Emission Standards for Off-Road Heavy-Duty Engines. The 12 major diesel engine manufacturers, CARB, and the EPA have signed a Statement of Principles (SOP) that charts regulated off-road diesel engine emission levels through the year 2008 (Table 1-5). Similar to the on-road agreement signed in June 1995, the SOP covers engines used in farm, construction, and industrial equipment and commits the manufacturers to bring $\mathrm{NO}_{\mathrm{x}}$ and PM down to about one-third of current emissions beginning in 1999. Companies that signed the agreement included Caterpillar, Cummins, Deere, Detroit Diesel, Deutz, Isuzu, Komatsu, Kubota, Mitsubishi, Navistar, New Holland, Wis-Con, and Yanmar.

An LNG-powered engine can meet all of these standards with current engine technology. Extensive engine upgrades will be required for engines powered by diesel to meet future standards.

On November 29, 1996, the EPA published proposed revisions to the primary and NAAQS for ozone and particulate matter. The proposed changes are summarized in Table 1-6.

The EPA has concluded that the existing primary standards for ozone and particulate matter are not adequate to protect the public from adverse health effects. In addition, the EPA and the Clean Air Scientific Advisory Committee unanimously concluded that the secondary standard for ozone does not adequately protect vegetation from adverse effects. 
Table 1-5. Off-Road Heavy-Duty Engine Emissions Standards (National Ambient Air Quality Standards)

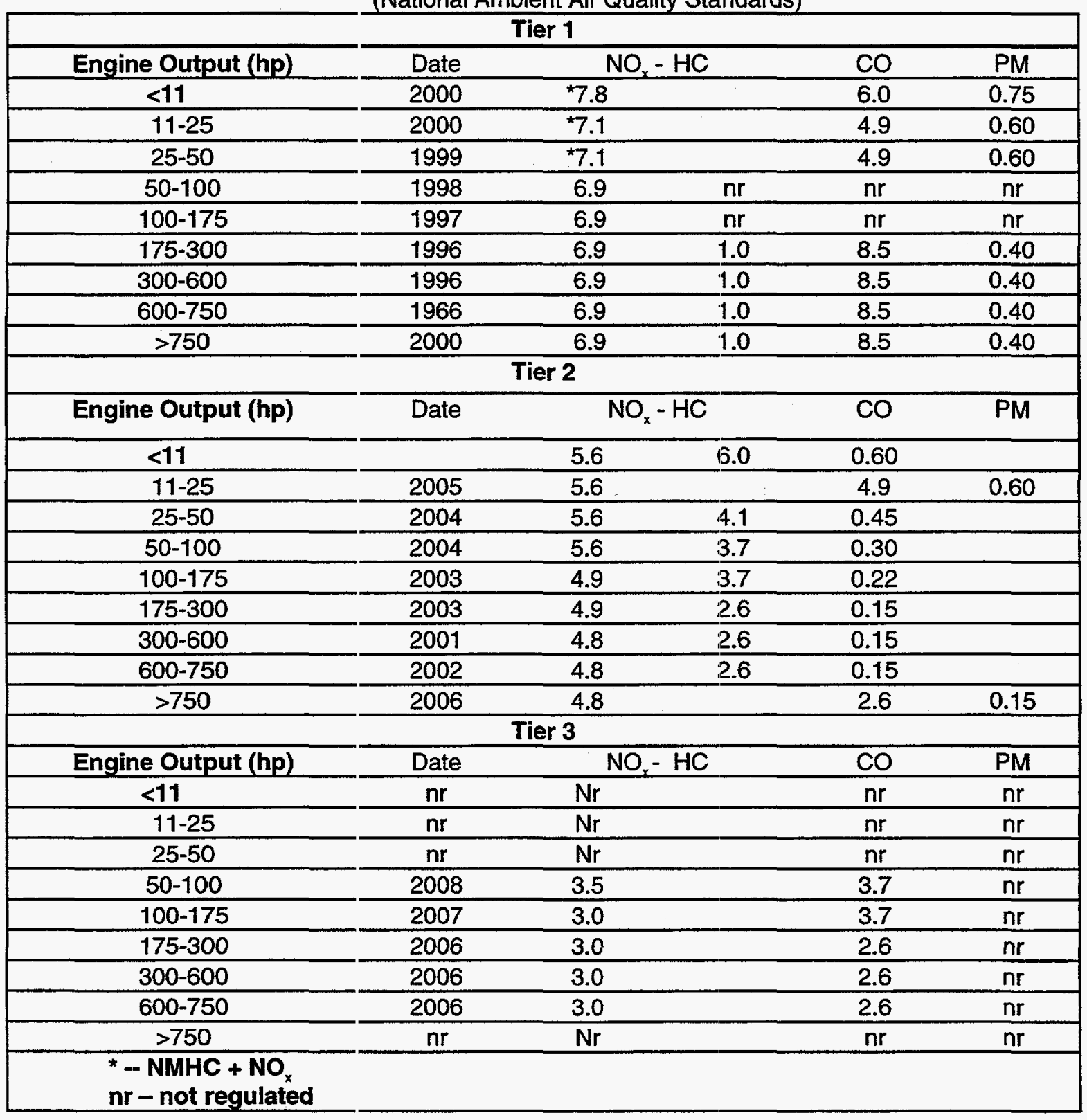

The proposed NAAQS revisior Is are intended to focus air pollution control strategies on the specific pollutants—ozone and fine particulate matter - that have been demonstrated to have the most harmful effects on public health. Fine particulate (less than $2.5 \mu \mathrm{m}$ ) matter and ozone have been demonstrated to cause health problems at levels well below the existing standards for both short-term and long-term periods of exposure.

Combustion sources and vehicle exhaust are the major sources of fine particulate pollution that will be affected by the proposed NAA'QS. Diesel engines are significant sources of VOCs and fine particulate matter.

There is some difference of opinion regarding the uncertainty of the scientific evidence and the quality of the database for PM health effects. For this reason, the EPA has also requested public comment on two 
alternative combinations of primary $\mathrm{PM}_{2.5}$ standards that reflect sharply divergent views as to the appropriate policy response to the available health effects evidence:

\section{Table 1-6. Existing and Proposed NAAQS for Ozone and Particulate Matter}

\section{Existing Standard}

$\begin{array}{ll}\text { Ozone } & 0.12 \mathrm{ppm} \text { avg. over } 1 \text { hour } \\ \mathbf{P M}_{10} & 50 \mu \mathrm{g} / \mathrm{m} 3 \text { avg. over } 1 \text { year } \\ & 150 \mu \mathrm{g} / \mathrm{m} 3 \text { avg. over } 24 \text { hours } \\ \text { PM }_{2.5} & \begin{array}{l}\text { none } \\ \text { none }\end{array}\end{array}$

\section{Proposed Standard}

0.08 ppm avg. over 8 hours

no change

use 98th percentile form

$50 \mu \mathrm{g} / \mathrm{m} 3$ avg. over 24 hours

$15 \mu \mathrm{g} / \mathrm{m} 3$ avg. over 1 year

1. A limited policy response option, consisting of an annual standard up to $20 \mu \mathrm{g} / \mathrm{m}^{3}$ with a 24 -hour standard up to $65 \mu \mathrm{g} / \mathrm{m}^{3}$.

2. A "highly precautionary" policy response option, consisting of an annual standard down to about $12 \mu \mathrm{g} / \mathrm{m}^{3}$ with a 24-hour standard set within a range from $20 \mu \mathrm{g} / \mathrm{m}^{3}$ to about $50 \mu \mathrm{g} / \mathrm{m}^{3}$.

Recognizing sharply divergent views, the EPA also solicits comments on an alternative 8-hour primary standard set at $0.07 \mathrm{ppm}$, using a concentration-based form, and on retaining the existing standard. Comments are also sought on establishing a "seasonal SUM06" secondary standard that would better protect plants from the cumulative effects of ozone in the longer term.

Pollution Prevention Act of 1990 and Subsequent Executive Orders-The Pollution Prevention Act of 1990 provided the EPA with the opportunity to initiate a series of voluntary initiatives in partnership with regulated industries to reduce emissions of pollutants to the environment. Initial emphasis was on reducing listed toxic chemicals, including benzene, xylene, toluene, and ethylbenzene, which are components of gasoline and/or diesel fuels. Subsequently, the EPA has initiated several other voluntary initiatives designed to encourage industries to reduce pollution voluntarily. In exchange, the EPA offers industry flexibility in the enforcement of many otherwise onerous provisions of federal hazardous waste, water quality, and air pollution statutes.

The Pollution Prevention Grants Program supports the establishment and expansion of state pollution prevention programs and addresses various sectors of concern such as energy, transportation, industrial toxins, and agriculture.

Funds awarded under this grant/cooperative agreement support innovative pollution prevention programs that address the transfer of potentially harmful pollutants across all media -air, land, and water. State agencies are required to contribute at least 50 percent of the total cost of their projects.

Conversion of heavy-duty vehicle fleets to LNG meets with the spirit and legislative intent of this law. Many EPA rules, policies, and initiatives indicate that the EPA would respond favorably to voluntary fleet conversion to clean LNG. The policy position that has developed is intended to encourage business to take proactive actions to prevent pollution rather than relying on the EPA to write regulations and initiate enforcement actions.

Intermodal Surface Transportation Efficiency Act of 1991 (ISTEA) - This act provides authorization for funds for transit bus purchases and the Congestion Mitigation and Air Quality (CMAQ) Improvement Program. 
CMAQ Improvement Program. CMAQ directs funds to state transportation programs and projects that are likely to contribute to air quality improvements and transportation services. The primary focus of the CMAQ Program is to implement transportation control measures that are part of state air quality implementation plans, known as SIPs. Eligible projects and programs, including alternative fuel conversions, must be included :n the transportation improvement program (TIP) developed by the metropolitan planning organizations in nonattainment areas.

States having ozone and/or CO nonattainment areas must use CMAQ funds in nonattainment areas. States with no nonattainment areas can use the CMAQ funds for any project eligible under CMAQ or ISTEA. Generally, the conversion of individual vehicles to alternative fuels is not eligible. However, the conversion or replacement of centrally fueled fleets to alternative fuels is eligible, provided that the fleet is publicly owned (or leased) and operated and the fleet conversion is in response to a specific requirement in the CAAA or the fleet conversion is specifically identified in the SIP as part of the emissions reduction strategy.

Under the above conditions, CMAQ funds are also eligible for establishing on-site fueling facilities and other infrastructure needed to fuel AFVs. This means the vehicles and facility must be publicly owned (or leased) and the use of AFV is must either be required under the CAAA or in the SIP.

Section 3 Discretionary and Formula Capital Program for Transits. Transit fleets can obtain up to 80 percent federal subsidy for the purchase of LNG buses. Transportation planning agencies can also obtain CMAQ funds to plan and implement a wide variety of projects that could include LNG transit buses.

Clean Water Act-The Clean Water Act established a broad range of programs to clean up water pollution and protect and restore sensitive water resources, such as the Great Lakes and coastal estuaries. As a result of more than 20 years of data collection and scientific research, it is now understood that emissions from gasoline- and diesel-powered vehicles are a major source of water pollution. In addition to direct pollution from large s] illls, chronic, low-level nitrogen and toxic loading - transported by storm water runoff and atmospheric ceposition - have been identified as major sources of contamination in several estuaries.

The National Estuary Program was formed to set reasonable, achievable goals for the recovery and protection of 29 estuaries, such as Chesapeake Bay, San Francisco Bay, and Tampa Bay. The estuary programs are administered by the EPA and involve many state, regional, and local agencies. Research to better define the magnitude of the atmospheric deposition problem is the primary action plan at this time. However, many programs are also targeting low-cost or no-cost mitigation measures to reduce $\mathrm{NO}_{\mathrm{x}}$ emissions, such as energy efficiency, fuel switching for power plants, and lower vehicle emissions.

Resource Conservation and Recovery Act (RCRA)—RCRA requires owners of petroleum storage tanks to install containment and leak-detection systems that meet or exceed standards. Tank owners must also establish procedures to provide monitoring, insurance, record keeping, and reporting to regulatory agencies. Finally, the owner nust demonstrate the fiscal capability to clean up contamination caused by a release of petroleum hydrocarbons.

Retrofit of equipment to comply with these requirements can add $\$ 100,000$ to $\$ 200,000$ to the cost of a typical underground storage system. And there are no guarantees the system will not fail and cause soil and groundwater contamination. Cleaning up soil and groundwater contamination at a single site can easily cost between $\$ 100,000$ and $\$ 1,000,000$. Many fleets abandoned on-site fuel stations because of 
the cost and liability associated with releases of petroleum hydrocarbons. LNG stations eliminate risk of soil and groundwater contamination resulting from fuel leaks and spills.

\section{Comprehensive Environmental Response, Compensation and Liability Act (CERCLA)—CERCLA} (Superfund) established a legal framework for the investigation and cleanup of environmental contamination caused by releases of chemicals, including petroleum hydrocarbons, into the environment. A large accidental spill of gasoline or diesel fuel could trigger the Superfund process if sufficient environmental damage is suspected. LNG stations eliminate risk of soil and groundwater contamination resulting from fuel leaks and spills.

\subsubsection{The Role of the Federal Government}

The main federal incentives for the purchase or conversion of individual AFVs are the federal income tax deductions of $\$ 2,000$ to $\$ 50,000$ for clean-fuel vehicles and the income tax credit of up to $\$ 4,000$ for electric vehicles. An income tax deduction is also available for installing refueling facilities for AFVs.

Except for the federal tax credits and deductions, most of the federal incentives are programmatic grants oriented toward large investments such as infrastructure and larger purchases. The lead agencies are DOE, the U.S. Department of Transportation (DOT), and the EPA.

U.S. Department of Energy-DOE fulfills the provisions of the Alternative Motor Fuels Act of 1988 and the EPAct and has provided funding for the incremental cost of federal fleet conversions. DOE's Office of Transportation Technologies, through the National Renewable Energy Laboratory (NREL), manages research, development, and demonstration programs for alternative fuels and advanced technology engines and vehicles. DOE also distributes funds to the states for implementation of state and local energy efficiency and AFV programs.

U.S. Department of Defense (DOD) - DOD is the single largest purchaser of transportation fuels on Earth. The Army, Navy, and Air Force each operate large fleets of land vehicles. The DOD also lets contracts for land transportation of passengers and cargo. DOD facility and fleet managers must comply with EPAct mandates as well as federal, state, and local environmental standards. Conversion to LNG offers DOD fleet and facility managers the opportunity to eliminate or prevent pollution from storage of petroleum products as well as releases resulting from accidents, spills, and leaks.

U.S. General Services Administration (GSA)_GSA is the federal government fleet management service. GSA purchases and leases light-duty vehicles to participating federal agencies. Some federal agencies, such as the U.S. Postal Service (USPS) and the Air Force, operate independently of GSA. GSA also specifies terms and conditions of federal contracts used to purchase transportation services. Conversion to LNG offers GSA fleet and facility managers the opportunity to eliminate or prevent pollution from storage of petroleum products as well as releases that result from accidents, spills, and leaks.

U.S. Postal Service-USPS owns and operates more than 100,000 vehicles, including heavy-duty tractors. USPS also lets contracts for intercity land transport of mail. USPS has made a major commitment to CNG light-duty vehicles and is evaluating applications in heavy-duty vehicles

U.S. Department of Transportation-DOT administers the disbursement of funds from the Highway Trust Fund to state and local agencies to purchase transit buses and implement the CMAQ Program. DOT also disburses funds to states for the construction and maintenance of roads and highways. In 
addition, DOT manages a research and development program targeted at developing advanced transportation technologies.

\subsubsection{The Role of State, Regional, and Local Government State Energy Offices}

Each state operates an energy office that is authorized to manage federal funds for energy programs. Priorities are set by the state. Some states support research, development, demonstration, and deployment contracts for energy conservation and AFV programs.

State Environmental Offices--Each state operates environmental protection and conservation programs that reflect the priorities of the citizens. Designated state agencies are also responsible for implementing federal environmental laws, governing air quality, water quality, and hazardous waste, and they receive federal funds to administer delegated programs. SIPs must describe how AFV programs can be used to achieve air quality improvemer.t goals.

State Transportation Agencies-Each state is responsible for planning and implementing highway and mass transit projects funded with federal and state funds. The state DOT works through local transportation planning agencies to establish priorities for highway and transit projects, including purchase of LNG buses and loc omotives by transit agencies and disbursement of CMAQ money. State transportation agencies also sujport local research and development projects.

State and Local Fire Marshals-Each state operates fire, emergency response, and safety agencies that administer programs to provide policy and technical guidance and oversight to local officials. Local fire marshals develop and enforce local fire and safety codes. These officials have the authority to approve or deny permits required to implement an LNG program.

State and Local Building Officials_-Each state operates building and land development agencies that administer programs to provide: policy and technical guidance and oversight to local officials. These officials have the authority to approve or deny permits required to implement an LNG program.

County and City Governments - Local elected officials and their staffs develop and enforce local building and zoning codes in their jurisdictions. These officials have the authority to approve or deny permits required to implement an LNG program. Local elected officials also serve on regional planning agencies that administer spending on transportation and public works projects. In addition, regional planning agencies interact with many other federal and state agencies in programs such as Clean Cities.

Regional Authorities-Many states have authorized regional authorities to manage environmental resources, such as air quality management districts, water resource management districts, and water supply districts. Several regional authorities, especially in California, support LNG research, development, demonstration, and deployment programs.

\subsubsection{Mobile Emission Reduction Credit (MERC) Trading}

The EPA established the national framework for emission reduction credit trading when it published the proposed Open Market Trading Rule on August 3, 1995. The rule defines how MERCs can be generated by voluntary reductions of mo or vehicle emissions. Weaver (1996) estimates that heavy-duty vehicles converted to operate on LNG could generate the $\mathrm{NO}_{\mathrm{x}}+\mathrm{VOC}$ credits shown in Table 1-7. 
Several state programs are under development. The most advanced are the California/South Coast Air Quality Management District and the Northeastern States Coordinated for Air Use Management/ MARAMA programs. New York Gas is developing NGV protocols. If emission caps and other measures to create value are adopted, Weaver estimates that MERC value could range from $\$ 1$ to $\$ 5$ per pound per year. A Class 8 tractor could generate $\$ 1,300$ to $\$ 6,500$ per year in MERC revenue.

Table 1-7. Potential MERCs from Conversion to LNG

$\begin{array}{lc}\text { Vehicle Type } & \begin{array}{c}\text { MERC Potential } \\ \text { (lb/yr) }\end{array} \\ \text { Medium Truck } & 350 \\ \text { Transit Bus } & 950 \\ \text { Class 8 Tractor } & 1,300 \\ \text { Locomotive } & 87,200 \\ \text { River Towboat } & 468,000\end{array}$

Unfortunately, although the MERC concept has a lot of potential, the programs have not yet been implemented, except for the California program.

\subsubsection{Clean Cities-A Government/lndustry Partnership}

The Clean Cities Program, a government/industry partnership, was inspired by EPAct. Clean Cities is a locally based government/industry partnership coordinated by DOE to expand the use of alternatives to gasoline and diesel fuel. By combining local decision-making with voluntary action by partners, the "grassroots" approach of Clean Cities departs from traditional "top-down" federal programs. It establishes an effective plan, carried out at the local level, for creating a sustainable, nationwide alternative fuels market.

Because line-haul heavy-duty trucks are ideal candidates for LNG conversion, LNG fueling infrastructure must extend along major truck routes. Clean Cities programs in Southern California, Texas, and Florida are stimulating development of "Clean Corridors" along major interstate highways, such as I-5, I-10, I-15 in the Southwest, I-35 in the Midwest, and I-75 and I-95 in the East.

Clean Cities builds on local initiative, provides options to local problems, and creates partnerships as the mechanism to develop solutions. Clean Cities works directly with local businesses and governments to guide them through the goal-setting, coalition-building, and commitment processes necessary to establish the foundations for a viable alternative fuels market. The Clean Cities network shares innovation "mayor-to-mayor," relates local problems to state and federal objectives, and provides continuous feedback to more than 1,200 industry and government stakeholders. DOE works with Clean Cities coalitions nationwide to:

- Create new jobs and commercial opportunities-Alternative fuels and AFVs can benefit the economy in many ways. Converting conventional vehicles to AFVs, developing new technologies and products, utilizing domestically produced alternative fuels, increasing crop (feedstock) production, and expanding the alternative fuel infrastructure all create commercial opportunities, new jobs, and businesses nationwide.

- Facilitate AFV production and conversion - By pledging AFV acquisitions through the year 2005, the 1,200 plus registered Clean Cities stakeholders have shown that significant demand exists for these vehicles. Clean Cities works to transform these pledges into validated vehicle 
acquisition and conversion plans useful to manufacturers challenged to develop market-driven production lines.

- Advance clean air objectives and increase public awareness - The Clean Cities Program advances the objectives of the Clean Air Act and seeks to integrate its 1990 Amendments into each Clean City coalition's decision-making process.

- Provide greater fuel choices-The variety of fuel choices has enabled Clean Cities to choose the alternative fuels that best serve their local community and economy. This choice gives the community an opportunity to utilize the fuels that provide them with the best fuel performance, reduced emissions, and financial incentives.

- Develop "Clean Corridors"-Clean Cities has recognized the need for "Clean Corridors" and will build links between existing Clean Cities to ensure that refueling facilities are available for regional transit.

- Expand refueling infrastructure-Concurrent with Clean Cities expansion of the AFV market, the program builds on fuel supplier commitments to provide the refueling infrastructure critical for servicing and maintaining AFVs. In addition, the program seeks to make available existing private refueling stations for wider use.

- Support upgraded fleets-Through the Clean Cities Program, DOE is able to provide local assistance to federal an 1 state requirements for AFV acquisitions and conversions.

Staffers at the Clean Cities Hot line-(toll-free (800) CCITIES)-answer questions on funding, alternative fuels and AFVs, program planning, and other program issues. The hotline also makes available several resources for Clean Cities use, including the following publications:

- The Road to Clean Cities outlines step-by-step instructions on becoming a Clean City.

- The Clean Cities Troulleshooting Guide offers helpful suggestions on solving the challenges Clean Cities may face.

- The Alternative Fuel Nows newsletter provides cities with quarterly updates on the Clean Cities Program.

DOE also has appointed Clean Cities program managers at each of the DOE Regional Support Offices to assist local Clean Cities with their alternative fuels market development. In addition, the vast network of local Clean Cities coordinators is available to share information and provide assistance. The names and phone numbers of the Clean Cities coordinators and the Clean Cities program managers at the DOE Regional Support Officis are available from DOE.

To obtain more information, contact the Clean Cities Hotline (800) CCITIES, or write to: U.S. Department of Energy, EE-33, Ilean Cities Program, 1000 Independence Avenue SW, Washington, DC 20585. Visit the Clean Cities Flome Page on the World Wide Web-it can be accessed through the Energy Efficiency and Renewajle Energy Network at: http://www.ccities.doe.gov.

\subsubsection{Interstate Clean Transportation Corridors}

Southwest Interstate Clean Transportation Corridor (ICTC)--The ICTC seeks to be the nation's first economically sustainable inulticity, multistate market for alternative fuel transportation. The goal of the ICTC is to develop a refuel ng infrastructure in the Western states that will support clean-fuel 
interstate trucks moving goods between the region's nonattainment areas. The project seeks to mobilize and concentrate public and private resources to achieve the critical mass necessary to compete with diesel- and gasoline-fueled vehicles. The ICTC will look for opportunities to ensure the economic viability of its stakeholder projects by expanding the utilization of existing alternative fueling infrastructure and linking new fleets of heavy-duty AFVs to existing fleets of light- and medium-duty AFVs (Gladstein, June 1996).

\begin{tabular}{|l||}
\hline \multicolumn{1}{|c|}{ Goals of the ICTC } \\
- The placement of 10 alternative fuel service stations in strategic \\
location along the corridor \\
The regular use of these stations by 250 new interstate HD AFVs \\
and 500 existing local AFVs \\
- The displacement of 4.7 million gallons of diesel fuel annually \\
The reduction in emissions of 286 tons of priority pollutants \\
annually \\
The generation of $\$ 19$ million in private investment.
\end{tabular}

The initial ICTC (Figure 1-7) will link the region's five major nonattainment areas: Las Vegas, Los Angeles, Sacramento, Salt Lake City, and the San Joaquin Valley. The prototype program will target the deployment of refueling infrastructure and of AFVs along three corridors that link these five areas. Beginning with the I-10/I-15 junction in San Bernardino, the ICTC will travel north along I-15 through Barstow and Las Vegas to Salt Lake City, then turn west along I-80 through Reno, Sacramento, and Berkeley to San Francisco, then turn south to follow the I-5/CA-99 between Sacramento and Los Angeles. The resulting triangular corridor will provide alternative fuel coverage for more than 1,800 miles of some of the nation's busiest interstate highways.

The ICTC will organize and focus the energy and resources of the federal, state, and local governmental agencies responsible for energy diversification, transportation, and air quality on the development of the corridor. The project will assist private interests seeking to expand the availability of alternative fuels in the movement and delivery of goods by leveraging public resources to attract private investment in CFVs and infrastructure. In doing so, the ICTC project will primarily focus on creating opportunities for those refueling and freight operations that can demonstrate that they are economically sustainable.

This project seeks to build on existing programs that promote alternative transportation and improved efficiency in goods movement, yet fuse these resources in a manner that has not yet been attempted. By strategically linking programs at the city, state, and federal levels for the purpose of establishing a cleaninterstate-goods-movement industry, the ICTC seeks to use market-based incentives to demonstrate that alternative fuels not only will provide enhanced energy security and environmental protection, but can provide a competitive advantage as well. The ICTC staff will coordinate the participation of the region's many stakeholders in the project, ensuring that stakeholders receive all the support possible to arrive at sound business decisions to invest in the ICTC's refueling infrastructure and AFVs.

To focus the project's efforts, the ICTC staff has adopted specific goals. By the end of the ICTC's term, the goal is to have in place commitments from public and private stakeholders to build 10 alternative fueling stations along the project's three primary corridors; deploy 250 new alternative fuel heavy-duty, long-haul trucks to regularly use these stations, and link at least 500 existing local AFVs to these new refueling facilities. As a result of these commitments, the ICTC will eventually displace more than 
4.7 million gallons of diesel annually, reduce emissions in priority pollutants by more than 286 tons a year, and generate nearly $\$ 19$ million in private economic activity.

\section{Figure 1-7. The Southwest ICTC Corridors}

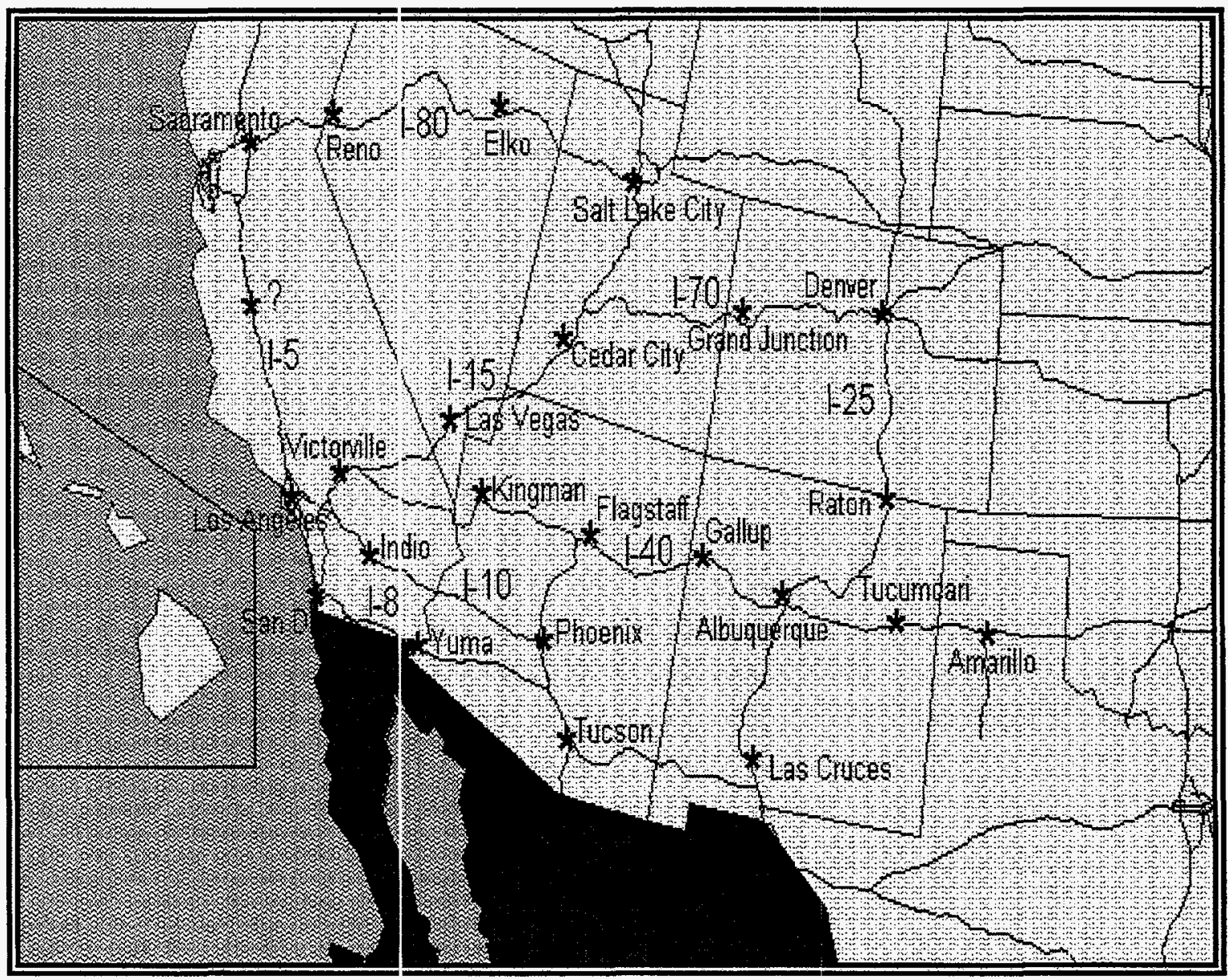

I-35 North American Free Trade Association (NAFTA) Superhighway Clean Corridor-A second possible ICTC project is along [-35 from the Mexican border north to the Canadian border. The I-35 Executive Committee Corridor Coalition supports development of fueling facilities for both LNG and CNG at regular intervals along the entire I-35 corridor and elsewhere along the so-called "NAFTA Superhighway" system to provide convenient natural gas fueling for heavy-duty trucks and automobiles. The committee resolution notecl that Mexico, Texas, Oklahoma, and Kansas offer abundant supplies of domestically produced and inespensive natural gas, which is well suited for transportation use. The resolution also noted that emissions from long-haul trucks operating on LNG would be very low. Particulate pollution would be virtually eliminated and $\mathrm{NO}_{\mathrm{x}}$ emissions would be cut by more than 50 percent compared to trucks operating on diesel.

The coalition was formed in 1994 to gain Congressional approval for a NAFTA Superhighway System designation, calling for I-35 to serve as the truck route for trade because of its central location and ties to the Mexican Pan-American Highway System. The proposed superhighway route runs from Mexico City north through Monterey and La redo to Dallas, Oklahoma City, Kansas City, and on to Minnesota and the Canadian border. 


\subsubsection{Global Climate Change Action Plan}

The EPA Office of Global Climate Change is moving forward to work with industry to develop programs to obtain voluntary reductions of greenhouse gas emissions, especially $\mathrm{CO}_{2}$ and $\mathrm{CH}_{4}$, across several broad sectors of the economy. These programs are targeted at stationary facilities that consume large quantities of fossil fuel energy or that release significant quantities of $\mathrm{CH}_{4}$ to the atmosphere as well as small businesses and energy-intensive consumer products, such as lighting and computers. Conversion of fleets and boilers to low-carbon fuels, such as natural gas (CNG and LNG), will reduce greenhouse gas emissions by as much as 20 percent.

Climate Wise-Climate Wise is a voluntary program designed to turn energy efficiency and superlative environmental performance into a corporate asset. The EPA and state and local environmental programs are creating opportunities for companies to save money, improve productivity, and protect the environment through voluntary strategies such as fuel switching, improving efficiency, and designing and making energy-efficient products that also reduce pollution. By entering into partnership agreements, businesses gain access to technical assistance, financial resources, and public recognition for pollution prevention activities. Programs operate under names such as Energy Star, Ag Star, and Green Lights.

Methane Reduction Programs-The EPA is developing outreach programs to promote $\mathrm{CH}_{4}$ recovery and use from a variety of sources, including landfills, coal mines, and waste from high-density cattle, swine, poultry, and dairy facilities. The EPA is working to develop incentives to capture fugitive $\mathrm{CH}_{4}$ for energy use. Unfortunately, commercial electricity prices are generally lower than the cost of electrical energy recovered from waste $\mathrm{CH}_{4}$ recovery projects. Energy recovery projects were viable only because of Section 29 tax credits. As of December 31, 1996, these tax credits are no longer available for new projects. The economics of methane recovery and conversion to liquid methane (LNG) and liquid carbon dioxide $\left(\mathrm{LCO}_{2}\right)$ may be a cost-effective solution to this growing problem. The $\mathrm{LNG}$ can be used to power heavy equipment and the $\mathrm{CO}_{2}$ can be sold for nonfood-grade industrial applications.

\subsubsection{EPA Environmental Leadership Program}

The EPA is evaluating ISO 14000 for use in its voluntary ELP, but is also considering the European Union's Environmental Management and Audit System and the United Kingdom's BC7750 standard. The goal of the ELP is to help companies voluntarily reduce their impact on the environment by implementing cost-effective, low-cost, and no-cost measures that eliminate toxic chemicals

\subsection{Private Initiatives that Affect Fleet Conversion to LNG}

\subsubsection{ISO 14000 Environment Management Standards}

Conversion of heavy-duty fleets to operate on LNG will be one of the most cost-effective environmental protection initiatives available to many companies and government agencies that adopt or participate in the ISO 14000 process. The first set of ISO 14000 Environment Management Standards was adopted in September 1996. These standards address how businesses and regulatory agencies interact with each other regarding environmental issues and regulatory compliance. Patterned after the widely adopted ISO 9000 Quality Control Standards for manufacture of products, ISO 14000 will encompass both organizational and product-oriented elements. The organizational elements to be included are environmental management systems (EMS), environmental auditing, and environmental performance. The three product-related elements will be life-cycle analysis, environmental labeling, and environmental aspects of product standards. 
Both ISO 9000 and ISO 14000 standards have the concepts of total quality management (TQM) as their foundation. The application of the existing standards in the ISO 9000 series and the upcoming ISO 14000 series to environmental issues will create an opportunity for fleet managers to adopt LNG as the fuel of choice in many heavy-duty vehicle applications.

Until about a decade ago, the Zirich-based ISO confined itself to technical and safety standards. However, the success of management-initiated quality control systems such as the Deming Program in improving product safety and reliability, coupled with an accelerating trend toward global manufacturing and trade, convinced manufacturers that a consistent, internationally recognized standard that used the TQM management systems concepts would benefit global trade and commerce.

First, the ISO developed the ISO 9000 quality control standards. Then, in 1993, the ISO turned its attention to EMS. Besides imp:oving environmental protection and performance, the resulting EMS standards, known as ISO 14000 , are expected to provide a credible alternative to traditional commandand-control regulation. They arddress systems and continuous improvement tools for all types of organizations, including companies in the manufacturing, transportation, and service industries. When final, ISO 14000 standards could give companies easier access to markets in other countries by eliminating the trade barriers inposed by conflicting national and regional environmental standards.

The ISO 14000 standards are bring developed by ISO Technical Committee 207, which is composed of representatives from 41 particifrating and 14 observing national delegations. The group includes representatives from industry, govemment, standards organizations, and environmental groups. The American National Standards Institute (ANSI) is the U.S. member of ISO. ANSI is sponsoring the United States Technology Advisory Group (TAG) for ISO 14000. TAG has more than 477 members, including representatives from ndustry, government, trade associations, environmental groups, and law and consulting firms, as well as private individuals.

Twenty standards have been developed to cover EMS, environmental auditing, environmental labeling, environmental performance evaluations, life-cycle assessment, and environmental aspects of product standards. The standards will te considered a "floor," or the minimum EMS requirements from which a company can continue to improve its system.

Five of the 20 standards were given draft international standard status during the July 1996 ISO meeting in Oslo, Norway:

- 14001, EMS - Specification with Guidance for Use

- 14004, EMS - General Guidance on Principles, Systems and Supporting Techniques

- 14010, Guidelines for İnvironmental Auditing - General Principles on Environmental Auditing

- 14011, Guidelines for Environmental Auditing - Audit Procedures - Audit of Environmental Management Systems

- 14012, Guidelines for Innvironmental Auditing - Qualification Criteria for Environmental Auditors.

To become certified, a company must demonstrate to an accredited registrar that its EMS meets the ISO 14000 criteria, which cover policy and planning, organizational structure and responsibilities, training, communications, documentation, auditing, performance measurement, and management review. Besides an effective system for complicnce with applicable laws and regulations, a company's EMS also must have proactive components, such as a measurable, demonstrated commitment to pollution prevention. 


\subsubsection{Sample ISO 14000 Environmental Management System}

The basic requirements of an EMS created to follow the ISO 14000 standards are summarized below.

- The organization shall establish and maintain an EMS

- Top management shall define the organization's environmental policy

- The organization shall establish and maintain:

- A procedure to identify the environmental aspects of its activities in order to determine those that have or can have significant environmental impact

- A procedure to identify and have access to legal and other requirements

- Documented environmental objectives and targets, at each relevant function and level within the organization.

Implementation and Operation-Roles, responsibilities, and authorities shall be defined, documented, and communicated to facilitate effective environmental management. Management shall provide resources required to implement and control the EMS and shall àppoint a specific management representative(s) who, irrespective of other responsibilities, shall have defined roles, responsibilities, and authority.

The organization shall identify training needs. It shall require that all personnel whose work may create a significant impact on the environment have received appropriate training.

The organization shall establish and maintain procedures for:

- Internal communication between various functions and levels of organization

- Receiving, documenting, and responding to relevant communication from external interested parties.

The organization shall establish and maintain information, in paper or electronic form, to:

- Describe the core elements of the management system and their interaction

- Provide direction for related documentation.

The organization shall:

- Establish and maintain procedures for controlling all documents required by this standard

- Identify those operations and activities associated with the identified significant environmental impacts in accordance with its policy, objectives, and targets

- Plan these activities, including maintenance, to ensure they are carried out under specified conditions

- Establish and maintain procedures to identify potential for and response to accidents and emergency situations, and for preventing and mitigating associated environmental impacts. 
Checking and Corrective Action-The organization shall establish and maintain:

- Documented procedures to monitor and measure on a regular basis the key characteristics of its operations and activities

- Procedures for defining responsibility and authority, handling and investigating nonconformance, taking action to mitigate the impacts, and initiating and completing corrective and preventive action

- Procedures for identify.ng, maintaining, and disposing of environmental records

- A program and procedures for periodic EMS audits.

Management Review-The organization's top management shall review the EMS to ensure its continuing stability, adequacy, and effectiveness.

\subsubsection{Sustainable Develıpment-A Market Driver for LNG Fuels}

The terms "sustainability" and "sustainable development" have come into widespread use. "Our Common Future" (or the "Brundtland Report," named after the Commission's Chair, Norwegian Prime Minister Gro Harlem Brundtlar d) defined sustainable development as "development which meets the needs of the present without en langering the ability of future generations to meet their own needs."

That Commission established several key principles of sustainability:

- That the needs of the future must not be sacrificed to the demands of the present

- That humanity's economic future is linked to the integrity of natural systems

- That protecting the environment is impossible unless we improve the economic prospects of the Earth's poorest peoples.

Many U.S. cities and communi ies, such as Portland, San Francisco, Austin, and Chattanooga, are working to become sustainable communities. They are aggressively challenging the status quo in a focused effort to preserve and frotect, and in some cases reclaim, the unique cultural, economic, and environmental values that maks: these communities unique, desirable places to live and work.

Sustainability Indicators-The first steps are to define "sustainability" and to develop indicators to monitor critical reserves, such as air quality. These sustainability indicators will then be used to develop plans needed to improve performance.

For example, many indicators a re being developed that affect cars, trucks, and buses. Among other things, these indicators include energy efficiency and air emission measures for transport of people and cargo and life-cycle analysis of fuels and transportation systems. LNG offers distant advantages over conventional fuels when evaluated in the context of sustainability indicators. For example, life-cycle emissions for production, distribution, and use of LNG are lower than those for diesel fuels. LNG and by-products of its combustion are much less toxic than that of diesel fuels.

There are several major attribu tes to this concept. The first is the distinction between growth and development. Dr. Herman Daly (Environmental Department, World Bank) describes the differences by defining "growth" as the "expansion in scale of physical dimensions of an economic system while "development" refers to qualitative change (improvement of degradation) of a physically non-growing economic system in a state of clynamic equilibrium maintained by its environment."

Another attribute of the concert is that it is not a new, revolutionary, or radical notion. People have become familiar with the idea lhrough the common usage of such terms as carrying capacity, sustained 
management practices, sustainable yield, systems approaches, limits to growth, and more. LNG supports sustainable development in that its use will significantly improve the quality of the environment.

At the June 1992 United Nations Conference on Environment and Development (the "Earth Summit" or UNCED) in Rio de Janeiro, Brazil, representatives from nearly every nation on Earth adopted the Brundtland principles in the form of international treaties and agreements designed to begin protecting natural systems while meeting the needs of the world's poor. At the same time, a "Global Forum" of citizens' groups from around the world developed grass-roots initiatives designed to monitor governments and push sustainability efforts beyond what governmental processes were able to do. These latter efforts were aligned with Agenda 21, one of five documents signed at the UNCED conference.

Agenda 21-Donald A. Brown (1994-95) describes Agenda 21 as a nonbinding, comprehensive blueprint for global action into the twenty-first century. He explains that "the greatest historical significance of Agenda 21 is that it puts environmental protection and economic development activities on the same footing as the notion of 'sustainable development." Brown concludes that Agenda 21 is a means of forcing the integration of environmental, economic, and social planning at the state level and that it should be used as a "tool for reconciling economic, environment, and development tensions and conflicts."

Local Initiatives: Public-Private Initiatives Are Critical-Today we are on the threshold of bringing these ideas to fruition-the question is "how"? In 1985, a Global Tomorrow Coalition report noted that the main problem in the development is not the lack of technical answers, but failure, for political and socioeconomic reasons, to put known solutions into effect soon enough and widely enough. Questions of democracy, the role of markets, the debt crisis, land tenure, and international institutions are central to the development process.

Recently, the U.S. representative in the Biosphere Program (1994: p. 2) concluded that, "A sustainable South Florida environment is achievable only through utilizing ecosystem management principles that recognize the inter-dependency of humans and their environment." Therefore, is the human environment part of or independent of the natural system? The consensus appears to be it is the successful integration of the two and that sustainability is the test of whether they are integrated in a way in which specified fundamental environmental constraints are not violated. For example, Colin Issacs, executive director of the Pollution Probe Foundation in Toronto, Ontario, spoke at "Environment and Economy, Partners for the Future," a conference on the theme of sustainable development held in December 1989. In his remarks at one session, he stated:

Sustainable development is sustainable development, not sustainable economic development, not sustainable DEVELOPMENT, but almost one word: sustainable development. It's not the economy or the economics that we are trying to sustain, it's the environment and the economy that we are trying to sustain. Sustainable development clearly means development in controlled quantity, enough to meet the globe's economic and environmental needs and no more.

Paul Hawken, in "The Ecology of Commerce: A Declaration of Sustainability" (1993), stated that "sustainability" can be defined in terms of carrying capacity of the ecosystem, and described with inputoutput models of energy and resource consumption. Sustainability is an economic state in which the demands placed on the environment by people and commerce can be met without reducing the capacity of the environment to provide for future generations. He goes on to note that sustainability means that services or products should not compete in the marketplace in terms of image, power, speed, or packaging, but instead should compete in a way that reduces consumption, energy use, distribution costs, economic concentrations, soil erosion, atmospheric pollution, and other forms of environmental damage. 
Overall, sustainability is an ethical consideration. The term by itself is meaningless unless it is used in the context of sustainable uses or of something that can be identified and measured.

For decades, society has tried to protect the environment by regulating the laws of supply and demand. Government has regulated indu stries and product manufacturers by the use of subsidies, user fees, and mandates. The result has been the addition of millions of dollars to the cost of products. A market-driven approach rather than a command-and-control approach to protect the environment can empower industries to manufacture products with an "efficiency of purpose" that actually reflects the real sources of pollution.

Many environmental policy-makers in government, industry, and activist groups now believe that giving people the right incentive and showing them how their lives can be better through the creation of jobs and new vital industries is perhaps the only way civilization can respond to the environmental challenges that confront us well into the next cəntury.

Concepts such as the development of a Global Environmental Commodities market are being proposed as incentives to protect the enviromment and to stimulate for the creation of new jobs, industries, food supplies, and increased government effectiveness for empowerment in all cultures.

\subsubsection{Coalition for Responsible Economies (CERES)}

A broad spectrum of socially responsible business and investment professionals, environmentalists, churches, community groups, and labor unions have banded together to form CERES-the Coalition for Responsible Economies. The group drafted a model statement of environmental policy, originally dubbed the "Valdez Principles," intendəd to help guide corporations move toward greater responsibility. The 10point code is now known as the "CERES Principles."

Commitment to Follow the CERES Principles Is Voluntary-How does a company assess its overall environmental impact? What are the yardsticks that can be used to measure progress? For the first time, the CERES Principles established a comprehensive process for corporations to evaluate themselves and set priorities for improvement. The Principles bind companies to goals such as pollution prevention, waste reduction, biosphere protection, energy conservation, and clean fuels.

Corporations of all types and sizes, ranging from General Motors to Stonybrook Farms, have committed to support the CERES Principles. CERES signature meetings provide an opportunity for officials from all member companies to compare notes. Currently, more than 60 companies have signed the CERES Principles. Aveda Corporation, manufacturer of natural personal care products, was the first to sign on. In 1993, Sun Company became the first Fortune 500 firm to adopt the Principles.

With his corporation joining ClERES 1 year after its establishment, General Motors' chief executive officer John Smith stated that the company wanted to show "economic growth, technology, and environmental quality can be compatible. On environmental issues, the stakes are so high that everyone ought to be pulling in the same direction."

Improvement, Not Perfection-CERES is the first to point out that signing the Principles does not mean a company is "green." Indeed, the Principles are careful to state that signatories are working toward "consistent, measurable progre:ss" in the implementation of the Principles. To prevent "greenwashing," the CERES Principles are not used for advertising or as an endorsement of a company's environmental performance. The benefits of farticipating in CERES involve a commitment to genuine improvement in corporate environmental resporsibility. 
Ultimately, the success of initiatives like CERES depends on senior managers realizing that ecological responsibility leads to a more efficient and profitable company. Conversion to LNG is one action that a company could take to demonstrate this commitment. Investors and corporate managers concerned about the environment may contact CERES executive director Bob Massie at 711 Atlantic Ave., Boston, MA 02111 (617) 451-0927. 


\subsection{LNG Production and Distribution}

Conversion to LNG provides the trucking industry with the opportunity to develop a more diversified and secure fuel supply. Diversificalion may ensure that adequate supplies are available to domestic truckers in the event of a political or military crisis in the oil-producing regions of the world. Perhaps more important, however, development of an LNG infrastructure will provide for increased competition among fuel suppliers that may serve to buffer future price shocks caused by short-term disruption of oil shipments from insecure foreigi sources as well as increased competition for petroleum.

The existing natural gas pipeline system provides a solid foundation for developing an extensive LNG fuel supply infrastructure. LNG has many uses within the existing natural gas production and distribution industry. This chapter outlines how LNG is produced and used by the natural gas industry to ensure adequate and reliable deliveries of natural gas to utility, residential, and industrial customers. Methods used to distribute LNG to customers throughout the world are also described and opportunities for distribution of LNG into the motor fuel market are identified.

Two comprehensive directories to the domestic and global LNG industry are The World LNG Sourcebook, which was published in March 1997 by the Zeus Development Corporation, and the World LNG Facilities Review (Nimoclss, 1996.) Also in March 1997, Zeus released its latest Global LNG Facilities Review. This document provides detailed descriptions of the more than 300 LNG facilities located throughout the world, from large export terminal liquefaction plants to small LNG vehicle fuel stations.

\subsection{Potential Supply from Existing Infrastructure}

For the past 5 years, LNG has teen sold for motor-fuel use from at least 18 facilities located in all regions of the United States and Canadi. Most of these plants are located within 250 miles of major urban areas and are supporting more than 20 LNG fleet demonstrations. The locations of 16 LNG plants with the capability to deliver LNG to nearly all major motor-fuel markets in the United States are shown in Figure 2-1. Many more LNG s jurces could be modified to supply LNG to the motor-fuel market.

In the United States, more than 150 plants produce or store LNG as part of their normal operations. These plants can be categorizec $\dot{c}$ as peak-shaving facilities, satellite storage plants, import terminals, nitrogen-rejection units (NRUsi, and certain types of chemical plants, such as olefin and synthesis gas plants. In addition, several hundred smaller cryogenic gas-liquid plants, located primarily in the central and western United States, might be modified to produce LNG.

Cryogenic gas plants refrigeratt: natural gas to remove ethane. One plant near Durango, Colorado, owned by Williams Field Services, has been converted to produce motor-vehicle-grade LNG. This LNG is dispensed at a station near Blocmfield, New Mexico. With modest capital investment, at least 135 existing cryogenic natural gas-liquid plants could be modified to supply LNG to the motor-fuel market (Houshmand, 1996).

Table 2-1 summarizes the types: of facilities that could be converted to supply LNG to the motor-fuel market, including the plants that have recently sold LNG fuels for use as motor fuel (Zeus Development, 1996). Table 2-2 provides a detailed list of more than 70 existing LNG facilities that could be modified to supply LNG fuels for transportition and other fuel uses (Midgett, February 1996).

The use of liquefaction plants dedicated to the LNG fuel market-ranging in size from 400 to 100,000 gallons per day-to produce LIVG from pipeline or other low-cost $\mathrm{CH}_{4}$ sources is economically and 
Figure 2-1. LNG Is Available throughout the United States

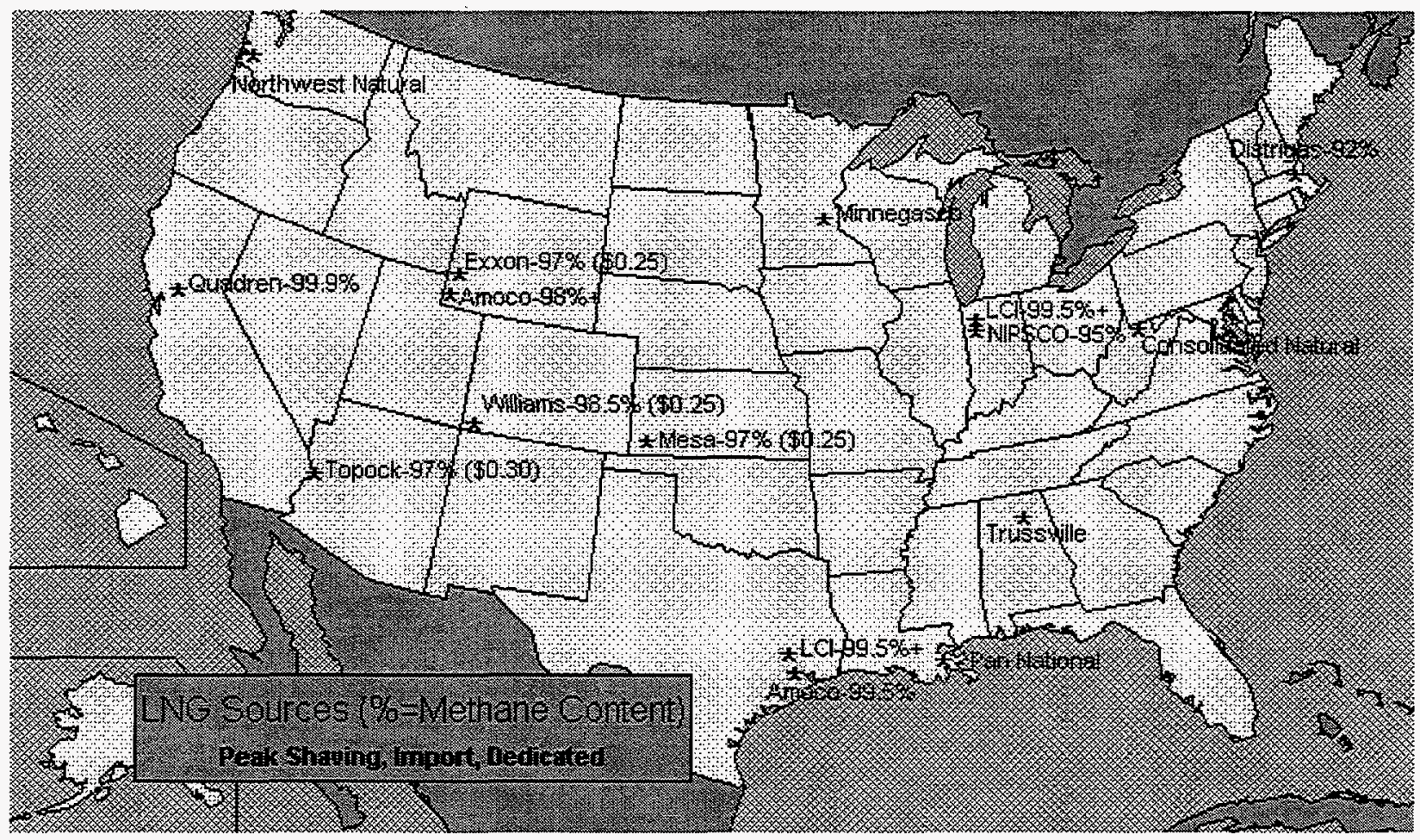

Table 2-1. Types of LNG Liquefaction or Storage Plants

\begin{tabular}{lccc}
\hline & $\begin{array}{l}\text { Estimated Total Plant } \\
\text { Count }\end{array}$ & $\begin{array}{l}\text { Recently Sold LNG for Motor- } \\
\text { Fuel Use }\end{array}$ \\
\hline Peak-shaving plants & 56 & 12 \\
Satellite storage & 31 & 0 \\
facilities & 41 & 0 \\
Import terminals & 3 & 2 \\
Gas synthesis plants & 39 & 02 \\
Olefin plants & 135 & 1 \\
Cryogenic gas plants & 2 & 0 \\
City-gate pressure drop & 1 & 0 \\
Export terminals & 2 & 2 \\
Dedicated plants & 10 & 3 \\
Nitrogen rejection units & 2 & 02 \\
Landfill plants & 285 & 20 \\
Total & & \\
\hline
\end{tabular}

technically feasible in niche markets. However, the high capital and operating costs associated with commercially available gas cleanup and liquefaction equipment are barriers.

In spite of the many environmental benefits, it is difficult to project an adequate rate of return for very small, dedicated LNG projects (up to 10,000 gallons per day [gpd] LNG) because of the relatively high costs of small gas cleanup systems and liquefiers constructed with existing technology. However, one possible near-term application for small liquefiers is the production of $\mathrm{LNG}$ from waste $\mathrm{CH}_{4}$ captured from solid-waste landfills, feedlots, or coal seam gas. Waste $\mathrm{CH}_{4}$ recovery projects may become 
Table 2.2. Domestic Facilities Capable of Supplying LNG

\begin{tabular}{|c|c|c|c|c|c|c|c|c|}
\hline Ref \# & Company & $\begin{array}{l}\text { Plart } \\
\text { Typi }\end{array}$ & City & $\begin{array}{l}\text { STI } \\
\text { PR }\end{array}$ & $\begin{array}{l}\text { Liquefaction } \\
\text { Capacity } \\
\text { (Gal/Day) }\end{array}$ & $\begin{array}{l}\text { Storage } \\
\text { Capacity } \\
\text { (Gal/Day) }\end{array}$ & $\begin{array}{l}\mathrm{CH}_{4} \\
\text { Purity }\end{array}$ & $\begin{array}{c}\text { Truck } \\
\text { Or Rail } \\
\text { Loading }\end{array}$ \\
\hline 1 & $\begin{array}{l}\text { Phillips } 66 \& \\
\text { Others }\end{array}$ & Export Term & Kenai & AK & $1,520,000$ & N/A & $99+1-\%$ & $N / A$ \\
\hline 2 & Alabama Gas* & Peak-Shaving & Coosada & $\overline{A L}$ & 29,855 & $7,567,612$ & $N / A$ & Yes \\
\hline 3 & Alabama Gas* & Peak-Shaving & Pinson & $\mathrm{AL}$ & 44,914 & $15,335,225$ & $\mathrm{~N} / \mathrm{A}$ & Yes \\
\hline 4 & Utilities Board ${ }^{*}$ & Peak-Shaviı & Trussville & $\mathrm{AL}$ & 52,531 & $4,987,039$ & $97+1-\%$ & Yes \\
\hline 5 & $\begin{array}{l}\text { Associated } \\
\text { Natural Gas }\end{array}$ & Peak-Shavinı & Yaroro & $\overline{A R}$ & $N / A$ & $2,310,165$ & N/A & Yes \\
\hline 6 & BC Gas* & Peak-Shavirıg & Delta & $\mathrm{BC}$ & 52,840 & $7,397,600$ & $96+1-\%$ & Yes \\
\hline 7 & $\begin{array}{l}\text { Quadren } \\
\text { Cryogenics }\end{array}$ & $\mathrm{NRU}^{\star \star \star *}$ & Sacramento & CA & 55,000 & 62,500 & $99+1-\%$ & Yes \\
\hline 8 & $\begin{array}{l}\text { Connecticut Nat } \\
\text { Gas }^{\star}\end{array}$ & Peak-Shavirıg & Rocky Hill & $\mathrm{CT}$ & 72,655 & $14,626,112$ & $N / A$ & Yes \\
\hline 9 & Del Marva Power & Peak-Shavirig & Wilmington & DE & 18,758 & $3,045,433$ & $\mathrm{~N} / \mathrm{A}$ & Yes \\
\hline 10 & Atlanta Gas Light* & Peak-Shavirig & Cherokee & $\mathrm{GA}$ & 135,799 & $25,204,680$ & $N / A$ & Yes \\
\hline 11 & Atlanta Gas Light* & Peak-Shavirig & Macon & GA & 123,381 & $18,901,925$ & N/A & Yes \\
\hline 12 & Atlanta Gas Light ${ }^{\star}$ & Peak-Shavirı & Riverdale & $\mathrm{GA}$ & 124,702 & $31,240,593$ & $\mathrm{~N} / \mathrm{A}$ & Yes \\
\hline 13 & United Cities ${ }^{\star}$ & Peak-Shavitig & Columbus & $\mathrm{GA}$ & N/A & $7,001,300$ & N/A & Yes \\
\hline 14 & $\begin{array}{l}\text { lowa-llinois Nat. } \\
\text { Gas* }\end{array}$ & Peak-Shavirig & Bettendorf & IA & 24,306 & $6,091,131$ & N/A & Yes \\
\hline 15 & Midwest Gas ${ }^{*}$ & Peak-Shavirıg & Des Moines & IA & N/A & $4,861,280$ & N/A & Yes \\
\hline 16 & Midwest Gas* & Peak-Shavirig & Waterloo & IA & 31,176 & $9,775,400$ & $\mathrm{~N} / \mathrm{A}$ & Yes \\
\hline 17 & $\begin{array}{l}\text { Northem Natural } \\
\text { Gas* }\end{array}$ & Peak-Shavirıg & Gamer & IA & 135,006 & $25,181,956$ & $\mathrm{~N} / \mathrm{A}$ & Yes \\
\hline 18 & $\begin{array}{l}\text { Intermountain } \\
\text { Gas* }\end{array}$ & Peak-Shavirig & Nampa & ID & 46,235 & $7,480,559$ & $\mathrm{~N} / \mathrm{A}$ & Yes \\
\hline 19 & Peoples Gas* & Peak-Shavirlg & Fisher & IL & 121,004 & $24,205,476$ & NA & Yes \\
\hline 20 & Citizen Gas ${ }^{*}$ & Peak-Shavirıg & Beech Grove & IN & 62,351 & $12,182,262$ & N/A & Yes \\
\hline 21 & Citizen Gas ${ }^{\star}$ & Peak-Shavir ig & Indianapolis & IN & 93,527 & $12,182,262$ & N/A & Yes \\
\hline 22 & $\begin{array}{l}\text { Kokomo Gas \& } \\
\text { Fuel }^{\star}\end{array}$ & Peak-Shavirıg & Kokomo & IN & 30,383 & $4,861,280$ & $\overline{N / A}$ & Yes \\
\hline 23 & NIPSCO* & Indus. Gas & Hammond & IN & 241,479 & $48,730,105$ & N/A & Yes \\
\hline 24 & $\begin{array}{l}\text { Air Products \& } \\
\text { Chemicals }\end{array}$ & Indus. Gas & New Orteans & LA & N/A & N/A & $99+1-\%$ & Yes \\
\hline 25 & Praxair & Indus. Gas & Geismer & LA & $N / A$ & N/A & $99+1-\%$ & Yes \\
\hline 26 & $\begin{array}{l}\text { Trunkline (Pan } \\
\text { Eastern) }\end{array}$ & Import Term. & Lake Charles & LA & $\mathrm{N} / \mathrm{A}$ & $75,591,055$ & $85+/-\%$ & Yes \\
\hline 27 & Bay State Gas* & Peak-Shavirıg & Ludlow & $\mathrm{MA}$ & $N / A$ & $12,181,469$ & N/A & Yes \\
\hline 28 & Boston Gas ${ }^{\star}$ & Peak-Shavirig & Dorchester & MA & $\mathrm{N} / \mathrm{A}$ & $25,155,800$ & $\mathrm{~N} / \mathrm{A}$ & Yes \\
\hline 29 & Boston Gas* & Peak-Shavirig & Lynn & MA & $\mathrm{N} / \mathrm{A}$ & $12,153,200$ & $\mathrm{~N} / \mathrm{A}$ & Yes \\
\hline 30 & Colonial Gas* & Peak-Shaving & Tewsbury & MA & N/A & $12,153,200$ & $N / A$ & Yes \\
\hline 31 & Distrigas & Import Term. & Everett & MA & $\mathrm{N} / \mathrm{A}$ & $40,911,370$ & $85+/-\%$ & Yes \\
\hline 32 & Fall River Gas* & Peak-Shaviig & Fall River & MA & $N / A$ & $1,890,351$ & N/A & Yes \\
\hline 33 & $\begin{array}{l}\text { Baltimore Gas \& } \\
\text { Elec.* }\end{array}$ & $\begin{array}{l}\text { Air Products \& } \\
\text { Chemical }\end{array}$ & Baltimore & $\mathrm{MD}$ & 57,596 & $12,113,570$ & $96+/-\%$ & Yes \\
\hline 34 & Minnigasco* & Peak-Shaving & Bumsville & $\mathrm{MN}$ & 62,351 & $12,285,880$ & N/A & Yes \\
\hline 35 & $\begin{array}{l}\text { Northem Natural } \\
\text { Gas }\end{array}$ & Peak-Shaving & Wrensnall & $\mathrm{MN}$ & 130,779 & $26,181,958$ & $N / A$ & Yes \\
\hline 36 & $\begin{array}{l}\text { Northern States } \\
\text { Power* }\end{array}$ & Peak-Shaviıg & St. Paul & MN & $\mathrm{N} / \mathrm{A}$ & $25,944,440$ & $N / A$ & Yes \\
\hline 37 & $\begin{array}{l}\text { North Carolina } \\
\text { NG }^{*}\end{array}$ & Peak-Shaving & Four Oaks & NC & $\mathrm{N} / \mathrm{A}$ & $12,182,262$ & $\mathrm{~N} / \mathrm{A}$ & Yes \\
\hline 38 & Piedmont Gas ${ }^{*}$ & Peak-Shaviing & Charlotte & NC & 52,351 & $12,467,598$ & $N / A$ & Yes \\
\hline 39 & $\begin{array}{l}\text { Public Service of } \\
\text { NC }^{\star}\end{array}$ & Peak-Shaving & Cary & $\mathrm{NC}$ & $N / A$ & $12,179,620$ & $\bar{N} / \mathrm{A}$ & Yes \\
\hline 40 & $\begin{array}{l}\text { Metro Util. } \\
\text { District* }^{*}\end{array}$ & Peak-Shaviıg & Omaha & NE & 74,769 & $12,390,980$ & N/A & Yes \\
\hline 41 & $\begin{array}{l}\text { WFS Gas } \\
\text { Resources* }\end{array}$ & Peak-Shavilig & Carlstadt & $\mathrm{NJ}$ & $>100,000$ & $24,359,240$ & $N / A$ & Yes \\
\hline 42 & Paiute Pipeline* & Peak-Shaving & Lovelock & NV & 67,371 & $12,179,620$ & N/A & Yes \\
\hline 43 & Brooklyn Union & Peak-Shaving & Brooklyn & NY & 626,154 & $196,139,438$ & N/A & No \\
\hline 44 & Con Edison* & Peak-Shaving & Astoria & NY & 55,786 & $12,238,272$ & N/A & $N / A$ \\
\hline
\end{tabular}


Table 2.2. Domestic Facilities Capable of Supplying LNG

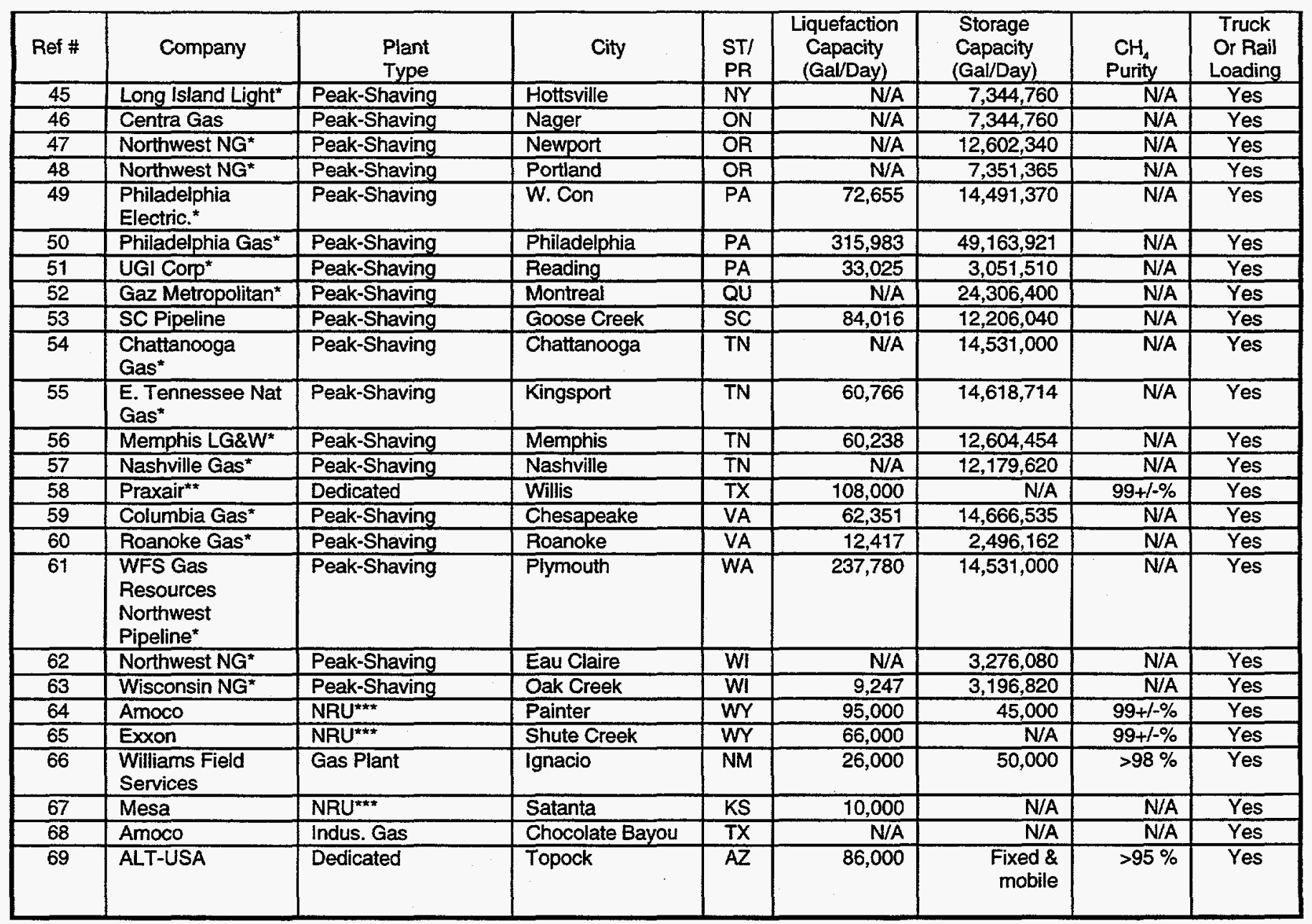

*Blazek, C., et al. Institute of Gas Technology Survey, LNG Observer, Winter 1991

**Under Construction ***Nitrogen Rejection Unit

economically viable when environmental restrictions discourage or prohibit continued discharge of $\mathrm{CH}_{4}$ and $\mathrm{CO}_{2}$ to the atmosphere.

\subsection{Peak-Shaving and Satellite Storage Facilities}

Peak-shaving facilities, sometimes called peaking plants, liquefy and store natural gas during warmer months for rapid reinjection into local pipelines during "peak" demand periods in cold weather. A typical peak-shaving plant produces between 20,000 and 130,000 gpd of LNG. Some plants, such as the one in Trussville, Alabama, have excess capacity. Trussville produces 60,000 gpd of LNG and has been aggressively marketing about 45,000 gpd of LNG to the vehicle market or to gas-injection satellite plants. Satellite storage plants perform essentially the same service as a peaking plant, except they do not liquefy gas on site but receive LNG from other facilities via transport truck. Approximately 60 peak-shaving plants and 35 satellite storage plants are operated in the United States and Canada. Several more are being designed or constructed.

Gas utilities use peak-shaving and satellite plants to ensure adequate gas supply during periods of high demand when pipeline supply and capacity are not sufficient to serve all customers. Although the plants are expensive to build and maintain because they are staffed 24 hours daily, utilities save the higher 
expense of sizing pipelines to handle short-duration peak flows - which may be five times the average annual demand. Even at costs of $\$ 20 / \mathrm{MMBtu}$ of gas delivered, peak-shaving facilities are often the most cost-effective means of ensuring adequate gas delivery.

Many peak-shaving plants, such as NIPSCO and Minnegasco, can store up to 25 million gallons of LNG in large, field-erected tanks. Satellite plants are generally smaller; some store as little as 50,000 gallons. As a rule of thumb, peak-shaving plants liquefy gas for about 200 days, and can reinject all their storage into the local pipeline in less thin 20 days. Years may pass, however, before high demand requires gas reinjection from peak-shaving or satellite plants.

Most peak-shaving and satellite plants were built between 1965 and 1980 . With natural gas deregulation, several new plants are expected; others may be shut down. More than 50 peak-shaving facilities may be able to supply more LNG for motor fuel purposes. Twelve units are already active in the market.

\subsection{Import Terminals}

In 1994, world LNG trade rose 6 percent to 88 billion cubic meters (about 38 billion metric tons), equivalent to a record 24 percent of all natural gas exports. North America, however, plays a very small role in the international LNG market. The continent has ample gas reserves that can be transferred efficiently to markets by pipelire. Consequently, only two import terminals, Distrigas/Cabot LNG in Boston, Massachusetts, and Parhandle Gas/Panhandle Eastern in Lake Charles, Louisiana, and one export plant, Marathon/Phillips in Kenai, Alaska, are actively handling LNG. Two more import terminals are currently idle. One is being retsofitted as a peak-shaving facility.

In spite of North America's minor role in the world LNG marketplace, imported LNG offers a very lowcost source of gas with significant delivery capacity in two regions, New England and Southwest Louisiana. As much as 8 million gallons per day could be supplied from import terminals if all four facilities, including the inactive Maryland and Georgia facilities, were operated at full capacity. Recent prices from the two active terminals ranged from $\$ 0.25$ to $\$ 0.35$ per LNG gallon. The output of the nation's only export facility near Kenai, Alaska, is fully committed to Japanese markets.

Two challenges face marketers who wish to sell imported LNG. First, imported LNG generally contains more than $10 \%$ NMHC, which falls outside the tolerances set by Cummins and Detroit Diesel Corporation (DDC) for their heavy-duty engines. Additional processing to remove the heavier hydrocarbons can solve this prcblem.

Second, part of the argument for using natural gas as motor fuel is that supplies of the fuel in North America are abundant and secure, whereas more than 50 percent of oil is imported. The use of imported LNG appears to contradict advocates'claims that natural gas supplies are more secure because they are domestic. Imported LNG faces the same national security problems as imported oil. For example, the government of Algeria, the sou ce of most LNG currently imported into the United States, has suffered growing instability in recent years. A government coup d'état by rebellious factions could lead to LNG supply disruptions.

On the other hand, global trade in LNG is developing rapidly because supply facilities are being built in regions that have not traditionaly been large oil producers. Large quantities of natural gas are frequently produced as a by-product of recovering relatively small quantities of oil. Because of the high cost or impracticality of building pipel ines, this by-product gas was once vented to the atmosphere and burned. Facilities are now being constricted to convert this by-product gas into LNG for shipment by tanker to markets in Japan, Spain, and el sewhere. New supplies of LNG are available from countries, such as Trinidad and Venezuela, located outside the large oil-producing regions of the Middle East. Additional 
supplies of LNG could be developed from other South American, Mexican, and Southeast Asian gas fields, as well as from fields in the Middle East and the former Soviet Union.

\subsection{Nitrogen Rejection Units}

Four NRUs currently offer LNG for motor-fuel use for a combined delivery capacity of 212,500 gallons per day. Another six NRUs process gas in the United States and Canada. Exxon and Amoco distribute LNG from NRUs located, respectively, in Shute Creek and Painter, in Southwest Wyoming; Quadren Cryogenics distributes from Sacramento, California; and Mesa from Satanta, Kansas. The quantity of LNG recovered from an NRU is a very small percentage of the total throughput of the plant.

The primary function of the NRU is to use cryogenic separation to remove nitrogen from raw gas to produce pipeline-quality natural gas. Most pipelines will not accept gas containing more than 4 percent nitrogen. When nitrogen levels in the raw gas exceed 20 percent by volume, cryogenic separation is cost effective when gas prices are high or when throughput justifies the investment in very large gasprocessing plants. For example, when natural gas prices are below $\$ 2.00$ per MMBtu, nitrogen rejection is costly unless production is more than 5 to 6 millimeters per square foot per day (mmsfd).

Nitrogen has a boiling temperature of approximately $-320^{\circ} \mathrm{F}\left(-195^{\circ} \mathrm{C}\right)$. To separate $\mathrm{CH}_{4}$ from the nitrogen-rich feedstock, the raw gas is cooled to roughly $-260^{\circ} \mathrm{F}\left(-162^{\circ} \mathrm{C}\right)$ so that the $\mathrm{CH}_{4}$ condenses, or liquefies. The nitrogen gas is cycled through heat exchangers to recover as much energy as practical and then usually rejected to the atmosphere.

Most of the liquid $\mathrm{CH}_{4}$ produced at the NRU is recycled through heat exchangers to cool incoming raw gas. As the raw gas cools, the liquid $\mathrm{CH}_{4}$ revaporizes and warms to near ambient temperature. This way, the plant recovers much of the energy expended to liquefy and separate the $\mathrm{CH}_{4}$ from nitrogen. $\mathrm{The}^{\mathrm{CH}}$ gas is then injected into transmission pipelines for distribution to market as natural gas. Some NRUs also liquefy and recover nitrogen and helium from the raw gas. Helium liquefies at roughly $-452^{\circ} \mathrm{F}\left(-270^{\circ} \mathrm{C}\right)$. Cryogenic liquids recovered from the NRUs are loaded into railcars or truck trailers for transport to market.

\subsection{Cryogenic Gas Plants}

In some regions of the country, especially Louisiana and Texas, natural gas contains rich mixtures of hydrocarbons heavier than $\mathrm{CH}_{4}$, including ethane, propane, butane, and natural gasoline. Cryogenic gasprocessing plants recover natural gasoline, butane, propane, and ethane from raw natural gas with a refrigeration process. More than 200 gas plants are operating in the United States to recover natural gasoline, butane, and propane. About 140 gas plants use cryogenic processes to cool the gas to $-127^{\circ} \mathrm{F}$ ($\left.90^{\circ} \mathrm{C}\right)$ to liquefy and recover ethane.

In a typical cryogenic gas plant, the raw gas is compressed to 700 to 800 psig and water and $\mathrm{CO}_{2}$ are removed. A turboexpander is used to cool the gas to $-160^{\circ} \mathrm{F}\left(-108^{\circ} \mathrm{C}\right)$ prior to fractionation in a demethanizer tower. The $\mathrm{CH}_{4}$ is recompressed and injected into the pipeline. Natural gas liquids, including ethane, are recovered for transport to market by rail or truck.

One cryogenic gas plant has been modified to produce a side stream of LNG for the vehicle market. Williams Field Services modified its Ignacio cryogenic gas plant near Durango, Colorado, using a proprietary liquefaction process designed to minimize external refrigeration, the need for additional equipment, and capital investment. 
The Ignacio cryogenic gas plant: was designed to process $350 \mathrm{mmsfd}$ of raw gas and produce between 500,000 to 700,000 gallons of natural gas liquids per day using a turbo-expander technology. Ethane's boiling temperature of $-127^{\circ} \mathrm{F}\left(.90^{\circ} \mathrm{C}\right)$, however, is higher than the temperature needed to liquefy $\mathrm{CH}_{4}$. Consequently, to liquefy and re:over $\mathrm{CH}_{4}$ from an ethane plant, additional refrigeration capacity must be added. Williams accomplished this by recovering the energy from the fractionation process and using the demethanizer overhead gas as the main cooling medium to liquefy a side stream of clean $\mathrm{CH}_{4}$. The side stream is cooled and then expanded successively in three separate flash tanks to produce LNG. The initial LNG plant has the capacity to produce 26,000 gallons of LNG per day and could be expanded to 50,000 gallons per day (Houshmand, 1996).

Prior to the Ignacio plant retrofit, the incremental cost of adding LNG recovery to a cryogenic gas plant had been higher than the cost of modifying NRUs, import terminals, or peak-shaving plants and was thought to be prohibitive. Williams reported the capital cost at $\$ 4.7$ million and the variable operations and maintenance (O\&M) cost a: $\$ 0.035$ to $\$ 0.040$ per LNG gallon. Design, permitting, construction, and commissioning time was only 6 months. The plant has been operating since February 1995.

Williams believes that its proprietary process will reduce the cost of adding LNG recovery to existing ethane plants and make it cost effective for the natural gas liquids industry to provide additional LNG sources. Approximately 135 plants could be retrofitted with this technology.

\subsection{Synthesis and Olefirı Petrochemical Plants}

Two synthesis gas plants, one operated by Air Products and Chemicals, Inc. (AP), near New Orleans and the other operated by Praxair, Inc., near Baton Rouge, have supplied LNG for motor-fuel purposes in recent years. The Praxair plant could produce and load out more than 20,000 LNG gpd. Neither plant was active at press time.

Synthesis gas plants produce licuid hydrogen and $\mathrm{CO}$, stored at $-423^{\circ} \mathrm{F}\left(-253^{\circ} \mathrm{C}\right)$ and $-314^{\circ} \mathrm{F}\left(-125^{\circ} \mathrm{C}\right)$, respectively. Methane gas and steam are the primary raw materials. Even though refrigeration is commonly used at synthesis gas: plants, capacity may be fully committed to the production of hydrogen and $\mathrm{CO}$. At the Praxair plant, for example, the LNG was produced by cooling and liquefying $\mathrm{CH}_{4}$ through a heat exchanger with liquid nitrogen.

At least one other type of petror:hemical manufacturing facility, olefin plants, can be modified to economically produce LNG. Amoco has modified its Chocolate Bayou olefin plant-south of Houstonto produce and load out approx mately 15,000 LNG gpd. Olefin plants produce ethylene and other primary ingredients for plastics from $\mathrm{CH}_{4}$. Ethylene is liquefied and stored at $-155^{\circ} \mathrm{F}\left(-105^{\circ} \mathrm{C}\right)$.

\subsection{Dedicated LNG Fuel Plants}

Transportation of LNG by trucl: is economically feasible for distances up to 250 miles. The cost of transport beyond this distance rnakes it difficult for LNG to compete against diesel fuel for commercial projects. Fortunately, small liquefaction plants can now be built to produce 60,000 to $100,000 \mathrm{gpd}$ of LNG from pipeline gas at compretitive costs. These types of plants can be designed to use either expander or mechanical cascade-mixed refrigerant technology.

One project dedicated to the furl market was built in Willis, Texas, and has been operating since the early 1990s. Widespread deployment of regional LNG fuel production plants should provide assurances to customers that LNG supplies will always be available and competitively priced. 


\subsubsection{Topock, AZ-Needle Mountain}

ALT-USA and El Paso Fuel Development Company plan to bring an LNG plant on-line in February 1997 at Topock, Arizona, with the capacity to produce $86,000 \mathrm{gpd}$ LNG. ALT-USA will market LNG from the Needle Mountain plant into industrial and vehicle fuel markets in the Southwest such as Los Angeles, California (200 miles); Phoenix, Arizona (250 miles); Las Vegas, Nevada (100 miles); Tucson, Arizona; Flagstaff, Arizona; Bakersfield, California; and San Bernardino, California. Market surveys have indicated that the daily demand for LNG within a 220 -mile radius from Topock is about 700,000 gallons.

The Needle Mountain plant will be located adjacent to a mainline compression station on the Mojave pipeline and is designed to use a mixed refrigerant liquefaction process that will produce LNG with 97 percent to 99 percent $\mathrm{CH}_{4}$ purity, depending on the quality of the feedstock gas. The plant will be able to handle wide production rates, operating in the 40 percent to 100 percent load-factor range. This will enable the company to match production with demand and shipping schedules.

The Needle Mountain plant will use a just-in-time delivery concept to minimize the need for large storage capacity at the plant. On-site tank storage will be limited to about 1 day's production. The balance of production will be in "mobile storage" on the road, that is, in tanker trailers on their way to customers.

More than 35 percent of daily production has been committed to customers. ALT-USA is aggressively seeking additional customers for the remaining capacity. The plant is a modular, field-erected design. The modular design and mobile storage will keep the initial capital investment around \$12 million and ensure competitive pricing for LNG customers in California, Arizona, and Nevada.

\subsubsection{Willis, TX-Praxair LNG}

CBI Services, Inc., designed and built the Willis LNG production plant for Liquid Carbonic Corporation. Conveniently located near Houston, Dallas, and Austin, the plant serves LNG vehicle customers throughout central Texas. The plant is now owned and operated by Praxair. The commitment by the Houston Transit System to use the high-quality LNG ( 99.5 plus percent $\mathrm{CH}_{4}$ purity) provided the initial justification for the facility. The plant has the capacity to produce 108,000 gallons of high-purity LNG per day from pipeline natural gas and has one million gallons of LNG stored on site.

\subsection{Other Sources of LNG}

Several other types of facilities could become economical LNG production sites, especially operations that produce low-grade $\mathrm{CH}_{4}$, which is now wasted to the atmosphere. Possible sources of waste $\mathrm{CH}_{4}$ include landfills, sewage treatment plants, coal seam vents, and feedlots for cattle, dairy cows, chickens, and hogs. Pipeline gate stations, large nitrogen-vaporization facilities, and other industrial facilities offer sources of waste energy that could be captured to drive refrigeration systems to convert moderate quantities of natural gas into LNG.

Unlike the gas plants that have both $\mathrm{CH}_{4}$ and refrigeration available, many facilities have only either waste $\mathrm{CH}_{4}$ or refrigeration energy. However, until the cost of small-scale gas cleanup and liquefier technology is reduced, these sources may be less economical to develop than larger facilities.

For example, several shut-in gas wells or coal seam vents could be manifolded together to feed a small liquefaction plant. LNG from remote wells could fill a market niche if the reserves are large enough to warrant the investment in liquefaction equipment and customers are within a reasonable trucking distance. Potential cost savings from using free or inexpensive gas must be weighed against the cost of trucking the 
LNG. The size of the liquefaction plant is also critical. Additional costs may be associated with gas pretreatment systems because w'aste gas is usually low quality.

Several landfill-gas liquefaction projects are being evaluated and at least one project has been constructed. Ecogas Corporation constructed one prototype liquefier on a small landfill in Fort Bend County, Texas, southwest of Houston. The facility is designed to produce 5,000 gpd of LNG. Also, several solid-waste management companies, a gas utility, and at least one municipal landfill operation have explored recovery of landilil gas and cryogenic recovery of $\mathrm{CO}_{2}$ and $\mathrm{LNG}$. The barriers to liquefying landfill gas have been availability and reliability of economic systems to remove oxygen, $\mathrm{CO}_{2}$, and other impurities prior to $\mathrm{CH}_{4}$ liquefaction.

\subsection{Small LNG Liquefiers_Emerging Opportunities}

Liquefying natural gas is a two-step process. First, feed preparation must remove any constituents in the inlet gas stream that may create a fouling or plugging problem at cryogenic temperatures. Water, oxygen, $\mathrm{CO}_{2}$, straight-chain hydrocarbo:ss, cyclic hydrocarbons, lube oils, dust, and hydrogen sulfide are examples of materials that must be removed. Second, refrigeration must remove energy from the gas in the form of sensible and latent heat sufficient to covert $\mathrm{CH}_{4}$ into a liquid at atmospheric pressure. Large liquefaction plants use various combinations: of unit processes to accomplish heat removal, including cascade systems with multiple refrigerants, cascilde systems with mixed refrigerants, expansion valves, expansion engines, and turboexpanders.

An investment of at least $\$ 1$ million is required for every 10,000 gpd of LNG production capacity.

Feed preparation can be accom]lished by a series of unit processes. Water can be removed by molecular sieves or dry-desiccants. Carbon dioxide can be removed by either amine or molecular sieve processes. Sulfur compounds will also be jicked up by the molecular sieve units. Other gas cleanup processes include solvent extraction using; various organic solvents, such as Solexol ${ }^{\mathrm{TM}}$, Rectisol ${ }^{\mathrm{TM}}$, methanol, and turpenes. Micron-size solids filters are used to capture trace quantities of absorbent dust and other contaminants. The design of the absorbers, the regeneration systems, and the selection of adsorbent materials and solvents are basel on the quality of the feed gas and the size of the system.

The selection of the liquefaction cycles can be more subjective. Typically, the decision is based on analysis of local conditions, including capital investment, operating costs, cost of gas, and throughput. In some cases, several different processes may be appropriate for a given application. Cascade systems use a series, typically three to nine, of mechanical compression-expansion cycle refrigerators, each with a single-component refrigerant, to progressively drop the feed gas to temperatures required to form LNG. The mixed-refrigerant cascade cycle requires less capital investment. A working fluid, which is a mixture of several refrigerants such as propane, butane, ethane, $\mathrm{CH}_{4}$, and nitrogen, is circulated through a single mechanical-compression refrigerator. Cryogenic engineering firms have many proprietary variations on these technologies.

Expander cycles refrigerate by expanding compressed gas isentropically through expansion turbines or engines while performing external work. In situations where high inlet pressures exist along with a large demand for low-pressure gas, a simple expander cycle refrigeration system can be cost effective. As an example, a system could be designed to use the pressure drop at a gate station to a power plant or large distribution system. More complex, but more efficient, expander cycles use intermediate refrigerants, such as nitrogen, as the working fluid.

Mechanical-compression cascade and expander cycle liquefaction systems are capital intensive. Because they are built with many complex machines with many moving parts and seals, they also require a high degree of operator skill and maintenance. Thus, at this time small liquefiers (less than 10,000 gpd of 
LNG) are not cost effective for producing LNG for motor-fuel applications. Several companies have tried to develop commercial systems. Small liquefiers that have been built and tested have used many different thermodynamic or liquefaction cycles, including expansion valves, expansion engines, the Stirling cycle, and simple liquid nitrogen heat exchangers. To date, no manufacturer produces small, inexpensive, efficient gas-cleanup systems integrated with conventional expansion cycle or compression cycle liquefiers.

\subsubsection{Stirling-Cycle Liquefiers}

Approximately 40 years ago, NV Phillips developed a line of commercial Stirling-cycle cryorefrigerators capable of liquefying 100 to 500 gpd of LNG. Approximately 3,000 of these machines have been sold for on-site production of cryogenic liquids, mostly oxygen and nitrogen, for military and laboratory applications. With proper gas cleanup, the Phillips machine is capable of producing LNG in quantities sufficient for demonstration projects (for example, at sites where transport of small quantities of LNG would be prohibitively expensive). Unfortunately, capital costs for the smallest gas cleanup and liquefier system, which would only produce 400 to 1,000 gpd of LNG, could easily exceed \$1 million.

\subsubsection{TADOPTR}

Cryenco Sciences, Inc., is developing a revolutionary liquefaction system, based on the Stirling cycle, that may be cost effective in niche LNG fuel applications. Research at Los Alamos National Laboratory (LANL) and the National Institute of Standards and Testing (NIST) has developed a cooling system that produces cryogenic temperatures in a machine with no moving parts and no seals. This system may make it economically feasible to produce LNG in quantities ranging from 500 to 10,000 gpd.

Cryenco has licensed the patent to use this technology to liquefy cryogenic gases. The acronym TADOPTR stands for thermo-acoustic driven orifice pulse tube refrigeration. The machine consists of two thermo-acoustic drivers (TAD), which function like compressors, and the (OPTR), which is a modified Stirling-cycle refrigerator.

The TAD is a device in which heat is converted into acoustic energy -an intense sound or pressure wave. Using helium gas as the working fluid, the energy in the pressure wave is coupled to and drives the pulsetube refrigerator.

The pulse-tube refrigerator is a variant of the Stirling-cycle refrigerator that typically has two pistons (one at the ambient heat exchanger and one at the cold end). A simple OPTR consists of two ambienttemperature heat exchangers, a regenerator, and a cold heat exchanger, arranged in series and filled with high-pressure helium gas. The cold piston is replaced with a passive heat absorber, which includes an orifice to impede gas flow and a large accumulator or buffer tank (both at ambient temperature) to absorb energy from the helium gas. The hot piston is replaced by the TAD, a thermo-acoustic engine.

The standing sound wave carries gas molecules back and forth along the temperature gradient between the high-temperature heat source and the ambient-temperature heat sink. The sound wave pressurizes and de-pressurizes the gas in phase with the thermal expansion and contraction in the TAD. This physical effect transforms heat energy to acoustic energy that sustains the standing wave and drives the pulse-tube refrigerator.

The first TADOPTR was built by LANL and NIST. It had a cooling capacity of 5 watts at $-250^{\circ} \mathrm{F}$ $\left(-153^{\circ} \mathrm{C}\right)$. Cryenco is currently building a scaled-up TADOPTR with the capability of producing 500 gpd of LNG. This plant will have approximately 7 kilowatts $(\mathrm{kW})$ of cooling capacity. The heat source for 
the TAD will be a burner fuelec by $\mathrm{CH}_{4}$ and heavy hydrocarbons removed during pretreatment of the inlet gas.

After the TADOPTR technology has been fully developed, Cryenco plans to manufacture a commercial 10,000-gpd unit fully integrated with the Cryenco LNG container tanks and fuel stations. A rugged machine with no moving parts or seals, TADOPTR has the potential to significantly reduce the capital and operating costs of deployin 5 LNG fuel stations. The TADOPTR may be the breakthrough technology needed to jump-start the LNG motor-fuels market as well as exploit many niche environmental applications, such as converting waste $\mathrm{CH}_{4}$ to $\mathrm{LNG}$.

\subsection{LNG Transport}

LNG has been transported in specially designed containers for more than 35 years. In 1959, the first transoceanic cargo was delivered to Canvey Island, UK. The latest ocean-going tankers have the capacity to carry 30 to 40 million gallon:; of LNG. Barges and railcars also carry LNG. Railcars have capacities of approximately 30,000 gallon;, barges about 1 million gallons. LNG has been transported extensively by tractor-trailer rigs for more than 25 years, primarily in the Northeast, to satellite gas plants.

Table 2-3. LNG Transport Capacities

\begin{tabular}{|lr|}
\hline Container Type & Approx. Capacity (Gallons) \\
\hline Ocean & $30,000,000$ to $40,000,000$ \\
\hline Barges & $1,000,000$ \\
\hline Railcais & 30,000 \\
\hline On-Hic & hwankers \\
\hline
\end{tabular}

\subsubsection{U.S. Department if Transportation Code}

The DOT governs the design, construction, and operation of transportation containers that carry cryogenic, flammable liquids under code DOT-MC338. Only specialized transportation trailers and railcars meet these criteria and jrovide enough liquid-volume capacity to transport LNG economically.

\subsubsection{Highway Transport Trailers}

All LNG used for motor fuel is transported by tractor-trailer. About 12 companies own or operate LNG transport trailers in the United sitates, ranging in size from Transgas in Lowell, Massachusetts, with 55 trailers, to several companies with just one (see Table 2-4).

Transport trailers include a wheel frame; horizontal, insulated storage tank (or Dewar); transfer valves and hoses; either a pressure-building coil or pump; safety equipment; and hazardous-material warning signs. The LNG tanks are unique in that they store and protect a cryogenic, flammable liquid. The containers must store LNG in liquid form at temperatures below $-260^{\circ} \mathrm{F}$ for extended periods of time. This is done by designing and tuilding the tanks to minimize heat gain from the outside. Most cryogenic transport containers, such as highway trailers or container tanks, are vacuum-jacketed. They are constructed with an aluminum or stainless-steel inner vessel and a carbon-steel outer jacket. The space between the inner and outer ves sel walls is insulated with multiple layers of mylar, plastic, and fiber and placed under an extremely low vacuum.

New LNG trailers can be purchased for roughly $\$ 200,000$ to $\$ 250,000$ each from at least four manufacturers: Cryenco of Deuver, Colorado; MVE Cryogenics of New Prague, Minnesota; Process 
Engineering Inc. of Plaistow, New Hampshire; and James Russell Engineering Works of Dorchester, Massachusetts.

According to manufacturers, a trade-off in designing an LNG transportation container, is finding the optimum point between strength, durability, and insulation efficiency. Transportation containers must be built to withstand dynamic loads (sudden shocks) that occur during transit and maintain the integrity of the vacuum-jacketed insulation system. The inner vessel is supported by a framework of struts attached to the outer shell. These supports conduct heat that is transferred to the product. Consequently, in general, the stronger and more durable the container design, the lower its insulation efficiency.

Table 2-4. U.S. LNG Transport Trailers and Railcars

\begin{tabular}{|c|c|}
\hline Trailer Owner or Operator / Home Base & Count \\
\hline Transgas, Lowell, MA & 55 \\
\hline Jack B. Kelley, Inc., Amarillo, TX & 26 \\
\hline Utilities Board of Trussville, AL & 8 \\
\hline Praxair LNG, Willis, TX & 7 \\
\hline LP Transportation, Chester, NY & 6 \\
\hline Atlanta Gas Light, Atlanta, GA & 2 \\
\hline Ecogas Cryogenics, Puyallup, WA & 2 \\
\hline Quadren Cryogenics, Sacramento, CA & ${ }^{\star} 1$ \\
\hline Minnegasco, Minneapolis, MN & 1 \\
\hline Northwest Natural Gas, Minneapolis, MN & 1 \\
\hline Mesa Pacific LNG, Los Angeles, CA & 3 \\
\hline Total Trailers & $113 * 2$ \\
\hline $\begin{array}{l}\text { Railcar Owner or Operator/Home Base } \\
\text { Union Pacific/Los Angeles, CA }\end{array}$ & 5 \\
\hline Total Railcars & 5 \\
\hline
\end{tabular}

Cryogenic transport of flammable materials has an exemplary safety record. During their 25 to 30 years of operation, cryogenic trailers carrying LNG, ethylene, or liquid hydrogen have been involved in many accidents. However, because of the strong design of the trailers and the double-walled, stainless-steel construction of the container tank, the internal vessels containing the flammable cryogenic fuels have prevented any serious incidents.

\subsubsection{Trailer Capacity}

Most trailers have a gross volumetric capacity (sometimes called "water capacity") of 11,600 to 13,000 gallons. However, because LNG expands as it warms, there must be space available to allow for this expansion. Precautions are taken to never fill a trailer beyond about 90 percent of water capacity. Furthermore, the trailers are designed to carry the maximum allowable weight. Consequently, highway weight limitations generally determine the amount of liquid that can be carried in a transport trailer.

The tare weight of an average class- 8 tractor and double-walled, vacuum-jacketed trailer is about 42,000 pounds. Because most states limit tractor-trailer rigs to 80,000 pounds, a 42,000 -pound rig will therefore carry 38,000 pounds of liquid payload. At 3.6 pounds per gallon of LNG, full-sized trailers typically carry a little more than 10,500 gallons of $\mathrm{LNG}$. 


\subsection{LNG Loading Terminals}

Almost all peak-shaving facilities are equipped with auxiliary LNG-trailer load-out capability. The loadout facilities may use pressure or gravity flow. The facilities are simple, consisting of insulated piping and flow valves. Few peak-shaving facilities are equipped with truck scales.

Most highway trailers use press ure-building coils to vaporize small quantities of LNG to build internal pressure to about 70 psig. This pressure is used to off-load the LNG. The pressure pushes the liquid out of the trailer though valves at the rear into station storage tanks.

Some cryogenic trailers are equipped with on-board pumps. These pumps are designed to transfer LNG at higher pressures than is poss. ble with pressure-building coils. These trailers can be used to transfer fuel to tanks in which the back pres: ure may exceed 100 psig.

\subsection{Railcars}

Union Pacific operates a fleet of cryogenic railcars. Although railroads often transport flammable cryogenic liquids such as ethylene, few, if any, tank cars were certified for LNG until 1994, when Union Pacific commissioned the General American Transportation Corporation to convert five vacuum-jacketed ethylene cars to LNG. Rail transport of LNG can be very cost effective. The industry will respond quickly when sufficient demanil to justify rail haul of LNG develops.

\subsection{Other Transportation Opportunities}

Trailers and railcars designed to carry other liquids, such as ethylene, might also be converted to LNG usage. According to Cesar Cavana, a California-based transportation consultant, 40 trailers and 69 railcars can transport ethylene in the United States.

Portable containers might also offer a means of transporting LNG. The Maryland Mass Transit Authority's fuel station is equipped with a trailer-mounted LNG storage tank that is towed to and from the Baltimore Gas \& Electric LNG liquefaction facility. JBK operates and leases several customized mobile fuel systems, known as ERVINGS.

At least one manufacturer offers frame-mounted, intermodal LNG container tanks that can be secured to transport trailers, railcars, or ships. The Cryenco TVACTM holds 5,350 gallons LNG gross and 4,450 gallons net. It is built to meet IMO-7 codes and can be stacked up to six high on ships. The TVAC ${ }^{\mathrm{TM}}$ also meets AAR- 600 codes ancl can be stacked two high and two deep on railcars.

Although LNG is transported to the United States from Algeria and from the United States to Japan, there is no active marine transportation of LNG within the United States. Projects in the early 1960s proposed to move LNG from Lake Charles, Louisiana, to the Midwest via river barge but were never implemented. Increased demand for LNG fuels will stimulate demand for domestic transport by rail, ships, and barges. The transportation industry will respond quickly.

\subsection{LNG Fuel Station Ilffrastructure}

Several LNG suppliers have provided fuel for small demonstration projects with heavy-and medium-duty trucks, railyard switcher locorrotives, line-haul locomotives, and ferry boats. Several transit authorities have installed central LNG fuel stations. More than 300 transit buses currently operate on LNG. An 
integrated network of LNG fuel stations, however, must be developed to support large numbers of trucks operating in local delivery and line-haul service.

Several groups are developing a regional LNG refueling infrastructure in the Southwest and elsewhere. For example, JBK in association with ALT-USA, is spearheading deployment of a network of LNG and LNG-to-LCNG stations in California, Arizona, Nevada, Utah, Texas, Colorado, and New Mexico along the Interstate Highway Corridors (I-5, I-8, I-10, I-15, I-25, I-40, I-70, and I-80), as shown in Figure 2-2.

Five sources of LNG will be available in 1997 to support development of this Southwest LNG fuel infrastructure. As shown in Figure 2-1, every major market in the region will be within an economic transport distance (about 250 miles) of one or more reliable sources of LNG fuels. This infrastructure program can serve as the model for deployment of LNG infrastructure in the Midwest, the Northwest, the Northeast, the Southeast, and the Mid-Atlantic.

Figure 2-2: Planned Jack B. Kelley Network of LNG Fuel Stations

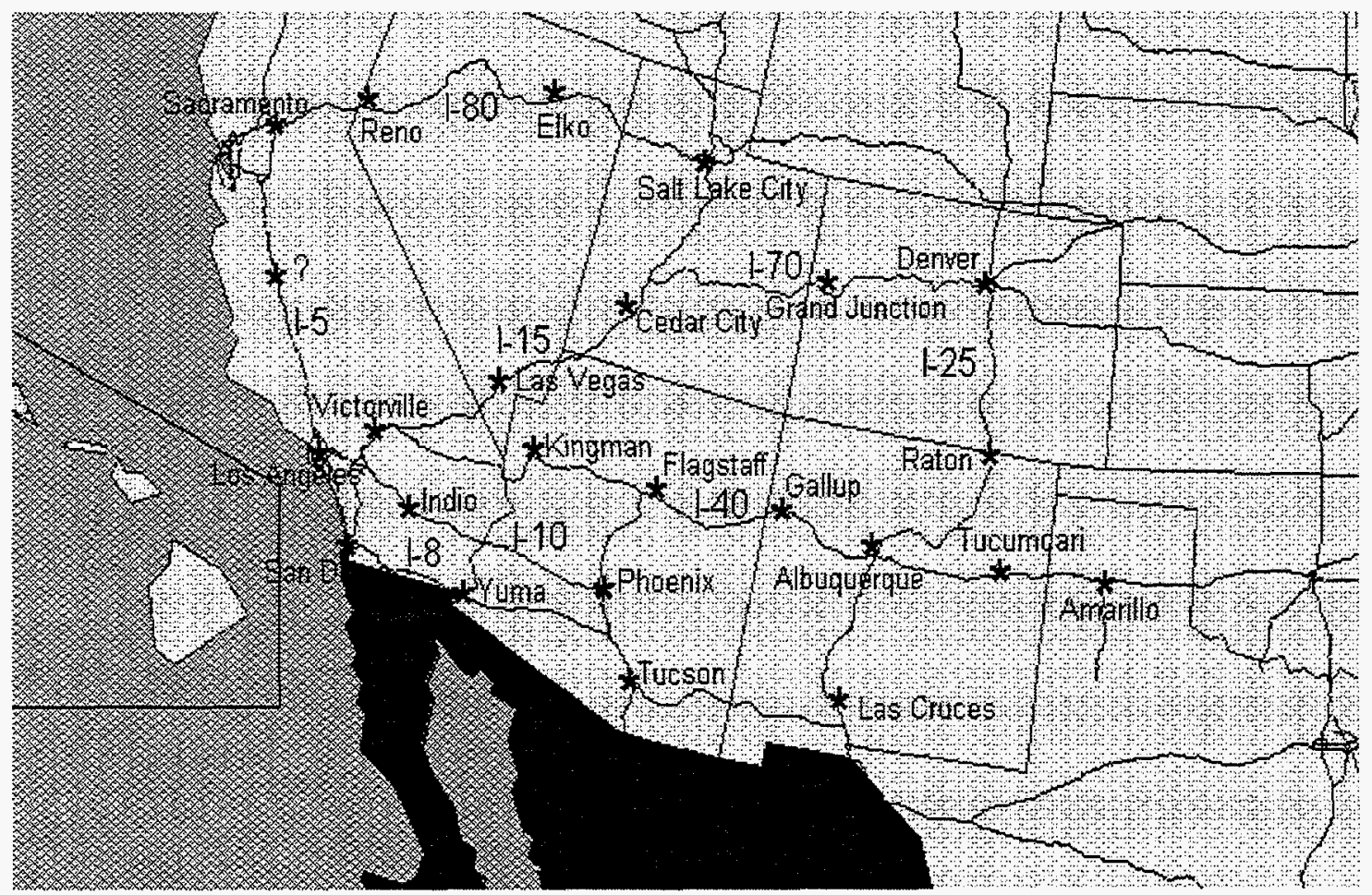




\subsection{LNG Fuel Stations}

LNG fuel station technology has changed significantly in the past 5 years. No longer "Buck Rogers" contraptions that appear to have been assembled from parts borrowed from the Apollo space program, the modern LNG fuel station has the look and the feel of contemporary diesel-fueling equipment. To the user, the cardreader, fuel nozzle, hose, dispenser, pumps, storage tanks, and delivery trucks all look and operate like the equipment found at the familiar gasoline or diesel fuel station.

The modern LNG fuel station should perform the following four basic functions:

- LNG transfer-receive LNIJ deliveries; transfer and measure flows to and from storage

- LNG storage-store LNG with minimum heat gain until needed

- LNG dispenser-transfer LNG from storage into the vehicle

- LNG control and safety systems-control operations and prevent unsafe conditions.

An LNG fuel station designed to handle cryogenic, flammable liquids, must be built to accommodate operating conditions not usually experienced by most drivers. Design practices and construction details vary somewhat from manufacturer to manufacturer, but overall technical and performance specifications have been founded on 50 years of cryogenic experience in demanding applications, such as aerospace, life support, electronics, and precision manufacturing. From the vapor-return hose to the cool-down cycle for the main fuel pump, many sophisticated design features are built into the modern LNG fuel station that make it reliable, safe, easy to operate, and cost effective.

This chapter explores the unique physical-chemical properties of LNG that must be understood by the planner and engineer if LNG is to be used safely and successfully as a motor fuel. It also provides background on the development of the LNG fuel station, including a discussion of failures, a description of the major station component; currently available from equipment suppliers, and a checklist of activities required to convert a site into an LNG fuel station. The statistical data and much of the information on state-of-the-art station design ir. Volumes I and II are derived frorn results of nationwide surveys, site visits, and analysis conducted by the M.W. Kellogg Company (Midgett, 1996), Acurex Environmental Corporation, and the Zeus Development Corporation for the Gas Research Institute (GRI).

\subsection{The Unique Characteristics of LNG}

To remain in the liquid state at atmospheric pressure, natural gas must be maintained at approximately $-260^{\circ} \mathrm{F}\left(-162^{\circ} \mathrm{C}\right)$; the exact temperature depends on the composition and pressure of the LNG. At these cold temperatures, butane, pentane, and heavier hydrocarbon gases, as well as mercaptan odorants, $\mathrm{CO}_{2}$, hydrogen sulfide, and water, will freeze. These components of natural gas are removed from LNG before the gas is liquefied. LNG, therefore, has fewer compositional variations and a higher $\mathrm{CH}_{4}$ content than natural gas from a pipeline.

LNG has unique physical-chenrical properties that must be understood if it is to be used safely and successfully as a fuel. For example, using the wrong materials or improper design can cause failures that could result in fire and injury. Less dramatic, but important failures have been caused by inexperience and poor coordination between station designers and engine manufacturers and have resulted in mismatched systems.

For example, based on experience with high-pressure CNG storage systems, engine designers specified a minimum inlet pressure of 150 psig for early LNG engines. The LNG storage systems and the engine fuel systems, however, can operate at much lower pressures. 
Unfortunately, this simple misunderstanding caused early system designers to either install expensive LNG fuel pumps or heat the LNG to raise the saturation pressure in the storage tank. Heating LNG required additional equipment, reduced the hold time of LNG on the vehicle, increased costs, and made LNG more inconvenient to use.

Subsequent research and development sponsored by DOE and GRI has coordinated efforts between engine, vehicle, LNG, and CNG industries and eliminated many of these early problems. Innovation is rapidly overcoming many of the technical problems that have long been perceived as barriers to widespread, commercial use of LNG fuels.

\subsubsection{Pressure and Temperature Are Important}

LNG exists at $-260^{\circ} \mathrm{F}\left(-162^{\circ} \mathrm{C}\right)$ at atmospheric pressure. In accordance with the first law of thermodynamics, heat flows from warm surrounding air into the cold LNG. This additional heat will warm the LNG and cause it to boil in the same manner, for example, as a pot of water on a hot stove. If the water vapor is allowed to escape, the temperature of the water will remain at the boiling point, $212^{\circ} \mathrm{F}$ $\left(100^{\circ} \mathrm{C}\right)$. If the pot is sealed and the boiling water vapor is trapped, however, the pressure in the pot will rise. The temperature of the boiling water will also rise. When heat is added to a pressure cooker, vapor (steam) is not allowed to escape until the pressure builds to a preset level controlled by the relief device.

In LNG applications, heat leakage causes the stored LNG to slowly warm and eventually boil. In large LNG storage tanks, such as in peak-shaving plants, import terminals, or baseload liquefaction plants, the boiling vapor $\left(\mathrm{CH}_{4}\right)$ is allowed to escape so that the temperature of the LNG does not increase. When $\mathrm{CH}_{4}$ is removed, the boiling $\mathrm{LNG}$ remains at $-260^{\circ} \mathrm{F}\left(-162^{\circ} \mathrm{C}\right)$.

With the smaller tanks used for LNG stations and vehicles, however, the boiling $\mathrm{CH}_{4}$ is not removed until it can be used. The $\mathrm{CH}_{4}$ vapor is trapped inside the storage tank and closed fuel system until it is withdrawn. If $\mathrm{CH}_{4}$ is not withdrawn, the pressure inside the tank will increase because the volume of the tank is fixed. The temperature of the LNG will also increase. This phenomenon, which is analogous to a pressure cooker, is illustrated in Figure 3-1.

Holding Time-The pressure in an LNG tank will increase until some of the vapor or liquid is used or until the relief valve releases the vapor. The rate of the pressure rise depends on the heat leak into the system. The higher the heat leak, the faster the pressure will rise.

Hold time (sometimes called shelf life) is the length of time LNG can be stored in a tank without venting. Hold time is a function of the rate of heat leak (flux) into the LNG system and the rate of fuel withdrawal. When heat flux is low and a vehicle is used frequently, an LNG tank will have a longer hold time than when heat flux is high and a vehicle is idle. If LNG vehicles are used frequently, venting will not be a problem. If LNG vehicles are going to be inactive for an extended period, LNG should be removed from the storage tanks.

Manufacturers of LNG storage tanks will sometimes quote hold times, assuming no vehicle use, to promote the effectiveness of their insulation. A consistent basis must be used when comparing tank hold times. For example, a hold time quoted from one manufacturer may be 20 days based on a pressure increase from 0 to $100 \mathrm{psig}$, while another may quote 4 days hold time based on a change from 80 to 100 psig. Yet in reality, both tanks may have the same heat flux (Lewis, July 1995).

Pressure-Temperature Relationships-Pressure-temperature (P-T) curves (Figure 3-2) show how temperature and pressure are related for LNG stored in a closed pressure vessel. When LNG is heated, the pressure and temperature rise. The bubble point curve represents the P-T conditions needed for liquid 
Figure 3-1. Illustration of LNG Holding Time

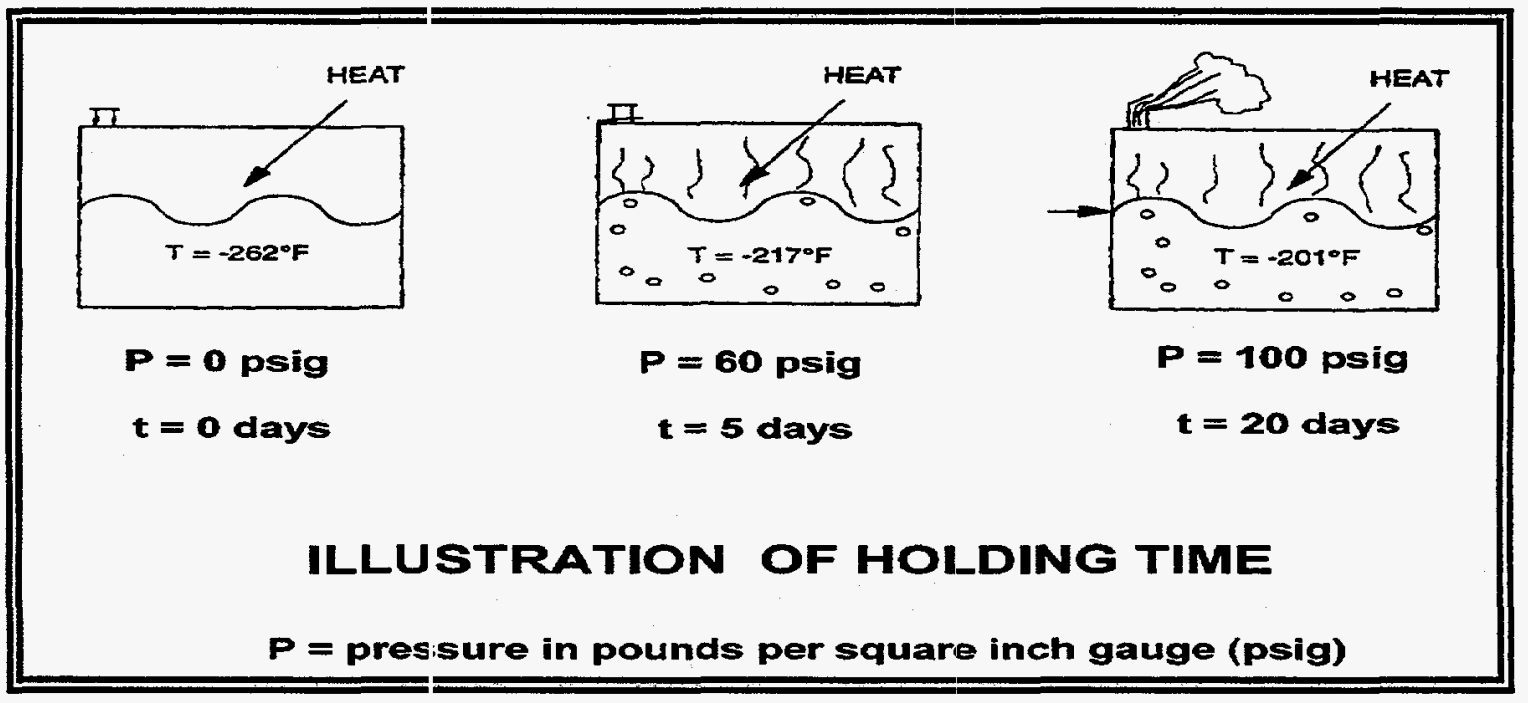

to evaporate into vapor. The dewpoint curve represents P-T condjitions needed for vapor to condense into liquid. LNG stored at P-T conditions below the bubble point curve exists as a "supercooled liquid." LNG stored at P-T conditions alove the dew-point curve exists as a "superheated vapor." For P-T conditions between the curves, the liquid and vapor co-exist in a condition that is commonly referred to as "saturated." Ideally, most LNG storage tanks should be operated in the supercooled liquid phase. Vehicular LNG tanks, however, operate in a "saturated" condition on or near the bubble point curve.

LNG Weathering or Enrichment-When LNG is vaporized, the $\mathrm{CH}_{4}$ boils off first and may leave behind a mixture of LNG with at slightly increased proportion of heavier components that do not evaporate as easily. In some situations, over time, the relative concentration of propane and other long chain hydrocarbons in LNG car increase to levels that become a significant fraction of the remaining LNG. This effect is called "enrichment" or "weathering."

The energy density of vapor from the heavier components-propane, butane, and ethane-is significantly higher than the energy density of $\mathrm{CH}_{4}$. The unplanned introduction of these higher energy vapors into an engine designed to burn $\mathrm{CH}_{4}$ vapor could degrade performance and even damage the engine. Therefore, weathering is a concern when designing LNG storage systems, purchasing LNG, operating LNG storage systems, and operating LNG en gines.

Pressure buildup in an LNG tank, resulting from excessive heat flux or long periods of vehicle inactivity, will eventually cause the storage tank relief valves to open and vent $\mathrm{CH}_{4}$ vapor. If venting occurs over a prolonged period of time, if an engine only pulls methane vapor from the fuel tank, and/or if new LNG is not added to the vehicle fuel tark, weathering could occur. Weathering could be an operating problem if the LNG being used has a high heavy-hydrocarbon content.

Research by GRI and others (Asker, Moulton, December 1992; Gibbs, Bechtold, Collision, November 1995; LNG Express, November, December 1991; LNG Express, October 1995) has concluded that the effects of LNG weathering can be controlled using appropriate fuel and vehicle management techniques. For example, LNG vehicles should be used frequently. If they are allowed to sit for more than 10 days, they should be fueled prior to uise. LNG vehicles that are to be stored for more than 10 days should have the LNG removed. Figures 3-3 and 3-4 illustrate how the composition changes as typical LNG weathers. 
Figure 3-2. LNG Pressure-Temperature Curves

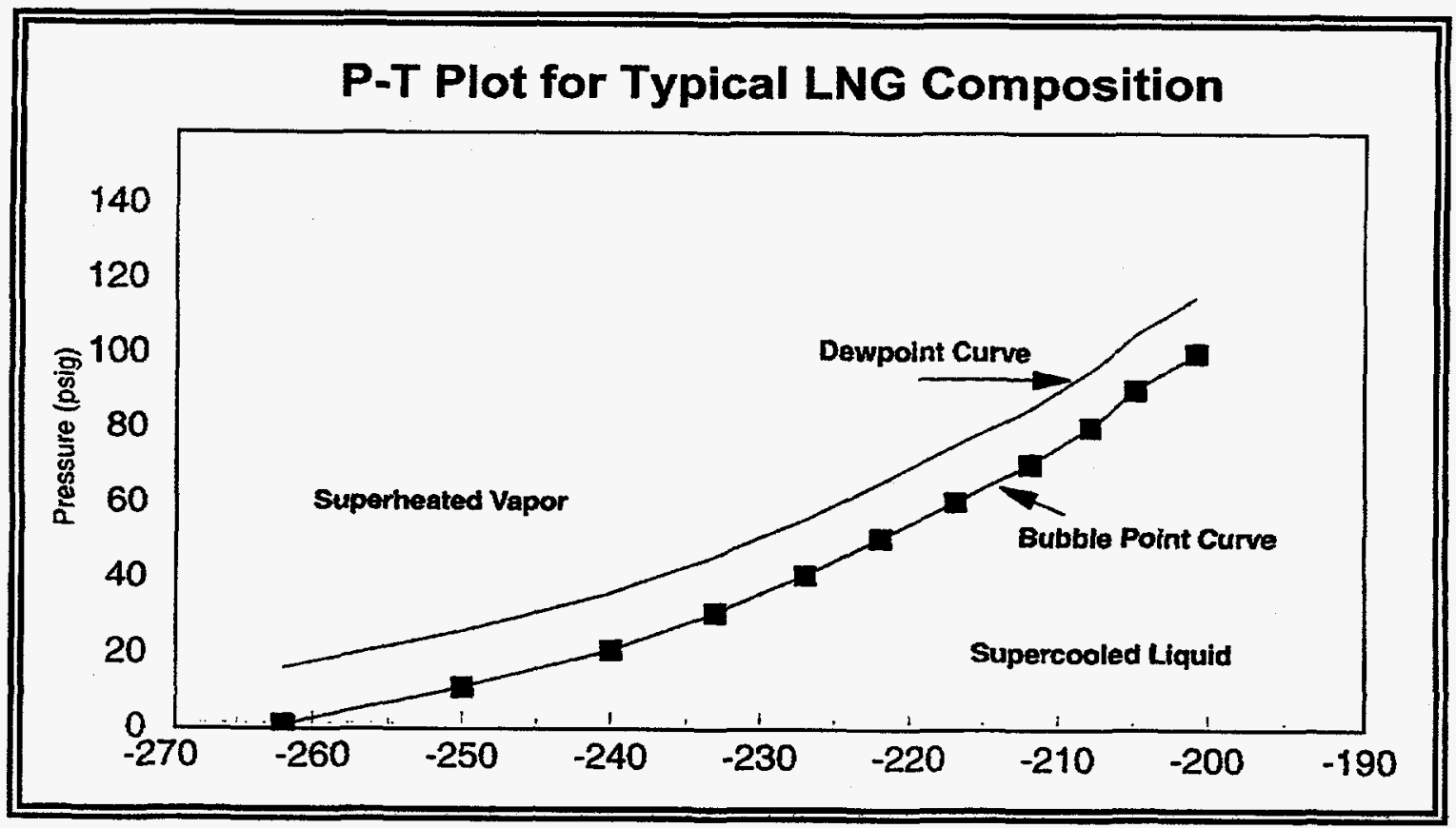

Figure 3-3. Weathering Example

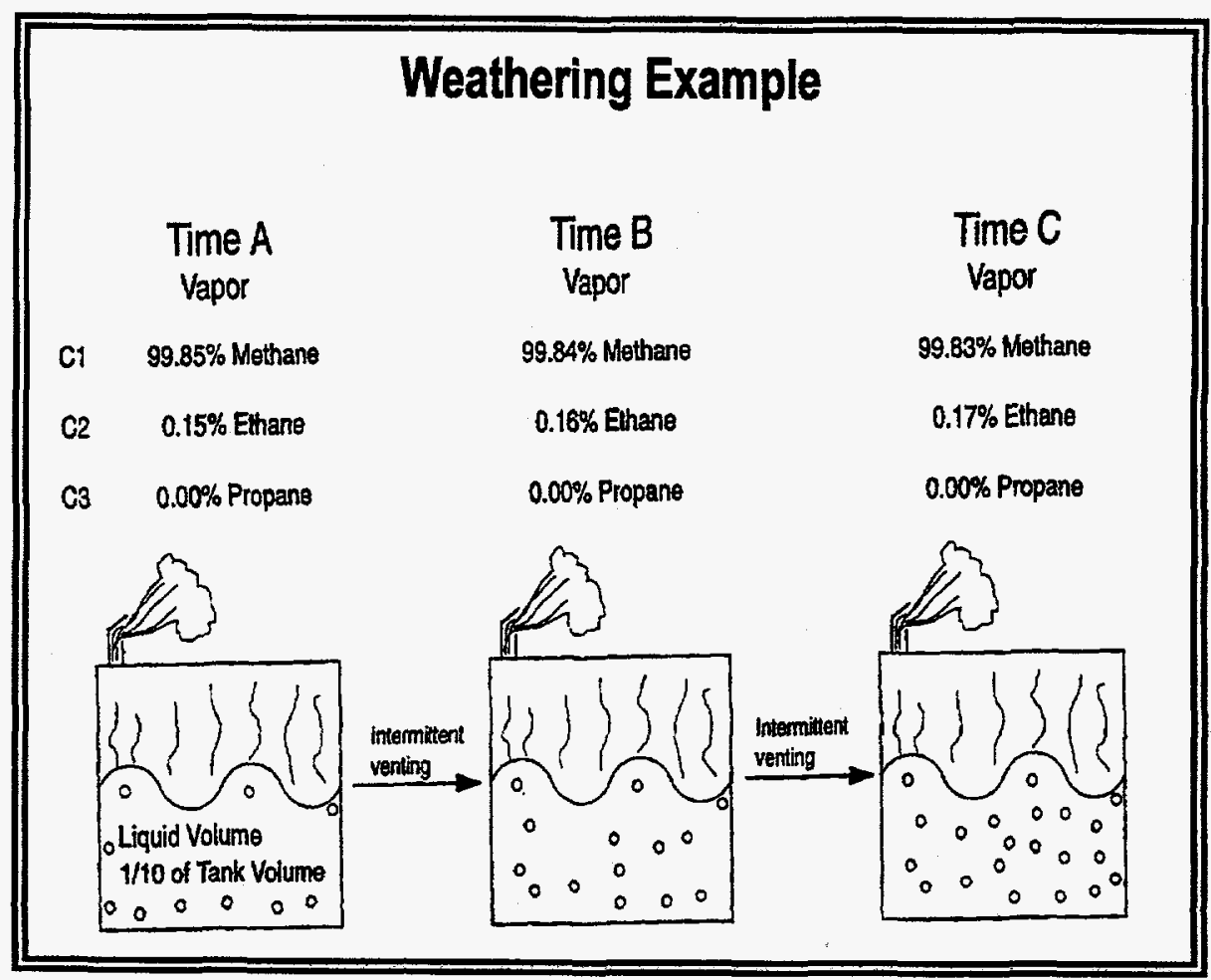


Figure 3-4. LNG Weathering

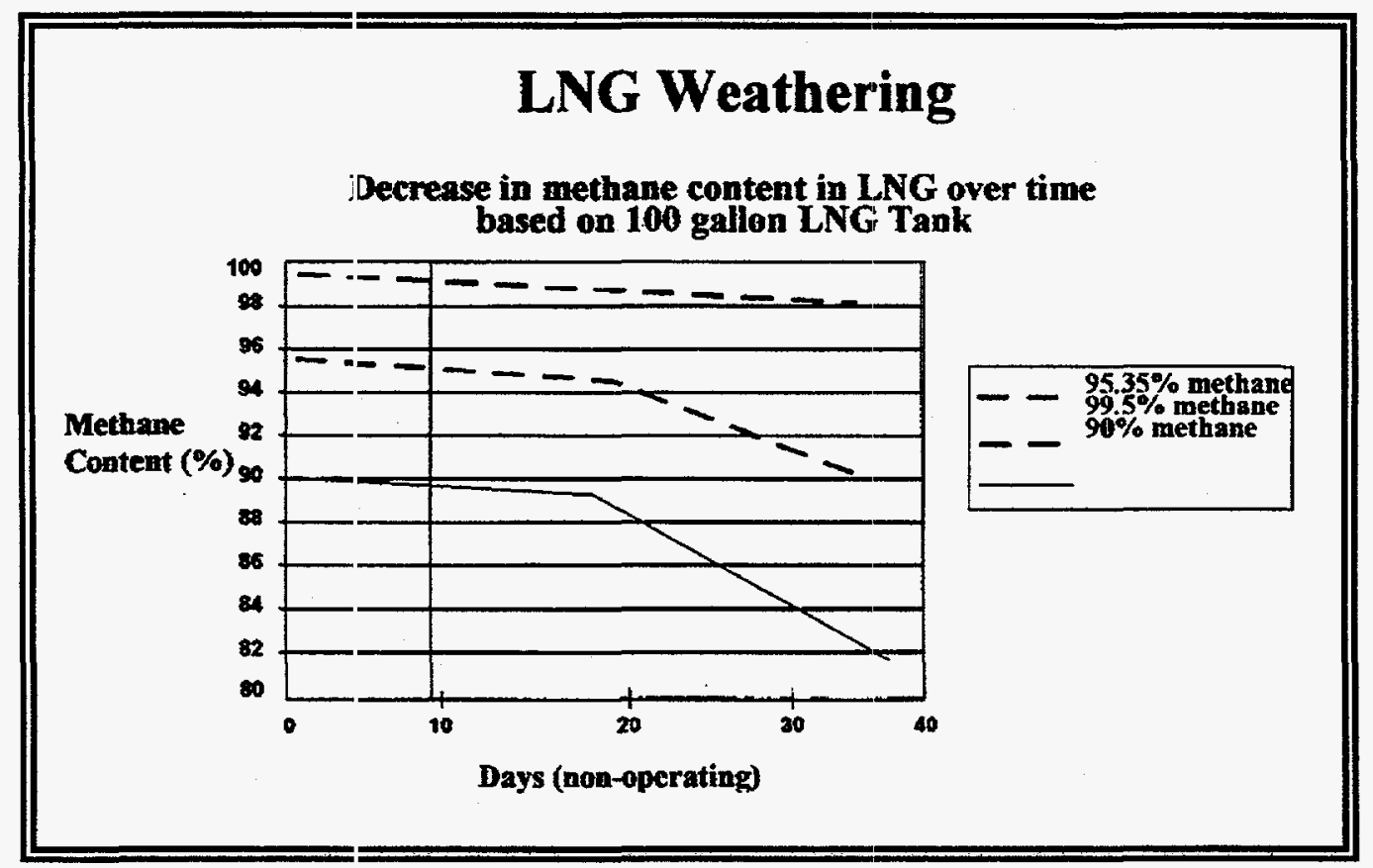

\subsubsection{What Is Saturation Pressure?}

Saturation describes the conditions of pressure and temperature where $\mathrm{LNG}$ and $\mathrm{CH}_{4}$ vapor coexist in equilibrium. Saturation is defined by any point between the bubble point and dewpoint curves shown in Figure 3-2. The LNG vehicle industry commonly refers to LNG saturation pressure as the point at which the LNG liquid boils.

Pure water boils at $212^{\circ} \mathrm{F}\left(100^{\prime \prime} \mathrm{C}\right)$ at normal atmospheric pressure of 14.7 per square inch absolute (psia). At higher altitudes, such as in Denver, Colorado, the "Mile High City," the normal atmospheric pressure is $12.7 \mathrm{psia}$ and water boils at $205^{\circ} \mathrm{F}\left(96^{\circ} \mathrm{C}\right)$. As illustrated in Figure 3-2, the boiling point of any liquid is pressure dependent. Therefore, saturation pressure is the pressure at a given temperature at which the liquid will boil (Lewis, January 1994).

Operating pressure is the pressire at which an LNG storage tank operates. Generally in LNG storage tanks, the operating pressure is the same as the saturation or bubble point pressure of the LNG, except during transient operations, such as when liquid is first introduced into the station, during vehicle loading, or if the storage vessel is stratified. Operating procedures and tank design should take into account the effects of stratification and trar sient operations.

When liquid is introduced into a vessel, inert gas, cold vapors, or warm vapors may be present. The liquid, if introduced from the bottom, will compress the vapors and raise the tank pressure above the bubble point pressure of the LNJG. In this case, the LNG is supercooled-meaning that is the tank pressure is greater than the LN' 3 bubble point pressure. Over time, especially if the LNG fuel tank contents are mixed, the pressure in the tank will decrease as heat is transferred from the warm vapor to the supercooled LNG.

Some tanks are designed to spray incoming LNG into the vapor space to cool or condense vapor and to warm the incoming LNG. Thi; approach will limit the pressure rise in a tank. If there is enough heat transfer, the tank pressure will end up being at, or slightly above, the resulting bubble point pressure of 
the warmed LNG. If stored LNG is supercooled, the heat leak into the tank will not cause a pressure rise until the LNG absorbs enough heat to raise its bubble point pressure to the operating pressure of the tank.

\subsubsection{Stratification}

The density of LNG decreases as temperature increases. Stratification occurs when stable thermal gradients form in an LNG storage tank because of differences in density. Warmer LNG rises to the top of the tank and colder LNG sinks to the bottom. Stratification can become an operational problem if the stratified LNG unexpectedly "rolls over" or is suddenly mixed.

When an LNG tank is heated from the side, warm LNG will rise to the surface and partially vaporize (flash) to reestablish thermodynamic equilibrium. The remaining warm LNG will float on top of the colder LNG and will not mix unless disturbed by pumping or the addition of new LNG. Warm LNG will continue to stratify until the entire tank warms to the same temperature. However, rapid mixing of a stratified tank can flash large quantities of LNG and cause rapid pressure increases in the tank.

Because the boiling temperature of LNG increases as pressure increases, stratification can also occur in a large tank that is heated from the bottom. The hydrostatic pressure of the LNG in a deep tank can increase the boiling point of the liquid in the bottom of the tank. Stratification can continue until the warmer, less dense LNG floats to the surface. This phenomenon is known as "rollover" and results in rapid vaporization and release of methane.

Very large atmospheric LNG tanks used in baseload or large import terminal projects are designed to minimize the effects of stratification and rollover. Because the amount of vapor released during a rollover in a large LNG tank is hard to predict, designers take precautions to assure the safest operation possible. Smaller pressurized tanks used in LNG fuel stations have the capability to contain the effects of a rollover, so the term is most often associated with large LNG storage tanks.

Mesa Pacific LNG has noted stratification in the LNG storage tank at its NGV Ecotrans station in Los Angeles after only 2 or 3 days of inactivity. The company found that circulating the LNG in the tank for approximately 20 minutes returns the LNG to a fully mixed state. Stratification in small tanks has not caused any incidents to date. If proper fuel management techniques are maintained, such as tank stirring or receiving regular deliveries, adverse effects of stratification in LNG fueling stations can be eliminated.

\subsubsection{LNG Conditioning}

Several pioneer natural gas engine suppliers, including Cummins (L-10-240G) and DDC (6V-92), developed fuel systems that require a high-pressure fuel supply. These early engines were designed for use with CNG fuel systems with fuel available at pressures as high as $3,000 \mathrm{psig}$. Even an empty CNG cylinder has a residual pressure of 500 psig. As a result, many early LNG vehicles installed LNG fuel systems that included cryogenic pumps to supply LNG at pressures up to $150 \mathrm{psig}$. These early systems were expensive and had major maintenance problems.

"Conditioned LNG" is the term used by the industry to describe LNG that is brought to a saturated condition by the addition of heat. When conditioned LNG is stored in a closed tank, additional heat will cause evaporation and an immediate increase in pressure. The on-board storage of conditioned LNG makes it possible to design vehicle tanks that can supply LNG at the higher pressures required by all types of engines, including the electronically controlled, fuel-injected engines. LNG can be conditioned at the fuel station, one the vehicle, or both. 
Listed below are the three ways to condition LNG at the fuel station (discussed in Section 3.12.2):

- Install a separate conditioning tank (two tanks needed for continuous operation).

- Condition all LNG in storaje (requires higher pressure operation).

- Condition LNG as it flows to the vehicle (use a fixed-or variable-pressure valve).

In addition, heat can be added to the on-board tank to condition LNG on the vehicle. One solution adopted by several manufacturers is to design LNG vehicle storage tanks that build internal by using heat exchangers.

The LNG industry has demonstrated that conditioned LNG can maintain internal tank pressures so that on-board pumps are not needed. This has resulted in a simpler, more reliable, and less expensive onboard fuel system. Unfortunately, the use of higher pressure tanks has also resulted in reduced hold times in vehicle storage tanks and reduced LNG storage capacity.

Many in the LNG industry question the cost-effectiveness of designing and building vehicle fuel tanks and fuel stations to condition L.VG. "There is little to be gained in fuel capacity or holding time as a result of varying the fuel pressure delivered to the vehicle," said George Kalet, Minnesota Valley Engineering's (MVE's) marketing manager for LNG systems at the LNG conference held in Los Angeles in January 1996. "Everyone will be a lot happier and our business a lot better when we don't have to worry about it anymore." MVE's approach has been to keep the on-board system simple and focus on the fuel station (Kalet, 1996). "If you put one of the fuel-conditioning systems in today, you'll probably not need it within the next 2 or 3 years," concluded Kalet.

Fortunately, all the engine man ffacturers are moving toward low-pressure LNG engine systems. Cummins and DDC are now minufacturing engines that require a minimum of 70 psig and 50 psig, respectively. A Society of Automotive Engineers standards committee has established 70 psig as a target for operating all engine control packages for the heavy-duty trucking industry.

As the engine original equipment manufacturers gradually lower fuel system supply and operating pressures, LNG conditioning (a necessary "evil") may no longer be necessary. Nevertheless, whether LNG is conditioned in the fuel station storage tank, in the on-board fuel tank, or en route to the dispenser, some experts predict that LNG conditioning may no longer be a problem; thus, the costs and complexity of LNG systems will be reduce 1 .

\subsection{LNG Refueling Station Fuel Transfer}

Several methods have been used to transfer LNG from the station storage tanks to LNG vehicles. When LNG is stored as a saturated liquid, it is difficult to pump without vaporizing a significant quantity of the liquid. For economic, operational, and environmental reasons, vaporized LNG should not be vented to the atmosphere (Acurex, 1995),

A problem common to $\mathrm{LNG}$ trınsfer systems is high back pressure in a warm vehicle tank. Pumps are often unable to generate enough pressure to overcome this back pressure. The solution is to use a vapor return line to relieve the pressure in the tank prior to LNG transfer. As soon as LNG flows into the tank the cold liquid will condense the remaining warm vapor in the tank ullage space and the tank will fill quickly. Most stations use a tw'o-hose dispenser system. LNG is pumped through one line and vapor is removed from the tank through the second line. CH-IV and MVE recently introduced single-hose dispensers that manage vapor return through the same hose that transfers LNG into the tank.

Figure 3-5 illustrates the five basic techniques that have been used at recently constructed LNG refueling stations. 
Figure 3-5. Five Fuel Transfer Techniques Used at LNG Fuel Stations

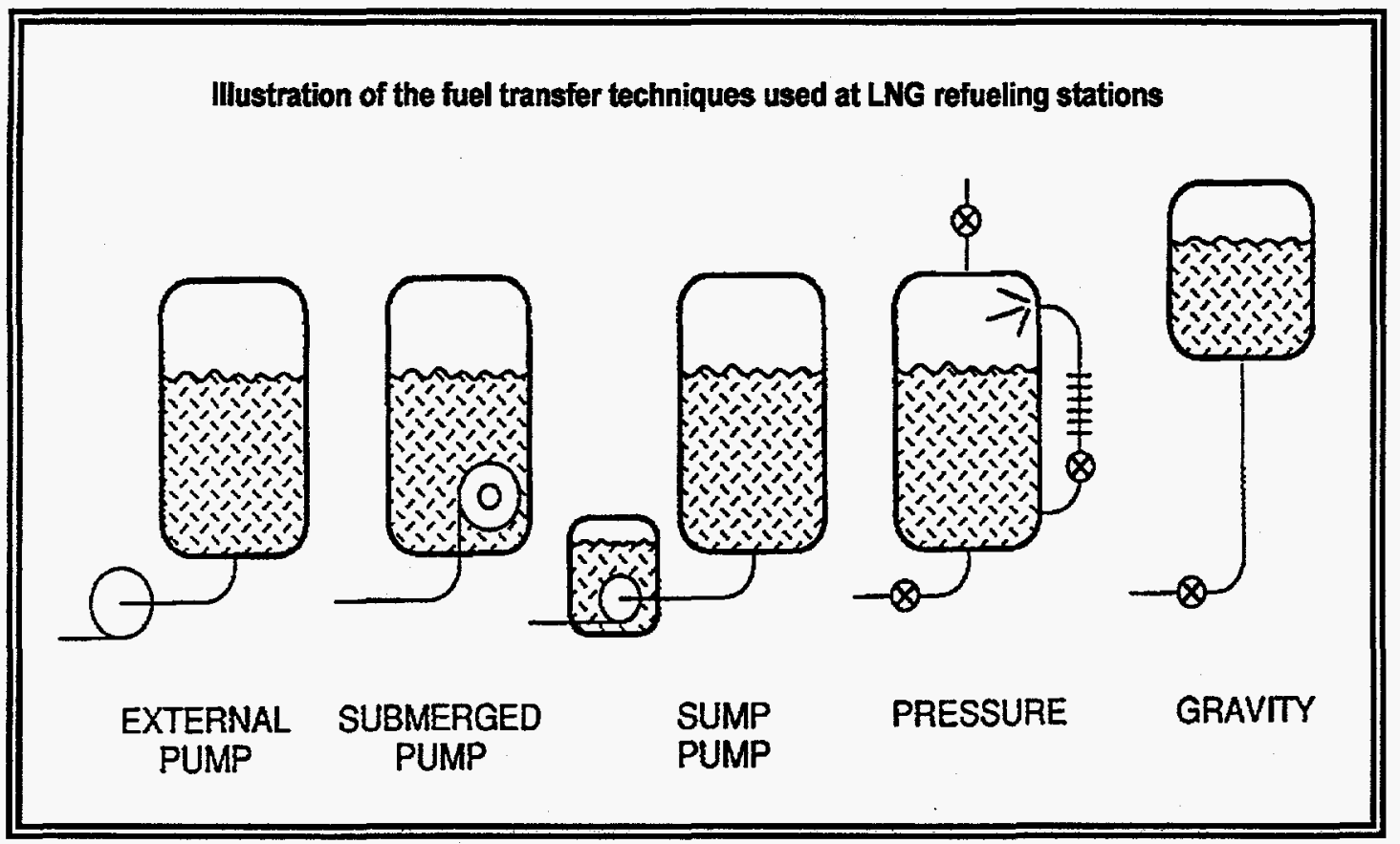

\subsubsection{External Pump}

As illustrated in Figure 3-5, the external pump is the most common fuel transfer method used for vehicle fuel stations. External pumps cost less than submerged pumps, but the pump warms to ambient temperature when not in use. A priming and cool-down procedure must be followed before an external pump can be used to fuel vehicles. Cool-down is usually accomplished by circulating LNG through the pump and back to the LNG storage tank until steady vapor-free flow is established. This prevents vapor lock. Electronic control modules have automated the cool-down process. Nevertheless, cool-down still requires 15 to 20 minutes, a delay that is unacceptable to many customers.

Occasionally problems arise from the difficulty of pumping saturated LNG with centrifugal pumps. It is common for cryogenic pumps to vapor lock because of heat leak (flux) into the system. Vapor lock can cause a pump to lose prime. LNG flows in warm piping and pumps create vapor. Vents from the pump casing back to the storage tank are required to allow the vapor to escape. Without vapor return, a cryogenic pump is almost impossible to operate. Vapor lock problems are commonly mentioned by station operators.

LNG pumps are also very sensitive to net positive suction head (NPSH) and suction piping configuration. Pressure drop as well as heat leak must be taken into account. Even when a centrifugal pump is installed below a tank to provide adequate NPSH, small variations in inlet and outlet conditions can cause singlestage pumps to cavitate. Cavitation generates vapor and stops liquid transfer. Cavitation problems have forced several sites to lower pumps or raise tanks to obtain the proper suction head. Pump requirements must be carefully evaluated before setting tank elevations (Beale, 1993). Cryogenic pump manufacturers include ACD, CS\&P, Cryostar, and Ebara Cryodynamics.

Houston Metro LNG refueling stations use external centrifugal pumps combined with slight pressurization of the LNG storage tanks to maximize the NPSH. This is an external pump and pressure transfer hybrid design. The pumps and drive motors are fully submerged in LNG when fuel is being transferred, but are dry between refueling episodes. Thermal insulation is applied around the pumps to 
minimize heat transfer. Even with this insulation and tank pressurization, the Houston Metro external pump system occasionally produces vapor that must be vented.

Another refueling system that uses an external pump for fuel transfer is the Cryenco LNG fuel station. The modular Cryenco station combines a transfer pump and electronic control modules with one or two Cryenco TVAC ${ }^{\text {TM }}$ 4,450-gallon LNG intermodal cryogenic container tanks. These modular stations have been installed at more than 10 crganizations, including the Los Angeles Airport, Wal-Mart, Santa Fe and Union Pacific Railroad Yard, and the JBK Ontario station. The pump skid incorporates a 7,200-rpm centrifugal pump which requires an NPSH of 2 psig and can supply LNG with a delta pressure up to 60 psig. The system includes two-line refueling capability (fill line and vent line), although a single line refueling can be used when the LNG vehicle fuel system and fuel condition permit. Excess vapor from the vehicle fuel tank is vented back to the TVAC ${ }^{T M}$ storage tank. These systems operate reliably and satisfactorily, although some vapor is generated during pump cool-down.

\subsubsection{Submerged Pump}

An obvious solution to the priming, cavitation, and vapor generation problems with external pumps is to submerge the pump inside the ING storage tank (Figure 3-5). This method was employed at the LNG refueling station installed at Yosemite National Park in the early 1970s. Submerged pumps require additional penetrations into the vacuum-jacketed tank, are difficult to access, and are expensive.

\subsubsection{Sump Pump}

The sump pump provides the aclvantages of a submerged pump but avoids the access and maintenance problems. The pump is submerged in a small pressure vessel located below the LNG storage tank. The pump is continuously submerged in LNG. This vessel can be easily isolated, drained, and opened to service the pump. Sump pumps are being used in several LNG refueling facilities. For example, refueling stations using sump pumps include those at DDC in Detroit, Michigan; Gary Public Transportation Corporation in Crary, Indiana; and EHM in Bloomfield, New Mexico.

\subsubsection{Pressure Transfer}

Simple pressure transfer is used in some LNG fueling facilities. A side stream of LNG is evaporated in a finned heat exchanger as shown in Figure 3-5. This increases the pressure within the LNG tank and pushes the liquid out the discharge line. Pressure build and LNG transfer should be performed as quickly as possible so that no excess heit is added to the LNG in the storage tank.

Some pressure transfer stations use two LNG tanks, a main storage tank and a small receiver tank. LNG is transferred to the receiver tank from the main tank. The small tank is then isolated and pressurized. Finally, the LNG is transferred to the vehicle fuel tank from the srnall tank.

Pressure transfer systems have three advantages over pump systems: simple construction, lower cost, and high-pressure capability. Construction is simplified and cost is lower because no pump is required.

High-pressure capability may enable pressure transfer systems to use single-hose fuel transfer to collapse the vapor back pressure in the vehicle tank.

Pressure transfer systems, however, do have disadvantages. First, the systems require long periods of time to build the pressures need ad to transfer LNG. In addition, after LNG transfer is completed, the high-pressure vapor (typically 50 to $150 \mathrm{psig}$ ) left in the LNG storage tank must be managed. If left in the tank, the remaining LNG will re-equilibrate to a higher temperature and pressure saturation state, which will substantially reduce hold time. In most systems, the vapor is simply vented to the atmosphere, 
but this is undesirable for environmental and economic reasons. Alternative vapor management methods avoid atmospheric venting, but they introduce substantial complexity into the system.

The Roadway Express fueling facility uses pressure transfer. Excess vapor is cooled, compressed, and sold back to the local distribution company (Jayaraman, 1993). Although this system operates satisfactorily, it is neither simple nor inexpensive.

MVE developed a pressure transfer system for the Greater Austin Transportation Corporation (GATC) LNG refueling facility (LNG Express, February 1993). The operation of this system is illustrated in Figure 3-6.

The vapor used for LNG transfer is compressed and used to fuel CNG vehicles. An LNG receiver tank is used to minimize the quantity of vapor generated and to avoid pressurizing the main LNG storage tank. Single-line refueling is used because the system can generate adequate pressures to overcome the LNG vehicle tank back pressures. One disadvantage to this technique is the considerable cost of adding the compression, storage, and dispensing equipment required to fill $\mathrm{CNG}$ vehicles.

\subsubsection{Gravity Transfer}

Gravity transfer is not known to be used in LNG vehicle refueling facilities. The storage tank would have to be elevated about 60 feet for every 15 psig pressure required. It is probably impractical because the tank would need to be elevated at least 360 feet to provide 90 psig. Delivering LNG to this elevated tank would be extremely difficult and expensive.

\subsection{Vapor Recovery and Handling Systems}

A near-empty LNG fuel tank will be filled with vapors in equilibrium with remaining LNG. Pressures in the tank can be very high. This pressure must be relieved before low-pressure LNG can be transferred into the tank. Recovered vapors must be properly managed.

Vapors in LNG tanks are recovered in one of two ways: through a vapor return system or a vapor collapse system. Vapor collapse systems are specifically designed to use the transferred LNG to cool and liquefy the vapor remaining in the vehicle fuel tank. LNG is sprayed into the ullage space of the vehicle fuel tank to collapse (recondense) the vapor. A vapor collapse system usually eliminates the need for a second vapor return line. The saturation pressure of the LNG vehicle tank may be increased, but this should not be a problem because conditioned LNG is generally required. The disadvantages of vapor collapse systems are that the hold time for the LNG fuel tank may be decreased, and that this type of system is difficult to design (Midgett, February 1996).

Vapor return systems use a line connected to the vehicle fuel tank to return vapor to the fueling station. The CH-IV/EHM Bloomfield station uses a patent-pending design to fill and return vapor through one hose. A two-hose system is used by other systems, and both systems work well. The two-hose system requires the user to connect an additional hose depending on the connector type. The recovered vapor must either be vented, recovered to the pipeline, or recondensed in the station storage tank. Ideally, vapor return systems would measure the vapor return flow rate to obtain accurate fuel consumption for the vehicles fueled.

Many stations bubble the vapor through the main storage tank. The cold LNG condenses the warm vapor and slightly increases the pressure in the storage tank. This works well as long as the LNG storage pressure is not increased too much. Most new stations use vapor return systems or return recovered vapor to a pipeline system. Most stations also vent excess vapors to the atmosphere (Midgett, February 1996). Future regulations may prohibit this practice. The five methods of controlling vent gas are discussed. 


\subsubsection{Flare System for Recovered Vapor}

One method of limiting methare emissions is to install a flare. This converts $\mathrm{CH}_{4}$ to $\mathrm{CO}_{2}$ and water. Carbon dioxide also contributes to the greenhouse effect but less so than $\mathrm{CH}_{4}$. Generally, flares are

|Figure 3-6. Pressure Transfer System

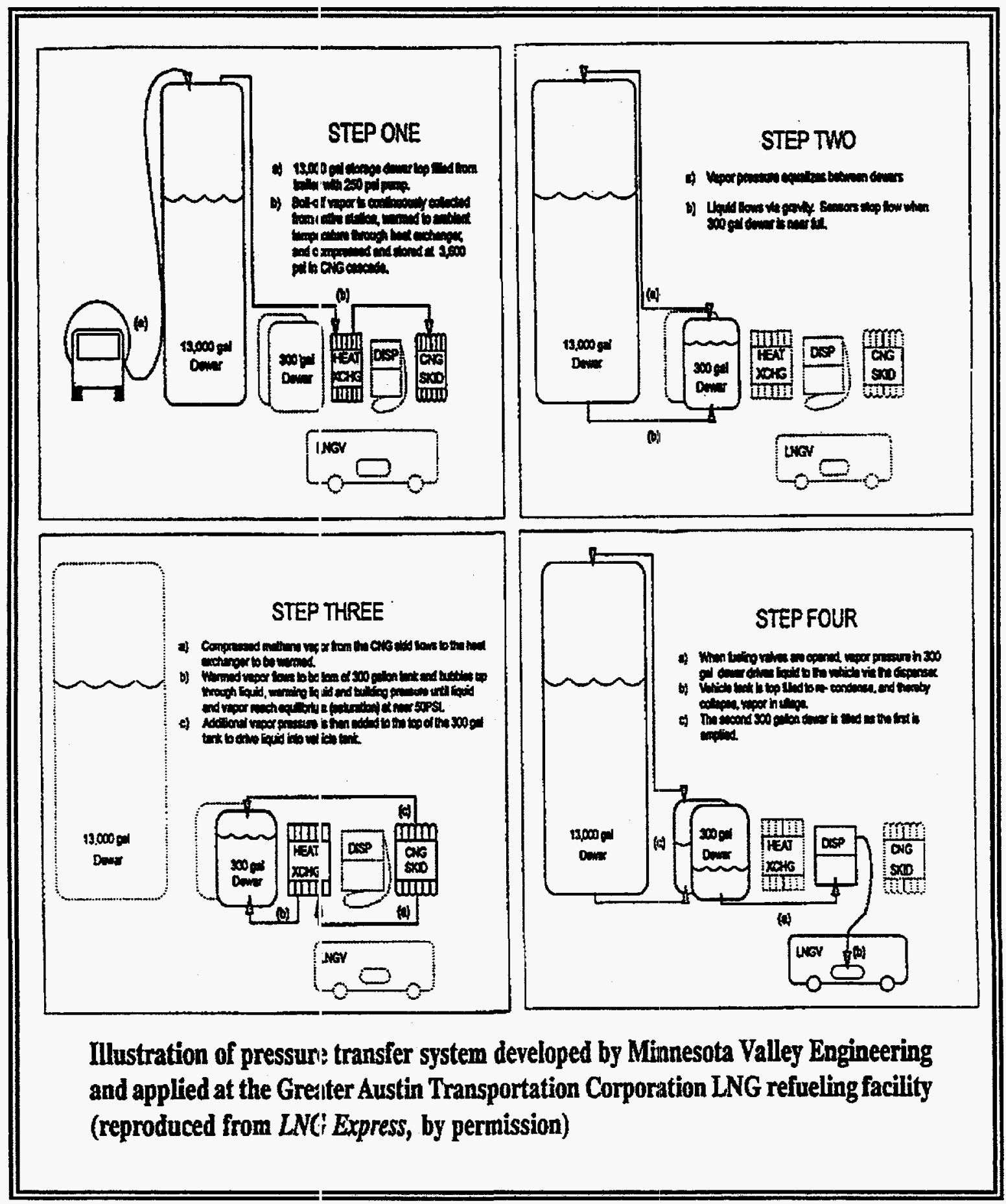


Figure 3-7. Use of a Flare to Handle Vapor

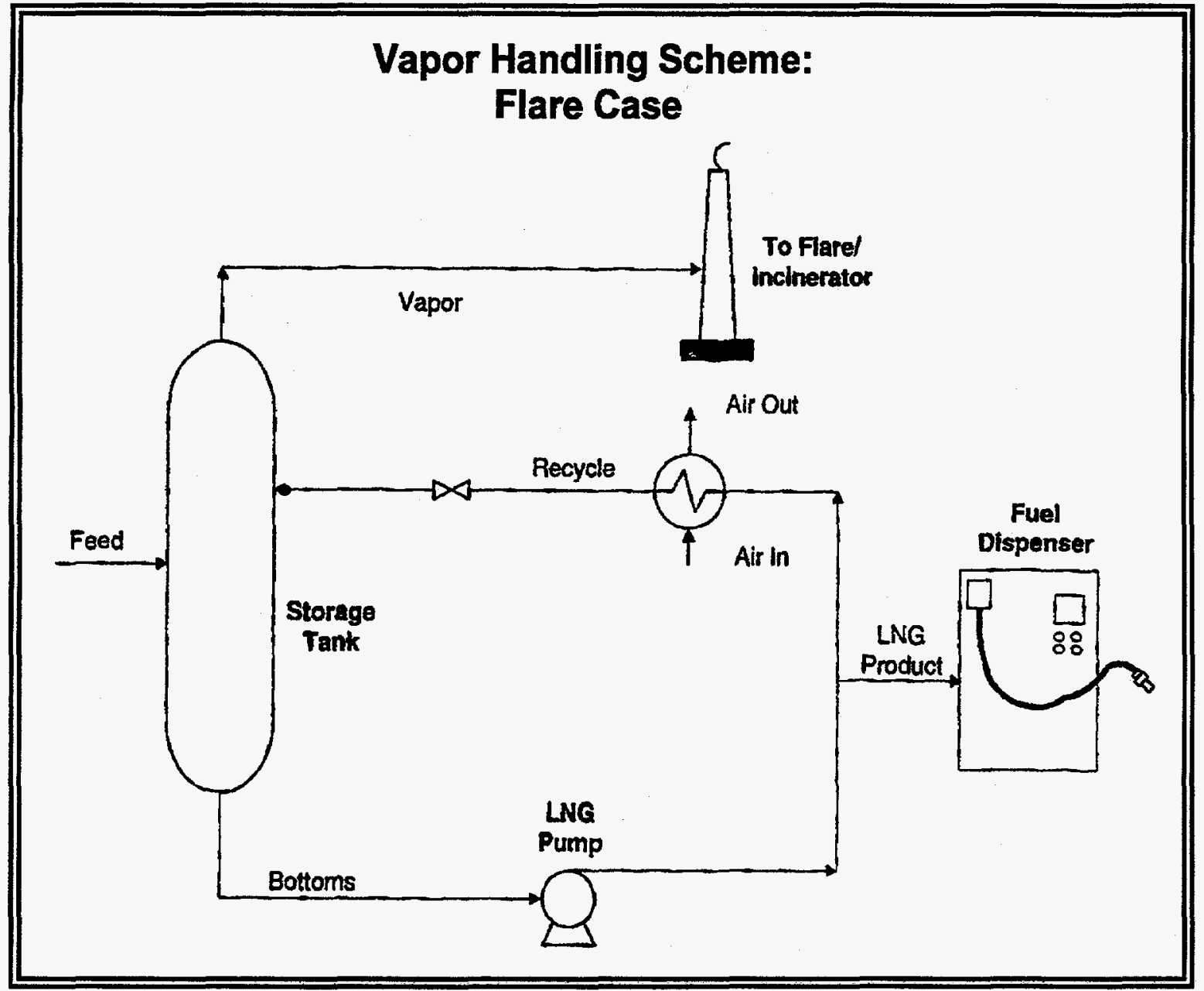

Source: Midgett 1996

low-maintenance items, so operating costs would not be expected to rise significantly, especially if the flare is spark ignited upon release (i.e., no continuous pilot). Figure 3-7 illustrates the schematic for a simple flare system.

\subsubsection{Vapor Recovery to Pipeline}

If a pipeline is available nearby, vapors can be an economic benefit in that recovered vapors can be sold. The cost of pipeline recovery is highly variable depending on the distance required to make the tie-in. Some gas utilities currently recover LNG vapors released into their Class B pipeline (up to $60 \mathrm{psig}$ ) systems-Northwest Natural Gas, for example-Other gas companies, such as Virginia Natural Gas, do not connect to a pipeline, because the Virginia public utility commission has indicated that such a connection would cause the LNG facility to fall under DOT Section 193 rules and trigger Federal Energy Regulatory Commission commerce issues. For Virginia Natural Gas, the added requirements would increase the cost of the base facility considerably. It expects to work with the state to resolve the regulatory issues and hopefully connect to pipelines in the future.

Subject to availability and these regulatory issues, a pipeline connection is one of the best vapor recovery schemes because an economic benefit from the vapor is realized with very little incremental operating cost (see Figure 3-8). If LNG stations become commonplace and, perhaps, are not even owned by the 
pipeline company, a future concern might be access to gas lines for vapor recovery. Gas companies might consider an outside conniction as risky to the integrity of the pipeline system. If a gas pipeline is not nearby, another alternative $i s$ to use the vapor as a fuel source. This option could provide some economic benefit from the gas if a fuel source were required (such as for natural gas-powered pumps and boilers), but the intermittent nature of the vapor releases make this option difficult to implement.

Figure 3-8. Vapor Recovery to Pipeline

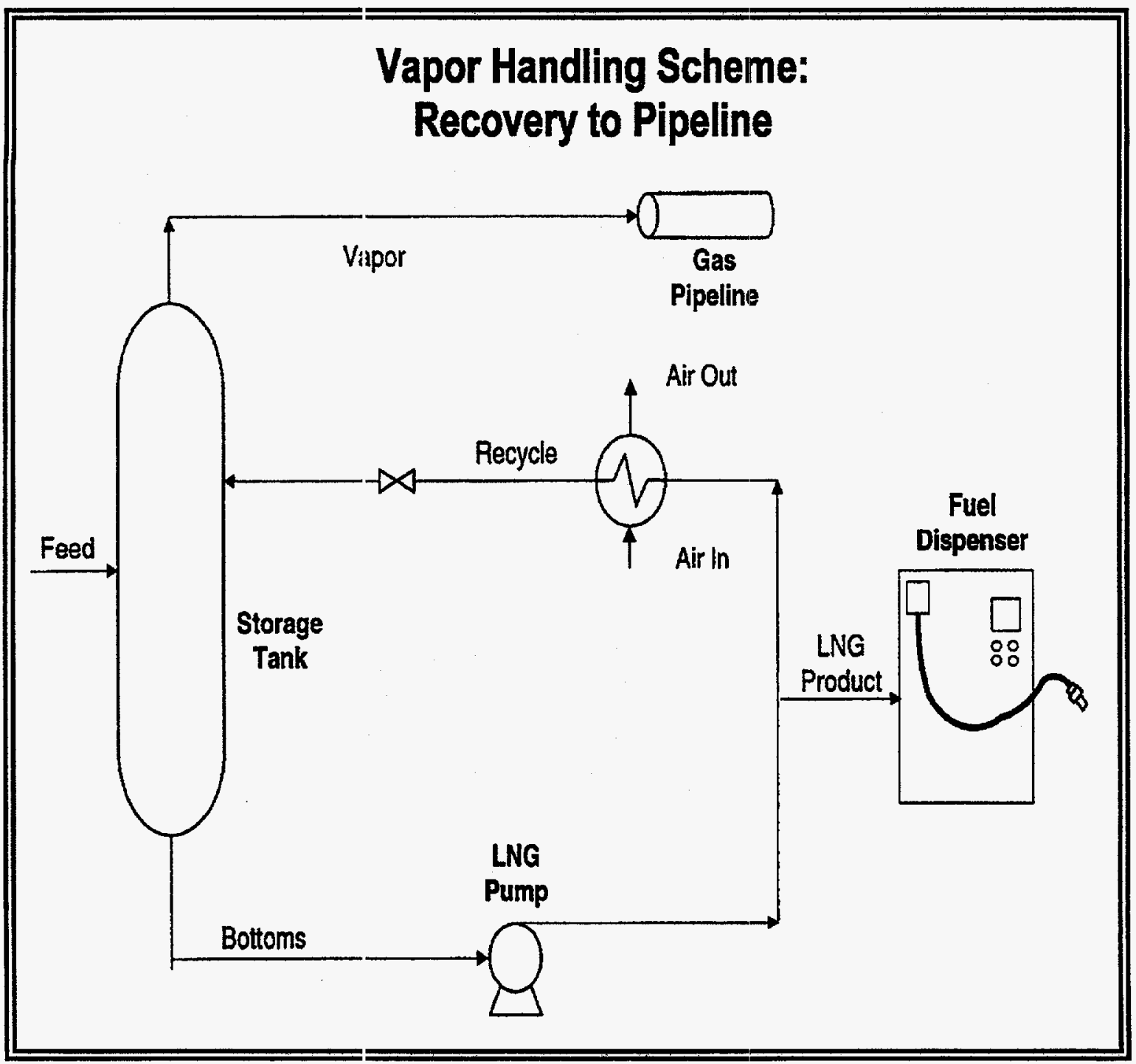

Source: Midgett 1996

\subsubsection{Liquefaction of Rt:covered Vapor}

The simplest vapor liquefaction option is to use liquid nitrogen (LIN) to liquefy LNG vapors in a heat exchanger by vaporizing LIN (see Figure 3-9). The condensed LNG could then be pumped back into the storage vessel. This approach allows pressure maintenance by condensation and full recovery of LNG vapors. $\mathrm{No}_{\mathrm{CH}}$ is vented; the only emission is nitrogen vapor. For every gallon of LNG liquefied, 1.4 gallons of $L I N$ are required (about 2.3 pounds LIN per pound $L N G$ ). If $L I N$ cost $\$ 0.20$ per gallon and the facility were run 5 percent of the time, the LIN costs for this facility would be $\$ 4,000$ per year. 
Figure 3-9. Vapor Liquefaction with Liquid Nitrogen

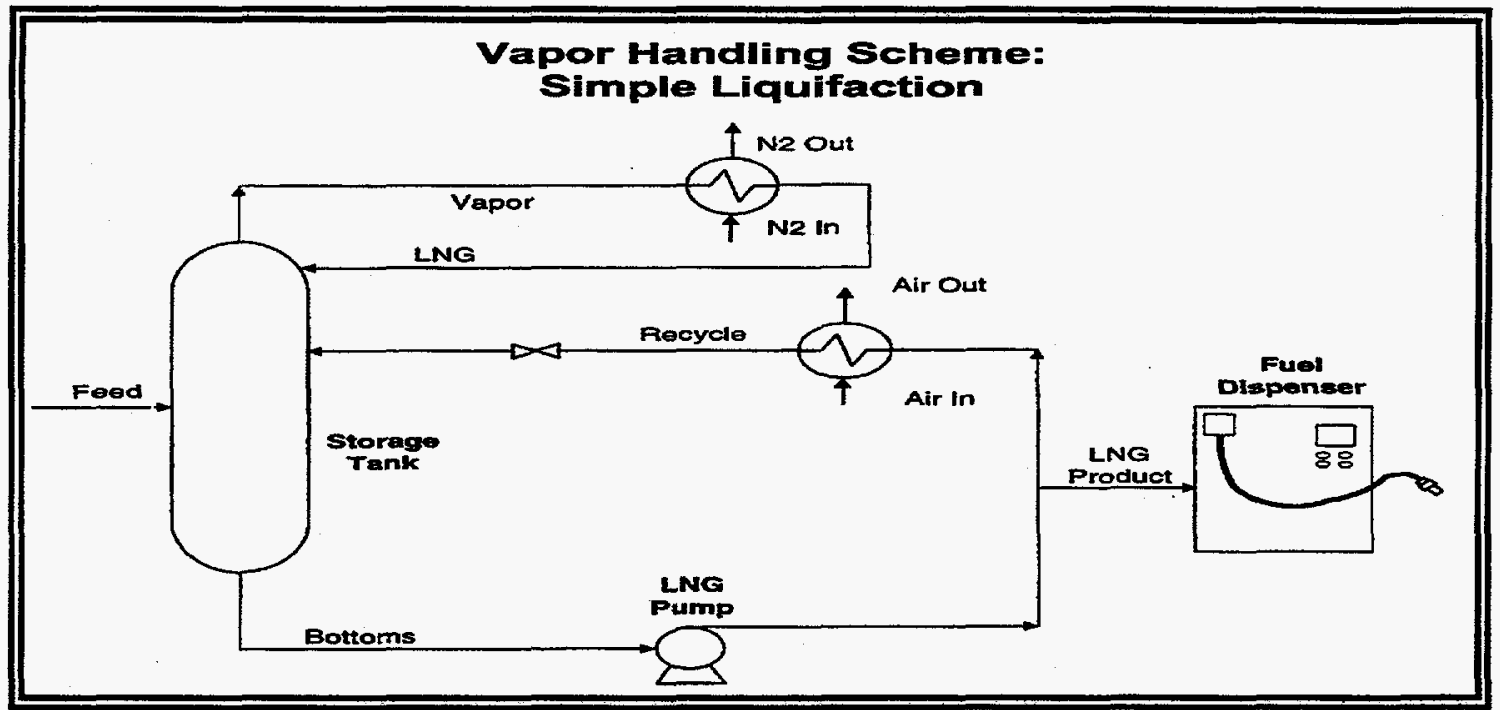

Source: Midgett, 1996

An alternative method of liquefaction would be to use a small mechanical liquefier, such as the Phillips Cryocooler or the TADOPTR. At this time, these machines are more expensive than the simple heat exchanger required for LIN liquefaction. However, should the TADOPTR development effort achieve cost objectives, then small, on-site liquefiers will be cost effective in this application.

\subsubsection{Pressurized Vapor Recovery}

This approach uses the LNG dispensed into the vehicle to condense the recovered vapor while increasing the saturation pressure, or "conditioning," of the LNG (see Figure 3-10). This vapor recovery approach works only if there is periodic loading of LNG, and the LNG saturation pressure requirement of the vehicle being filled is higher than that in the storage tank. Operation and maintenance of the additional equipment result in higher operating costs. This is one of the simplest mechanical liquefaction schemes because heat is rejected into the cold fluid.

\subsubsection{Vent to Atmosphere}

The least expensive and simplest approach to vapor management is to simply vent the $\mathrm{CH}_{4}$ vapor to the atmosphere (see Figure 3-11). The environmental and safety consequences of this practice are minimal, given the relatively small, and infrequent, nature of most releases. However, releases of vent gas to the atmosphere, while legal and convenient, convey a negative image to the public and are not recommended, except under emergency conditions.

\subsection{Refueling Dispensers}

Many LNG refueling systems include a dispenser module that integrates functions such as flow control, flow measurement and totalizing, pressure regulation, host support, and leak detection. The LNG comes into the dispenser from the storage tank(s) through insulated rigid tubing and exits in an insulated flexible hose. The fill hose is typically 0.5 - to 1.0 -inch flexible (corrugated) stainless steel and is usually vacuumjacketed for insulation. It is large and heavy and best handled with a hose tower and counterbalance system. 
Figure 3-10. Pressurized Vaporr Recovery

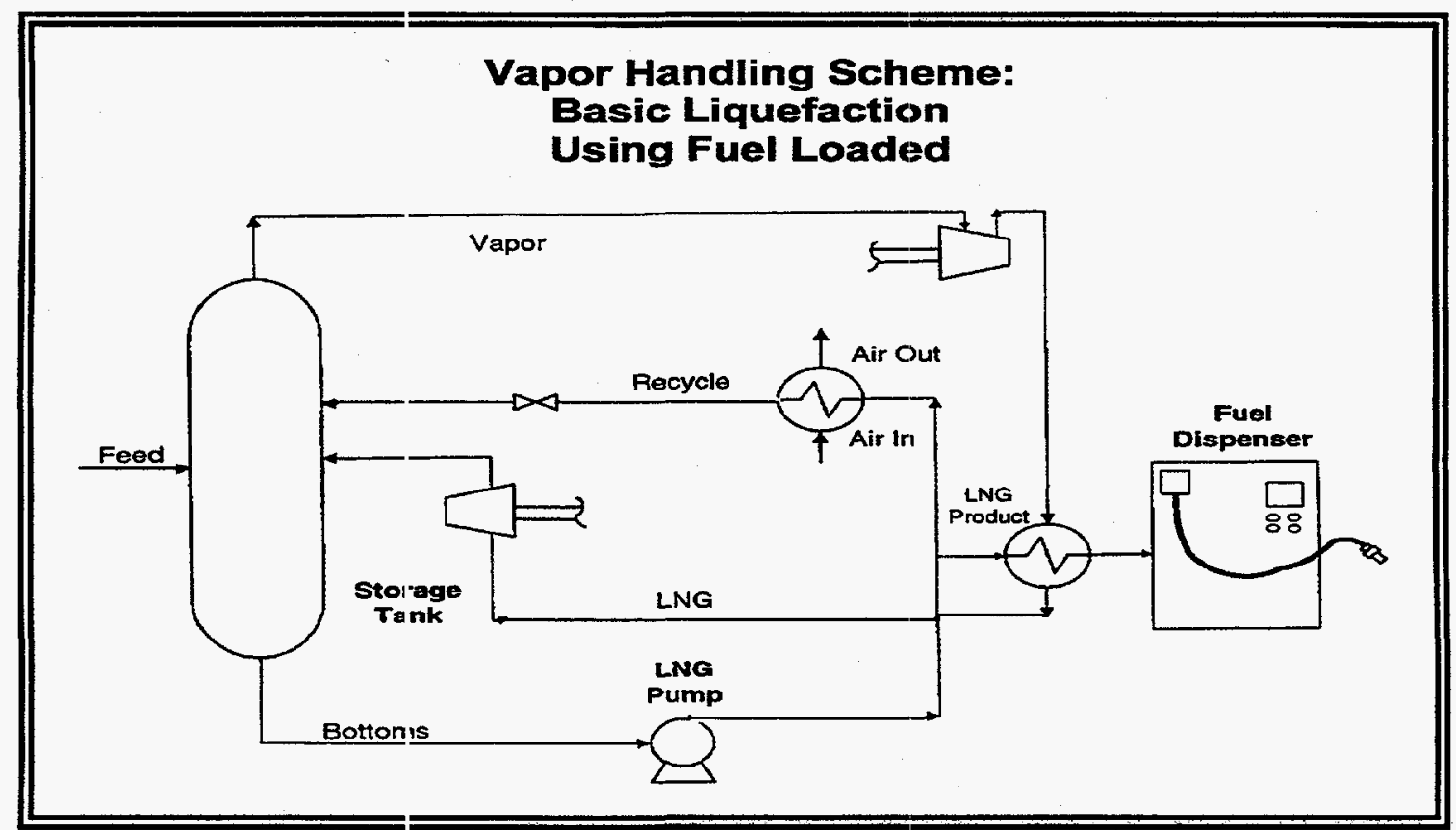

Source: Midgett 1996

Figure 3-11. Vent to the Atmosphere

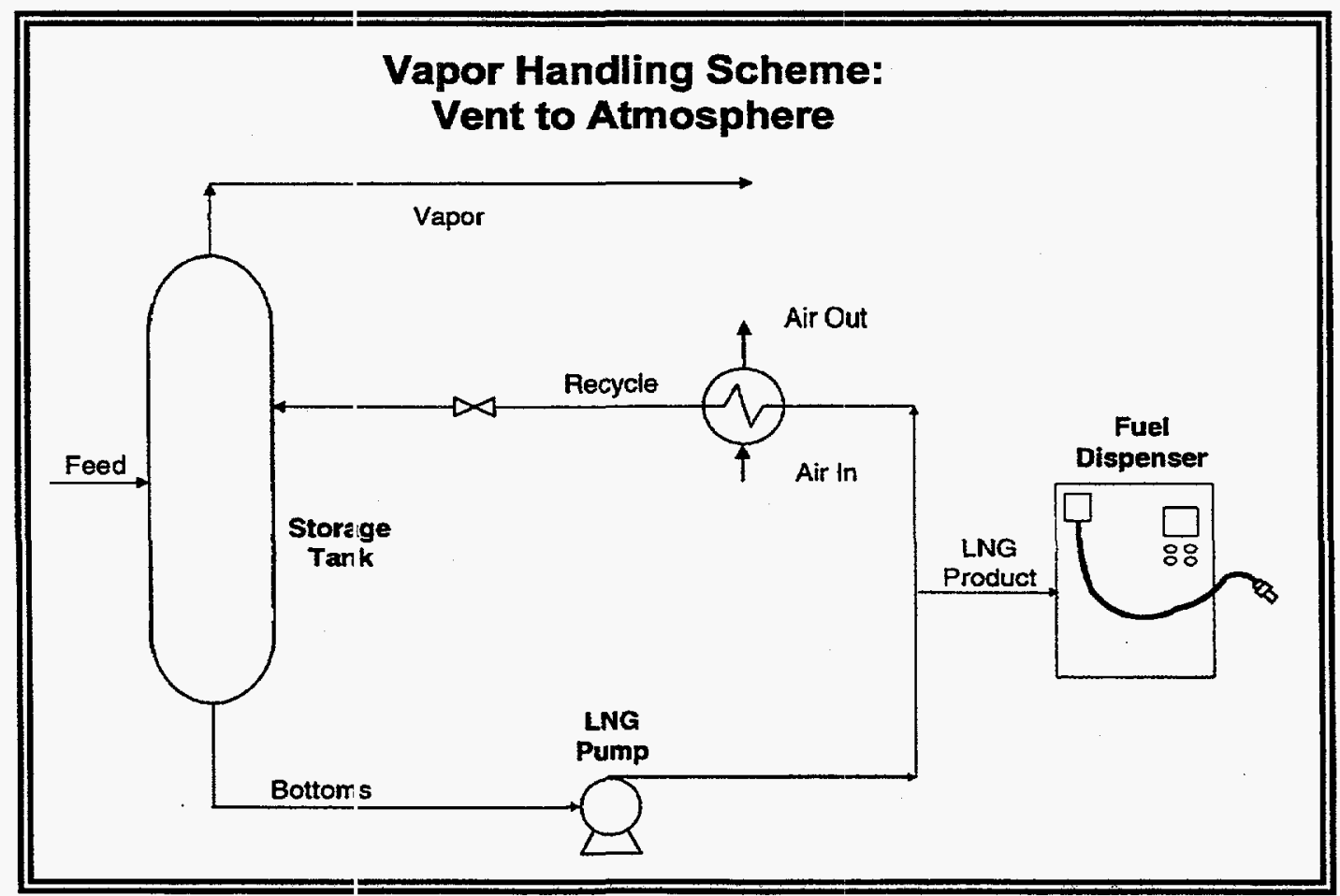

Source: Midgett, 1996 
Note that if the LNG refueling system includes vapor recovery, the vapor must be processed through the dispenser and something must be done with it. Vapor return from the coupling to the dispenser may be accomplished using either two parallel hoses or a single coaxial hose. In the past, returned NG vapor was usually vented, but this is undesirable for both environmental and economic reasons. In some cases, the vapor can be recondensed by mixing it in the LNG storage tank. This is usually undesirable as it tends to slightly increase the saturation pressure (and temperature) of the stored LNG. Another option is to recompress the recovered natural gas vapor and sell it to the local (gas) distribution company. This is now done at the Roadway Express project and has been reported to work satisfactorily. It is theoretically possible to reliquefy the vapor using a small-capacity liquefaction unit, but no cases where this was actually done were identified.

Aside from the fuel transfer and vapor management issues, the main technology problem associated with the dispenser, which deserves more research and development, is the ability to accurately measure the quantity of LNG actually transferred into the vehicle tank during refueling. This is seldom accomplished satisfactorily, primarily because any return vapor or liquid (due to overflowing) must be accounted for. The LNG refueling station fuel transfer and dispensing technology being developed by Cryenco, CH-IV, and others will enable highly automated single-line LNG vehicle refueling, very similar to gasoline- and diesel-fueled vehicle refueling.

A basic question affecting LNG transfer and dispensing equipment design pertains to the need for natural gas vapor recovery simultaneous with (or perhaps just prior to) LNG refueling, as in a two-line refueling system.

The need for vapor recovery using a second line arises from the need to off load vapor from the vehicle fuel tank ullage. When an LNG vehicle is about to be refueled, it is likely to be low on fuel, so that the vapor-filled ullage is a large fraction of the tank volume, and the tank pressure may be high. For example, the ullage vapor may be saturated at a high temperature and pressure, depending on the vehicle use history and fuel system design. It is undesirable to vent this vapor to the atmosphere for environmental, economic, and safety reasons.

The two-line approach is to off load this vapor as (or before) the LNG is on loaded. The off loaded vapor is usually fed back to the facility LNG storage tank where it is condensed as it mixes with the cooler, lower pressure LNG. That slightly increases the saturation temperature of the LNG in the facility tank, and thereby decreases its hold time. Also note that this approach is not possible with a single-tank pressure transfer system because the vapor cannot flow into a higher pressure tank; a two-tank pressure system is needed when using a pressure transfer system.

The single-line approach is to top fill the vehicle fuel tank with LNG saturated at a lower temperature so that it collapses (condenses) the vapor in the ullage; therefore, no vapor off-loading is usually needed. Single-line refueling can be accomplished if:

- The incoming LNG saturation temperature is significantly below that of the vapor in the vehicle tank ullage.

- The LNG refueling pressure is greater than the initial vehicle tank pressure.

- The vehicle fuel tank is equipped for top filling, with a sparger or other device to facilitate mixing of the incoming LNG with the ullage vapor.

Most current LNG vehicle refueling stations utilize two-line refueling. This is usually because the vehicle fuel tanks are designed for this and/or because the fuel transfer pressure is inadequate to overcome the initial vehicle tank pressure. Examples of two-line refueling systems include the Houston Metro stations 
and various Cryenco TVACTM modular LNG stations. The MVE LNG station at GTAC in Austin, Texas, is an example of a single-line refueling facility.

Cryenco, in cooperation with subcontractor CH-IV Corporation, is developing advanced LNG transfer and dispensing technology to $b ;$, demonstrated in conjunction with the on-site TADOPTR liquefier. This technology is intended to provicle improved performance relative to the prior and current LNG refueling station system for transferring and dispensing LNG. The overall layout of the LNG transfer and dispensing system is sketched in Figure 3-12, and the technical features are summarized below.

The LNG fuel transfer system vill use a vessel-mounted, submerged-motor pump-the sump pump option. Key to the success of th is system is the pump, which is well suited for LNG vehicle refueling requirements. The pump will bə a feedback-controlled, variable-speed, inducer-equipped, vertical-shaft, thrust-equalized, submerged-motor-driven, multistage centrifugal pump. It will be located in a continually flooded vessel that is separate from, but close-coupled with, the LNG storage tank. Specific pump design features and corresponding performance benefits are summarized below:

- True variable-speed operation- "Affinity Laws" predict the performance of centrifugal pumps as their speed is changed. The control logic will use these laws to dictate the pump speed based on refueling requirements (e.g., from low-flow recirculation cooling to high-flow transfer to a vehicle fuel tank initially at a high pressure). A variable-speed driver ( 220 volts, single-phase) that can vary the pump speed over its required operating envelope will be used.

- Pump speed feedback-Tachometer feedback will be used to provide true speed control-the controller will directly cont rol the pump speed. Other LNG refueling facility pumps operate with "inferred" speed, meaning that the controller signals the pump to speed up or slow down, but there is no feedback. This advance is of significant importance when refueling LNG vehicle with various fuel tank pressures.

- Lower NPSH requirement--The separate sump vessel serves not only as a vapor disengagement vessel, but it is also a stilling well to provide a stable liquid phase to the pump impeller. The pump also incorporates an induces; and these features combine to minimize the NPSH required for cavitation-free pump operation.

- Higher delta pressure - The multistage design of the pump provides much higher delta-pressure capability relative to single-stage centrifugal pumps. This is important because it enables LNG transfer to vehicles with inilially high tank pressures, and this permits use of a single-line refueling system, as will be discussec. in more detail subsequently.

- Thrust equalization mechanism-Most centrifugal pumps used for cryogenic service have a narrow operating envelope to ensure that the pump operates in a balanced thrust condition. When pumps operate outside this envelope, they generate thrust in the direction of the pump shaft. This is a primary cause of pump-bearing failure. This pump will employ a hydraulic design that neutralizes the thrust and allows the integrated pump and motor to "float" on the bearings. This enables a wide operating envelope with equalized thrust.

- Cold standby - The pump and sump vessel design will facilitate long periods of standby (without ice buildup, condensation in the motor windings, or substantial vapor generation) in the cold mode for immediate refueling response without needing a cool-down cycle. The vessel will also reject any heat to the main tank via thermal siphoning of the LNG. 
- Safe operation-The pump and motor will be fully submerged in the sump vessel with no shaft seals, thereby minimizing potential releases of flammable liquids or vapors. Because the pump will not continually cycle between warm and cold states, there will be less chance of leaks or failures.

- Low maintenance-The facts that the pump and motor are fully submerged, the pump shaft thrust is neutralized, and the pump is not subjected to thermal cycling will serve to maximize the pump lifetime and minimize maintenance requirements.

- Quiet operation-The pump and its motor will emit very little noise because they are fully submerged in the sump vessel.

There are important benefits to the LNG transfer and dispensing system being developed in this program. First, it will enable single-line refueling. It will also minimize vapor generation from the refueling facility and from the vehicle fuel tank. The previously discussed separate insulated sump with a fully submerged and constantly cold pump and motor will minimize vapor generated by the refueling facility. The feedback-controlled, variable-speed, multistage centrifugal pump will enable single-line refueling. When required, the system will automatically sense high initial vehicle tank pressures, automatically adjust the pump speed to overcome this pressure, and on load LNG. The cooler on-loaded LNG will collapse the ullage vapor and reduce the pressure in the vehicle tank; no off-loading of LNG vapor (in a second refueling line) will be necessary. Therefore, a minimum of vapor will be generated, eliminating the need for vapor venting to the atmosphere.

Figure 3-12. Advanced LNG Fuel Station Schematic

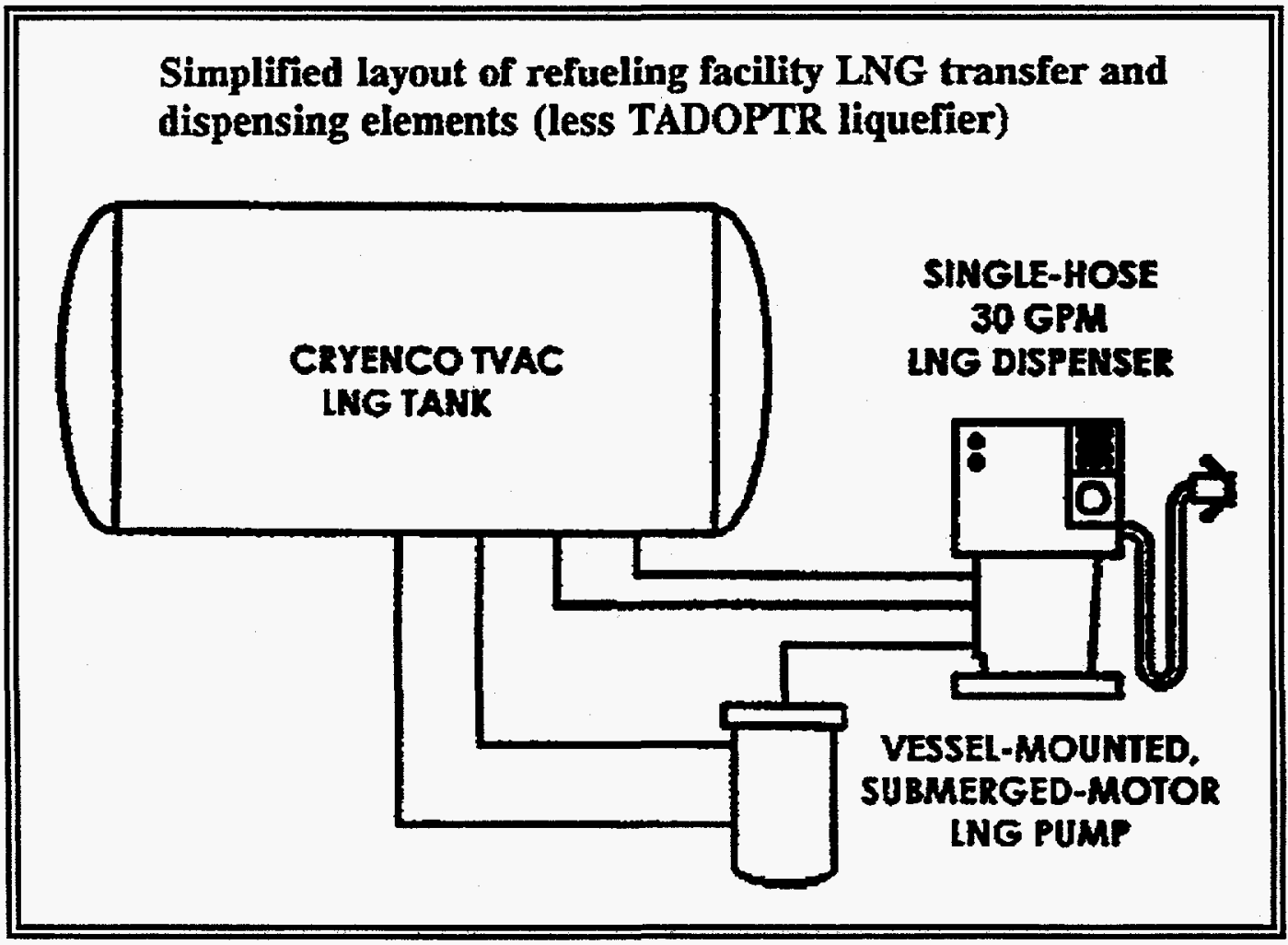

The advanced LNG transfer and dispensing technology will enable the refueling facility to be designed for highly automated operation. A goal is to make the facility operation virtually transparent relative to gasoline or diesel fueling facility operation. When an LNG vehicle arrives for refueling, the operator 
removes the insulated hose from the dispenser, attaches the hose coupling to the vehicle, and activates the dispenser switch. The dispenser shuts off at the conclusion of refueling; this signals the operator to uncouple the hose from the vehicle, and return it to the dispenser.

\subsection{Refueling Couplings}

An LNG fueling station requires special connectors. Engine manufacturers require the LNG in the vehicle to be at a certain saturation pressure; each manufacturer has requirements ranging from 50 to more than 100 psig. LNG is transferred under pressure to the fuel tank, thus allowing recovery either by recondensation or by returning the vapors to the station. Connectors must also minimize the amount of liquid lost when the connection is detached to prevent exposure to the cryogenic liquid.

Of those who responded, 61 pe:cent used Parker connectors, 44 percent used Moog connectors, and 22 percent used another type of connector ( 28 percent of the respondents used more than one type of connector) (see Figure 3-13).

A common problem that the inclustry experiences is leaking connectors. Because LNG is so cold, it causes metal to contract. This sontraction makes removable connections difficult to design. Houston METRO had trouble with its Parker connector freezing to the vehicle during fueling because of condensation and freezing of water from surrounding ambient air. These problems appear to have been remedied by the latest generation of connectors. The latest generation Parker connector uses a nitrogen purge to prevent moisture from accumulating on the connector face. As a result, using the Parker connector will require an on-site nitrogen source (typically bottled nitrogen).

Connecting the hose to the vehicle is the main user operation. Ergonomic issues should be considered to make the operation as smooth as possible. Although it has never been tested, a vehicle nozzle could be oriented at a 30- to 45-degree $u_{\text {p }}$ angle to make it easier for the operator to connect the hose (Charles Collison, Metropolitan Transit Authority, personal communication). For this design, proper precautions to prevent water accumulation in the nozzle should be evaluated. This approach is currently employed with gasoline fill connections, and could be adopted by future LNG fleets.

As previously discussed, prior industry concerns about connectors have been resolved. The latest generation of Moog and Parker fittings have experienced no problems; however, further advances could be realized, especially to limit tie number of connections required to fuel. Currently, stations require two or three connections to fuel LNiG: a liquid fueling line, an electrical ground, and sometimes a vapor return line, depending on the faıility's design philosophy. Moog manufactures a connection that combines the liquid and vapor return lines into one unit for those stations requiring both, but no connection that includes the elestrical ground exists from any manufacturer. Connection manufacturers should produce a connector that includes the electrical ground in their designs, eliminating the requirement of this additional connection.

Whittaker Controls is developing a new type of LNG fuel nozzle designed to permit bare-handed use. It will feature a lightweight, quick-connect system that is user-friendly and fail-safe. The development effort is supported by CALSTART and the Defense Advanced Research Projects Agency.

Connectors currently are not interchangeable; thus, station and fleet operators must choose the connection vendor up front. Standardization of connectors would improve availability and lower costs; however, this is not expected in the near future. 
Figure 3-13. LNG Fuel Nozzles and Receptacles

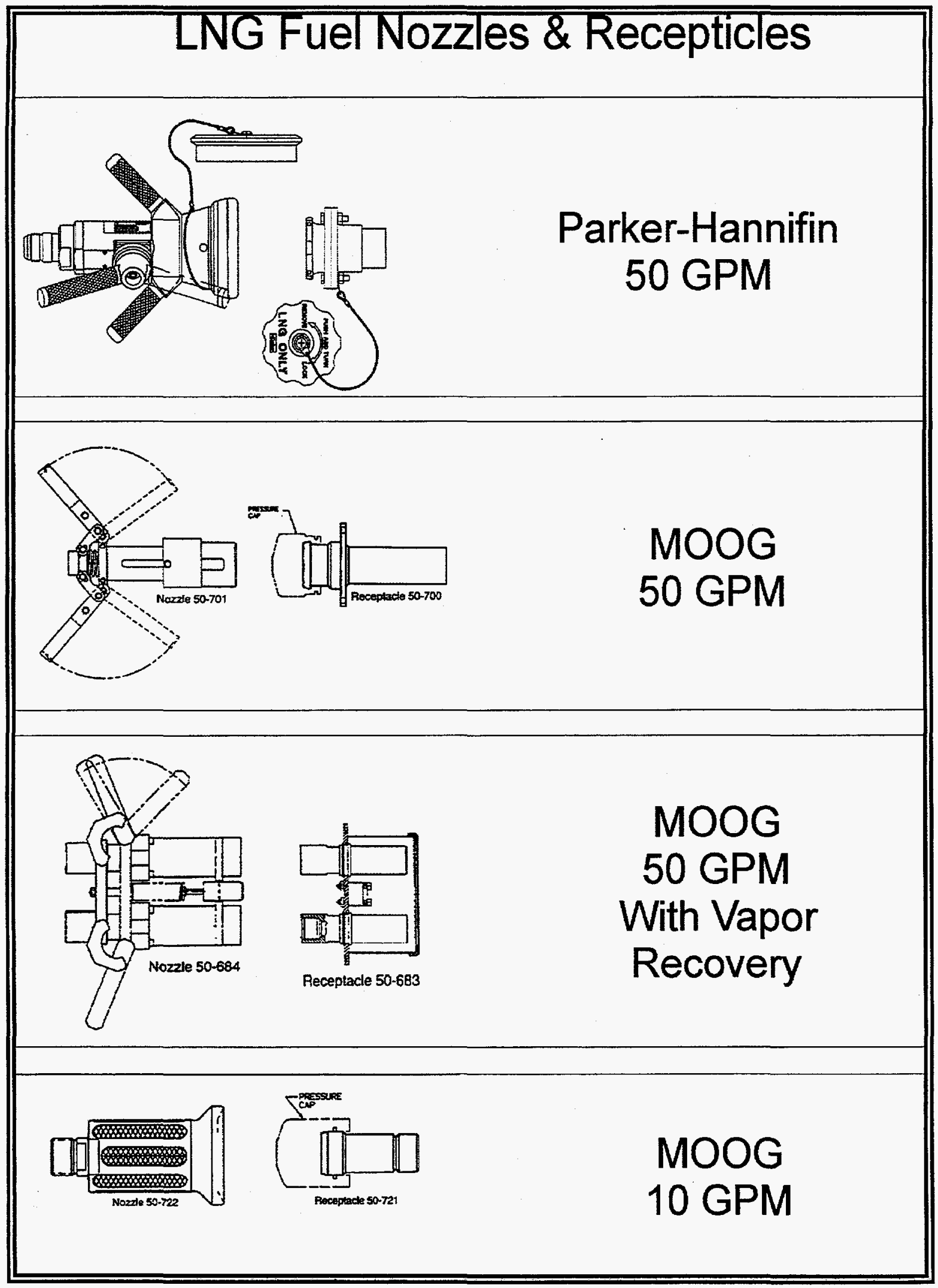




\subsection{LNG Station Instrımentation}

Instrumentation has become more sophisticated as the LNG industry has developed. Early stations, such as the Northwest Natural Gas fieling station built in 1982 by the now-dissolved Beech Aircraft Alternate Energy Division, used hard-wijed controls. This type of system required an electrician to make even minor adjustments to the control logic. Programmable controllers are now the standard for all LNG stations. Between 1990 and 1994, Northwest Natural Gas updated its system to a programmable controller, adding an automatic cool-down sequence and an autornatic shutdown when the vehicle fuel tank is full.

To diagnose a problem with an LNG station, multiple temperature and pressure measurements are required. However, in older stations, lack of instrumentation is a problem. Unless the instrument (or at least a tap for the instrument) is available, such data as saturation pressure and site-specific temperature in a line will be unknown and the station will be more difficult to troubleshoot.

Most of the new stations currently being developed by all of the major station manufacturers include fully automated operation as well as system and safety status monitoring. Most include emergency shut down features. In the event of a leak and/or fire, the station is automatically placed in a fail-safe mode until the problem is corrected. These advanced systems include numerous other automated functions to improve performance as well as simplify the fueling process.

\subsection{LNG Measuremerit Systems}

LNG flows can be difficult to measure accurately because of the relatively large changes in density that occur as temperature and pressure conditions vary. In addition, because saturated LNG is stored under pressure near its boiling point, a small pressure drop associated with LNG transfer can cause bubbles to form in the liquid, creating a two-phase flow condition that is especially difficult to measure.

Nevertheless, Micro Motion Ccriolis mass flow meters have been used successfully on LNG stations by Cryenco and other manufacturers. NIST tests on a coriolis meter in cryogenic service using LIN found that temperature and pressure effects on meter performance are insignificant. The standard deviation of the test data was less than 0.2 percent. Coriolis meters are reportedly accurate to \pm 0.15 percent and have the ability to measure a wide range of flow. The disadvantage of mass flow meters is their relatively high cost (Valentine, Keilty, March 1995), although they are becoming more common throughout the industry.

Orifice plate meters are inexpensive, costing only 4 percent of an equivalent mass flow meter, but are only accurate to \pm 1.7 percent. Volumetric flow measurement with a turbine meter can be accurate to \pm 0.5 percent. The cost is rouglily the same as that of a mass flow meter.

Positive displacement meters cost 40 to 50 percent less than mass flow meters and have an accuracy of 0.25 to 0.5 percent.

The density of LNG varies with temperature, pressure, and composition. Therefore, volumetric flow measurements must be adjusted for actual operating conditions to obtain an accurate measurement. Conventional volumetric flow ineters, such as turbine meters or orifice flow meters, can yield significant errors when two-phase fluids (such as combined liquid and vapor) are measured. Station manufacturers should have the capability to calibrate and certify their meters. For retail sale, state weights and measures agencies may make this a requirement. 


\subsection{Auxiliary Equipment and Piping}

Equipment and piping for LNG stations must be constructed from materials certified for cryogenic service. Stainless steel and high-nickel ( 9 percent) steels have become the industry standard for all piping, valves, fittings, pressure vessels, and other equipment that is in direct contact with cryogenic liquids.

Most LNG fueling stations, transport trailers, and container tanks are supplied with heat exchangers for controlling saturation and building pressure in the storage vessels. These star-finned tube heat exchangers use heat from ambient air to vaporize the LNG. Gas-fired or liquid heat exchangers may also be used, especially in LNG-to-LCNG stations.

Station piping must be insulated to minimize heat gain when LNG is transferred. Piping may be wrapped with multilayer insulation (MLI), also called superinsulation, polyurethane foam, or any other good insulator. In addition, vacuum jacketing is sometimes used on piping and pump housings in LNG fueling stations. In larger LNG facilities, the thickness of the insulation is calculated to prevent condensation on the outer surface. Figure 3-14 shows the frequency of usage for different types of insulation systems used in LNG stations. If a particular insulation has a higher thermal conductivity, a greater thickness will be required to get the same performance. MLI has the lowest thermal conductivity of known insulators, thus justifying a higher unit cost.

Figure 3-14. Usage of Various Insulation Methods to Reduce Heat Leaks

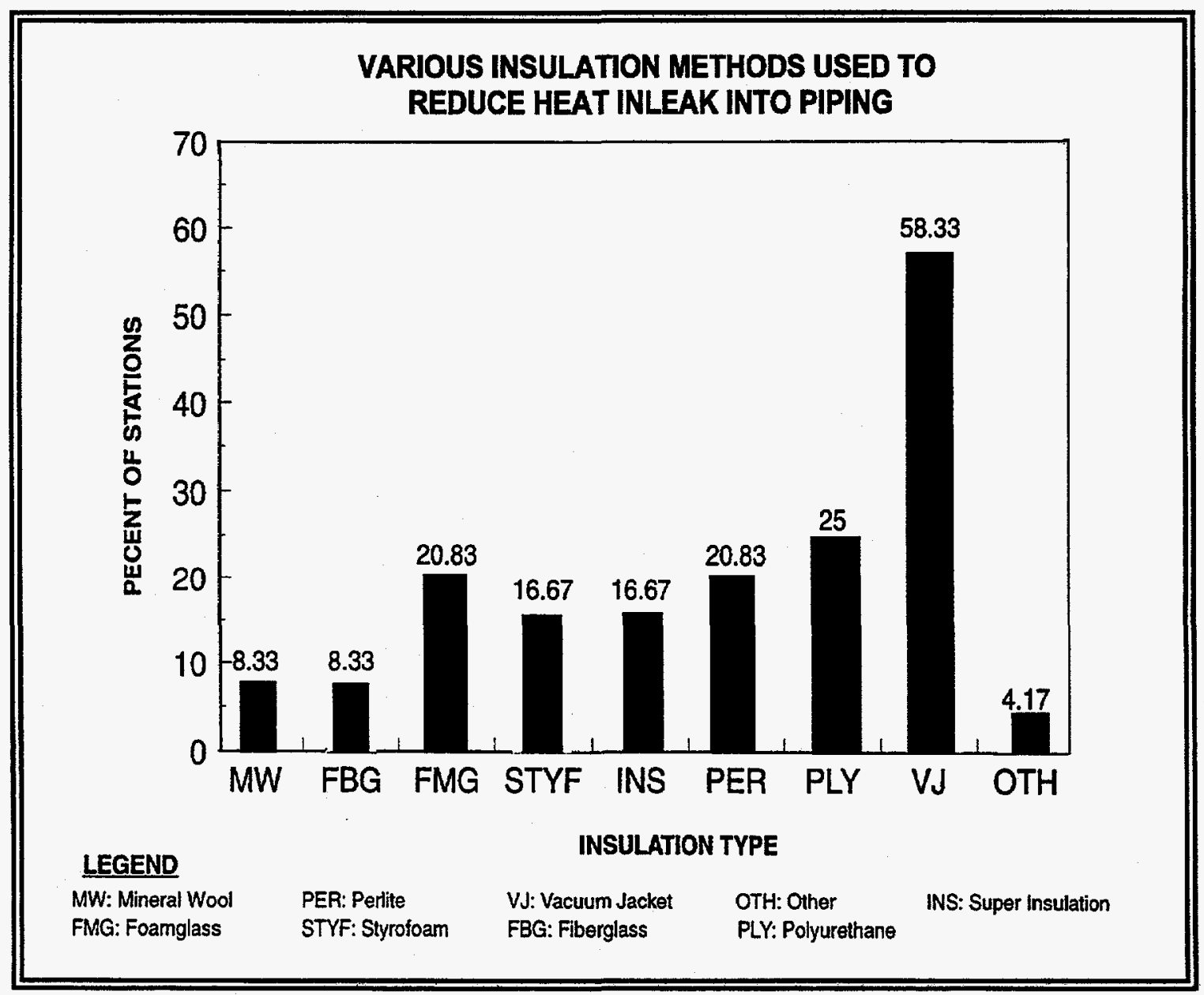


LNG piping design must account for thermal contraction and expansion. When metal piping is cooled from ambient temperature to $-162^{\circ} \mathrm{C}\left(-260^{\circ} \mathrm{F}\right)$, it contracts. If this contraction is not allowed by the station design, severe stresses are enccuntered that could break the line or damage the equipment attached to the line. Bellows joints, expansion loops, and flexible hose are normally installed to allow LNG piping to contract without undue stress.

Cryogenic materials and fabricition methods must be used. Use of welded connections in LNG service is recommended. The use of flanges or threaded connections should be minimized to reduce maintenance requirements. Contraction and expansion of the piping as it warms and cools with use causes threaded connections to leak and loosens flange bolts. Flanges will require regular maintenance and tightening. If threaded connections are used, the connections should be back-welded or sealed. When connections are required, Swagelok or Gyrolol-type fittings (dual-ferrule, swage-type fittings) should be used.

\subsection{Operation and Maintenance Issues}

Many of the LNG fuel stations surveyed (Midgett, 1996) have had significant O\&M problems caused by factors ranging from improper design to component failure to operator error. These early LNG fueling stations were frequently first- or second-generation systems and were generally fine- tuned by trial and error. Many of the problems hive been extensively reported in the professional and trade literature and have resulted in significant improvements by established LNG fuel station suppliers and also in the introduction of new systems.

\subsubsection{Design Decisions Determine Operation and Maintenance Costs}

Most problems associated with LNG fuel stations can be anticipated with careful engineering review. For example, new system designs or enhancements that may not have a well-established track record should be identified. Adequate attention to O\&M issues is also very important.

LNG stations and components available today have solved the problems that compromised the basic station operation. Today, station suppliers compete to provide the fuel station that is the easiest to operate, the most reliable, and the most cost effective to maintain.

The cost of operating and mainlaining an LNG station varies widely depending on the initial cost and forethought put into the origina station design. For example, some stations with flanges and threaded connections report having to tighten bolts periodically. Others report leaky connectors, accessibility issues, and bulky, hard-to-handle equipment. As a rule, with LNG stations, you get what you pay for. Investment in a slightly more expensive station can reduce $O \& M$ costs significantly.

For example, flanges are less expensive than welded fittings, but flanges leak. Fittings and connections should be checked every 2 weeks, or more frequently if warranted. Facilities with leaking connections are unsafe and difficult to operate. They also cause the $\mathrm{CH}_{4}$ sensors to alarm, which in turn trips the unit. For this reason, some stations have rerouted the $\mathrm{CH}_{4}$ sensor alarm signals when the pump is in operation, so instead of tripping, the sensors notify the operator. Using welded fittings makes it easier to maintain a leak-tight system, eliminating these types of problems, and significantly reducing costs.

Ergonomics play an important role in enhancing the O\&M of an LNG fueling station. If the equipment is hard to access or difficult to haridle, operators become frustrated, and mistakes can be made.

Counterbalanced fuel hose arms; or remote access for the control of certain valves should be considered in the design of the facility. Code; may require that shutdown and isolation valves be accessible from outside the secondary containment wall. 
From a design standpoint, operator training is very important. Operators need to understand the meaning of saturation, stratification, recondensation, and weathering, and this understanding can be gained most effectively with hands-on training. Additionally, protective equipment should be easy to use and comfortable; otherwise, it may not be used. Most companies specify a minimum of eye protection and leather gloves.

\subsubsection{Parts and Service Are Important}

At this time, LNG system components are not normal off-the-shelf items at a local parts house; they must be ordered from the manufacturer. Having spare parts available for key items could make the difference between being able to fuel your fleet or shutting down operations. Most parts are special order items and may not be available in an emergency. Having spare parts on hand improves reliability. Reputable station manufacturers and service companies supply parts lists, stock critical parts, and set up maintenance schedules.

As the use of LNG becomes more widespread, this issue will not be as important. There are very few reliability data from LNG refueling stations. The Los Angeles Department of Airports maintains spare parts in its program, and indicates this is a factor in its high bus availability.

\subsection{LNG Storage Tanks}

LNG refueling facilities should have sufficient on-site fuel storage to meet fleet needs. Single or multiple tanks located above ground are most commonly used. Underground tanks may also be used. Modular container tanks are the most flexible option for first-time LNG users. They are available in a standard size of about 4,500-gallon capacity each and can be installed quickly on either temporary or permanent foundations. Shop-built tanks, ranging in size from less than 2,000 to about 50,000 gallons in size, also can be installed relatively quickly. However, a 50,000-gallon tank is effectively the largest size tank that can be shop-built and shipped by rail.

If the LNG is delivered by tank truck, it is most economical for the facility to receive a full (rather than partial) load of 10,000 to 12,500 gallons. A tank that can hold 13,000 to 18,000 gallons is recommended. A 13,000-gallon tank would allow the facility to keep approximately 3,000 gallons on hand in reserve and still receive a full trailer load of fuel.

Railcars deliver about 30,000 gallons per load. An LNG station serviced by rail should have at least 40,000 -gallon storage capacity. Storage tanks required to receive shipments by barge or ship would be much larger and would be custom-designed and field-erected. A typical barge would typically deliver 1 million gallons or more and a tank ship 30 to 40 million gallons.

The major suppliers of shop-built LNG storage tanks are MVE, Cryenco, and Taylor Wharton Process Engineering. CBI is a major supplier of field-erected LNG storage tanks.

LNG station storage tanks are vacuum-jacketed, dewar-type pressure vessels. The inner vessel is fabricated from stainless steel, 9 percent nickel steel, or aluminum alloy. The outer tank (jacket casing) is usually carbon steel. The inner vessel is surrounded with insulation, either a super insulation wrap or a granular material such as Perlite. The space between the inner vessel and jacket is also evacuated to a very high vacuum, which is the primary source of insulation. Piping is usually stainless steel both inside and outside the tank. Valves must be either bronze or stainless steel. Tank design and construction must meet appropriate American Society of Mechanical Engineers (ASME) codes and various National Fire Protection Assocation (NFPA) 57 and 59A standards. 


\subsubsection{Above-Ground Tianks}

All the sites surveyed by Midgett used double-walled LNG storage tanks mounted above ground. These tanks are vacuum-jacketed presisure vessels ( 96 percent) insulated with either expanded perlite (44 percent) or multilayer insulation (44 percent). Perlite is a nontoxic volcanic glass rock, which has good insulating characteristics.

MLI for the LNG vehicle industry is normally composed of thin glass pads, or glass paper, separated by highly reflective layers of aluminum or mirrored mylar.

Fueling station storage vessels should be designed to have a very low heat leakage. The LNG industry uses an unusual unit of measuris to compare heat leaks expressed as percent per day boil-off of pure $\mathrm{CH}_{4}$ at constant pressure. The typical heat leak for a 20 million-gallon storage tank at atmospheric pressure may be 0.06 percent per day. Fleat leakage for an LNG station storage tank of 13,000 to 20,000 gallons should be less than 1 percent por day.

Figure 3-15 shows the percentage of stations that have storage capacities within various ranges. Storage capacity should consider the anount of fuel the facility is required to handle. A 1-week supply is a good rule of thumb. On smaller facilities, which are not expected to use much fuel, the capacity of the LNG delivery transport is the main consideration for storage capacity requirements. A typical truck trailer holds 10,000 to 12,500 gallons.

Figure 3-15. Total Station Storage Capacity

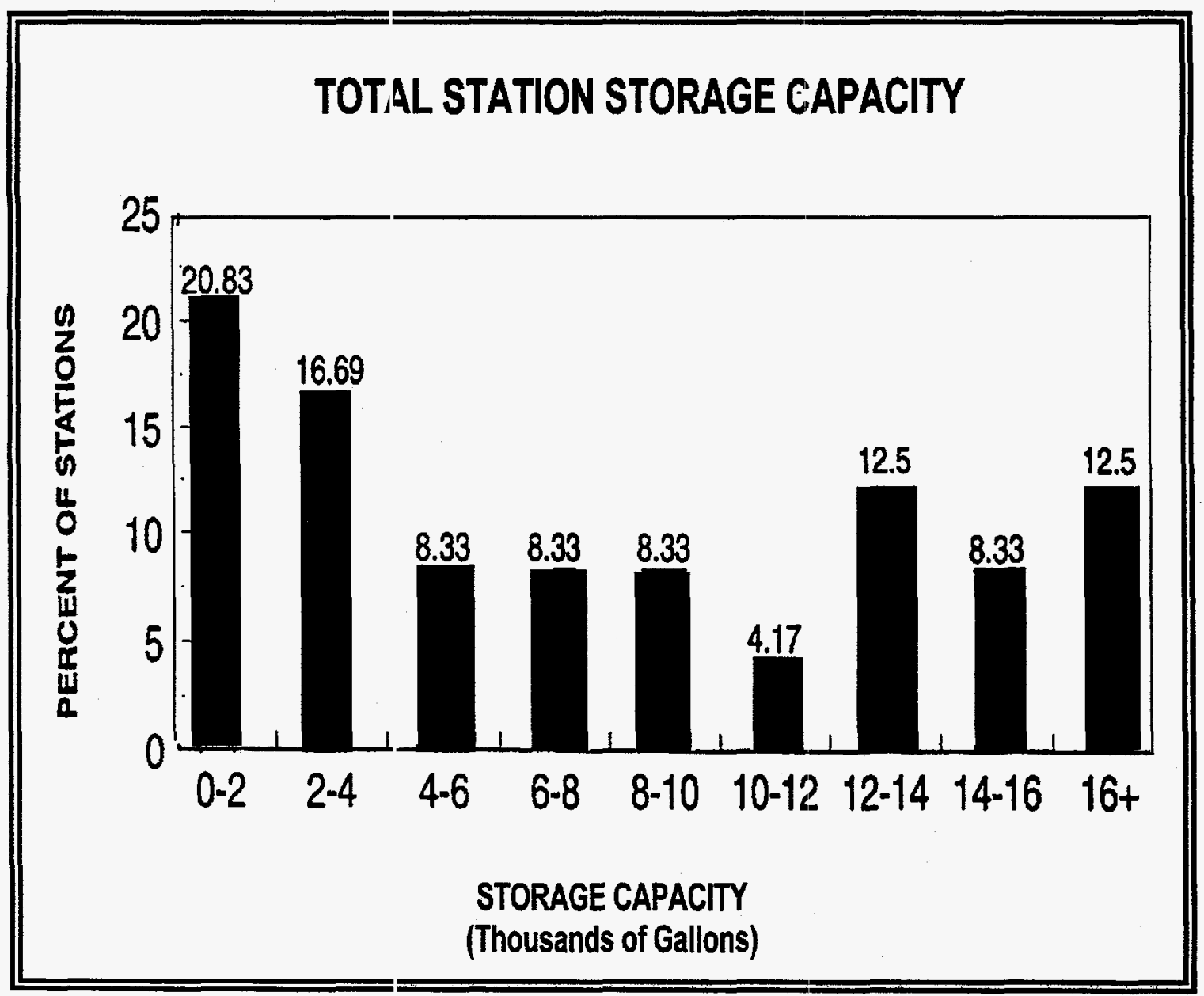


Figure 3-15 illustrates that many fueling stations have small tanks, i.e., less than 4,000 gallons, and a significant number have capacity to receive a full load from a typical LNG truck trailer. If a facility has less than 13,000 gallons of storage, coordinating LNG shipments could be a problem and the facility may have to take a partial load. Therefore, unless a facility is so small that a full transport would cause excessive losses resulting from boil-off, the storage tank should be large enough to receive a full shipment.

Station storage tanks are typically filled by pumps controlled by flow, pressure, or level. A vapor ullage (void space in the tank) of about 5 to 10 percent is desired after filling to allow the liquid to expand as it warms. If the tank is overfilled, liquid will fill the ullage space and expanding liquid will lift the relief valves and pass liquid out the vent lines. This is more of a problem with small LNG vehicle fuel tanks than with the large storage tanks. On large vertical tanks, liquid level measurement is fairly accurate because the hydrostatic head difference between the top and bottom of the liquid is large.

Small horizontal tanks, such as LNG vehicle fuel tanks, have very small hydrostatic heads and small ullage volumes, making conventional level measurement almost impossible. Smaller hydrostatic head differences in smaller volume tanks is one of the reasons most LNG level gauges on vehicles do not work well. Most companies have learned to gauge by trial and error when the LNG vehicle tanks are near full. Anker Gram \& Associates Ltd., Cryenco, and MVE have developed proprietary tank internals to prevent overfilling.

\subsubsection{Underground Tanks}

Underground tanks may soon become feasible for LNG fueling stations. Anker Gram, CVI, and PTL \& Associates, along with GRI, have been involved in a project to incorporate underground cryogenic storage into an LNG fuel station design. Baseload facilities do not place atmospheric LNG storage tanks on the ground without providing heaters to prevent ground freezing and frost heave. Frost heave occurs when the soil around a cold vessel freezes and expands, putting the vessel under stress. Anker Gram estimates the associated costs of heating the ground around an underground LNG fuel station tank would be minimal.

The metal outer shell of an LNG tank may provide a pathway for sufficient heat flow to prevent ground freezing around the tank. Tests currently under way indicate that a buried tank used in an LNG fueling station may not require ground heating.

Here are the advantages of underground tankage:

- Smaller sites can be used

- Shorter setback requirements may allow more compact site development

- Improved containment of product in the event of spills

- Aboveground spill containment systems are not needed

- Reduced risk of vandalism

- Reduced risk of damage from vehicles

- Greater protection for the tank in the event of fire

- More compact design will reduce system heat leakage

- Station can look like a gasoline or diesel fueling station.

Underground LNG storage will not need the groundwater monitoring and leak detection or the regulatory compliance systems required for gasoline and diesel stations, because, unlike other liquid fuels, LNG will not contaminate groundwater or soil. If a leak were to occur, released LNG would vaporize and migrate upward rather than down into groundwater. LNG tanks are constructed of stainless steel with double-wall 
containment and are designed as pressure vessels. LNG tanks are inherently safer than conventional mild steel, composite, or fiberglass underground gasoline or diesel tanks.

Installation of an underground :.NG tank, however, would require consideration of additional features not included in aboveground systerns. Corrosion protection through surface treatment and/or cathodic protection should be evaluated for the soil conditions found on the site. Also, either a submerged in-tank pump, an underground pump house, or a negative suction head pump in the dispenser above must be used to lift the LNG out of the tank. Anker Gram has been developing a negative suction head pump for LNG use.

Large LNG facilities use submerged in-tank pumps accessible from the top of the tank, but these pumps cannot be used easily with the vacuum-jacketed, multilayer, insulated tanks used in station designs. MVE has been considering a tank design that will allow an installed accessible submerged pump.

The first underground LNG storage tank was installed by CVI in Washington, Pennsylvania, in 1997.

\subsection{LNG Intermodal Container Tanks (TVAC ${ }^{\text {TM }}$ )}

JBK is using an LNG intermodil container to bring LNG fuels to locations where it is not feasible to construct permanent stations. The TVAC ${ }^{\mathrm{TM}}$, manufactured by Cryenco, was the first intermodal cryogenic container tank. The ' IVAC $^{\mathrm{TM}}$ has a capacity of 4,450 gallons of LNG. TVAC ${ }^{\mathrm{TM}} \mathrm{s}$ are used in stand-alone applications to ship LNG fuels by truck, rail, barge, or ship. The TVAC ${ }^{\mathrm{TM}} \mathrm{s}$ also serve as fuel storage tanks for temporary anc: permanent LNG stations, LNG-to-liquefied compressed natural gas (LCNG) stations, and the mobile LNG fuel station known as ERVING (Equipment Refueling Vehicle Natural Gas). JBK's standard LNG fuel station is designed for initial use with one or two TVAC ${ }^{\text {TM }}$ s. Additional TVAC ${ }^{\mathrm{TM}} \mathrm{S}$ can be added to increase storage capacity when justified by fuel demand. In addition, the TVAC ${ }^{\mathrm{TM}} \mathrm{S}$ can be replaced with larger, shop-fabricated, or field-erected tanks when customer fuel demand makes the use of the fixed tanks more cost effective than the TVAC.

\subsection{LNG and LNG-to-L.CNG Refueling Stations}

Several manufacturers provide integrated LNG and LNG-to-LCNG fueling stations. Integrated stations incorporate all the components needed to operate a fully functional fuel station into shop-fabricated, manufactured modules that are fully warranted to meet performance specifications. Major suppliers are Cryenco, HydraRig/Drexel, MVE, and CVI.

Because the station component:; are packaged in modules, fuel stations can be constructed to supply LNG alone, LCNG alone, or both LNG and LCNG. In most situations, the most cost-effective approach to developing a network of stations would be to select locations where both LNG and LCNG can be dispensed to light-, medium- and heavy-duty vehicles. However, when sufficient fuel load is committed, either stand-alone LNG or LCNG stations can be cost effective.

\subsubsection{LNG-to-LCNG Stations}

LNG-to-LCNG systems have bəcome one of the fastest-growing segments of the LNG market for natural gas vehicles, especially centrally fueled fleets that consume large quantities of fuel. These systems pump LNG as a liquid to the desired CNG pressure and then vaporize the liquid into high-pressure gas. Initially, LCNG systems were sized to supply average flows of about $250 \mathrm{scfm}$. This size LCNG system costs about the same to install as a comparable compressor-based station. However, experience has demonstrated that larger LNG-10-LCNG stations are significantly less expensive to build and operate. 
Once the LNG production and delivery infrastructure is in place, increased throughput can be achieved for very modest incremental investments. For example, the capital investment required to build a large LCNG station is one-fourth to one-third that of an equivalent-size CNG compression facility. Virginia Natural Gas (Wrocklage, 1996) reports that a LNG-to-LCNG station with fill capacity of 250 scfm cost $\$ 393,000$, or $\$ 1,572 / \mathrm{scfm}$. However, a station with four times the capacity, $1,000 \mathrm{scfm}$, costs only $\$ 396,000$, or $\$ 396 / \mathrm{scfm}$.

Experience has also demonstrated that operating costs of an LNG-to-LCNG station can be much lower than those of a compressor-based station. Approximately 90 percent less work is required to pump a liquid to high pressure and then vaporize it at high pressure than to directly compress low-pressure gas to high pressure. Thus, energy costs for operating an LCNG station are lower. For example, Virginia Natural Gas reported the following monthly fuel and operating costs for a small station that supports 11 vehicles per day:

$\begin{array}{lr}\text { Utilities } & \$ 102 \\ \text { Fuel } & \$ 920 \\ \text { Maintenance } & \$ 800 \\ \text { Transportation } & \$ 600 \\ \text { Total } & \$ 2,422\end{array}$

LCNG provides consistently high fuel quality, as water and oil are completely eliminated and heavy hydrocarbons can be reduced to a minimum. In addition, LCNG is provided as a cold, high-pressure gas. Thus, LCNG has the potential to overcome the heat of compression problems associated with fast-fill CNG stations using compressors. There are no interruptions during peak usage periods and cylinders can be quickly filled to full, rated capacity.

The typical LCNG fuel station consists of several modules, including LNG storage, CNG storage, LCNG pump, vaporizer, odorizer, and dispenser. Controls are incorporated into each module as shown in Figure 3-16. An LCNG system can be designed to provide LCNG to a vehicle at 2400,3000 , or 3600 psig, as needed. The LCNG customer operates the dispenser in a similar manner as current CNG dispensers. The customer has a visible display indicating the price of the LCNG, the cost of the transaction, and the total amount of fuel dispensed. Modern LCNG stations include the following key components:

LNG Storage Module- LNG is stored on site in an aboveground or below ground cryogenic storage tank, as described in Section 3.10.

LNG Pump Module-The LNG pump module is the heart of the station. This pump is used to transfer LNG from the delivery truck to storage and from storage to vehicles. The pump itself can be mounted external to the storage tank or submerged (see Section 3.2 for more information on LNG pump configurations). Continually submerged pumps require no cool-down period and are the most efficient and convenient design. Unfortunately, submerged pumps may also be the most expensive configuration.

LCNG Pump Module-The LCNG pump module uses a high-pressure piston pump to transfer LNG from the LNG tank to the high-pressure vaporizer. Output pressures are typically about 5,000 psig and can go higher.

Piping - The design of the refueling station is per ANSI B31.3 for the transfer of LNG. The piping on the suction side of the transfer pump should include a remotely operated shutoff valve. The valve should fail in the closed position in the event of leak detection, loss of actuation pressure, or electrical power. These provisions prevent discharge of LNG in the event of system failure or accident. All connections should be threaded, flanged with full bolting, or, preferably, made with full-penetration welds. 
Vaporizer Module-The LNG vaporizer and piping must be designed for a working pressure greater than the maximum discharge pressure of the LCNG pump. The discharge valve of each vaporizer, piping, components, and relief valves installed upstream of the discharge valve must be suitable for operation at cryogenic temperatures. The vaporizer is provided with instrumentation to monitor outlet temperature. A low-temperature switch should be installed on the vaporizer discharge to prevent LNG from entering CNG cylinders and other equip ment not designed for LNG temperatures. The vaporizer should have a safety relief valve sized for not less than 120 percent of vaporizer rated flow capacity. After vaporization, the gas is odorized and routed 10 the priority panel/domeload where it is sent either to the LCNG storage cascade or to the dispenser, as needed.

Odorizer-LCNG must be odırized before use or discharge into LCNG storage containers. The odorant gives LCNG a distinctive sulfur or "rotten egg" smell.

Figure 3-16. Typical LNG-to-LCNG Fuel Station Modules

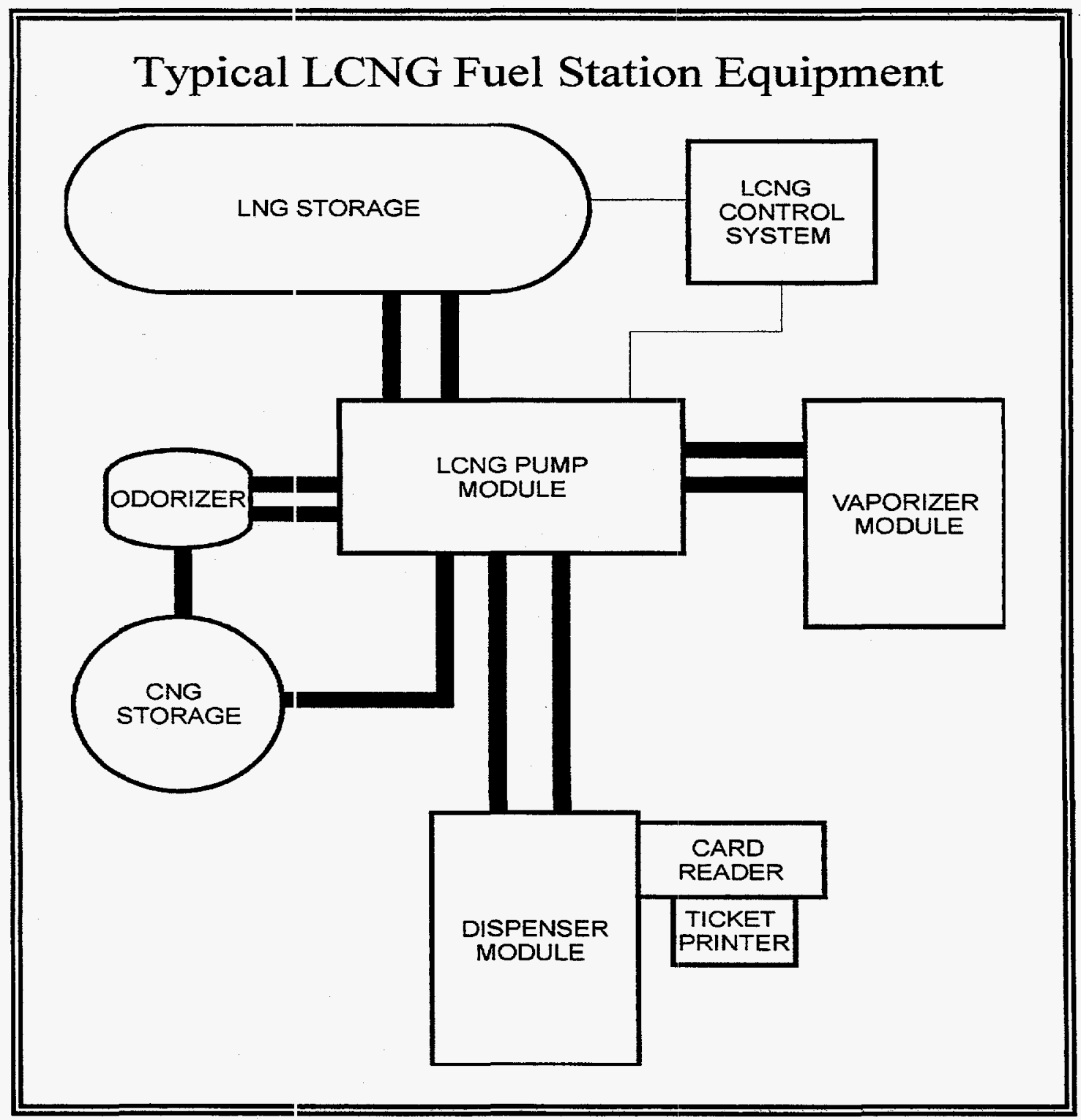


LCNG Dispenser-A standard CNG dispenser with CNG nozzles and receptacles designed for the desired pressure can be used to dispense LCNG into vehicles. The nozzle should be designed to prevent accidental discharge of fuel and will only allow flow when it is connected to the vehicle receptacle.

\subsubsection{LNG Fuel Station with Conditioning}

A typical LNG station consists of an assembly of four modules. They are the storage module, LNG pump module, dispenser module, and vaporizer module. An option to the system will be a ticket printer, as shown in Figure 3-17. The controls are included as part of the individual modules.

Figure 3-17. Typical LNG Fuel Station Modules

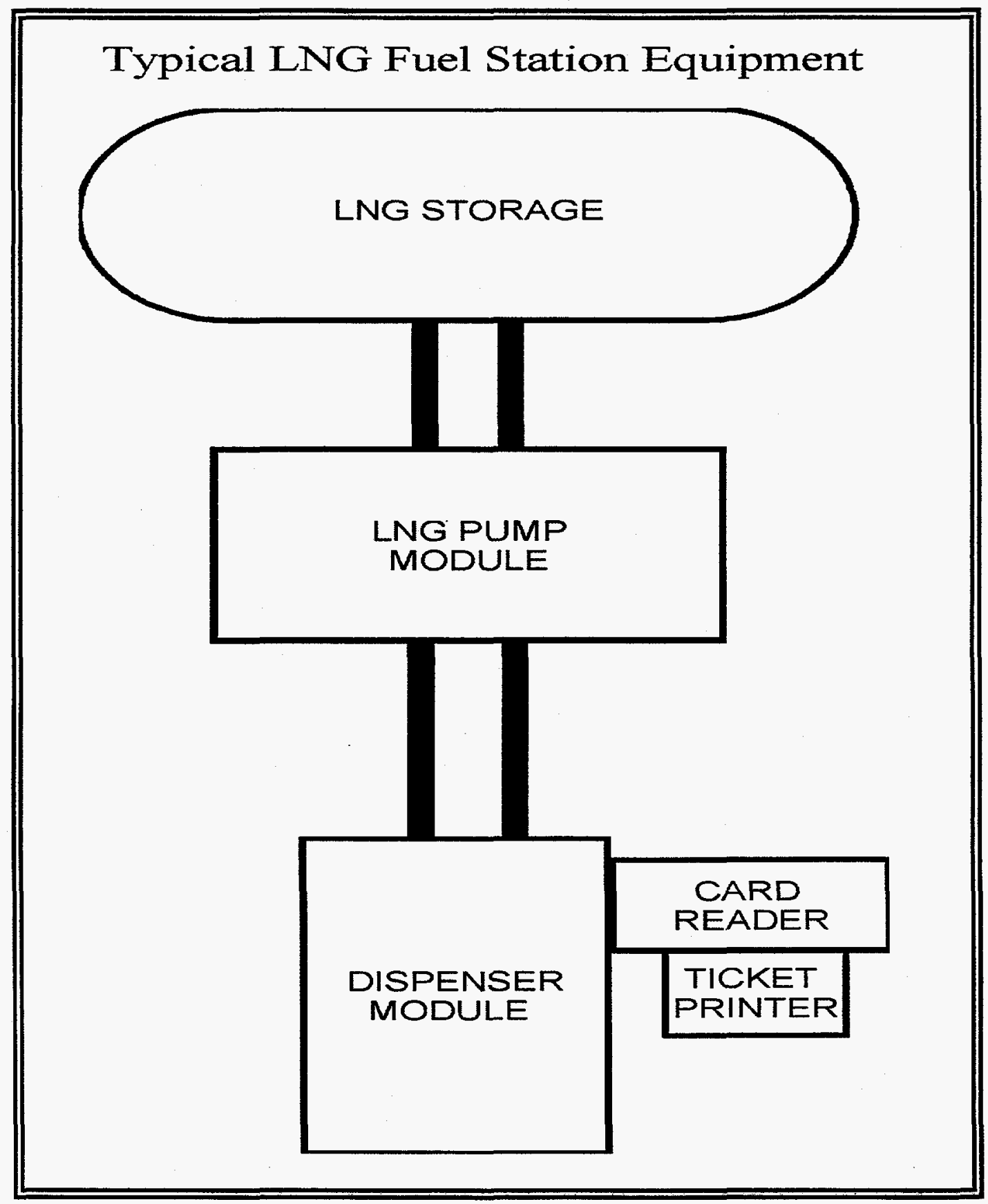


The LNG system dispenses LNG to a vehicle at rates up to $50 \mathrm{gpm}$. Currently, medium- and heavy-duty LNG-powered vehicles require the refueling station to supply LNG at pressures between 80 and 130 psig.

Many vehicle fuel systems require that saturated or "conditioned" LNG be supplied by the station at these pressures. There are three ways to design a station to dispense conditioned LNG. First, the entire station storage tank can be managed tc maintain conditions required to dispense saturated fuel to vehicles. Second, an intermediate storage: tank can be used to manage a smaller quantity of LNG at saturated conditions. Third, LNG can be conditioned as it is transferred into the vehicle fuel tank. Although the first two options will work for demonstration projects with a few vehicles, heating LNG in the storage tank is very inefficient and has several drawbacks. Neither practice is desirable for a commercial LNG fuel station.

Therefore, station manufactures's now supply modular stations that condition the LNG by adding heat as the LNG is dispensed into the vehicle fuel tank. This innovation allows the fuel station operator to maintain low-pressure, sub-cooled LNG in the main storage tank. Kwik Konditioner is the trade name of the system offered by Cryenco. Condition on the Fly is the trade name used by Drexel/HydraRig.

$\underline{\text { Kwik }}$ Konditioner fits downstream of the current LNG pump module. A portion of the LNG flow is diverted to a heat exchanger and warmed during transfer. The warmed LNG is then mixed with the LNG flowing to the vehicle fuel tank. The amount of heat added is determined by the downstream pressuretemperature saturation curve and is controlled by the station control system.

The LNG dispenser module measures fuel flow and controls the vapor recovery system. Vapor recovery may be needed to reduce high pressures in the vehicle fuel tank prior to fueling and to recover excess boil-off during fueling. Either single-hose or two-hose systems are used. Vapor from the vehicle tank is mixed with recirculated LNG, condensed, and returned to the storage tank. The Micro motion coriolis flow meter is used by most stations to measure the LNG flows to the vehicle with an accuracy of 0.5 to 1 percent.

The LNG customer operates the dispenser like a diesel dispenser. A cardlock system is used to gain system access and record the transaction. The dispenser readout is activated when the diverter valve is turned to fill the vehicle. The customer can monitor a visible display indicating the price of the LNG, the transaction cost, and the total quantity of LNG dispensed. A printer can provide a record of the transaction.

\subsection{Mobile Fuel Station-“ERVING”}

The LNG-ERVING vehicle is a. mobile refueling station for LNG-powered vehicles. It is assembled by JBK and uses fuel station components provided by Cryenco (see Figure 3-18). Similar equipment is offered by other manufacturers, for example, MVE's QRS mobile refueling station. When dispatched to a fleet, the ERVING has the capability to provide conditioned fuel, saturated to a level that will meet the demand of the individual fleet ciperators.

LNG-ERVING consists of a trailer-mounted TVAC, skid-mounted LNG transfer pump and dispenser, and the Kwik Konditioning unil.: The unit simply needs to be connected to 220 -volt electrical service and it is ready to dispense fuel. The: LNG-ERVING contains 4,450 gallons of LNG in the TVAC.

The LNG/LCNG ERVING mobile fueling unit has the capability to fuel CNG vehicles in addition to LNG vehicles. LCNG fueling is accomplished with a second skid-mounted evaporator and dispenser. LNG is fed from the skid transfer pump to a high-pressure pump. The LNG is pressurized to 4,300 psig, vaporized, odorized, and disper sed directly into the vehicle. 
Figure 3-18. Mobile Fuel Stations-the Jack B. Kelley ERVING

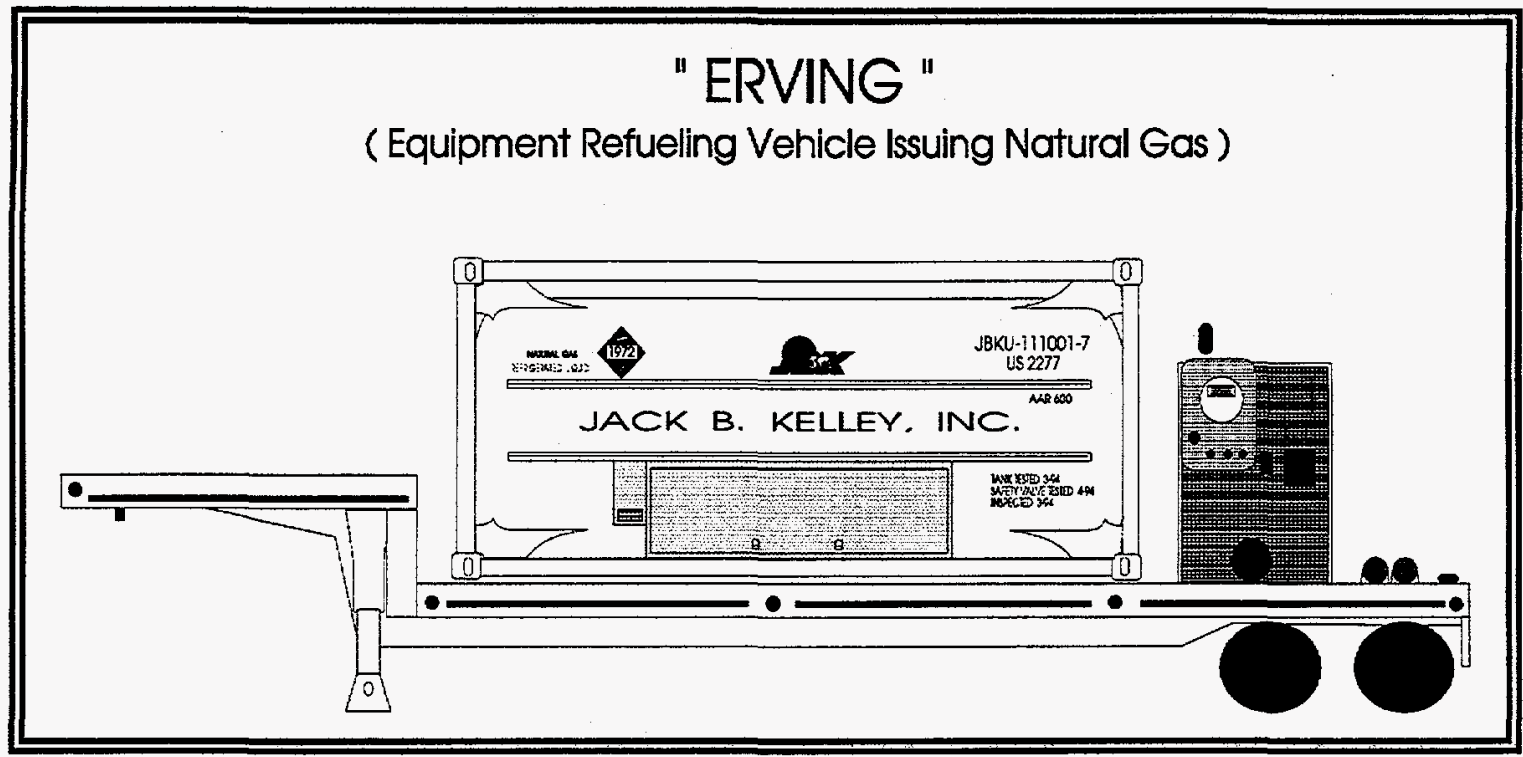

JBK provided two LNG/LCNG ERVING units to the Atlanta Olympic Games to support the operation of natural gas-powered buses throughout the $21 / 2$-month event. ERVING units are also in operation at the following facilities during permanent station construction: DDC, Detroit, Michigan; Gary Public Transportation Corp., Gary, Indiana; JBK, Amarillo, Texas; and JBK, San Manuel, Arizona.

\subsection{LNG Station Siting and Code Compliance}

Siting an LNG station requires complete disclosure of many details of the proposed facility to local building code and fire safety officials. Because most public officials have had no experience with flammable, cryogenic liquids, the site developer should anticipate detailed and, perhaps, exhaustive requests for information, including detailed drawings that show the site layout, distance to adjacent structures, traffic flow, and other safety-related information. In addition, plans and specifications for the storage tank and station equipment may be requested.

If buildings are located near the proposed site, local officials may also request hazard and safety analysis for the site. This could require estimates of downwind $L N G$ vapor dispersion hazards in the event of an LNG spill or release. A fire safety analysis could also be requested that describes potential effects of thermal radiation from $L N G$ pool fires. If more detailed hazard analysis is required than possible with the empirical methods specified in NFPA 57 and 59A, two simple hazard assessment computer models are available from GRI.

The Dense Gas Dispersion (DEGADIS) model predicts LNG vapor dispersion distances in the event of an accidental spill. The model can account for evaporating pools of LNG and high-velocity jet releases from pressurized storage tanks. The DEGADIS provides a more accurate prediction of vapor dispersion than conservative methods based on simple Gaussian dispersion by accounting for vapor dispersion physics. The model can help resolve misunderstandings or disputes with adjacent property owners or public officials over the location or layout of a proposed station.

The LNGFIRE model estimates radiation from LNG pool fires with better accuracy and validity than empirical methods. 
The model calculates fire radia ion hazard distances surrounding LNG storage facilities, employing methods and approaches based on publicly available data and empirical descriptions of LNG pool fires.

The following two pages are ccide compliance and site checklist summaries of all the information normally required to site and pirmit an LNG fuel station. 


\section{Code Compliance - Site Check List}

\section{LOCATION}

Station must not be directly below power knes over 600 volts.

Located in a place to minimize damage, bumper structure to protect from cars, if within $8^{\text {* }}$ of exhaust must be shiekded against direct heat.

\section{FOUNDATION}

Foundations and exposed supports shall be made of materials with a melting point of 2,000 degrees $F$ or higher.

Foundation and supports must be fire resistant for no less than two hours.

Components which carry or otherwise are exposed to cryogenic temperatures shall be installed or operated so that freezing and movement of the ground and ground water do not place stresses on components.

Concrete shall be as specified by ACI $304 \mathrm{R}$ and $\mathrm{ACl}$ 318. Tests for compressive strength and for the coefficient of contraction of the concrete at the projected low temperatures will be carried out unless prior test data on these properties are available.

Aggregate shall be a specified by ASTM C33-Dense and physically and chemically sound to provide a high strength and durable concrete.

Preumatic mortar shall be specified in ACI 506R

Steel for reinforcing concrete shall be a specified in ASTM A82, ASTM A185 and ASTM A615.

\section{SEISMIC DESIGN}

Non-stuctural metalic bariers incorporated in and functioning compositely with pre-stressed concrete and serving primarily as moistures bariers for intemally insulated tanks, or come in direct contact with LNG during noma operations shall be of metal classified for either "primary component" or "secondary component."

Seismic investigation performed to determine geologic and seismic characteristics of the LNG facility and the surrounding region.

Detect and identification surface faulting as appropriate, and determine potential for such faulting.

All equipment and components which are buried, mounded or otherwise considered "In the ground" shall be protected to minimize corrosion.

Investigate the characteristic of the materials underlying the site as they relate to the vibratory motion from bedrock through the soil if the facility is not grounded on rock as well as the potential for soil liquefaction and degradation.

Determine vertical and horizontal response spectra correlating the acceleration, velocity and displacement with the seismic characteristics of the soil and damping factors of the structural systems in the range of anticipated natural periods of vibration.

Determine the Safe Shutdown Earthquake (SSE occurring 10,000 years) and Operating Basis Earthquake (OBE occurring 475 years), container should be designed for OBE and a stress limit check made for SSE.

The LNG container should be designed to remain operable during and after OBE or SSE

Determine wind and snow loaded as outlined in ASCE 7, Building Codes

Prior to start of design and construction of foundation, a subsurface investigation shall be conducted by a qualified soils engineer to determine the stratigraphy and physical properties of the soits underfying the site.

Electrical grounding and bonding shall be provided in accordance with NFPA 77 and NFPA 70.

nfpa.vsd:page-1 
Equipment must be at least $10 \mathrm{ft}$ from any building opening.

Building exclusively for LNG fueling facility shall bo constructed of non combustibles, and doors and windows located for easy egress in case of emergenc'.

2,001-15,000 gal must be at leas $25 \mathrm{ft}$ from important buildings or adjoining property lines, $5 \mathrm{ft}$ between tanks.

15,000-30,000 gal must be at least $50 \mathrm{ft}$ from important buildings or adjoining property lines, $5 \mathrm{ft}$ between tanks.

Point of transfer shall not be less than $25 \mathrm{ft}$ from important buildings or adjoining property.

3 ft clear space shall be provided for access to all valves and fitings on multiple groups of containers.

2,000-and up gal capacity, must have impoundment area, (either liquid, graded, or drained) to prevent liquid flow to property, important builcings, equipment, reaching sewers, drains, waterways, or any closed top channel.

Any ambient vaporizer or heated vaporizer installed with $50 \mathrm{ft}$ of equipment shall have automatic shutoff valve in liquid ine at least to ft from vapoizer and should close the line of pressure.

Vaporizers and primary heat source shoukd be located at least $50 \mathrm{ft}$ from source of ignition.

\section{IMPOUNDMENT}

The LNG facility container impour idment shall be able to contain no less than the combined volume of the containers it serves.

Flammable liquid storage tanks shall not be located within an LNG impoundment area.

Provisions made to clear the rain ind water from the impounding area, pumps cut off when exposed to LNG temp. Piping valves and fittings suitable for con inuos exposure to LNG, gravity drainage must prevent LNG escape.

Impounding system shall be designed to withstand the SSE while empty and the OBE while holding the volume specified.

TANKS

Must be vented to a safe point of discharge. Vent stacks protected from foreign material. Must have provisions for drainage.

Where LNG containers stored in a rea that are subject to flooding, container secured in manner to prevent flotation, and release of LNG.

\section{SAFETY}

If night time fueling, must have pe manent adequate lighting at points of transfer and operation.

Lightning protection shall NOT be :equired on LNG storage container's.

Must have suitable means to protect a facifity from combustible or hazardous liquids which can encroach on area.

Provision for securing all equipme tt from tampering, must have security fence or enclosure if none in place. Must be 2 exits if more than $1250 \mathrm{f}^{2}$

ntpavertpacos 2 


\subsection{LNG Vehicles}

It is technically feasible to convert any type of vehicle to operate satisfactorily on LNG. However, the initial cost of the LNG fuel tank and the lack of infrastructure has convinced most LNG developers that the LNG industry should focus on medium- and heavy-duty fleet vehicles.

LNG vehicle economics are strongly dependent on the types of vehicles, fuel consumption, and the cost and availability of LNG supplies. The technology is available for LNG fueling of vehicles ranging from privately owned or fleet automobiles to large, line-haul tractor trailer trucks.

The most important factor affecting LNG economics is the ratio of initial capital cost to operating cost. Fuel is the major operating cost for most medium- and heavy-duty vehicles. LNG is favored when the higher initial equipment cost can be amortized by the fuel cost savings. Vehicle use schedules and refueling procedures are also important; heavy vehicle usage (meaning high fuel consumption) and regular refueling at highly utilized fleet facilities are characteristics favoring LNG economics. Other factors such as the cost of maintenance facility modifications required to safely service LNG vehicles can also affect the economic trade-off.

Emissions standards are different for each class of vehicles, and this can affect LNG vehicle economics. The CAAA set a variety of emissions standards for automobiles, trucks, and buses. CARB recently passed very strict emissions regulations that phase in for vehicles sold in California starting in 1994 and favor LEVs operating on alternative fuels. In addition to these emissions standards, air quality-driven rules and regulations instituted by local governments may create opportunities for LNG vehicles.

For example, emissions reduction credit trading programs (which are being implemented in California and are being considered elsewhere) may provide incentives for conversion to NGVs that are certified to meet LEV emissions standards. These emissions standards and regulations, and other relevant legislative programs such as ISTEA and EPAct, have effects on LNG vehicle economics.

\subsection{Fleet LNG Vehicles}

GRI divided the fleet market into the following six categories (Powar, 1994):

- Buses

- Line-haul trucks

- Heavy- and medium-duty pickup and delivery (P\&D) trucks

- Light-duty pickup and delivery trucks and vans

- Fleet automobiles

- Off-highway vehicles and equipment.

Figure 4-1 illustrates some of the types of vehicles in each of these categories. Some vehicles are shown in two categories because they are made in both heavy- and medium-duty and light-duty versions. These vehicle categories are discussed below and those with the best potential for superior LNG vehicle economics are identified.

\subsubsection{Transit Buses, Shuttles, Motor Coaches, and School Buses}

Operating experience has demonstrated that buses are excellent candidates for conversion to LNG. The bus industry is very competitive and must be very responsive to customer needs. In addition, the transit bus industry was singled out by federal legislation to produce vehicles that would produce much lower 
Figure 4-1. Categories of Fleet Vehicles

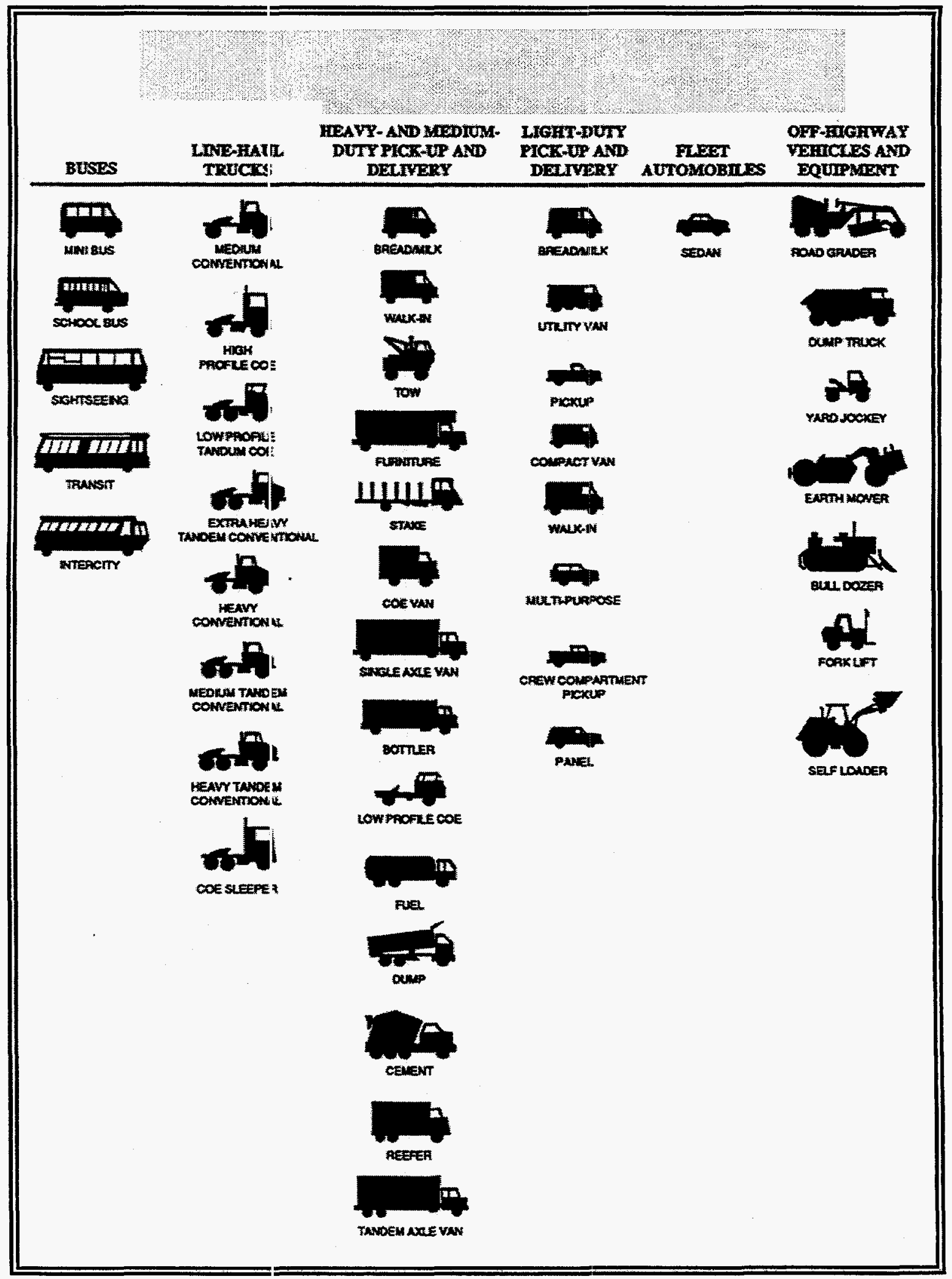


tailpipe emission of fine particulates and operate exclusively on cleaner, alternative fuels. Because much of the funding for transit bus purchases is derived from federal highway taxes, the industry has been responsive to these laws and requirements.

Transit, Shuttle, and School Buses-Transit buses are very attractive candidates for LNG fueling for many reasons. As discussed in Section 1, urban transit buses are subject to more strict federal emissions and fuel quality standards than other heavy-duty vehicles. In fact, the Clean Air Act requires transit buses to comply with the tailpipe particulate emission standard of $0.05 \mathrm{~g} / \mathrm{hhp} / \mathrm{h}$ for their full useful life. If EPA testing determines that the particulate standard is not being satisfied, the EPA can require that all new and rebuilt urban buses "shall be capable of operating, and shall be exclusively operated, on low-polluting fuels."

Natural gas fuels offer transit operators the opportunity to comply with this stringent performance standard with minimal regulatory agency monitoring, testing, and compliance paperwork. In addition, transit operators report that ridership improves when buses do not emit black smoke. Customers notice that natural gas-powered transit buses are cleaner and quieter than diesel buses.

Transit buses are driven daily and consume large quantities of fuel, 40 to 100 gallons per day per bus. They are usually refueled at night at central maintenance facilities operated by well-trained maintenance personnel. LNG fuel stations are very cost effective when compared to compressor-based stations.

Although transit authorities are local or regional entities, about 80 percent of the bus purchase cost is subsidized by the Federal Transit Administration. Another 10 percent may also be paid by state agencies. The remaining 10 percent is paid by the transit authority or local agencies. Facility improvement costs are also subsidized. Fuel costs, however, are not subsidized and represent one of the major operating costs. Because transit authorities are exempt from the federal excise tax on motor fuels, the economics of conversion were adversely affected by the FET imposed on LNG fuels until October 1997.

Bus manufacturers offer many natural gas models to transit customers for shuttle operations as well as revenue passenger use. To date, most transit bus authorities have used CNG storage; however, transit authorities in Houston and El Paso, as well as the Los Angeles Airport Parking Shuttle have had good operating experience with LNG, especially on longer routes that may exceed the range of a CNG storage system. For example, Sun Metro in El Paso obtains LNG at a cost of $\$ 0.379$ per LNG gallon or about $\$ 0.57$ per diesel equivalent gallon. The cost of diesel fuel is $\$ 1.03$ per gallon, a saving of about $\$ 0.47$ per gallon for the 3-year term of the contract.

Transit authorities can use LNG to establish fuel stations at satellite depots to service long-haul routes. LNG stations also can be used to produce LCNG wherever it is needed. The Atlantic Olympic Committee used mobile LNG and LCNG stations to support bus operations for the 1996 Summer Games.

Transit bus manufacturers offering natural gas equipment include:

- Orion Bus Industries, Ltd.

- Gillig Corporation

- Transliner: NeoPlan USA

- New Flyer Industries Ltd.

- NOVA Bus. 
Shuttle bus manufacturers offering natural gas equipment include:

- El Dorado National Compiany

- Blue Bird

- Champion Motor Coach

- Goshen Coach

- Metrotrans Corporation

- North American Transit

- Specialty Vehicles, Inc.

School buses are also candidatis for LNG and LCNG fuels. Hundreds of school buses operate on CNG and serve school districts throughout the nation. Vehicle performance and safety have been excellent. Many school boards, however, have not converted to natural gas because of the high cost or unavailability of fueling infrastructure. Scho ll bus depots that are not served by local utility pipelines or that operate long-haul buses are excellent candidates for conversion to LNG and LCNG fuels.

School bus manufacturers offering natural gas equipment include the following:

- Blue Bird

- Carpenter

- Navistar International

- Thomas Built Buses

- Matthews

- Spartan Motors.

Motor Coaches-Motor Coac nes consume large quantities of fuel. However, coaches may frequently operate in inter-city routes and thus may require a well-established network of fueling stations before conversion to LNG would be fisasible. Nevertheless, coaches are strong candidates for LNG conversion when routes are well defined and fueling infrastructure can be developed in the required locations.

For example, the Idaho National Engineering Laboratory (INEL) employees more than 6,000 people in a 900-square-mile nuclear test facility located in the Idaho desert. INEL operates a fleet of more than 140 motor coaches, more than 700 light-duty vehicles, and more than 900 heavy trucks and construction equipment to transport people and equipment throughout the facility. INEL operated a fleet of five LNG motor coaches and more than 40 LNG trucks in 1996. These MCI motor coaches had a range of 450 miles using DDC engines and CVI tanks.

Airport limousine service and sightseeing are two motor coach applications that could be converted to LNG in many major cities. These coaches travel fixed routes and are centrally maintained. They frequently operate in large urben regions that have air quality compliance problems. As an added benefit, the high-density LNG storage systems do not reduce the baggage or cargo capacity of the coach.

\subsubsection{Line-Haul Trucks}

Line-haul trucks are excellent candidates for conversion to LNG. They typically use Class 7 and 8 tractors equipped with high-ho!sepower diesel engines capable of hauling heavy loads long distances at high speeds. Line-haul trucks can easily carry sufficient LNG fuel to travel up to 500 miles per trip and typically consume 50 to 200 gallons of fuel per day.

Many line-haul trucks are owned by retail companies who use them to distribute products from regional terminals to retail stores or cus omer sites. National companies, such as Wal-Mart, Home Depot, and 
United Parcel Service, are concerned about their corporate image and often use environmental marketing strategies. They are using LNG in selected locations. These companies, plus regional businesses, such as grocery stores and food distributors, are strong candidates for LNG conversion.

Fuel cost is a significant factor in line-haul truck economics. Many line-haul trucks operate terminal-toterminal. These fleets could be converted to operate on LNG simply by installing LNG stations at each terminal. Many line-haul trucks need to refuel on the road in addition to central terminal fueling. For this reason, LNG refueling stations must be located at reasonable intervals along major truck routes to provide truckers with the confidence that LNG fuel will be available when needed.

The proposed Southwest ICTC is intended to sponsor development of LNG fueling infrastructure that will support LNG-fueled line-haul interstate trucking. Similar corridors could be developed along major interstate highways in all regions of the nation.

Manufacturers offering LNG-powered line-haul trucks include:

- Freightliner Corporation

- Kenworth Trucking Company

- Freightliner Custom Chassis Corporation

- Navistar International Transportation

- Peterbilt

- Mack Trucks, Inc.

- Volvo GM Heavy Duty Trucks.

These vehicles are now available with the Cummins L10-300G engine in a variety of chassis configurations. For example, Peterbilt offers an LNG low-cab-forward Model 320G with a Cummins L10-300G dedicated natural gas engine and a 135-gallon LNG fuel tank. Kenworth also offers a tractor (T800) with the Cummins L10-300G engine that is used in revenue service. DDC and Caterpillar natural gas engines are also available for line-haul trucks.

\subsubsection{Heavy- and Medium-Duty P\&D Trucks}

As illustrated in Figure 4-1, P\&D service includes many types of trucks that weigh more than 8,500 lb gross vehicle weight. Medium- duty and heavy-duty P\&D trucks have several characteristics that make them ideal candidates for conversion to $\mathrm{LNG}$ :

- Each truck typically consumes 50 to 150 gallons of fuel per day and must comply with federal emissions regulations for heavy trucks.

- Trucks return to a central terminal each day for fuel and maintenance.

- Many fleets prefer to maintain on-site fuel facilities and trained service personnel.

- Natural gas engines derived from popular diesel or gasoline models are readily available.

Many P\&D trucks are also owned by retailers that are concerned about their corporate image. Fleets owned by food distributors, grocery stores, garbage haulers, department stores, utilities, and delivery services are strong candidates for conversion to LNG.

Many manufacturers offer Class 2 through Class 7 trucks to serve the heavy- and medium-duty P\&D market, including: 
- Freightliner Corporation

- Kenworth Trucking Compsiny

- Freightliner Custom Chass s Corporation

- Navistar International Transportation

- Peterbilt

- Mack Trucks, Inc.

- Crane Carrier Corporation

- Volvo GM Heavy Truck Cisrporation

- Chevrolet

- Ford

- Hino

- GMC Truck

- Isuzu

- Mitsubishi

- Fuso

- UD Trucks.

\subsubsection{Light-Duty P\&D Trucks and Vans}

Light-duty P\&D trucks and vans are manufactured to comply with light-duty federal emission standards. As Figure 4-1 shows, this category also includes service vans. Many, but not all, fleet vehicles in this category refuel at a central terminal. Many light-duty $P \& D$ vehicles fuel at card-lock stations or at truck stops. These vehicles typically consume 10 to 50 gallons of fuel per day.

Most vehicles in this category, especially service trucks and vans operated by energy service companies, are excellent candidates for natural gas fuels. Vehicles used in applications that consume less than 15 to 20 gallons of fuel per day are excellent candidates for CNG fuel storage. Vehicles that consume more than 15 to 20 gallons per day are candidates for LNG fuel storage.

Perhaps the most cost-effective means of supplying natural gas fuels to P\&D trucks and vans is at central fueling or retail card-lock stations that offer both LNG and LCNG. The LNG can be used by heavy-duty trucks, the LCNG by LDVs. In addition, LNG makes it possible to supply natural gas fuels at remote locations where pipeline gas is not available. LNG and LCNG stations also provide a consistently highquality fuel to fleet operators.

In response to the federal fleet conversion mandates and orders from the natural gas utility industry, the three major domestic producers of light-duty trucks and vans have been offering a variety of OEM NGVs since 1992, all with CNG storage systems.

A brief summary of the history and status of LDVs offered by Ford, General Motors, and Chrysler follows.

Ford-Ford offers both the F-Series pickup truck and the E-Series Econoline van in dedicated and bi-fuel configurations through the Qualified Vehicle Modifiers (QVM) program. From 1994 through 1996, Ford offered the F-Series pickup, bot a the 150 and the 250 models, with a 4.9-liter, inline 6-cylinder, natural gas bi-fuel prep-ready vehicle. For the 1997 model year, the F-250 regular cab pickup is available with a 5.4-liter, V-8 modular engine, with either 15 or 21 gge CNG cylinders. Two 13 -inch $\times 60$-inch CNG cylinders will be mounted in the bed of the pickup with one 13 -inch $\times 48$-inch underbody CNG cylinder to obtain 21-gge storage and 301)- to 350-mile range. This dedicated vehicle is targeted to meet ULEVIILEV certification. 
The 1997 Ford Econoline E-250 and E-350 regular and extended-length cargo vans and the E-350 extended-length club wagon will also be available with the 5.4-liter, V-8 engine certified for ULEV/ILEV emissions. CNG fuel capacity on the vans, however, will be limited to 8.5 and 17.6 equivalent gallon configurations. Fuel will be stored in one 12 -inch $\times 72$-inch underbody CNG cylinder mounted midships with an option for two 14.5 -inch $\times 32$-inch CNG cylinders mounted aft of the rear axle.

General Motors-General Motors began offering CNG-powered pickup trucks in 1992. The most popular NGV product was the Sierra pickup with a 5.7-liter dedicated engine and three underbodymounted CNG cylinders. In subsequent years, General Motors expanded its product line to include a variety of truck and car platforms. Unfortunately, General Motors withdrew all its products from the market in 1995 after a series of CNG cylinder failures. General Motors re-entered the fleet truck NGV market for the 1997 model year with a bi-fuel C25 series pickup equipped with a 5.7-liter engine and 13.2 gge of CNG.

Chrysler-Since 1992, Chrysler has offered dedicated natural gas full-size Ram/Dakota vans and pickup trucks and Caravan/Voyager minivans, which were the first production vehicles to be certified in California as LEVs and ULEVs, respectively. The Ram/Dakota uses a 5.2-liter, fuel-injected V-8 engine optimized for natural gas. For the Ram van, chassis-mounted cylinders hold 11.1 gge for a range of 100 to 150 miles with an option for 14.4 gge. The Ram pickup holds 17 gge and the Dakota pickup holds 14.5 gge.

The minivan uses a 3.3-liter, fuel-injected V-6 engine optimized for natural gas. Four chassis-mounted cylinders hold the 8.2 gge for a range of 100 to 150 miles.

Unfortunately, sales of the vehicles did not match expectations and Chrysler withdrew from the NGV market in 1996.

\subsubsection{Fleet Automobiles}

Fleet automobiles include passenger cars, such as rental cars used by business fleets, government fleets, and police cars. Many of these fleets operate from central maintenance facilities; however, refueling stations may be widely distributed. Fuel consumption varies greatly for individual vehicles, but will typically range from 8 to 20 gallons per day. However, LNG is not generally stored onboard automobiles for three reasons:

1. Fleet managers prefer to purchase OEM-warranted automobiles and are reluctant to purchase conversions that are not warranted by OEMs. Unfortunately, there are no OEM-provided LNG automobiles for sale at this time.

2. LNG equipment cost is high relative to vehicle fuel consumption.

3. CNG automobiles are readily available from major OEMs.

Many CNG vehicles are available from OEMs. Models vary from year to year, but General Motors and Ford offer a variety of sedans, minivans, vans, and pickup trucks. In addition, CNG imports will be available from Honda for the 1998 model year.

In the 1997 model year, Ford continued to offer the full-size Crown Victoria with a 4.6-liter dedicated natural gas engine. Ten equivalent gallons of fuel are stored in four CNG cylinders mounted underbody and in the trunk. The Contour bi-fuel sedan offers both natural gas and gasoline power with a 2.0-liter engine. The vehicle carries 14.5 gallons of gasoline and 4.2 equivalent gallons of natural gas in a single trunk-mounted CNG cylinder. 
General Motors has announced it will offer sedans and minivans for the fleet market for the 1998 model year.

Honda will offer the Civic DX-NGV for the 1999 model year. The Civic will have a 4-cylinder engine optimized for natural gas and certified for ULEV emissions. The chassis-mounted cylinder will store 7.4 gge for a range of 200 to $2: 50$ miles.

As with $P \& D$ trucks, perhaps the most cost-effective means of supplying natural gas fuels to fleet automobiles is at central fueling or retail card-lock stations that offer both LNG and LCNG. LNG makes it possible to supply natural ga; fuels at remote locations where pipeline gas is not available. LNG and LCNG stations also provide a consistently high-quality fuel to fleet operators.

\subsubsection{Aftermarket Conversions}

In addition to OEM-supplied vehicles, thousands of aftermarket conversions of gasoline-powered, lightduty trucks and automobiles and medium- and heavy-duty buses and trucks have been made by a small number of companies that specialize in aftermarket conversions. Available LNG storage tanks are presented in Section 5 and engines and conversion systems in Section 6.

LNG can be used to facilitate conversion of gasoline and diesel vehicles to natural gas fuels. LNG can be used in applications where range requirements preclude the use of CNG storage systems. For example, INEL is adding LNG tanks to a. fleet of more than 40 Ford and General Motors pickup trucks that are frequently required to travel more than 120 miles between fuel stops. The National Park Service plans to convert seven Chance RT50 buses that operate in Grand Canyon National Park to LNG.

\subsection{Off-Highway Vehicles and Equipment}

Off-highway vehicles and equijment include such diverse items as generator sets, air compressors, cranes, forklifts, wheel loaders and pavers, agricultural and mining equipment, and a variety of work and recreational boats. Until recently, off-road vehicles and equipment engines were exempt from emission controls. The new particulate cff-road emission regulations agreed to by the engine industry will accelerate commercial developinent of cleaner diesel engines and "clean diesel fuels" during the next 10 years.

Unfortunately, the improvements required for diesel engines to achieve low emissions will be expensive. Although the incremental cost of clean diesel engines and "clean diesel fuels" has not been disclosed, it is certain that diesel engines will be more expensive to buy and operate after the emission standards take effect. Existing engine technology and LNG, however, can be used to achieve very low emissions at lower fuel cost than current rack diesel prices.

\subsubsection{Mining, Construction, and Landfill Equipment Applications}

Surface mining, underground mining, construction, and landfill operations use large, high-horsepower trucks and earthmoving equipment that operate for extended periods and consume hundreds of gallons of fuel per day. Annual domestic demand for mobile equipment, such as articulated haulers, backhoe/loaders, crawler dozer;, crawler excavators, crawler loaders, wheel loaders, mini-excavators, motor graders, rigid haulers, sclapers, skid-steer loaders, and wheeled excavators, ranges between 70,000 and 120,000 units per year. In addition, domestic demand for stationary equipment, such as drill rigs, grinders, crushers, and engine-prowered pumps and compressors, ranges from 50,000 to 100,000 units per year. Large numbers of forklifts and trucks of all sizes are also purchased. 
These pieces of equipment use medium- or heavy-duty diesel engines with power and torque requirements similar to those used on many on-road NGV applications. The engine companies, such as Caterpillar, Cummins, DDC, and others, have the capacity to produce natural gas engines for use in offroad equipment.

For example, Caterpillar offers a 240-ton mine haul truck that uses a 2,400-bhp version of the CAT $3516 \mathrm{~B}$ engine, a motor grader that uses a 500-bhp version of the CAT 3412E engine, and a D11 dozer with a CAT $3508 \mathrm{~B}$ engine rated at $850 \mathrm{bhp}$. All these engines are available in natural gas models for use in locomotives and in industrial- and electric-power applications. There should be very few, if any, technical barriers to using LNG to power these engines on heavy equipment. To date, however, very little LNG has been used in off-road applications.

Owners could require contractors to bid the use of LNG-powered equipment. With proper planning, contractors will find that fuel costs with LNG may be significantly lower than with diesel fuel. This will provide an incentive for contractors to order new equipment from the manufacturer with fully engineered and warranted LNG storage tanks and optimized engines and transmissions.

Surface Operations-Off-road equipment is usually fueled on site or at a central location by skilled operators. Many construction companies operate fuel trucks that deliver fuel to the equipment at the work site to minimize downtime. The modular LNG fuel stations described in Section 3 are ideally suited to use at remote construction sites. With sufficient planning and engineering, most off-road equipment could be adapted to operate on LNG.

Caterpillar, Case, and International have made some equipment available with natural gas engines and some owners, like the Sanitation District of Los Angeles County, have converted trucks and heavy equipment operating at landfills. If sufficient orders are placed for new equipment, manufacturers will supply it at nominal incremental cost.

Because many landfills and construction sites, and even many mines and quarries, are located near urban areas, voluntary conversions to low-emission equipment could generate emission credits from regional air quality programs that could be used to offset the cost of conversion. In addition, conversion of landfill equipment to LNG could significantly reduce fuel costs when the landfill operator captures landfill $\mathrm{CH}_{4}$ for conversion to LNG fuels. Likewise, coal mines produce natural gas as a by-product of the mining operation. This $\mathrm{CH}_{4}$ also could be captured and liquefied on site to produce fuel for mining equipment.

\subsubsection{Industrial, Agricultural, and Specialty Vehicle Applications}

Modern farm equipment ranges in size and fuel consumption from small, general-purpose tractors that are seldom used, to large, self-propelled harvesting machines that operate continuously. Some fixed equipment, such as irrigation pumps, consume large quantities of fuel and are absolutely essential to the success of the farm.

Tractors and Harvesting Equipment-General-purpose farm tractors use diesel engines, ranging in size from $40 \mathrm{bhp}$ to larger than $150 \mathrm{bhp}$. They typically include a power takeoff to operate specialty equipment, such as chippers, snow blowers, manure spreaders, saws, and pumps. A general-purpose tractor can consume 50 to 100 gallons of diesel fuel per day during periods of intense use. However, the tractor will also sit idle for extended periods.

Expensive, highly specialized equipment, such as harvesting combines, are frequently leased. A service company may own and operate several of these machines under contract. 
These machines have large engines ranging from 150 to $500 \mathrm{bhp}$. Several machines are frequently operated together and may be in nearly continuous use during harvest periods. These machines are fueled on site from fuel trucks.

Conversion to LNG could be cost effective for some farms. Fuel use patterns would have to be evaluated to determine average and peak usage rates as well as frequency of use. For example, intense seasonal usage followed by much lower, but steady, daily consumption could support LNG. Some of the major manufacturers of farm tractors include:

- Ford New Holland

- AGCO White

- AGCO Allis

- John Deere Company

- Massey Ferguson

- Kubota

- JI Case.

None of these tractor manufact urers offer natural gas options at this time. However, many of the natural gas engines used in buses and trucks, including Cummins, Caterpillar, John Deere, and DDC, could be installed in these machines, either as OEM equipment or as aftermarket conversions.

Irrigation Pumps, Gen-Sets, and Specialty Applications-Irrigation pumps are often powered by diesel engines. In many locaticns irrigation pumps are required to operate nearly continuously for extended periods of time, often for several months, and then they sit idle for several months. For example, engine-powered pumps used in citrus groves have the three following uses:

- Pump excess water during jeriods of heavy rainfall

- Pump irrigation water during dry periods

- Pump water during hard freezes to protect trees from damage.

An irrigation pump in a citrus grove could easily operate for 3,000 to 4,000 hours in a typical year. A typical grove in South Florida rnight use five to ten pump stations. The modern pump station is equipped with a medium-duty, 20- to $12(\mathrm{l}$-bhp diesel engine and a 500-gallon diesel tank. The station is located adjacent to an access road. Oprration of the pump engine is controlled by water level and/or temperature. An electronic control unit monitors water level and/or temperature sensors and turns the pump on or off, as needed. The electronics pacicage also monitors operating parameters, such as fuel supply and oil levels, and calls for service via cellular phone when needed. The storage tank is filled by a skilled worker from a small truck, as needed. LNG could be very cost effective in this application.

Many industrial applications such as gas compression, irrigation, standby power, flood control, absorption air-conditioning, wastewater treatment, oil production, and refrigeration use the same model natural gas engines used in heavy-duty vehicles. Modular LNG container tanks and trailer delivery systems make it possible to use natural gas engines for these applications in any location.

Logging and Timber Hauling-Modern flatwood timber operations use many pieces of heavy equipment. However, harvest and transport of the logs to the mill is the most energy-intensive operation. Heavy equipment is used to prepare land for replanting, maintain roads needed for site access, cut trees, stage logs, and load the logs onto flatbed trailers. Cut trees are then hauled by truck to a pulp mill, sawmill, or chip mill for processing. Most of this equipment is centrally fueled or fueled in the field from trucks. Cut trees are generally !auled to a mill within 100 miles of the harvest site. LNG could be cost effective in many flatwoods timber applications. 


\subsubsection{Railroad Locomotives}

Railroad locomotives are attractive candidates for LNG fueling.

Diesel-electric railroad locomotives are powered by large-bore, medium-speed, two-stroke and fourstroke cycle diesel engines with 8 to 20 cylinders. These engines are directly coupled to electric generators, which power the motors driving the wheels. Locomotive engines operate at eight defined throttle notches, which are set for the appropriate loads and speeds. Tractive power ratings for locomotives range from 1,000 to 4,000 bhp depending on service requirements.

Locomotives are good candidates for LNG fueling for two reasons-economics and emissions. Railroads consume large quantities of diesel fuel. The cost savings resulting from the difference between natural gas and diesel fuel prices can easily justify the upfront capital cost of LNG fuel equipment for the service life of the locomotive. Locomotive diesels have very high $\mathrm{NO}_{x}$, and particulate emissions could be substantially reduced by conversion to LNG. However, until locomotive emissions limits take effect, there will be no legal requirement for railroads to reduce emissions. Various LNG locomotive projects are currently under way, ranging from laboratory research on direct-injection natural gas engines to field demonstrations of LNG-powered switchyard locomotives.

Line-Haul Locomotives-The Burlington Northern (BN) and AP, project field demonstration uses General Motors Electromotive Division locomotives converted to dual-fuel pilot-ignition LNG fueling by Energy Conversions, Inc. (ECI). Following an extensive 500-engine-hour durability test and field trials, two locomotives with LNG fuel tenders were placed into commercial coal service between Decker, Montana, and Superior, Wisconsin. Performance has been excellent over 400,000 miles of operation at full-rated power.

Most diesel-electric locomotives store diesel fuel in tanks mounted on the locomotive, although a few use diesel fuel tender cars. Because LNG occupies a larger volume than diesel fuel and requires an insulated tank, tender cars will probably be used for all long-distance LNG railroad applications. Although specific standards for LNG tender cars have not been promulgated, the technology for their design and construction exists. Two LNG tender cars have been built to support the BN-AP project. The first tender was designed to fuel one locomotive. The second tender can fuel two locomotives simultaneously. Each tender holds approximately 20,000 gallons of LNG at approximately $100 \mathrm{psig}$. The tenders are constructed with double-wall, vacuum-jacketed, Perlite-insulated tanks mounted on 100-ton railcar frames.

Switchyard Locomotives-In October 1994, two LNG-fueled, 1,200 horsepower switch engine locomotives were delivered for testing to the Santa Fe Los Angeles area railyard. Two similar engines operate at the Union Pacific Los Angeles switchyard.

The MK1200G is a 1,200-horsepower switchyard locomotive fueled by LNG. LNG allows the MK1200G to produce the lowest $\mathrm{NO}_{\mathrm{x}}$ emissions of any locomotive in its horsepower class. The MK1200G is designed for improved performance to meet the demands of large switchyard operations.

The MK1200G was manufactured by MK Rail and uses the following technology:

- The Caterpillar G3516 spark-ignited, turbo-charged, after-cooled low-emissions V-16 engine

- Electric motors and generators by KATO Engineering, a division of Reliance Electric

- The MK-LOC, a state-of-the-art microprocessor-based locomotive control system, provides enhanced operator control and self-diagnostics

- An MVE LNG-fuel management system, including cryogenic tanks, process piping, vaporizer, and controls 
- A modern, high-visibility s:ab design incorporating human engineering and safety improvements

- A broad array of high-tech performance and safety sensors/controls.

Each MK1200G unit is supplied complete with prime mover, alternators, trucks, and accessories for single- or multiple-unit operation. The MK1200G is a completely integrated and unified switching locomotive.

Engine-The CAT G3516 SIT'A power plant delivers extremely low emissions with $\mathrm{NO}_{\mathrm{x}}$ emissions only $2 \mathrm{~g} / \mathrm{bhp}-\mathrm{h}$. Microprocessor-based control systems deliver precise systems control, have fewer moving parts, and facilitate maintenance through real-time diagnostics and analysis. The new designs enhance reliability and yield low life-cycle costs.

LNG Fuel Tanks-The MK1200G is equipped with a unique LNG fuel management system. The system is thoroughly engineered in compliance with a stringent set of safety, reliability, and performance standards. LNG is stored on the locomotive in three specially designed, cryogenic fuel tanks with a combined capacity of 1,400 gallons. Each tank is constructed with a stainless-steel inner pressure vessel that holds the LNG and a stainless-steel outer shell. A 1-inch layer of super insulation is wrapped around the inner vessel in an evacuated chamber between the pressure vessel and the outer shell. The center tank has an outside diameter of 25 inches.

All three tanks are assembled and installed on the underside of the locomotive frame in a special structure that has been designed and testied to provide increased strength and support. The tanks are constructed and certified in accordance with all applicable requirements of ASME Code Section VIII, Division I.

LNG filling ports are located on each side of the locomotive and are equipped with emergency fuel cutoff actuators. Tanks are equipped with baffle plates to minimize fuel sloshing.

LNG Fuel System-The LNG iuel system is controlled by the MK-LOC microprocessor control system and consists of an array of cryogenic process piping and valves. The piping and valves are located at the rear end of each fuel tank and are routed and configured to optimize safety and protection. All process piping and valves are designed and manufactured in accordance with ANSI Code B31.3.

Vaporization System-LNG is converted to a gas in the vaporizer. The vaporizer is a tube-and-shell heat exchanger that uses engine coo.ing water to heat the LNG. It is designed to operate at temperatures ranging from $-260^{\circ} \mathrm{F}$ to several hundred degrees above the temperature of the engine jacket water. Gaseous fuel from the vaporizer is delivered to the CAT G3516 SITA engine intake for final pressure modulation, metering, and injection.

\subsubsection{Marine Applications}

Many recreational and work boats could be candidates for conversion to LNG. Boats, ranging in size from ocean-going bulk carriers to small work boats, have been converted to operate on natural gas fuels. Most ocean-going bulk LNG crrriers have the capability to use boil-off from LNG in their cargo tanks to fuel their engines. Virginia Natural Gas has operated a small LCNG ferry boat in Chesapeake Bay since 1995. The Elizabeth River Ferry is fueled from an LNG-to-LCNG station at Harbor Park in Norfolk, Virginia. The University of Alabama sponsored a project several years ago to convert a gulf shrimp trawler to operate on LNG. Honda recently supplied two natural gas-powered, 90-bhp, 4-cycle outboard engines to Tampa Baywatch. These engines operate on CNG and power a 24-foot catamaran runabout that is used to patrol the Bay. 
The most attractive marine applications for LNG are diesel work boats and large gasoline recreational boats that operate in rivers, lakes, and harbors near urban nonattainment regions for air quality, or near areas that suffer chronic problems in marinas and waterways from oil spills and discharges.

Typical applications could include tour boats, charter fishing boats, river towboats, harbor tractor tugs, utility boats, pilot boats, offshore oil service boats, crew boats, work boats, police boats, and pleasure boats. The boats range in size from 19 to 70 feet. All these boats use marine engines that can be configured to operate on natural gas. At this time, emissions from small boats are not controlled and marine engines, many of which are two-cycle, tend to have high emissions.

Conversion to $L N G$ could result in significant reductions in $P M$ and $N O_{x}$ emissions. Secondary benefits would include reduced pollution from oil spills and leaks.

Gasoline inboards are used in power boats as large as 35 feet; however, the trend is to convert to diesel for safety reasons and to get more efficiency and reliability. High-speed diesels are used in boats as small as 24 feet and as large as 70 feet. The pleasure craft market is tending toward higher powered engines to obtain increased performance.

Again, many of the engines used in vehicle or industrial applications are also used in the marine market. Although Caterpillar, Cummins, DDC, General Motors, Volvo Penta, and others do not offer a natural gas marine engine, many of the marine diesel engines, such as the Caterpillar 3516, are derivatives of engines that have extensive natural gas experience. Engines used in marine applications range in size from $9 \mathrm{bhp}$ to more than 3,400 bhp and could be supplied in natural gas versions.

Honda has demonstrated that smaller vessels can be retrofitted with LCNG storage tanks located in the same hull spaces currently dedicated to diesel or gasoline. Additional projects are needed to demonstrate applications of both LNG and LCNG fuels. Potential marine LNG applications in key marine markets in the United States are discussed in the following section.

West Coast-On the West Coast, large commercial harbors in California, such as San Diego, Los Angeles, Oakland, and San Francisco, support heavy ocean-going and coastal commercial and military traffic. In addition, hundreds of small marinas support charter boats and recreational watercraft. Nearly all the boats operating in these waters are in nonattainment areas. The Portland-Columbia River System in Oregon and Tacoma-Seattle-Vancouver in Puget Sound also support large numbers of work boats and recreational watercraft that operate in nonattainment areas. A network of LNG fuel stations for work boats, ferry boats, fishing boats, and recreational watercraft could be developed to serve these vessels. LNG is available near all of these ports.

Great Lakes-The Great Lakes support large numbers of commercial and recreational watercraft. Lake boats have some unique features because they operate exclusively on fresh water. In particular, lake boats tend to have longer service lives than salt water boats. For this reason, the economic return from conversions to LNG could be more attractive to the owners. Many lake boats operate extensively in air quality nonattainment areas, such as lower Lake Michigan between Milwaukee, Gary, and Chicago, and between Detroit, Cleveland, and Buffalo on Lake Erie. LNG is available near most of these ports.

Atlantic Coast-In the Northeast and Mid-Atlantic regions, many commercial boats operate in harbor, intracoastal, and nearshore service in regions regulated by the Northeastern Ozone Transport Commission. Ferry boats, fishing boats, pilot boats, harbor tugs, towboats, and a variety of gasoline- and diesel-powered recreational watercraft between Portland, Boston, New York, Philadelphia, and Chesapeake Bay could support a network of LNG fuel stations. LNG is available near all of these ports. 
Southeastern ports from Norfok to Miami and the Florida Keys are excellent candidates for conversion to LNG fuels because of the envilonmental sensitivity of these waters for the tourism and fishing industries. Tow-boats, fishing boats, ferry boats, tourist boats, tug boats, military work boats, and gasoline- and diesel-powered recreational boats could be converted to LNG. The Atlantic Intercoastal Waterway (AIWW) supports a steady flow of traffic between the Northeastern harbors and Florida. Many marinas along the AIWW, especially in Florida, have serious problems with water contamination resulting from spills and leaks of gasoline and diesel fuels. However, LNG supplies are located near marinas between Chesapeake Bay and Savannah, but not in Florida.

Gulf Coast-The Gulf Coast Intracoastal Waterway (GIWW) from Southwest Florida to Brownsville, Texas, supports a wide variety of work boats and recreational watercraft. Charlotte Harbor, Sarasota Bay, and Tampa Bay in Florida support large numbers of charter fishing boats, tourist boats, towboats, and recreational watercraft. Unfortunately, these coastal rivers and estuaries are very sensitive to pollution. LNG could help solve many di:ficult environmental problems in these waters, ranging from excessive nitrogen emissions from boat exhausts to leaks and spills in heavily used marinas. LNG is not readily available in South Florida.

Segments of the GIWW between Northwest Florida, Mobile Bay, New Orleans, and the Alabama, Mississippi, Louisiana, and Texas coasts carry heavy towboat traffic in addition to many ferry boats, charter boats, casino boats, miltary work boats, oil service boats, and recreational watercraft.

\subsection{Aerospace Applications}

LNG is a very attractive aviation fuel. The heating value of LNG is about 13 percent higher than jet fuel, by weight. This benefit could ke used to increase the range or the carrying capacity of an aircraft. The low temperature and high laten: heat of vaporization of LNG can be used to provide more cooling to turbine blades and combustor cans. This could result in higher turbine intake temperatures, much higher power output, and higher engine efficiency without an increase in engine compression. LNG fuels could also be used to cool aircraft skin during high-speed atmospheric flight. Emissions from LNG aircraft turbines would be significantly lower than emissions from kerosene-powered engines. Airports are now becoming the major sources of air pollution in urban areas throughout the world. It is very difficult to control emissions from an aircraft jet engine without compromising flight characteristics. However, aircraft fuel storage systems conld be redesigned to accommodate LNG fuel systems. German and Russian aircraft designers have experimented with LNG engines and fuel storage systems on popular passenger aircraft manufactured by Airbus and Tupolov. American efforts have been focused on classified military applications. The Aurora Mach 6 reconnaissance aircraft is reportedly powered by LNG. 


\subsection{LNG Vehicle Fuel Systems}

LNG-powered vehicles can either be purchased directly from manufacturers or converted from existing gasoline- or diesel-powered vehicles. In either case, the LNG fuel system must be matched to the fuel pressure and flow requirements of the engine and the duty-cycle of the vehicle. The ideal LNG vehicle has an engine and LNG fuel system optimized to work together. In other words, the engine is designed to operate most efficiently with the most cost-effective LNG storage and fuel delivery system.

LNG vehicle tanks operate at the temperatures and pressures defined by the saturation curve (see Figure 3-2) because the tanks are well mixed. Ideally, the tank operates at as low a temperature and pressure as possible. As the saturation pressure of LNG rises, the LNG becomes less dense. Table 5-1 shows the effect of saturation pressure on boiling point, density, and heat of vaporization.

\section{Table 5-1. Effect of Saturation Pressure on LNG Physical Properties}

\author{
Saturation Pressure \\ Boiling Point \\ Density \\ Heat of Vaporization
}

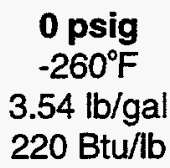

$100 \mathrm{psig}$
$-200^{\circ} \mathrm{F}$
$3.08 \mathrm{lb} / \mathrm{gal}$
$186 \mathrm{Btu} / \mathrm{lb}$

Vehicles operating at higher saturation pressures have less effective fuel storage capacity than vehicles operating at lower pressures. A storage tank can deliver the largest quantity of fuel per unit volume, per unit weight, and over the longest holding time if the LNG is stored at as low a pressure as possible. When either the temperature or pressure of the LNG in the storage tank increases, the density of the LNG decreases and holding time of the LNG tank decreases.

Unfortunately, many natural gas engines are designed to use high fuel pressures, some up to 200 psig. The higher pressure fuel systems on these early engines were designed for use with high-pressure CNG storage systems. The engine designers were not aware of the need to also configure the natural gas engines for low-pressure operation with LNG storage systems. An engine optimized for use with LNG should be designed for low fuel pressures.

Lower pressure LNG systems are more cost effective than high-pressure systems. An engine that requires high-fuel pressures also requires a much more complicated LNG fuel system. Unfortunately, many modern electronic fuel-injected natural gas engines are supplied only with the higher pressure gas injectors developed for CNG vehicles. Therefore, LNG fuel systems must be capable of supplying fuel to the natural gas engine at pressures ranging from $20 \mathrm{psig}$ to over $150 \mathrm{psig}$.

This is done using a variety of ingenious techniques, ranging from pumps to pressure-building circuits, as described in the following sections. High-pressure fuel systems also create a need for LNG conditioning systems. The challenge for LNG system designers is to optimize the performance of the vehicle fuel storage, delivery, and engine systems to minimize system capital and operating costs.

\subsection{LNG Vehicle Components}

The LNG fuel system must be designed to store LNG for extended periods, without venting gas, yet be capable of providing all the fuel required by the engine on demand. LNG is stored as a liquid at the lowest possible temperatures. However, the fuel system must supply vapor, not liquid, to the engine.

Vehicles are generally equipped with an LNG fuel-coupling receptacle, one or more double-walled, vacuum-jacketed LNG storage tanks with safety relief valve, liquid-vapor pressure-control system, heat 
exchanger or vaporizer, pressure regulator, natural gas mixer or fuel injection system, and a natural gaspowered engine.

Modern engines are equipped with electronic control units that monitor engine performance and exhaust gas composition and automatically adjust the air-fuel mixture to optimize performance and emissions. Public transit vehicles are also equipped with $\mathrm{CH}_{4}$ detection and fire suppression systems.

Figure 5-1 illustrates the primary fuel system components that are unique to LNG vehicles. Currently available LNG vehicle components and their functions are described briefly in this section. Areas where improvements are needed are also discussed.

\subsubsection{Fuel Valves}

The fuel valves prevent $L N G$ vapor from entering the engine when it is not running. The fuel system has both manual shut-off valves and a solenoid-actuated valve. The solenoid-actuated valve is controlled by the ignition switch and the vacium switch. The vacuum switch is located on the intake manifold and is closed when a vacuum is created by the rotation of the engine. When the ignition switch is in the "on" position and the vacuum switch on the intake manifold is closed, the solenoid actuator is energized and the fuel valve is open. The soltnoid valve is either installed upstream of the engine fuel system or integrated into the liquid/vapor control system. These valves are used with both mechanical gas mixerfumigation systems and electronic-controlled fuel-injection systems.

\subsubsection{Pressure Regulator}

The pressure regulator supplies natural gas vapor to the engine at the pressure required by the engine fuel management system. If the ençine uses a simple fumigation system with mechanically controlled methane-air mixers, very low vapor pressures-only a few inches of water-are required. However, electronically actuated natural gas fuel-injector systems used on some engines may require gas pressures ranging from $50 \mathrm{psig}$ to $150 \mathrm{psig}$.

Demand-activated diaphragm regulators are always used with mechanical mixers. If the engine is turbocharged, the diaphragm must be vented against the appropriate boosted manifold pressure. Natural gas fuel-injector systems are generally supplied with an electronically controlled metering valve. Fuel injection systems sometimes use a conventional diaphragm regulator to pre-adjust fuel pressure.

On early LNG systems, diaphragm regulators were often low-pressure regulators adapted from CNG or LPG systems. Minor problems with these off-the-shelf regulators for LNG vehicles were reported. For example, large turbocharged LIJ engines, such as the Cummins L-10 240G, require the regulator to deliver high gas flow rates. This can be a problem when the LNG tank pressure drops to a level near the boost pressure. Variations caused by inertia forces acting on the diaphragm have also been reported. However, no fundamental techrology problems appear to be associated with pressure regulation. These operational problems have beer. solved either by improving existing equipment or by designing regulators specifically for LNG engines.

\subsubsection{Heat Exchanger ("'Vaporizer")}

When LNG flows from the tank to the heat exchanger, it is usually vaporized by heat transfer in the uninsulated fuel line. The heat exchanger is designed to raise the temperature of the vapor to ambient temperature. Thus, the frequen ly used term "vaporizer" is technically incorrect. Heat exchanger is a more appropriate term. 
Early LNG vehicle heat exchangers were usually adaptations of LPG vaporizers that used engine coolant to heat the natural gas. Material changes were required to accommodate cryogenic temperatures. A system developed by Beech Aircraft in the early 1980 s combined the heat exchanger and pressure regulator into a single unit.

Figure 5-1. LNG Fuel System Components

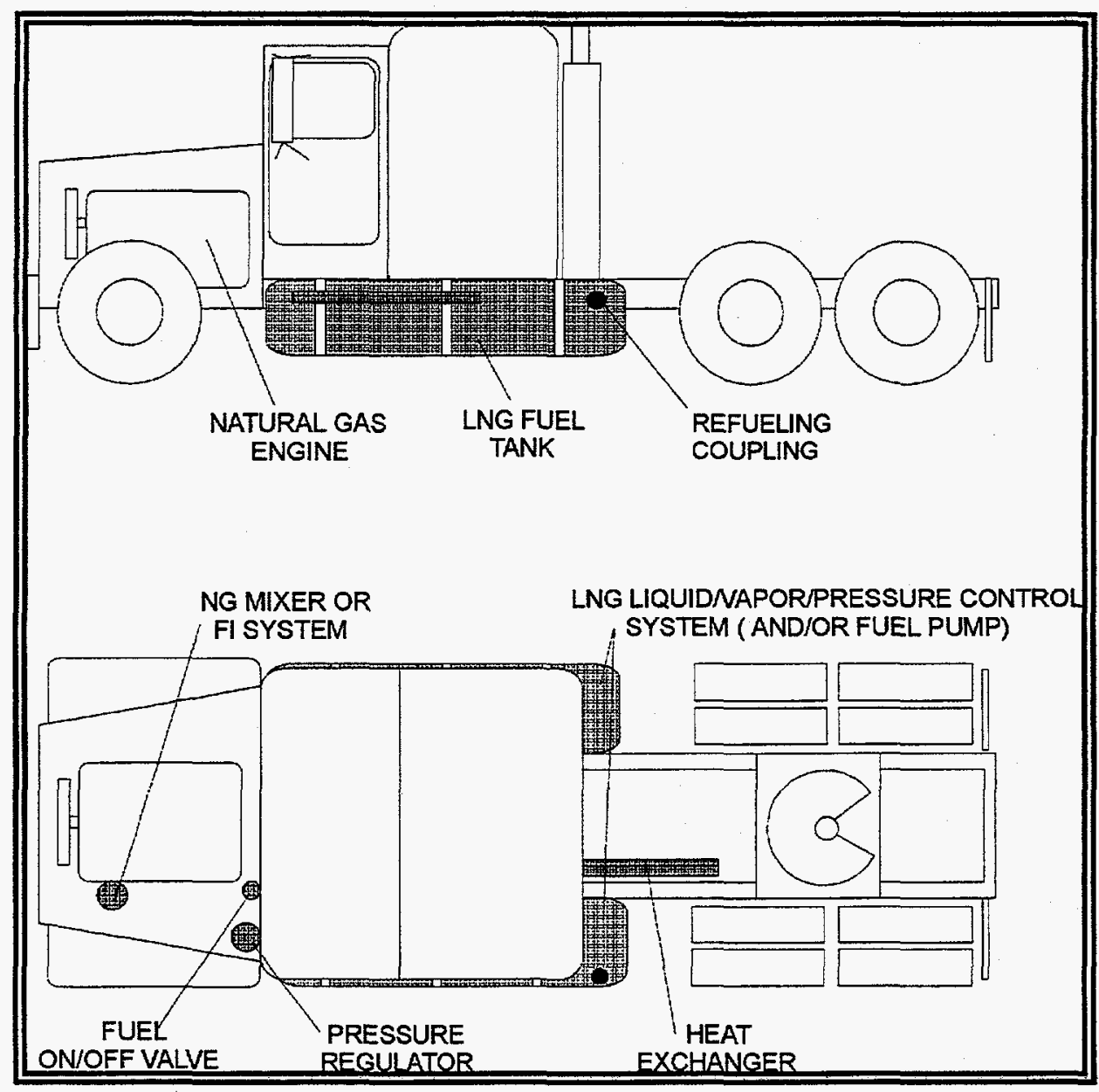

A design problem for heat exchangers that use engine coolant is that the outlet gas temperature may not closely track the engine intake air temperature. This could make it difficult to precisely control the fuelair ratio, which could cause unacceptable exhaust emissions. Simple engine coolant heat exchangers may not be adequate for LNG vehicles that must certify to strict exhaust emission standards. Variations in fuel density and fuel-air ratios also can cause operational problems for lean-burn LNG engines.

To provide more precise control of the gas temperature relative to the intake air temperature, two-stage heat exchangers have been used on some recent heavy-duty LNG vehicles.

The first stage uses engine coolant to heat the LNG. The second stage uses ambient intake air to warm the LNG vapor to near ambient temperatures. For example, the Cummins L-10 240G-powered Gillig transit bus uses this type of two-stage heat exchanger system. 


\subsubsection{Fuel System Pipirig}

LNG vehicle fuel system piping should be stainless steel. Gasket and seal materials must be certified for cryogenic temperatures. Tefloin is the most commonly used seal material. Because of the potential for leaks, LNG fuel systems shouli be designed with as few joints as possible. Welded fittings should also be used when possible. Non-welded joints should use compression-type fittings (e.g., Swagelock and Gyrolock) or equivalent qualified cryogenic fittings. Obviously, special care must be taken when servicing LNG vehicle fuel systems because of possible high pressures and cryogenic temperatures. Leaks or spills can potentially cause cryogenic burns or create a fire hazard.

\subsubsection{Liquid-Vapor Pressure Control System}

Heat transfer to the vehicle LN'G tank warms the LNG until it vaporizes, thus increasing the pressure in the tank. LNG tank manufacturers use various liquid-vapor pressure control systems to maintain the tank pressure within desired limits. This minimizes venting and extends the tank "hold time." With these systems, vapor, rather than liquid, is initially sent to the engine if the pressure in the tank is above a set point. When the tank pressure falls below the set point, the tank controls automatically switch to supply liquid to the engine. The liquid is vaporized in the fuel line and heat exchanger downstream of the LNG tank.

The most common pressure corttrol systems use solenoid-actuated valves and pressure switches. Another approach to pressure control is an automatic, but passive, system using a "phase selection" valve. The passive phase selector is actuated by the vapor pressure.

\subsubsection{Fuel Transfer to the Engine}

Natural gas engines require a stzady flow of vapor at a specified pressure. This can be accomplished with pressure transfer or with a fuel jump. With either method, if the pressure drops below the required set point, the engine will stop. If the fuel flow is interrupted, the engine will labor or stall. The transfer method depends on the required pressures.

Carburetted engines use mechanical gas mixers and operate fine with natural gas pressures less than 30 psig. Turbocharged engines with gas mixers downstream of the turbocharger may require gas pressures up to $50 \mathrm{psig}$. Electronic-controlled fuel-injection systems require fuel pressures from about 50 to 150 psig. Some of the older aftermarket conversions are derived from CNG systems. These require pressures as high as $300 \mathrm{psig}$. I)irect-injection engines may require pressures as high as 3,000 psig.

Fortunately, engine designers have recognized that LNG vehicles operate most efficiently at low storage tank pressures. As a result, engine fuel pressures are being lowered as new technologies are introduced. LNG fuel systems that operate at pressures less than 150 psig should be adequate for most available engines.

Pressure Transfer-Moderatt:-Pressure LNG Tank-Moderate-pressure tanks operate at pressures up to 150 psig and may be used to supply fuel continuously at pressures between 50 and 120 psig. These pressures are adequate for most natural gas engines equipped with electronic fuel-injection systems, such as the Cummins engines. During periods of heavy fuel demand, tank pressure is maintained above the required engine pressure by adding heat. Because heat leak may not be adequate to maintain pressure, some manufacturers use engine heat to warm the LNG; others use electrical heaters. 
Pressure Transfer-Low-Pressure LNG Tank-Low-pressure LNG fuel systems and tanks typically operate in the 20 to 80 psig range and can reliably supply fuel at pressures up to about 30 psig. This is adequate fuel pressure for engines that use conventional gas mixers and carburetors. Turbo-charged engines, however, could have a problem under heavy load conditions.

Pump Transfer-Low-Pressure Tank-Low-pressure tanks can be used to supply LNG to engines with high-pressure fuel systems only if an LNG pump or a compressor is used to boost the pressure.

Unfortunately, gas compressors are expensive and complicated machines to install and operate. They require a lot of power to operate and are not recommended. LNG pumps also are complex and expensive solutions because of the special problems associated with pumping saturated cryogenic liquids. It is very difficult to design an LNG pump external to the LNG tank that would maintain prime. Although external pumps are not recommended, submerged LNG pumps are feasible.

Some LNG vehicles use a pump submerged in a low-pressure LNG tank to supply gas to engines requiring more than $150 \mathrm{psig}$. The pump is powered by a drive system external to the tank. Most systems have been fabricated by CVI, Inc., primarily for use in transit buses powered by DDC 6V-92 PING engines and operated by Houston Metro.

The CVI system uses a reciprocating, single-acting, low-speed ( 0 to 60 stokes per minute), positive displacement, submerged pump capable of operating with a near-zero NPSH. The pump is powered by a hydraulic driver mounted external to the tank. The hydraulic pump is driven by the engine. This system works satisfactorily, although the pump drive introduces an additional heat transfer path into the LNG tank, the overall system is expensive, and long-term durability has not yet been demonstrated.

\subsubsection{Use of Cooling Energy}

The total energy required to vaporize and warm LNG to ambient temperature is approximately $380 \mathrm{Btu} / \mathrm{lb}$. The heat of vaporization for $\mathrm{LNG}$ is about $220 \mathrm{Btu} / \mathrm{lb}$. The sensible heat required to warm the $\mathrm{LNG}$ from $-260^{\circ} \mathrm{F}\left(-162^{\circ} \mathrm{C}\right)$ to ambient temperature is approximately $160 \mathrm{Btu} / \mathrm{lb}$. The overall efficiency of the LNG vehicle would be improved if systems could be developed to use this energy.

Vehicles have been built to test the concept of using the LNG to provide refrigeration or air-conditioning (Anker Gram, 1973). Systems were reported to function; however, many difficulties of balancing cooling with demand, icing, and cold storage, apparently have limited the practical use of this technology on vehicles. The increasing use of LNG to LCNG also raises the possibility that the cold energy associated with producing LCNG could be captured and used at the fuel station for various applications, such as space conditioning or refrigeration.

A promising use of the "cold" energy on an LNG vehicle would be to let the latent and sensible heat cool the intake air. In theory, charge cooling would increase the density of the fuel-air mixture, which would increase the power output of the engine. A cooler charge could also lower $\mathrm{NO}_{\mathrm{x}}$ emissions because intake temperature and peak combustion temperature may be reduced. Shell Research in the United Kingdom developed a system, but experienced problems with icing. Shell ran the LNG through an engine intake air heat exchanger, but reported severe frost formation at full-throttle operation. Shell found that the "...close matching of fuel gas and air temperatures was a valuable feature." Unfortunately, commercial systems do not use the LNG to pre-cool charge air.

\subsection{Fuel Tanks}

LNG vehicle tank technology has benefited from 50 years of research and development for other aerospace and industrial cryogenic applications, particularly liquid rocket propulsion. High-volume commercial demand for cryogenic tanks for medical, food service, military, aerospace, and agriculture 
applications has developed tank fabrication practices and technologies that produce a rugged and reliable product. LNG vehicle tanks ar e currently offered for sale commercially, with capacities from 18 to more than 160 gallons.

Low-pressure LNG tanks typically operate in the 20 to 80 psig range and can reliably supply fuel at pressures up to about $30 \mathrm{psig}$. Higher pressure tanks with pressure-build circuits operate at peak pressures up to $150 \mathrm{psig}$ and continuously supply fuel at pressures of 100 to $120 \mathrm{psig}$. Low-pressure tanks have several inherent advantages over higher pressure tanks, such as lower material costs, up to 30 percent less weight, and up 1:0 14-day hold times. Snyder Tank Company claims that its 100-gallon, low-pressure tank weighs less than a comparable-size diesel tank.

The following manufacturers have developed cryogenic tanks custom designed for LNG storage on vehicles:

- CVI, Inc.

- Cryenco

- Cryogas USA (formerly Gibson Technical Services)

- Essex Cryogenics

- MVE

- Snyder Tank Corporation ('Tryogenic Fuels, Inc.)

- Taylor-Wharton.

The basic design concept is the same for all cryogenic liquids, a vacuum-jacketed dewar designed to minimize heat transfer to the stored cryogenic fluid. Vehicle tanks, however, must be designed to withstand the vibration and abuse typical of heavy-duty vehicle operations and to interface with a variety of LNG fueling stations. Structural members in vehicle tanks are generally constructed of heavier materials than stationary tanks. Figure 5-2 is a schematic of unique design elements of an LNG vehicle tank.

An LNG tank manufactured in accordance with ASME Code or DOT Specification $4 \mathrm{~L}$ includes the following materials:

- Inner Vessel: Austenitic stainless steel type 304

- Jacket Casing: 304 stainless or carbon steel

- Piping: Austenitic stainless steel type 304/316

- Supports: Reinforced polymer, ceramic, or stainless steel

The inner pressure vessel of a vehicle tank should be constructed of stainless steel. The outer vessel should be constructed of stainless or carbon steel. Tanks should be built and certified to DOT Specification $4 \mathrm{~L}$ for the commercial transport of cryogenic liquids. Perlite or multilayer insulation, sometimes referred to as "super insulation," consists of multiple layers of aluminized mylar separated by silk or nylon loose-weave cloth. It should always be used in the space between the tanks to minimize radiation heat transfer. A vacuum of less than $10^{-4}$ torr is maintained to minimize convection heat transfer. The inner pressure vessel is suspended within the outer tank using support systems designed to minimize heat conduction and provide structural strength and integrity. Support system designs are proprietary and protected by pa:ents. Stainless-steel or low-conductivity fiberglass-reinforced polymer suspension elements are usually' used.

The inner vessel usually contains slosh baffles. At a minimum, the inner vessel is penetrated by a liquid withdrawal line, a vapor withdrawal line, and a liquid top-fill line. The inner vessel may also be penetrated by lines and sensors required to measure liquid level, prevent stratification, control pressure 
Figure 5-2. LNG Vehicle Fuel Tank Design Elements

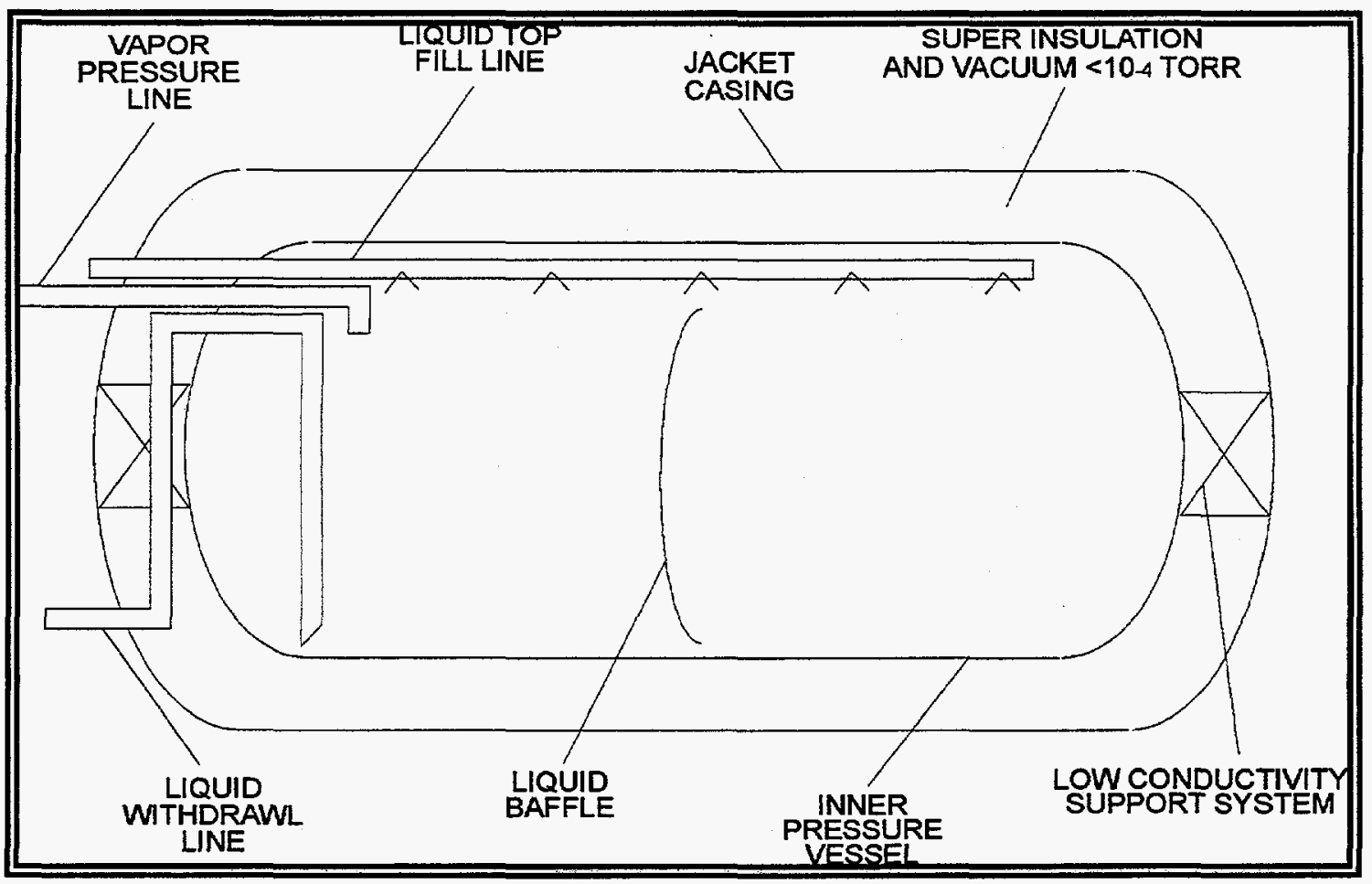

buildup, and add heat. Heat exchanger coils, spray-bars (spargers) to condense ullage vapor, and/or submerged pumps are installed by various manufacturers.

LNG vehicle tanks are typically cylinders with elliptical heads. Figure 5-3 and Figure 5-4 are photographs of typical LNG vehicle fuel tanks. Figure 5-3 shows a 30-gallon LNG tank produced by MVE for medium-duty trucks. Connection plumbing and a handling-ring are visible on the end of the tank. Plumbing should be protected by the shroud at the end of the tank. Figure 5-4 shows a 160-gallon LNG tank made by CVI for transit bus applications. This tank uses a submerged LNG pump to provide high fuel pressures.

\subsubsection{Hold Time, Relief Valves, and Vents}

A key consideration for selection of LNG vehicle tanks is hold time. That is the length of time a tank will hold LNG until heat gain causes a pressure buildup that must be vented. Tanks are protected from overpressure by two relief valves. The first is set at the tank maximum allowable working pressure, about 230 to 235 psig; the second is set at 350 psig. Hold time obviously depends on the condition of the tank prior to filling, including the pre-fill liquid-to-vapor ratio, as well as tank construction.

\subsubsection{Ullage}

A vapor space, or ullage, must always be left in the tank after filling to allow for additional vaporization and liquid expansion, which occur as the temperature and pressure increase. Ullage is typically 5 to 15 percent of the tank volume. Specifically, if and when the tank reaches its vent pressure, there should still be ullage so that the tank does not vent liquid. 
The leading tanks feature proprietary devices to prevent overfilling. Stated LNG vehicle hold times are at always at least 5 days, are commonly 7 days, and longer times of 10 or even 14 days are sometimes quoted.

\subsubsection{Tank Level Measurement}

Measurement of the liquid level in the LNG tank using a vehicle fuel gauge is still not as accurate as needed by many customers. Various methods have been employed for liquid level measurement including float gauges, differential pressure gauges, and capacitance gauges, but none have proven totally satisfactory in vehicle tank applications. Drivers participating in demonstrations who do not keep fuel records sometimes run out of fiel simply because they neglect to fill the tank.

\subsubsection{Overfill Protection}

Overfill during fueling is an operational concern. When LNG is loaded into a vehicle, the fuel tank must not be overfilled, especially when the LNG is at the saturated pressure-temperature condition. Thus, filling should stop when 5 to 15 percent ullage is left in the tank. The exact percentage depends on the set point for the tank relief valve and the saturated P-T of the LNG being loaded into the fuel tank (Cryenco, 1996).

Newer stations, such as those offered by Cryenco and CH-IV Corporation, are designed with pressure and temperature sensors that automatically stop fueling when the vehicle tank is filled to the correct level. Return lines are also used to recover vented gases and liquids. However, with older design stations, overfill can cause release of liquid through pressure relief and vent lines, which creates a safety hazard for the operator. Overfill protection is a rapidly evolving technology.

Cryenco offers a tank with a patented overfill protection device. This "smart" system enables the controls on the LNG refueling station to sense when the onboard LNG tank is filled to the correct level. The device determines the proper fill levels based on the saturated condition, including pressures and temperatures, of LNG in both the filling station tank and the vehicle tank.

\subsubsection{Tank Mounting}

Tanks mounted longitudinally should be placed with the plumbing end toward the rear of the vehicle. This will ensure that the liquid pickup tube will always be submerged when the vehicle is accelerating or going uphill. The plumbing end of the tank should always be shielded from direct exposure to high temperatures from exhaust pipes. This protects elastomeric seals from damage.

The tank can be mounted by siraply strapping the tank to the vehicle chassis. A rubber-backed steel strap can be located at each end of the tank, just inboard of the head-to-shell weld seam. The combined straps should have a design failure point of at least eight times the weight of the tank and the fuel.

\subsubsection{Research and Development Needs}

Field-testing to resolve nagging issues related to on-road durability, reliability, and performance is needed to strengthen customer acceptarice. Near-term improvements are needed to improve the customer interface with the LNG fuel stalion and vehicle. LNG fuel tanks should have more reliable liquid level measurement and overfill protertion systems, and lower cost tanks are also needed. Vehicle, engine, and fuel tank manufacturers should collaborate to develop more integrated fuel storage and supply systems that are less expensive to manufacture and install. 
Long-term research is needed to develop lightweight, conformal LNG storage tanks that could be easily integrated into smaller vehicles. Research is also needed to develop lightweight materials that do not outgas and compromise the vacuum insulation.

Figure 5-3. 30-Gallon LNG Tank for Medium-Duty Vehicle Applications (photo courtesy MVE Cryogenics)

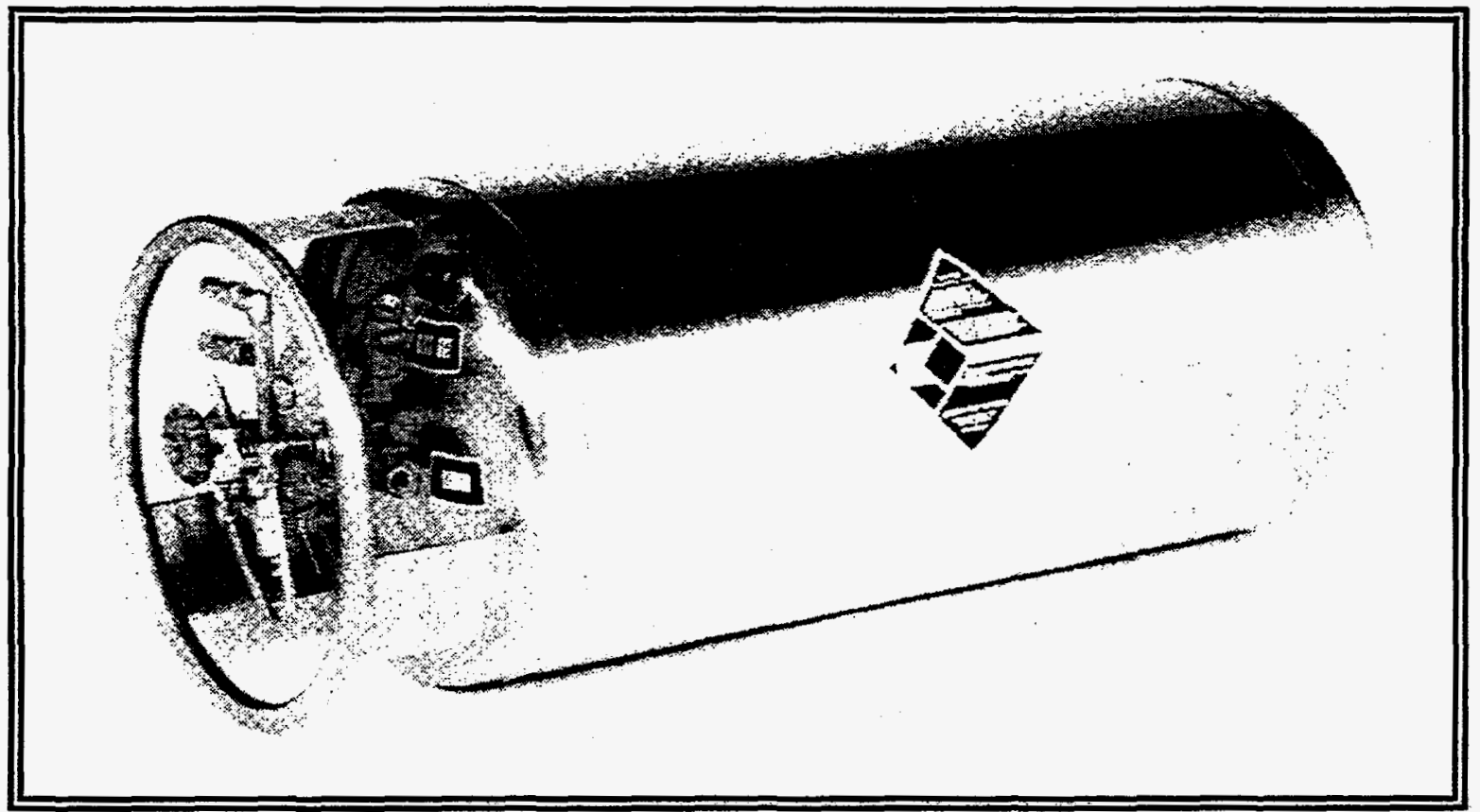

Figure 5-4. 160-Gallon LNG Tank with Submerged Pump for Transit Bus Applications (photo courtesy CVI, Inc.)

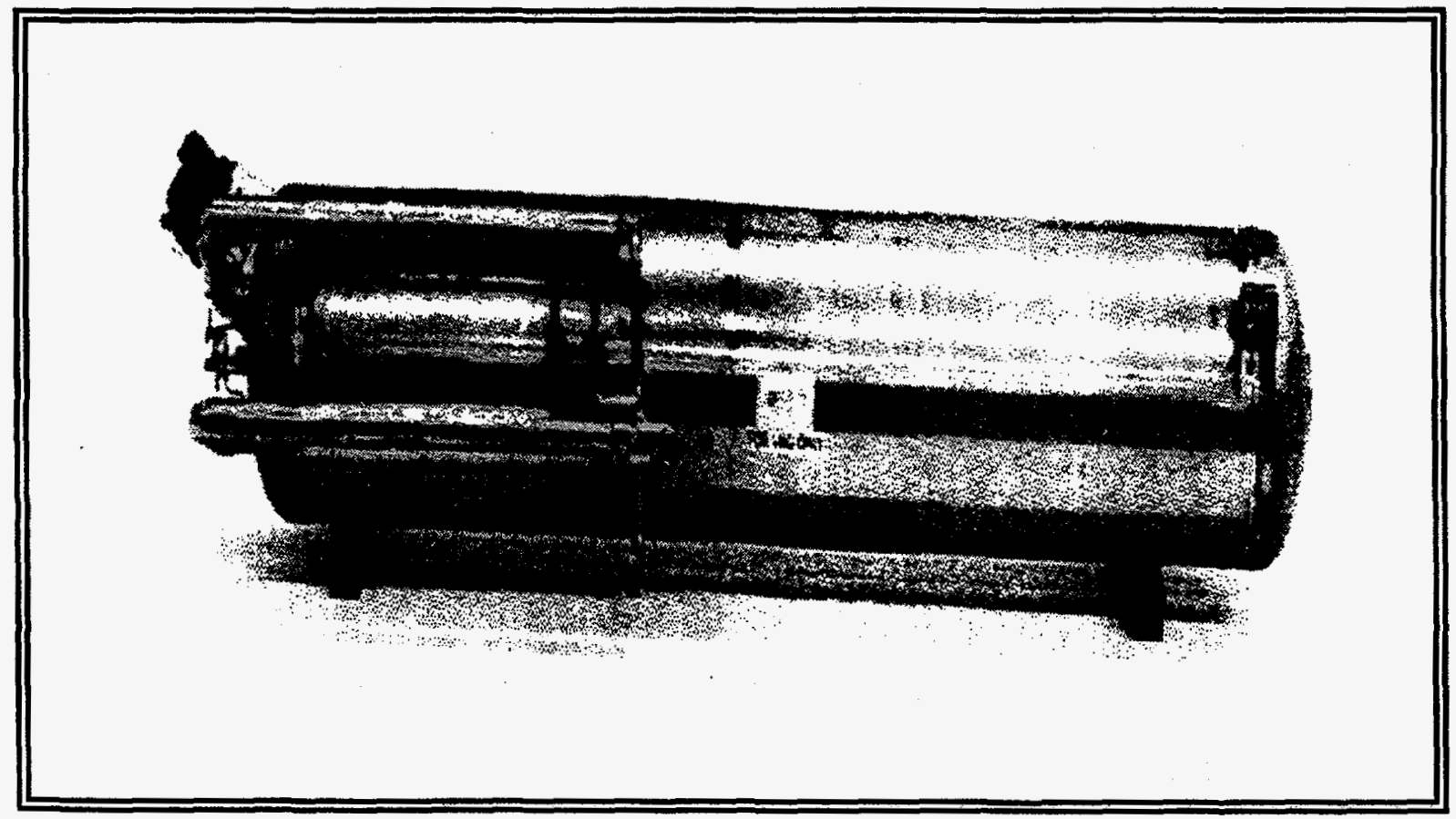




\subsection{Natural Gas Engines and Power Systems}

Many articles in the popular tra.de journals targeted at the fleet manager, the mechanic, and the heavyduty engine industry give the reader the impression that conversion of medium-duty and heavy-duty engines to natural gas fuels is a difficult and complex task. The articles discuss the use of natural gas fuels in the context of many coutemporary issues that are critical to the continued prosperity, and perhaps the very survival, of the diesel ingine, such as tailpipe emissions, fuel efficiency, fuel quality and specifications, environmental liability, occupational health and safety, fire hazards, initial equipment cost, mechanic and operator training, and reliability. The broad range of technical data, personal testimonies, and opinions, often offering conflicting information, make it difficult to objectively evaluate the benefits and costs of the use of natural g,as fuels in engines. This section briefly discusses the development of natural gas, gasoline, and diesel fuels; the evolution of the internal combustion engine; and the most popular, commercially available natural gas engines.

The internal-combustion engine: is universally used to power our industrial economy and to provide unprecedented mobility. Open-cycle piston engines are used in nearly all motor vehicles, except for a small number of battery electric drive vehicles. In open-cycle engines, fuel is burned with air, the combustion gases are used to dis work, and the spent gases are exhausted to the atmosphere. Both opencycle piston and turbine engine:s are used in stationary power applications.

Modern engines must be designed to extract as much work from the fuel as possible (be efficient) while preventing the discharge of hannful chemicals to the atmosphere. Contemporary environmental standards require open-cycle engines to bə extremely clean. Unfortunately, it is difficult to achieve low cost, efficiency, performance, and environmental goals when the basic fuel is a complex mixture of petroleum hydrocarbons and chemical additives.

\subsection{Natural Gas Is Not a New Engine Fuel}

Natural gas fuels make it possitle for engine designers to achieve both high efficiency and extremely low emissions with open-cycle engiies. To achieve best results, however, engines must be optimized to operate on natural gas, rather than be simple conversions of diesel or gasoline engines.

Fortunately, it is not difficult to design clean, efficient, and reliable natural gas engines. However, it is difficult for a fleet operator to buy a natural gas engine at a competitive price when they are not mass produced and marketed.

The engine industry has a long liistory of modifying engine designs and production schedules to accommodate changes in fuel quality or fuel availability. In fact, one of the first engines built was powered by $\mathrm{CH}_{4}$ and was demonstrated in 1867 by Henry Otto at the Paris Exposition. But, at that time, methane gas was difficult to harıdle and liquid fuels were sought. Gasoline was first used in the fourstroke, Otto-cycle, spark-ignition engine around 1884. Rudolph Diesel introduced the first compression ignition, diesel-cycle engine in 1893 using an air blast to inject the fuel (powdered coal) into his highcompression engine. Shortly af terward, he adopted the Ackroyd-Stuart mechanical gas-oil injector to create the compression-ignition diesel engine.

In the past 100 years Otto- and diesel-cycle engines have been continuously improved to operate on a broad range of gaseous and liquid fuels, especially petroleum-derived gasoline and diesel fuels. The composition of liquid fuels has thanged frequently as new technology, wartime demands for higher power engines, increased emphisis on efficiency, and, most recently, requirements for low emissions have created demand for fuel additives and reformulation that achieved desired results. Gasoline and diesel fuels have evolved to doninate the transportation engine market; natural gas fuels have been limited to large, stationary power applications. 
From about 1910 to the 1960 s, gasoline engines dominated the U.S. transportation market because of the relatively light weight of the engine block and the superior performance of leaded, high-octane gasoline. In the past 30 years, however, environmental problems have made gasoline engines more expensive and less attractive, especially in the large-engine market. As a result, high-performance diesel engines have steadily gained market share in medium- and heavy-duty commercial applications because of the development of turbochargers and the inherant high thermal efficiency, ruggedness, reliability, and lower operating cost of the diesel cycle. Emissions reductions from gasoline and diesel engines, however, still continues to be a technological and economic challenge.

Hybrid engines that use design elements of both the Otto and diesel cycles have also been developed for military, marine, and stationary power applications. For example, multifuel heavy-duty engines, with both spark-ignition and pilot-ignition configurations, have been used very successfully for more than 60 years. These engines are capable of operating on a wide spectrum of petroleum and natural gas fuels with minimal modifications to the basic engine designs.

In addition, lean-burn, stratified-charge engines have been developed. Lean-burn, spark-ignition engines combine high thermal efficiency with low emissions. In recent years, lean-burn technology has been developed for several high-performance heavy-duty gas engines.

LNG or LCNG will become the fuels of choice for nearly all medium- and heavy-duty fleet vehicles that require superior performance, low operating costs, significant emissions reductions, and other environmental and public health benefits. Ironically, natural gas, the fuel of choice for today's engines, is the same simple, clean fuel- $\mathrm{CH}_{4}-$ used by Henry Otto to develop the spark-ignition engine 130 years ago. The engine industry is "going back to the future."

\subsection{Natural Gas Engines}

Various natural gas engines are commercially available or in development for motor vehicle and stationary applications. Design strategies used by manufacturers include dedicated natural gas, bi-fuel gasoline, dual-fuel diesel, and multifuel engines with either spark-ignition or pilot-ignition combustion systems. Engines are available as OEM production models, factory-rebuilt engines, and aftermarket conversions.

In the past 10 years, GRI, DOE, NREL, and others, in association with Cummins, Hercules, Mack, Ford, Chrysler and other engine and vehicle manufacturers, have supported an aggressive program to develop commercial natural gas engines for a variety of co-generation, industrial, air-conditioning, and transportation applications. NGV engines have been developed in power ratings appropriate for a broad variety of applications, including LDVs, heavy-duty trucks, off-road equipment, boats, and locomotives.

Conversion costs for diesel and gasoline engines vary widely, depending on several variables. These may include the horsepower rating of the engine, the number of cylinders, the type of conversion system, whether an engine rebuild is performed at the time of conversion, the type and size of onboard natural gas storage system, the type of engine controls, the type of emission controls, the number of engines produced, and other many other commercial factors. The incremental cost, or premium, for a natural gas engine can range from slightly more than a baseline gasoline engine to more than $\$ 50,000$.

The cost for the spark-ignited diesel conversion system for six-cylinder engines begins at approximately $\$ 7,200$. Dual-fuel and lean-burn conversion systems begin at about $\$ 5,000$. These estimates are for the engine conversion systems only, and do not include the cost of onboard LNG storage tanks, transfer pumps, CNG cylinders, tubing, engine overhauls or rebuilds, or labor. These conversion systems do not 
optimize the engines for natural gas and are, therefore, not as efficient or clean as dedicated OEM engines.

Many engine design strategies have been discussed in technical journals and trade magazines and presented at conferences and trade shows. The trade-offs associated with the most popular technologies used in heavy-duty natural gas engines significantly affect efficiency, fuel economy, performance, and emissions. Most heavy-duty natural gas engines derive from diesel-cycle engines and are converted to either stoichiometric spark-ignition or pilot-ignition combustion strategies. The resulting natural gas engine generally has lower emissions, similar performance, slightly lower efficiency, and higher heat rejection than its diesel counterpart.

The four most common engine design strategies for converting medium- and heavy-duty diesel engines to operate on natural gas are as follows:

1. Dedicated, spark-ignited lean-burn

2. Dual-fuel pilot ignition

3. Stoichiometric spark-ignition

4. Direct injection.

These diesel conversion strategies, gasoline engine conversion strategies, aftermarket conversion systems, and available OEM engines are discussed in the following sections.

\subsubsection{Lean-Burn Combustion}

The most common type of engine conversion is "lean-burn combustion," in which 30 to 50 percent excess air is used in the combustion process. The use of excess air has three benefits. First, sufficient oxygen is available to obtain complete combustion, thus producing low $\mathrm{CO}$, particulate, and hydrocarbon emissions. Second, the extra air lowers ovirall combustion temperatures and reduces $\mathrm{NO}_{\mathrm{x}}$ formation. Third, leanburn combustion increases thermal efficiency. In lean-burn engines, emissions are controlled largely within the combustion chamber, rather than relying on exhaust after-treatment. Ultra-low emissions are obtained with a strategy of low engine-out $\mathrm{NO}_{\mathrm{x}}$ and use of a simple oxidizing catalyst. The capability to achieve low engine-out $\mathrm{NO}_{\mathbf{x}}$ is constrained only by the lean misfire limit and allowable hydrocarbon emissions.

Lean-burn combustion is currently being pursued by all the major gasoline and diesel engine manufacturers, and some afternlarket companies, as the preferred technology for heavy-duty natural gas engines. Compared to diesels, these engines offer significant reductions in $\mathrm{NO}_{\mathrm{x}}$ while virtually eliminating smoke- and fuel-derived particulate emissions. Thermal efficiency approaches that of diesels at wide-open throttle, but is significantly lower than diesel at part-load conditions.

Lean-burn, spark-ignition natural gas conversions of several gasoline and diesel engines have been developed for transportation and stationary power applications. As a result, several companies now offer extremely clean, fuel-efficient natural gas engines designed for service in power, co-generation truck, and bus applications that form the core of the commercial market.

\subsubsection{Dual-Fuel “Pilot-Ignition” Diesel Combustion}

Dual-fuel engines that operate on both diesel and natural gas fuels have existed since the early 1900 s. "Pilot-injection" and "fumigation" are other terms used to describe elements of this combustion system. A dual-fuel engine operates on a mixture of diesel and natural gas. The diesel injection system is left in place, but the diesel injectors or common rail fuel pump is modified to inject only enough diesel fuel to obtain auto-ignition. Natural gas is then introduced into the cylinder to provide the energy required for 
the power stroke. In mechanical systems, the natural gas is mixed or "fumigated" into the intake air just prior to introduction into the engine cylinder. Modern engines use electronic control systems to inject low-pressure natural gas directly into the intake manifold or throttle body. Both fuels are used together to power the engine. In general, emissions from dual-fuel engines are lower than emissions from diesel engines, but higher than emissions from dedicated natural gas engines. Engine efficiency of modern dualfuel engines is higher than that of lean-burn, spark-ignited engines.

Because the dual-fuel engine uses both diesel fuel and natural gas, emission reductions are closely related to the duty cycle of the vehicle. Engines that operate continuously at high load have lower emissions relative to diesel than engines that operate at idle or partial load for extended periods.

The payback period required to recover the initial investment in a dual-fuel engine is a direct function of the amount of fuel displaced. Diesel displacement for an engine can range from only 50 percent for a transit bus that operates at low loads and idle speed for extended periods to as much as 99 percent for large, stationary power and marine engines that operate continuously at constant loads.

Stoichiometric dual-fuel natural gas engines can certify to ultra-low emission standards through the use of a three-way catalyst and electronically controlled fuel injection.

\subsubsection{Stoichiometric, Spark-Ignition Diesel Combustion}

Most gasoline and some diesel engines use stoichiometric combustion strategies, which means that the mixture of fuel and air used in the combustion process is chemically balanced. The fuel system is designed to provide just enough air (oxygen) to combust the fuel. Stoichiometric combustion with sparkignition is one strategy used to convert diesel engines to dedicated natural gas engines. These simple, spark-ignited natural gas conversions generally have very low emissions, but have less power and are less efficient than stoichiometric diesel or lean-burn natural gas engines.

Diesel engines can be converted to natural gas by adding a spark-ignition system and natural gas delivery system. Natural gas may be delivered to the engine cylinder by simple mechanical fumigation with intake air in a low-pressure mixer or by electronically controlled direct injection into the throttle body or intake manifold. Additional engine modifications, including redesigned pistons, customized camshafts, and improved seals, may be made. The compression ratio may or may not be modified. If the engine uses electronic controls, an interface with the OEM electronic control module must be installed. The OEM diesel delivery system is completely removed.

Many gas injection strategies are available to the engine builder. Older, nonelectronic engines use lowpressure mixers and carburetors that are simple and reliable. Mechanical mixer systems, however, may not provide the precise mixture control and cylinder-to-cylinder distribution possibility offered by modern electronic injector systems and needed to meet emission standards. Electronically controlled natural gas injectors require moderate natural gas pressures to operate properly.

Closed-loop engine control systems require an oxygen sensor in the exhaust line and some type of electronic control system, whereas open-loop control systems have no feedback system and rely simply on preset engine controls. Use of natural gas fuels in mechanically controlled diesel engines has been shown to significantly reduce some emissions compared to diesel. However, certification of diesel and natural gas engines to current emission standards generally requires electronic control systems. The use of aftermarket conversion kits that are not fully integrated and warranted with manufacturer's hardware and software is not recommended.

Stoichiometric natural gas engines can meet future ultra-low emission standards through the use of a three-way catalyst and electronically controlled fuel injection. 


\subsubsection{Direct Injection}

Theoretically, a natural gas en that further advances will be made. Unfortunately, for the past 70 years, the focus of engine research and development has been to optimize performance of diesel and gasoline engines. Work to reduce emissions and improve efficiency has besn a priority only in the past 20 years or so.

Several engine manufacturers are conducting research on direct-injection natural gas engines. For example, direct injection of LNG into the cylinder has the potential for savings by using LNG's physical energy or "cold" energy to achieve higher effective energy densities. Late-cycle direct injection may enable natural gas engines to auto-ignite. However, late-cycle, direct cylinder-injection requires injectors capable of producing pressures exceeding $1,000+$ psig. Other ignition strategies being explored for direct-injection natural gas engines include judicious scavenging of exhaust heat.

\subsubsection{Conversion of Gasoline Engines to Natural Gas}

Until recently, it was relatively easy to convert spark-ignition gasoline engines to burn natural gas. Because spark-ignition enginesi generally have compression ratios of 10.5 to 1 , fuel pre-ignition is less of a problem than with higher-coinpression engines. The older mechanically controlled carburetor engines were converted simply by replacing the gasoline fuel system with a natural gas mixer designed to blend natural gas with incoming air. However, modern electronically controlled engines require significantly more engineering to integrate the conversion system with the OEM engine control and diagnostic systems. Conversion systems nust be compatible with the onboard diagnostic systems. These advanced systems must use engine and exhaust sensors and electronic modules to fine-tune the injection of gas into each cylinder.

\subsubsection{Other Issues Associated with Heavy-Duty Natural Gas Engines}

All natural gas engines can operate with either LNG or LCNG fuel systems. Because the LNG is vaporized en route to the engine, the engine installed on an LNG vehicle will see virtually the same fuel as the engine on a compressed natural gas vehicle. However, LNG and LCNG systems operate at different fuel pressures and velicles must be designed appropriately.

Fuel Pressure--The fuel pressure required by a particular engine fuel system can have a significant impact on the cost and performance of the fuel storage and delivery system. For example, the DDC 6V92 engines installed on several Houston Metro transit buses require higher fuel intake pressures than could be provided by the low-pressure fuel storage tanks. LNG fuel pumps were required to transfer the fuel from the low-pressure storage tank at the pressure required by the engine. The Cummins L10-300G engines installed on the JBK fleet, however, do not require LNG pumps. The moderate pressures required by these engines can tie provided with a higher pressure tank with pressure build capabilities.

Fuel Quality-Engines are sersitive to variations in fuel quality. For example, fuel with variable concentrations of propane could cause some engines to experience variable emissions or performance. Some engine designs may require fewer safeguards against changes in composition than others. Nevertheless, LNG and LCNG offer fleet operators the opportunity to specify a consistent, high-quality fuel. Standard fuel quality enajles the designer to precisely define lean misfire limits and control stoichiometric combustion. This will yield increased efficiency and extremely low exhaust emissions. 
Charge Air Cooling-LNG operation may provide a good opportunity for charge-cooiing, inter-cooling, or after-cooling, although control and icing problems must be solved. Integration of the LNG heat exchanger with an intake charge cooler or turbo-charged engine inter-cooler, could increase the density of the intake charge and increase maximum power.

\subsection{OEM Natural Gas Engines}

Most diesel engine manufacturers are developing or offering natural gas versions of their more popular engines. The availability of a particular model, however, at the time you want it, at a competitive price, is more problematic. The status of some of the more popular natural gas engines is discussed below.

Figure 6-1 summarizes the horsepower ranges for some of the most popular medium- and heavy-duty diesel engines manufactured in the United States for the transportation market. Manufacturers currently offer or are developing many of these engines in natural gas models. Aftermarket conversion kits are also available for retrofit of either spark-ignition or pilot-ignition natural gas fuel systems for several of the more popular engines.

Cummins, Caterpillar, Mack, Navistar/International, and DDC are the most active OEM suppliers of heavy-and medium-duty engines for the bus and truck market. Tecogen and Deere also provide engines for the medium-duty market. Chrysler, Ford, General Motors, and the Japanese manufacturers provide light-duty engines for their sedans, vans, minivans, and pickups.

\subsubsection{Cummins Engine Company}

Cummins Engine Company has made a significant commitment to commercial production of a family of natural gas engines ranging in power from $150 \mathrm{hp}$ to $450 \mathrm{hp}$ (see Figure 6-2). The B5.9G, C8.3G, and L10G engines are available today. The M11G, rated at $340 \mathrm{hp}$, is scheduled for commercial production in 1998. The N14G is being developed. CARB has certified the B5.9G, the C8.3G and the L10G natural gas engines produced by Cummins for bus and truck applications. The lean-burn engines, which are fully compatible with CNG and LNG fuel-delivery systems, feature advanced, full-authority, electronic controls and closed-loop air/fuel ratio management.

They meet CARB emissions standards without the use of a catalytic converter and comply with 1997 EPA emissions standards without using an exhaust catalyst (see Figure 6-3). Using an oxidation exhaust catalyst, the L10G, the B5.9G and the C8.3G meet 1998 CARB ULEV standards. The L10G, available with 300 and 280 ratings, delivers peak torque of $900 \mathrm{lb}-\mathrm{ft}$ at $1,300 \mathrm{rpm}$ and the C8.3G, available at two ratings yielding 250 , delivers peak torque of $750 \mathrm{lb}$ - $\mathrm{ft}$ at $1,400 \mathrm{rpm}$ for one rating and $660 \mathrm{lb}-\mathrm{ft}$ at 1,400 $\mathrm{rpm}$ for the second rating. The B5.9G is available in $150 \mathrm{hp}$ and $195 \mathrm{hp}$ ratings. These engines have maximum parts commonality for ease of maintenance and repair.

Additional information is available from the Cummins Web site (http://www.cummins.com). 
Figure 6-1. Heavy-Duty Natural Gas OEM Engines

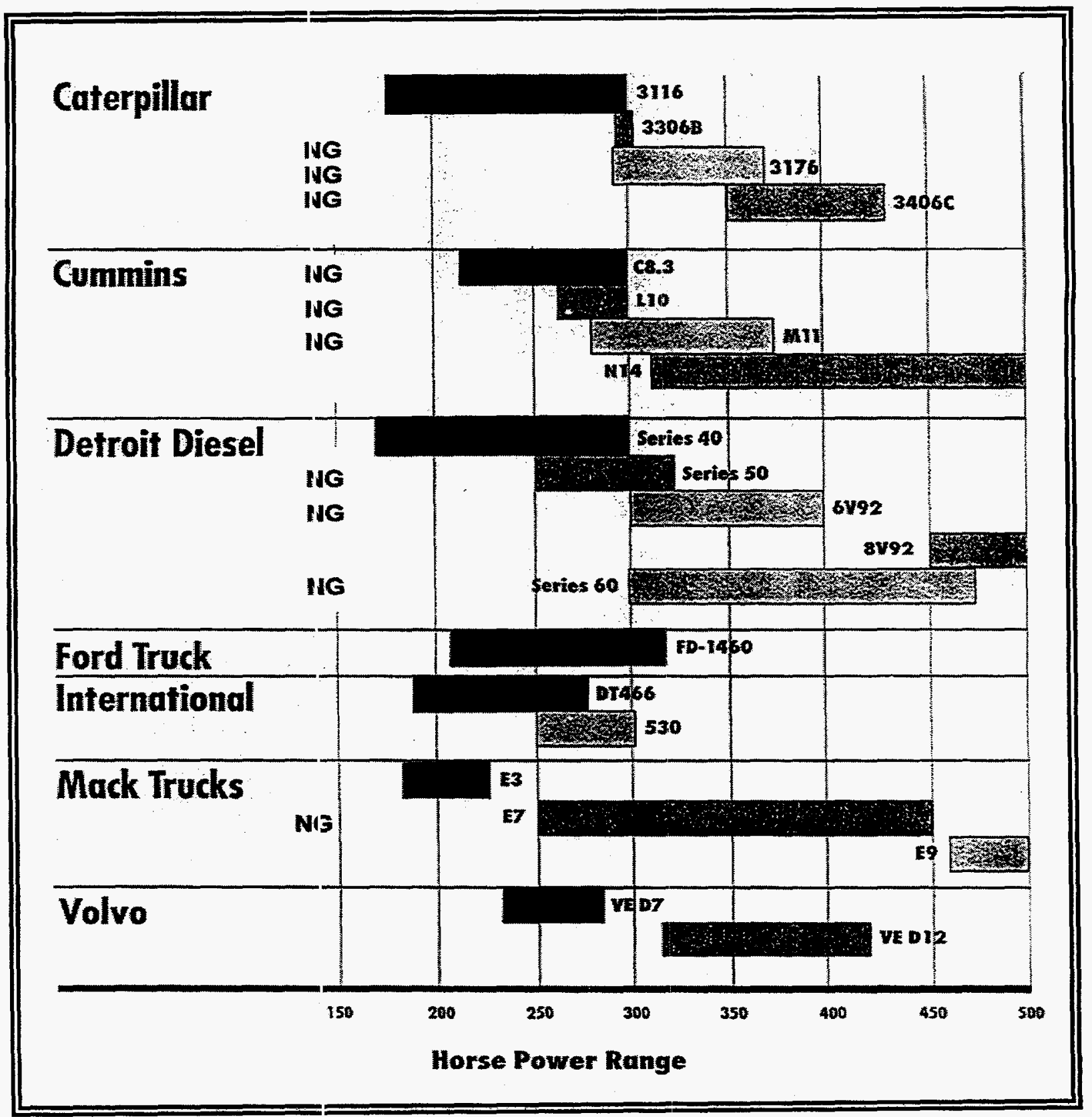


Figure 6-2. Cummins Natural Gas Engines

\section{Cummins Automotive NG Engines}

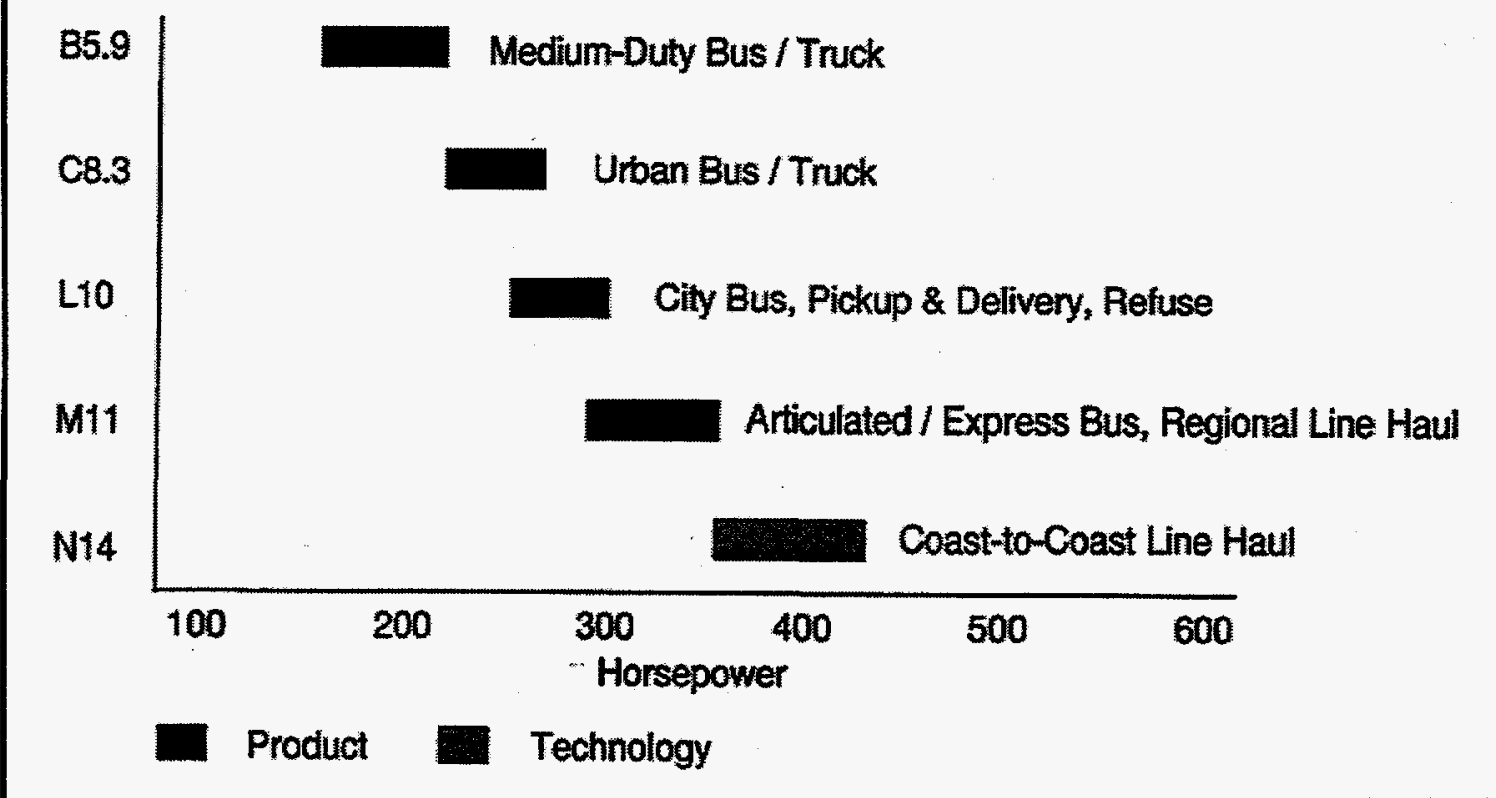

Figure 6-3. Typical Emissions from a Natural Gas Engine

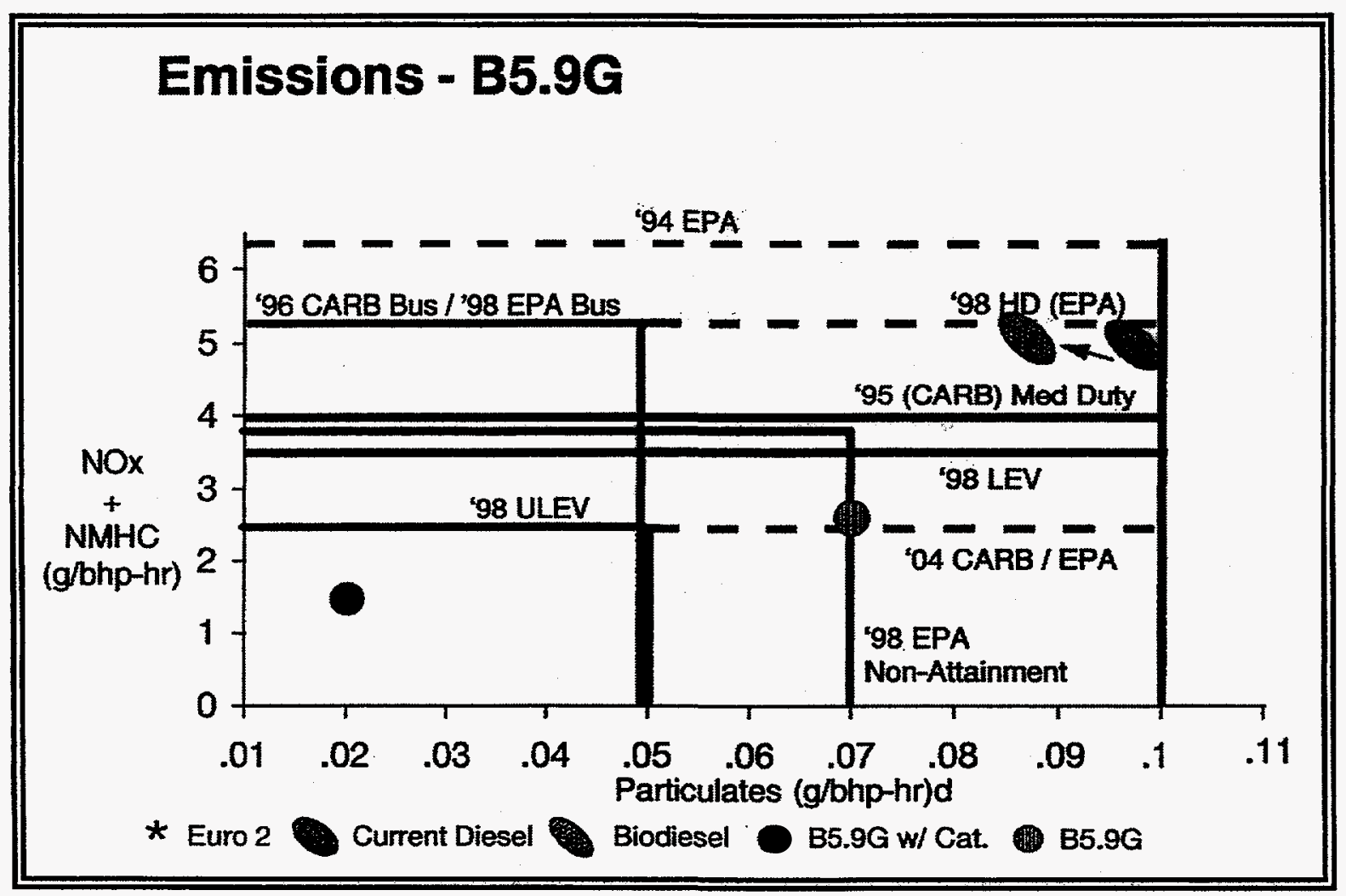




\subsubsection{Detroit Diesel Corporation}

DDC offers two natural gas en gines, the Series $30 \mathrm{G}$ and the Series 50G, ranging in power from $210 \mathrm{bhp}$ to 275 bhp. The series 60G, a 300-bhp to more than 450-hp engine, is in development. The older 6V92 engine is also in natural gas service, generally with transit fleets.

The Series 30 G is a 7.3-liter, four-stroke, eight-cylinder engine using spark-ignited, lean-burn combustion, turbo-charging, ard electronic engine controls to provide superior fuel economy and knockfree operation. The engine is available rated at $210 \mathrm{bhp}$ with a peak torque of $485 \mathrm{lb}-\mathrm{ft}$ at $1,500 \mathrm{rpm}$. A new piston has been designed for a low-pressure gas supply capable of CNG or LNG operations.

The Series $50 \mathrm{G}$ is an 8.5 -liter, tour-stroke, four-cylinder engine using spark-ignited, lean-burn combustion and electronically controlled low-pressure gas metering. It delivers torque and power ratings nearly identical to the Series 50 diesel engine. Standard ratings range from $260 \mathrm{bhp}$ to $275 \mathrm{bhp}$ with peak torque of $890 \mathrm{lb}-\mathrm{ft}$ at $1,200 \mathrm{pm}$. The engine has a 10:1 compression ratio. It is certified to CARB standards without a catalytic ccnverter.

\subsubsection{Caterpillar}

Caterpillar offers a broad range of dedicated and dual-fuel natural gas-powered, factory-warranted engines for vehicle and industrial applications. The 3176B, 3126B, 3406E, C10, and C12 dual-fuel engines are available or are being developed through Power Systems Associates as described below. The dedicated natural gas engine designed for heavy-duty truck applications is the G3306. MK Rail used the $3516 \mathrm{~A}$ engine for an LNG-powered locomotive.

Dedicated Natural Gas Engines-The G3306 is a 10-liter engine that uses a stoichiometric, sparkignition combustion strategy. It is rated at $250 \mathrm{bhp}$ at $2100 \mathrm{rpm}$ and torque of $820 \mathrm{lb}-\mathrm{ft}$ at $1200 \mathrm{rpm}$. Certified emissions are below the 1998 federal standard with a three-way catalyst.

Dual-Fuel Engines-Power Systems Associates and Clean Air Partners, Inc--Caterpillar Inc., in association with Power System:; Associates and Clean Air Partners, Inc. (CAP), offers the 3176B natural gas dual-fuel engine. This 10.3-liter pilot-ignition design offers a state-of-the-art, electronically controlled, multipoint, port-injected natural gas injection system with Caterpillar's electronically controlled diesel injection system. The engine is available in $270 \mathrm{hp}$ to $350 \mathrm{hp}$ configurations certified to meet transit bus $1996 \mathrm{LEV}$ emi ssion standards. The natural gas injectors require $100 \mathrm{psig}$ rail pressure.

In addition to the warranted ducl-fuel engine, a modification kit has been developed to convert existing $3176 \mathrm{~B}$ diesel engines to the dual-fuel system. The system allows full use of the standard Caterpillar diesel electronic diagnostic and fleet management information systems. Full diesel operation is available at any time should the vehicle $r$ un out of natural gas. In addition, the engine can be converted back to diesel at trade time.

The average substitution of natural gas for diesel is 80 percent. Under sustained heavy load use, substitution could exceed 90 percent; under light load conditions, substitution will be less.

Additional dual-fuel engines are in development that use the same efficiency and operating characteristics as the 10 -liter $3176 \mathrm{~B}$ engine. The 7.2-liter, dual-fuel 3126 engine will be rated in the 200 to $300 \mathrm{bhp}$ range and the 14.6-liter $3406 \mathrm{E}$ will be rated from 350 to $485 \mathrm{bhp}$. The 3126 is designed for medium-duty applications. Work is also under way to develop natural gas dual-fuel conversions for the 10-liter C-10 and the 12-liter C-12. LEV emission levels will be available as an option for all ratings. Contact kvcmpbell@catpower.com for inore information. 
Morrison Knudson-The proven CAT G3516 STA power plant is used to power the MK1200G electricdrive locomotive. The engine produces $1,200 \mathrm{bhp}$ with extremely low emissions (only 2 grams of $\mathrm{NO}_{\mathrm{x}}(\mathrm{bhp} / \mathrm{h}$ ). The engine requires very little maintenance when operated on $\mathrm{LNG}$; it was modified to enhance reliability and maintainability and yield the lowest possible life-cycle cost. Microprocessorbased control systems deliver precise systems control, have fewer moving parts, and facilitate maintenance through real-time diagnostics and analysis. The 3516 engine is commonly used in marine applications, such as large tractor tugs and harbor tugs.

Industrial Gas Engines and Generator Sets-Caterpillar offers a series of industrial natural gas engines ranging in size from the $40 \mathrm{hp}$ at $900 \mathrm{rpm}$, four-cylinder model G3304 to the 4,700 hp at 1,000 rpm, 16cylinder model G3616. These engines can be set up to operate on the most economical fuel available, but can be changed from one fuel to another. The Cat Electronic Ignition System and electronic air/fuel ratio control are used in a lean-burn, open-chamber combustion strategy, allowing the engine to be tuned to meet stringent $\mathrm{NO}_{\mathrm{x}}$ emission standards.

\subsubsection{John Deere}

Development of the John Deere PowerTech 8.1-liter natural gas engine was accelerated through support by NREL, GRI, Southern California Gas Company, and Consolidated Natural Gas Company. The engine has been operated for the equivalent of more than 1.6 million miles in 18 test buses and on dynamometers. The engine has been certified to CARB 1997 heavy-duty emissions standards with emissions well below the limits.

John Deere designed the engine to use a lean-burn combustion system with a full-authority electronic control system for throttle, fuel, ignition, governor, and wastegate; closed-loop and adaptive-learn control system; coil-on spark plug ignition system; and a liquid-cooled and wastegated turbocharger. The engine is rated at $250 \mathrm{hp}$ at $2,200 \mathrm{rpm}$, with peak torque of $800 \mathrm{lb}-\mathrm{ft}$ at $1,350 \mathrm{rpm}$, performance that is

comparable to diesel. Fuel economy has also been equal to diesel, ranging from 6 to 7.4 miles per gallondiesel equivalent in operations in Colorado. Deere claims the engine has better responsiveness and acceleration than diesel.

John Deere has worked closely with Blue Bird Corporation to integrate the PowerTech engine with a compressed natural gas fuel system into the Blue Bird school bus chassis. Additional information is available at the Deere Power Web site (http://www.deere.com/jdpower).

\subsubsection{Ford Motor Company}

Ford Motor Company offers a broad line of light-duty natural gas sedans and trucks. The F250 pickup truck and E250-350 Econoline van/Club Wagon were offered in 1997 in both dedicated and bi-fuel versions. The Contour sedan is also offered in a bi-fuel configuration. The dedicated Crown Victoria, introduced into full production during the 1996 model year, was also offered in 1997.

\subsubsection{Tecogen}

Tecogen offers two dedicated natural gas engine systems, the Tecodrive diesel conversion for the Navistar DT and DTA 466 (7.6-liter) engines and the Tecodrive 4300, a 4.3-liter V-6 engine, rated at 140 hp with peak torque of $195 \mathrm{lb}-\mathrm{ft}$ at $1,400 \mathrm{rpm}$.

The Tecodrive 4300 is based on a GM 427-cubic-inch engine block that has been optimized for natural gas with an 8.3:1 compression ratio, electronic engine controls, and fuel injection. The engine is certified to meet CARB standards. 
The Tecodrive diesel conversion system offers spark-ignition, an electronic engine control, and sequential port injection and closed-loop uel-air mixture control. The stoichiometric combustion process incorporates the more-complet 2 -expansion cycle (the Miller cycle) by modifying the valve timing to control the charge temperature and avoid detonation while retaining the high expansion ratio to provide diesel-like thermal efficiency. The converted engine produces $235 \mathrm{hp}$.

\subsubsection{Fairbanks Morse}

In 1893, Fairbanks Morse was the first U.S. company to successfully market a gasoline engine, and in 1924 Fairbanks developed the ĩrst true compression ignition engine. The company specializes in medium-speed engines ( 400 to $900 \mathrm{rpm}$ ) for marine and stationary power applications ranging in size from $640 \mathrm{bhp}$ to more than $29,1000 \mathrm{bhp}$. The company has been a major provider of opposed piston engines and the Colt-Pielstick engines for power generation in hundreds of challenging marine, offshore, and stationary power and co-generation applications as well as main propulsion systems for more than 45 different classes of U.S. Navy vessels.

Fairbanks Morse engines are available either with dedicated spark-ignition or dual-fuel pilot-ignition natural gas with only 1 percent pilot ignition oil. The pre-combustion chamber ignition design yields emissions of less than 1 gram/thp-h $\mathrm{NO}_{\mathrm{x}}$ for all engines with no after-treatment.

The OP 8-1/8 Series engines are available in 4- to 12 -cylinder models rated at 160 to $300 \mathrm{bhp} / \mathrm{cylinder}$. The Colt-Pielstick PC2 Series 4-cycle/turbocharged engine is a powerful "shock qualified" medium-speed engine that is widely used for co-generation and emergency standby power where reliability and quick startup are critical. It is availatle in 6- to 18 -cylinder models rated at 650 to $737 \mathrm{bhp} / \mathrm{cylinder}$.

The PC4. 2 engine is the largest medium-speed engine manufactured in the United States. It is used primarily in marine applications and is available in 6- to 18-cylinder models rated at 1,629 bhp/cylinder. This engine is 60 percent more fuel efficient than competitive gas turbines and requires less engine room space than slow-speed diesel engines.

\subsection{Aftermarket Natural Gas Engine Conversions}

Many companies offer a variety of aftermarket services and products, ranging from highly engineered conversion kits to individual ccmponents. This section describes the services and products offered by some of the companies active in the conversion of medium-duty and heavy-duty diesel engines to natural gas service.

Aftermarket conversion systems for heavy-duty engines are offered by Vinyard Engine Systems, CAP, Electronic Fuel Control, Inc. (EFC) (formerly Combustion Labs), Econogas, and ECI. Other companies that are major suppliers of natural gas engine components and conversion systems include IMPCO Technologies, GFI, and DAI Controls/Synchro-Start Products, Inc.

\subsubsection{Clean Air Partners, Inc.}

CAP develops and distributes proprietary vehicle conversion kits for both OEM and aftermarket conversions or retrofits. CAP rvorks with BKM, Echlin, DTC, Servojet, and others to develop, manufacture, and distribute elestronic-injector technology and natural gas fuel systems for bi-fuel gasoline and dual-fuel diesel er gines. The company (or affiliates) has supplied natural gas fuel systems for General Motors, Chrysler, Hercules, Cummins, Mercedes, Ricardo, MAN, Belarus, Varity/Perkins, 
and Caterpillar engines. Recently, CAP partnered with Beacon Power Systems to develop NGV conversion kits for the GM V-8 engines used on the full-size van, pickup, and postal service vehicles.

\subsubsection{Electronic Fuel Control, Inc.}

EFC, formerly Combustion Laboratories, offers a closed-loop natural gas, dual-fuel diesel conversion system that can be installed on mechanically controlled, 4-cycle, non-pre-chambered diesel engines. OEM integrity is maintained. Components added to the engine include the natural gas injectors and mixer, the control electronics and sensors, a diesel pilot actuator, a dash-mounted diesel/natural gas selector switch, and an oxidation catalyst. Natural gas pressures at the injectors must be between 125 and 200 psig. The system is speed and load sensitive and will displace up to 80 percent of diesel fuel when operated on natural gas.

Conversion systems have been installed on more than 400 medium- and heavy-duty vehicles operated by many pioneers in the natural gas vehicle business, including the city of North Miami, Atlanta Gas Light, and Walt Disney World.

\subsubsection{Econogas}

Econogas has developed a diesel pilot fuel system for conversion of large-displacement, four-stroke diesel engines to "dual-fuel" natural gas operation. The conversion system incorporates a fumigation strategy for introducing natural gas into the cylinder with the intake air. The conversion can be installed on engines with both mechanical or electronically controlled diesel injectors. Components added to the engine include the gas-air mixer, the gas control module, the electronic control module, a dash-mounted diesel/natural gas selector switch, and an exhaust catalyst.

The Econogas system has been installed on several trucks operated by Waste Management in the Denver area. The kit is certified to meet Colorado emission requirements. The developer claims 60 to 80 percent displacement of diesel fuel with natural gas.

\subsubsection{Vinyard Engine Systems}

Vinyard provides dedicated gaseous fuel conversion for diesel engines. Lean-burn combustion technology is used, controlled by a computerized engine-management system. The company claims conversions provide equal power and torque to the base diesel with excellent fuel economy and one-third the emissions of diesel, and that new and used engines can be economically converted. Kit components include pistons, rings, cylinder heads, turbocharger, fuel components, and the engine-management system. Several conversion packages are available for four-stroke diesel engines, such as Cummins 6BT 5.9 liter, Cummins 4BT 3.9 liter, Cummins L10 liter, Cummins N14 liter, Cummins NTC 350, 400, and Navistar DT-466. Fully remanufactured engines are also available for certain stationary applications, such as gen-sets and pump stations.

\subsubsection{Energy Conversions, Inc.}

ECI provides natural gas fuel systems and engine rebuild kits for large stationary engines. The ECI conversion has been applied to EMD 645 E3 locomotive diesel engines. It uses early-cycle, low-pressure gas injection similar to the PING system for DDC two-stroke diesels. However, microprocessor control is employed, the EMD pistons are modified, and a complex charge air cooling and heating system is used to provide optimum engine operation at all throttle notches (i.e., from 100 percent diesel at idle to more than 90 percent natural gas at maximum power). 
The ECI system reportedly achieves full diesel-rated power with a lean-burn combustion system. Preliminary exhaust emission tests have been conducted on the Burlington Northern LNG locomotive in cooperation with Southwest Research Institute. Because there are no emissions standards or test procedures applicable to locomotives, the tests were run at various notch settings while measuring power, $\mathrm{rpm}$, emissions, and fuel consumption. At notch $8, \mathrm{NO}_{\mathrm{x}}$ was reduced by 50 to 63 percent from 8.4 to 11.4 $\mathrm{g} / \mathrm{bhp}-\mathrm{h}$ on diesel to about $4.2 \mathrm{~g} / \mathrm{bhp}-\mathrm{h}$ on natural gas. PM and NMHCs were reduced slightly. CO increased slightly, but at $10 \mathrm{~g} / \mathrm{thp}-\mathrm{h}$, it was still relatively low. ECI personnel believe that all emissions would be lower for their current LNG engine relative to this early unoptimized engine.

\subsubsection{Southwest Research Institute}

EMD, in cooperation with Union Pacific Railroad and Southwest Research Institute, is developing an LNG-diesel, dual-fuel, pilot-ignition system based on the EMD16-71063A engine. The EMD system uses late-cycle, high-injection fressure with hydraulically actuated gas injectors located in the cylinder head near the diesel fuel, and $\mathrm{r} \in$ duced exhaust emissions. Development is proceeding from computer analyses and single-cylinder engine tests through full-scale engine tests, locomotive conversion, and field tests.

The combustion system, called LACHIP, reduced $\mathrm{NO}_{\mathrm{x}}$ emissions by 65 percent, from 11 to $3.5 \mathrm{~g} / \mathrm{bhp}$-h. Field tests are planned on a F5SPH passenger/commuter locomotive at the federal test tracks in Pueblo, Colorado, and at the Southern California Regional Rail Authority. The direct-injection gas injection was developed by Moog Controls. L.NG locomotive engine development is also under way at Caterpillar, DDC, and General Electric. These and the previously discussed projects are summarized in Table 6-1.

Table 6-1. Summary of Current LNG Locomotive Engine Development Projects

\begin{tabular}{|c|c|c|c|c|c|c|}
\hline Manufacturer & Model & Technology & $\begin{array}{l}\text { Gas Admission } \\
\text { Pressure (psig) }\end{array}$ & $\begin{array}{l}\text { Ignition } \\
\text { Strategy }\end{array}$ & $\begin{array}{l}\text { Tractive } \\
\text { Power } \\
\text { (hp) }\end{array}$ & $\begin{array}{l}\text { Stage of } \\
\text { Development }\end{array}$ \\
\hline Caterpillar & G3516 SI & $\begin{array}{l}100 \% \text { gas } \\
\text { zonversion, } \\
\text { hrottled }\end{array}$ & $\begin{array}{l}35 \text { to regulator, } \\
<1 \text { to mixer }\end{array}$ & $\begin{array}{l}\text { Spark- } \\
\text { ignited }\end{array}$ & $\sim 1,200$ & $\begin{array}{l}\text { Prototype in } \\
\text { service by } \\
\text { MKRail }\end{array}$ \\
\hline DDC & $16 \mathrm{~B} 149$ & $\begin{array}{l}\text { Jual-fuel, } \\
\text { | igh-pressure, } \\
\text { late-cycle gas } \\
\text { injection }\end{array}$ & $-3,000$ & Pilot diesel & 2,000 & Planning stage \\
\hline $\mathrm{ECl}$ & EMD645E3 & $\begin{array}{l}\text { Jual-fuel, low- } \\
\text { pressure gas } \\
\text { injection }\end{array}$ & 100 & Pilot diesel & 3,000 & $\begin{array}{l}\text { Field-Testing: } \\
\text { revenue service } \\
\text { since December } \\
1991\end{array}$ \\
\hline EMD & $16-71063 A$ & $\begin{array}{l}\text { Dual-fuel, } \\
\text { ligh-pressure, } \\
\text { late-cycle gas } \\
\text { injection }\end{array}$ & $>3,000$ & Pilot diesel & 4,000 & $\begin{array}{l}\text { Under } \\
\text { development; } \\
\text { field-testing } \\
\text { expected late } \\
1997\end{array}$ \\
\hline GE & DASH-8 & 'àas injection & $\begin{array}{l}\text { Information not } \\
\text { available }\end{array}$ & $\begin{array}{l}\text { Information } \\
\text { not available }\end{array}$ & 4,000 & $\begin{array}{l}\text { Under } \\
\text { development; } \\
\text { field-testing } \\
\text { expected late } \\
1997\end{array}$ \\
\hline
\end{tabular}




\subsubsection{DAl Controls/Synchro-Start Products, Inc.}

DAI Controls Divisions, Synchro-Start Products, Inc., develops electronic metering and control systems to convert gasoline engines to bi-fuel operation and diesel engines to dedicated natural gas. The Translator is the bi-fuel system. It is designed to work with the OEM ECU to control the flow of fuel to the engine.

The Translator reads the signal sent from the ECU and relays a modified signal to the natural gas metering system. This approach takes full advantage of the vehicle ECU and its capability to precisely adjust fuel/air delivery. All ECU features are retained, including built-in diagnostic functions. The Translator system features adaptive learning and simple installation. Pro-Lean conversion kits are used to convert diesel engines to spark-ignition natural gas. The kits use a lean-burn combustion strategy.

\subsubsection{Beacon Power Systems, Inc.}

Beacon Power Systems, Inc., developed the popular natural gas conversion kit for USPS vans. The company also develops kits for the GM full-size van and pickup. The company specializes in developing complete bi-fuel or dedicated vehicle conversion systems for specific applications featuring CARBcertified, closed-loop, computer-controlled fuel-injection systems using the OEM-supplied computer together with a patented electronic translator. Kits are fully engineered to integrate components, simplify installation, reduce complexity, and achieve good emissions, storability, driveability, and reliability. All OEM diagnostics are retained and functional and all required parts are provided and warranteed.

\subsubsection{IMPCO Technologies}

IMPCO is one of the largest suppliers of natural gas engine fuel systems and components. Components include a wide range of regulators, fuel mixers and carburetors, adaptors, valves, and gas filters suitable for virtually any engine conversion. IMPCO equipment is widely used on materials-handling equipment, industrial engines, small engines, and automotive applications.

In addition, IMPCO offers advanced engineered conversion kits for specific engine families. These products feature hot-wire anemometry, adaptive learning, and electronic digital microprocessors. The adaptive digital processor is an advanced electronic controller that calculates the airflow induced through the feedback mixer by measuring manifold pressure and engine speed. It also measures exhaust oxygen and analyzes both sets of data to control the air-to-fuel ratio. The advanced fuel electronics system is a microprocessor-based engine-management system that uses the engine speed and gaseous, hot-wire, fuel mass flow measurement to control the air. 


\subsection{L.NG/LCNG Project Case Studies}

\subsection{Los Angeles International Airport-Los Angeles, CA}

The City of Los Angeles Department of Airports is currently operating 21 LNG-powered Gillig Phantom buses at the LAX Airport. These buses are powered by Cummins L10G engines. LAX is currently planning to order 6 to 17 additional LNG-powered buses in the future.

The fuel supplier for this project is Mesa Pacific LNG. Customer fuel price is $\$ 0.55$ per gallon.

The estimated fuel consumption for these buses is 1,300 gallons per day.

ALT-USA supplied the fuel station and MVE supplied the vehicle fuel systems.

\subsection{Sun Metro-El Pasc, TX}

Sun Metro Transit is currently operating 77 LNG-powered buses and 27 LCNG-powered buses. Sun Metro has awarded contracts for an additional 62 natural gas-powered buses with delivery expected in early 1997. Sun Metro has set i goal to have its fleet 100 percent LNG/LCNG powered by 1999.

The fuel supplier for this project is Mesa Pacific LNG. Customer fuel price is $\$ 0.38$ per gallon.

The estimated fuel consumption for these buses is 6,000 to 7,000 gallons per day.

MVE supplied the fuel station and Cryenco, Stewart \& Stevenson, and MVE supplied the vehicle fuel systems. The bus manufacturers are Supreme Coach, Orion, Chance, New Flyer, and TMC.

\subsection{Houston Metro-Houston, TX}

Houston Metro is currently operating more than 160 buses and 13 nonrevenue vehicles powered by LNG. Houston Metro plans to have more than 306 natural gas-powered vehicles in its fleet.

The fuel supplier for this project is Praxair LNG. Customer fuel price is $\$ 0.53-\$ 0.61$ per gallon.

The estimated fuel consumptior for these buses is 8,000 gallons per day.

John Welch, Inc./Drexel and CVII supplied the fuel station and MVE and CVI supplied the vehicle fuel systems. The engine suppliers include DDC, Stewart \& Stevenson, and Cat/Power Systems.

\subsection{Jack B. Kelley, Inc.--San Manuel, AZ}

JBK currently owns 17 LNG-pcwered, class 8 heavy-duty tractors. The trucks include one Navistar with a Cummins L10-300G engine, 10 Kenworths with Cummins 110-300G engines, three Navistar with 3176B DFNG engines, and thre ₹ Navistar with Cummins N14 engines converted to natural gas by Vineyard Energy Systems. These tractors were in revenue service until September 1997 when the mines they hauled acid to were closed down.

The fuel supplier for this projec: is Exxon. Customer fuel price is $\$ 0.55$ per gallon. 
The estimated fuel consumption for these tractors is 5,000 gallons per day (pending all trucks being dispatched on loads).

ALT-USA supplied the fuel station and Cryenco supplied the vehicle fuel systems. The engine suppliers include Cummins, Cat/Clean Air Partners and Vineyard Engine Systems.

\subsection{Santa Fe Railroad-Vernon, CA}

Santa Fe Railroad is currently operating two LNG-powered locomotives at the Los Angeles Junction railyard.

The fuel supplier for this project is Amoco. Customer fuel price is unavailable.

The estimated fuel consumption for these locomotives is 500 gallons per day.

ALT-USA supplied the fuel station and MVE supplied the vehicle fuel systems. The engine manufacturer is Caterpillar (which was OEM in the MK locomotives).

\subsection{Gary Public Transportation Corporation-Gary, IN}

GPTC is currently operating five LNG-powered buses with more planned for the future. GPTC, partnering with Green Fuels, has purchased a new permanent LNG/LCNG fueling station to service its bus fleet.

The fuel supplier for this project is NIPSCO. Customer fuel price is unavailable.

The estimated fuel consumption for these buses is 700 gallons per day.

ALT-USA supplied the fuel station and CVI supplied the vehicle fuel systems. The engine supplier is Cummins. 


\subsection{Commercial Status of LNG Fuels: Barriers and Opportunities}

\subsection{Summary}

LNG is the alternative fuel closest to competing with diesel in the marketplace. However, it is very difficult to line up all the many factors needed for LNG to get a commercial start as a motor fuel, which is spreading discouragement amcng the stakeholders. However, all is not lost, and determined, crisp execution can still make LNG successful (Gladstein, June 1996).

A number of demonstration projects have been undertaken to test the use of LNG in bus and truck fleets. One major bus fleet, in Houston, operates a large number of dual-fuel LNG/diesel buses. Another, in El Paso, Texas, operates more than 40 buses dedicated to LNG fuel. At LAX, 14 Gillig buses with Cummins L10 engines operate on LNG. The total number of LNG buses operating at LAX is expected to grow to 46 in the near future.

A number of manufacturers culrently offer heavy-duty engines capable of using either LNG or CNG. Some truck builders are now prepared to build trucks to order that have natural gas engines and fuel storage and delivery systems for LNG. Available horsepower ratings cover the needs of typical trucking applications.

Several suppliers of LNG have indicated an interest in supplying LNG as a motor fuel. Price is a matter of negotiation, but recent discussions indicate that LNG might be able to compete on a price basis with diesel fuel, at least if air agencies provide some financial incentives to help the initial projects. In California, LNG is already avalable for vehicle refueling at five sites.

Nevertheless, LNG faces obsta:les that must be overcome if $L N G$ is to obtain an important market share. It will be important for LNG suppliers to provide credible long-range business plans to fleets that are considering using LNG as a fuE:1. Early deliveries of LNG will often be made at a financial loss. Fleets will expect the LNG supplier tc become profitable and to have staying power. They must be convinced before embracing a technology that could be abandoned in the future.

Motor vehicles used in the United States could be supplied with LNG either through the existing LNG trade or new liquefaction facilities. BN, Santa Fe, and Union Pacific have demonstrated the use of LNG in locomotives as an alternative to diesel fuel, and studies show that LNG can offer lower operating costs than diesel fuel for locomotives.

\subsection{Engine and Vehicle Technology Issues and Commercialization Status}

Some engine manufacturers currently offer natural gas heavy-duty engines suited for various vehicle applications. The same engine may be used regardless of whether the delivery of gas to the engine is from compressed natural gas cylinders or from liquefied natural gas storage tanks. Other manufacturers offer conversion kits for existing gasoline and diesel engines to convert them to use natural gas.

Manufacturers usually produce "lean-burn" engines that offer low- $\mathrm{NO}_{\mathrm{x}}$ emissions (about half those of diesel engines) without the need for $\mathrm{a} \mathrm{NO}_{\mathrm{x}}$ reduction catalyst. In demonstration fleets and early commercial applications, the natural gas engines have shown adequate performance, although engine thermal efficiency (or fuel economy) cannot reach diesel levels and the $\mathrm{NO}_{\mathrm{x}}$ emissions have not always been at the expected low levels. 
Available engines cover horsepower ranges suitable for vehicles from the size of pickup trucks to a size suitable for a large over-the-road truck. However, trucks built to date have been limited in number, really representing demonstration quantities. An exception is the operation by Cummins West of two LNGfueled trucks in regular delivery service in San Leandro, California. Only recently have large truck builders such as Peterbilt, Kenworth, and Freightliner agreed to respond to commercial orders for large trucks fueled by LNG, although the manufacturers wish to avoid selling in small quantities and are looking for a substantial order (20 or more vehicles) to justify the expense of commercial engineering of the on-board fuel supply and delivery systems. The first commercial-scale truck order was placed by JBK for 10 Kenworth LNG trucks powered by the Cummins L10G engine rated at $300 \mathrm{hp}$.

No manufacturer of large locomotives currently offers an LNG version. BN recently has operated an LNG conversion of a GM line-haul locomotive in unit train service in the Midwest. In addition, Morris Knudson supplied four switch engines in the Los Angeles basin, which are being operated by Union Pacific and Santa Fe. This equipment is currently running on LNG.

\subsection{Availability of LNG as a Motor Fuel}

Amoco and Exxon in Wyoming and Mesa Pacific in Kansas are prepared to offer supplies of LNG motor fuel, and have supplied LNG for the initial demonstrations in California. Various gas and electric utilities are also prepared to offer LNG, and Praxair LNG has a smaller LNG production facility in Texas. Price is a matter of negotiation, but "gate" prices in the range of 30 to 40 cents per LNG gallon are typical. An LNG truck might use 2 gallons of LNG for each gallon of diesel fuel used by a corresponding diesel truck. Therefore, LNG might appear to be competitive with diesel fuel. However, after cost of delivery and dispensing, these prices do not allow LNG to be competitive with diesel fuel on an operating costper-mile basis, unless the user fleet is within a few hundred miles of the LNG production facility. (Higher costs for the LNG truck, compared with the diesel counterpart, also add cost. Hence, LNG is rarely able to compete with diesel at the present time.)

New LNG production facilities could be built in the neighborhood of new customer fleets if the number of customer vehicles is large enough. Commercial firms have offered to build such liquefaction facilities and supply LNG for sale. The Praxair LNG facility in Texas was constructed on this basis.

In Southern California, LNG is available at three locations: LAX, Mesa Pacific/NGV Ecotrans in downtown Los Angeles, and the Union Pacific rail facility and the Santa Fe rail yard in the Los Angeles basin. Currently, all these except Mesa Pacific/Ecotrans are private-access facilities only, although the LAX facility will soon be open to the public. LNG is also offered at two locations in Northern California, one of which is a public-access site. A new major public-access facility is expected to be built in the near future at the Ontario airport in the South Coast air basin.

\subsection{Key Stakeholders in Commercializing LNG as a Motor Fuel}

- Some North American gas producers who already produce LNG as part of gas-processing operations

- Some gas utilities with facilities and experience in LNG peak-shaving operations

- Business entities who wish to sell LNG

- Truck companies with experience in trucking LNG

- Engine manufacturers

- Truck and locomotive builders

- Truck fleet operators and rail companies

- Government agencies with interests in energy diversification and air quality. 


\subsection{Benefits and Costs of LNG as a Motor Fuel}

\begin{tabular}{|c|c|}
\hline \multicolumn{2}{|c|}{ Supply and Distribution } \\
\hline Benefits & Costs \\
\hline $\begin{array}{l}\text { - Adequate domestic supp y of LNG at } \\
\text { relatively low price at the production facility } \\
\text { - Experience in transport, storage, and some } \\
\text { approaches to dispensing } \\
\text { - LNG can be supplied as a high-quality, } \\
\text { consistent fuel. } \\
\text { - LNG import terminals and peak-shaving } \\
\text { plants are near large cities. } \\
\text { - LNG fuel stations can be designed to } \\
\text { dispense both LNG and CNG. }\end{array}$ & $\begin{array}{l}\text { - Gas field LNG production plants are not } \\
\text { near major urban areas } \\
\text { Distribution of LNG in small volumes over } \\
\text { long distances is expensive. } \\
\text { LNG cannot gain cost advantage over } \\
\text { diesel except when demand can be } \\
\text { focused at a few sites and made to grow } \\
\text { quickly. This requires precise execution } \\
\text { of business plan to avoid unacceptably } \\
\text { high early loses. } \\
\text { - Economical local production of LNG can } \\
\text { only be created with an adequately large } \\
\text { customer base, which can be difficult to } \\
\text { organize. } \\
\text { Small, on-site liquefiers are not cost } \\
\text { effective } \\
\text { New, large-scale LNG production facilities } \\
\text { and import terminals face significant local } \\
\text { opposition }\end{array}$ \\
\hline
\end{tabular}

\begin{tabular}{|c|c|}
\hline \multicolumn{2}{|c|}{ Health and Safety } \\
\hline Benefits & Costs \\
\hline $\begin{array}{l}\text { - Overall, LNG is safer thar gasoline. } \\
\text { - Overall, LNG is as safe as; diesel. } \\
\text { - There are no major safety risks for large, } \\
\text { frequently used vehicles. }\end{array}$ & $\begin{array}{l}\text { - LNG has a poor safety image. } \\
\text { - Indoor maintenance facilities and garages } \\
\text { housing LNG vehicles require customized } \\
\text { ventilation and monitoring. } \\
\text { - Special training is required. } \\
\text { - Fuel "boil-off" from out-of-service vehicles } \\
\text { must be detected and managed. }\end{array}$ \\
\hline
\end{tabular}

\begin{tabular}{|c|c|}
\hline \multicolumn{2}{|c|}{ Energy and Vehicle Technology Issues } \\
\hline Benefits & Costs \\
\hline $\begin{array}{l}\text { Several commercial naturial gas heavy-duty } \\
\text { engines are available. } \\
\text { Truck and bus builders offer commercial } \\
\text { LNG vehicles for large orcers of at least } 10 \\
\text { vehicles. }\end{array}$ & $\begin{array}{l}\text { - The efficiency of natural gas engines is } \\
\text { lower than that of comparable diesel } \\
\text { engines, especially at low loads. } \\
\text { LNG applications are best for line-haul } \\
\text { trucks with minimal amounts of operation } \\
\text { at low load. } \\
\text { Although LNG offers much more compact } \\
\text { energy storage than CNG, practical tank } \\
\text { configurations still do not allow trucks to } \\
\text { match the range of diesel trucks. A } \\
\text { typical range for an LNG truck might be } \\
500 \text { miles. Ranges this short may limit } \\
\text { applications or increase cost because of } \\
\text { frequent refuelings. }\end{array}$ \\
\hline
\end{tabular}




\begin{tabular}{|c|c|}
\hline \multicolumn{2}{|c|}{ Economics } \\
\hline Benefits & Costs \\
\hline $\begin{array}{l}\text { LNG is available at production sites at costs } \\
\text { considerably lower than rack diesel prices. } \\
\text { Lubrication oil, maintenance and repair cost } \\
\text { of natural gas engines may be lower than } \\
\text { costs for comparable diesel engines. }\end{array}$ & $\begin{array}{l}\text { - Transport of LNG by truck more than } \\
1,000 \text { miles is not cost competitive with } \\
\text { diesel. } \\
\text { - For customer fleets remote from LNG } \\
\text { production facilities, achieving cost parity } \\
\text { with diesel and gasoline requires high } \\
\text { volumes and efficient operations. } \\
\text { Generally, at least } 40 \text { or } 50 \text { heavy trucks } \\
\text { or buses with corresponding demand of } \\
2,000 \text { to } 3,000 \text { gallons per day are } \\
\text { required to justify refueling facility. }\end{array}$ \\
\hline
\end{tabular}

\subsection{Strategic Opportunities}

- Natural gas versions of many popular heavy-duty engines are available.

- Some OEM LNG bus and truck chassis are available-at a premium price.

- LNG can be cost-competitive with diesel fuel in rail and truck operations in a few favorable situations.

- Value of $\mathrm{NO}_{\mathrm{x}}$ reductions in heavy-duty engines may be marketable in certain urban areas.

- Subsidies and incentives are available from public agencies to defray risk in the early, high-cost phases of an LNG implementation.

- A well-implemented LNG strategy makes money for all partners, although the fuel provider may need to make several years of investments before turning the corner to profitability.

\subsection{Strategic Threats}

- All the stakeholders need to arrive at the same conclusions and concerted actions in order for the cost of the early deployment phase to be held to manageable levels - this has proven very difficult to achieve.

- Low prices for diesel fuel, in the $\$ 1.20$ to $\$ 1.30$ range at the pump, make an LNG strategy one of modest up-side potential but substantial downside risks if execution is faulty.

- Reduced-NO $\mathrm{N}_{\mathrm{x}}$ diesel technologies and LPG technologies are beginning to create formidable competition for air quality incentive funds badly needed by LNG in the early deployment years; these technologies may dampen market interest in LNG.

\subsection{Suggested Key Elements of a Commercialization Strategy for LNG}

- LNG suppliers with substantial resources must commit to a business and pricing strategy that is credible to fleet customers.

- The business strategy must convince potential customer fleets that they will not be purchasing technology that is a potential orphan - fleets are very aware of the California heavy-duty methanol experience.

- Large fleet commitments must be secured to create large truck orders to get per-vehicle costs down; combining the demands of several fleets at a limited number of refueling sites will be important as well. 
- Early deployments must take advantage of financial incentives available from air quality programs to offset initial high cost when volumes are low-this is best arranged by customer fleets and local air agencies.

- To qualify for financial incentives, it will be very helpful for engine manufacturers to certify natural gas engines to meet California optional low- $\mathrm{NO}_{\mathrm{x}}$ standards.

- Where possible, bus and tnıck fleet applications should be coordinated with rail and other fuel applications to get volumes: up and costs down. 
ublic reporting burden for this collection of information is estimated to average 1 hour per response, including the time for reviewing instructions, searching existing data sources, thering and maintaining the data needed, and completing and reviewing the collection of information. Send comments regarding this burden estimate or any other aspect of this illection of information, including suggestions for reducing this burden, to Washington Headquarters Senvices, Directorate for Information Operations and Reports, 1215 Jefferson avis Highway, Suite 1204, Arlington, VA 22202-4302, and to the Office of Management and Budget, Paperwork Reduction Project (0704-0188), Washington, DC 20503.

\begin{tabular}{|l|l|l|}
\hline AGENCY USE ONLY (Leave blank) & $\begin{array}{l}\text { 2. REPORT DATE } \\
\text { December } 1997\end{array}$ & $\begin{array}{l}\text { 3. REPORT TYPE AND DATES COVERED } \\
\text { Subcontract report }\end{array}$ \\
\hline
\end{tabular}

\section{TITLE AND SUBTITLE}

quefied Natural Gas as a Transportation Fuel for Heavy Duty Trucks: Volume I

AUTHOR(S)

ate of Utah Office of Energy Services; Jack B. Kelley, Inc.; Bruderly Engineering Associates, Inc.; and Cryenco Sciences,

ck B. Kelley, inc.

O. Box 50539

marillo, TX 79159-0539

\section{SPONSORING/MONITORING AGENCY NAME(S) AND ADDRESS(ES)}

tional Renewable Energy Laboratory

17 Cole Boulevard

flden, CO 80401-3393

5. FUNDING NUMBERS

(C) ACl-6-15700-01

(TA) FU535010

\section{. SUPPLEMENTARY NOTES}

\section{a. DISTRIBUTION/AVAILABILITY STATEMENT}

ational Technical Information Service

S. Department of Commerce

85 Port Royal Road

ringfield, VA 22161

ABSTRACT (Maximum 200 words) This report provides a brief introduction to the physics and chemistry of liquefied natural gas (LNG); an overview of severa going LNG projects; the economics of converting fleets to LNG; a summary of both mandated and voluntary federal programs; a summary of LNG fuel station chnology; a description of the LNG production and distribution infrastructure; and a description of available LNG technologies.

\section{SUBJECT TERMS}

quefied natural gas; alternative transportation fuels

SECURITY CLASSIFICATION OF REPORT

\section{SECURITY CLASSIFICATION} OF THIS PAGE

\section{SECURITY CLASSIFICATION} OF ABSTRACT
8. PERFORMING ORGANIZATION REPORT NUMBER

10. SPONSORING/MONITORING AGENCY REPORT NUMBER

NREL'SR-540-23094
15. NUMBER OF PAGES

140

16. PRICE CODE

20. LIMITATION OF ABSTRACT 